\title{
Osteoporosis in the European Union: medical management, epidemiology and economic burden
}

\author{
A report prepared in collaboration with the International Osteoporosis Foundation (IOF) \\ and the European Federation of Pharmaceutical Industry Associations (EFPIA)
}

\author{
E. Hernlund • A. Svedbom • M. Ivergård • J. Compston • \\ C. Cooper • J. Stenmark • E. V. McCloskey • B. Jönsson • \\ J. A. Kanis
}

Received: 29 November 2012 / Accepted: 11 March 2013/Published online: 11 October 2013

(C) The Author(s) 2013. This article is published with open access at Springerlink.com

\begin{abstract}
Summary This report describes the epidemiology, burden, and treatment of osteoporosis in the 27 countries of the European Union (EU27).

Introduction Osteoporosis is characterized by reduced bone mass and disruption of bone architecture, resulting in increased risk of fragility fractures which represent the main clinical consequence of the disease. Fragility fractures are associated with substantial pain and suffering, disability and even death for affected patients and substantial costs to society. The aim of this report was to characterize the burden of osteoporosis in the EU27 in 2010 and beyond.

Methods The literature on fracture incidence and costs of fractures in the EU27 was reviewed and incorporated into a model estimating the clinical and economic burden of osteoporotic fractures in 2010.
\end{abstract}

\author{
E. Hernlund $\cdot$ A. Svedbom $\cdot$ M. Ivergård \\ OptumInsight, Stockholm, Sweden \\ J. Compston \\ Department of Medicine, Addenbrooke's Hospital, Cambridge \\ University, Cambridge, UK \\ C. Cooper \\ MRC Lifecourse Epidemiology Unit, University of Southampton, \\ Southampton, UK \\ C. Cooper \\ NIHR Musculoskeletal Biomedical Research Unit, Institute of \\ Musculoskeletal Sciences, University of Oxford, Oxford, UK \\ J. Stenmark \\ International Osteoporosis Foundation, Nyon, Switzerland
}

Results Twenty-two million women and 5.5 million men were estimated to have osteoporosis; and 3.5 million new fragility fractures were sustained, comprising 610,000 hip fractures, 520,000 vertebral fractures, 560,000 forearm fractures and 1,800,000 other fractures (i.e. fractures of the pelvis, rib, humerus, tibia, fibula, clavicle, scapula, sternum and other femoral fractures). The economic burden of incident and prior fragility fractures was estimated at $€ 37$ billion. Incident fractures represented $66 \%$ of this cost, long-term fracture care $29 \%$ and pharmacological prevention $5 \%$. Previous and incident fractures also accounted for $1,180,000$ quality-adjusted life years lost during 2010. The costs are expected to increase by $25 \%$ in 2025 . The majority of individuals who have sustained an osteoporosis-related fracture or who are at high risk of fracture are untreated and the number of patients on treatment is declining.

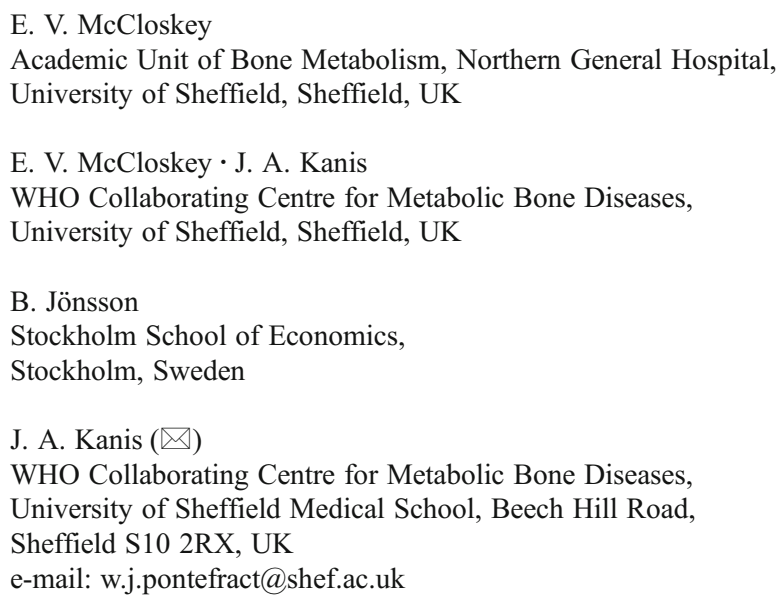


Conclusions In spite of the high social and economic cost of osteoporosis, a substantial treatment gap and projected increase of the economic burden driven by the aging populations, the use of pharmacological interventions to prevent fractures has decreased in recent years, suggesting that a change in healthcare policy is warranted.

\section{Table of Contents}

1. Introduction to osteoporosis

Summary and key messages

1.1 Introduction and aims of the report

1.2 Measurement of BMD

1.3 Defining osteoporosis

1.4 Prevalence of osteoporosis

1.5 Defining osteoporotic fracture

1.6 Common osteoporotic fractures

1.6.1 Hip fracture

1.6.2 Vertebral fracture

1.6.3 Distal forearm fracture

1.7 Fracture burden worldwide

1.8 The future burden

References

\section{Medical innovation and its clinical uptake in the} management of osteoporosis

Summary and key messages

2.1 Introduction

2.2 Use of BMD

2.2.1 Availability of DXA

2.3 Assessment of fracture risk

2.3.1 Assessment risk with BMD

2.3.2 Clinical risk factors (CRFs)

$2.4 \quad$ FRAX $^{\circledR}$

2.4.1 Utilisation of FRAX ${ }^{\circledR}$

2.5 Treatment of osteoporosis and prevention fracture

2.5.1 General management

2.5.2 Major pharmacological interventions

2.5.3 Future developments in the treatment of osteoporosis

2.5.4 Vertebroplasty and balloon kyphoplasty

2.5.5 Fracture liaison services

2.6 Cost-effectiveness of pharmaceutical interventions

2.7 Adherence, compliance and persistence

2.7.1 Measurements of adherence

2.7.2 Adherence in a real world setting

2.7.3 Adherence and anti-fracture efficacy

2.7.4 Cost-effectiveness and adherence

2.8 National guidelines and reimbursement policies for the management of osteoporosis in the EU

2.8.1 Compliance with guidelines

2.8.2 Imperfect health care practice

References

\section{Appendix A}

Literature review of recent adherence literature in the EU

1 Methods

2 Results

2.1 Study characteristics

2.2 Persistence

2.3 Compliance

2.4 Data synthesis

2.5 Determinants and outcomes of adherence in reported studies

3 Discussion

References

3. Epidemiology of osteoporosis

Summary and key messages

3.1 Epidemiology of osteoporosis and fracture

3.2 Population at risk

3.3 Prevalence of osteoporosis

3.4 Incidence of fractures

3.5 Incidence of hip fractures

3.6 Incidence of vertebral fractures

3.7 Incidence of forearm and other osteoporotic fractures

3.8 Number of incident fractures

3.9 Prior fractures

3.10 Mortality due to fracture

3.11 Deaths due to facture

References

\section{Burden of fractures}

Summary and key messages

4.1 Introduction

4.2 Methods and materials

4.2.1 Model design

4.2.2 Cost of fracture and imputations methods

4.2.3 Costs of pharmacological prevention of fracture

4.2.4 Health utility and QALY implications of fracture

4.2.5 Societal value of QALYs

4.3 Results

4.3.1 Costs of osteoporosis excluding values of QALYs lost

4.3.2 Life-Years lost due to fracture

4.3.3 QALYs lost due to osteoporosis

4.3.4 Value of QALYs lost due to osteoporosis

4.3.5 Cost of osteoporosis including value of QALYs lost

4.3.6 Cost of osteoporosis compared to other diseases

4.4 Burden of osteoporosis up to 2025

4.4.1 Secular trends

4.4.2 Demography up to 2025

4.4.3 Prevalence of osteoporosis as defined using the WHO diagnostic criteria up to 2025

4.4.4 Number of incident fractures up to 2025 
4.4.5 Cost of osteoporosis up to 2025 excluding QALYs lost

4.4.6 Projection of QALYs lost due to osteoporosis up to 2025

4.4.7 Cost of osteoporosis up to 2025 including QALYs lost

References

\section{Uptake of osteoporosis treatments}

Summary and key messages

5.1 Uptake of osteoporosis treatment

5.2 Data and methods

5.3 Pharmacological treatment

5.4 Market shares

5.5 Population coverage

5.6 Uptake of individual treatments

5.6.1 Alendronate

5.6.2 Denosumab

5.6.3 Etidronate

5.6.4 Ibandronate

5.6.5 PTH (1-84)

5.6.6 Raloxifene

5.6.7 Risedronate

5.6.8 Strontium ranelate

5.6.9 Teriparatide

5.6.10 Zoledronic acid

5.6.11 Summary

5.7 Patients eligible for treatments and treatment gap

5.8 Proportion of patients treated

References

\section{List of abbreviations}

BMD

BMI

$\mathrm{cm}$

CPI

CRF

$\Delta$

DALY

DDD

DXA

ECCEO

EMA

EU

EU5

EU27

FRAX $^{\circledR}$
Bone mineral density

Body mass index

Centimetre

Consumer price index

Clinical risk factor

delta (difference)

Disability adjusted life year

Defined daily dosage

Dual-energy X-ray absorptiometry

European Congress on Clinical and

Economic aspects of Osteoporosis

and Osteoarthritis

European Medicines Agency

European Union

Refers to 5 countries of the

European Union (France, Germany,

Italy, Spain and the UK)

Refers to the 27 countries of the

European Union

WHO fracture risk assessment tool g

GDP

GPRD

GLOW

HR

HRQoL

HRT

ICER

IMS

IOF

IU

$\mathrm{m}$

$\mathrm{m}^{2}$

$\mathrm{mg}$

MPR

NHANES

NHS

NICE

NOGG

POSSIBLE EU Prospective observational study investigating bone loss experience in Europe

p.a.

PTH

PPP

QALY

QCT

RCT

SARA

SERM

SD

TEO

T-score

UK

$\mathrm{UN}$

URL

WHO

WTP

Z-score

gram

Gross domestic product

General Practice Research Database

Global Longitudinal Study of

Osteoporosis in Women

Hazard ratio

Health Related Quality of Life

Hormonal replacement treatment

Incremental cost-effectiveness ratio

International Marketing Service

International Osteoporosis Foundation

International Unit

million

square meter

milligram

Medication possession ratio

National Health and Nutrition

Examination Survey

National Health Service (in UK)

National Institute of Health and

Clinical Excellence

National Osteoporosis

$$
\text { Nuidaline }
$$

per annum

Parathyroid hormone

Purchasing power parity

Quality-adjusted life year

Quantitative computer tomography

Randomised clinical trial

Swedish adherence register analysis

Selective estrogen receptor modulator

Standard deviation

Test d'Evaluation de l'Observance number of SDs by which BMD in an individual differs from the mean value expected in young healthy women

United Kingdom

United Nations

Uniform resource locator

World Health Organization

Willingness to pay

number of SDs by which BMD in an individual differs from the mean value expected for age and sex

\section{Foreword}

Osteoporosis, literally "porous bone", is a disease characterized by weak bone. It is a major public health problem, affecting hundreds of millions of people worldwide, predominantly postmenopausal women. The main clinical consequence of the 
disease is bone fractures. It is estimated that one in three women and one in five men over the age of 50 worldwide will sustain an osteoporotic fracture. Hip and spine fractures are the two most serious fracture types, associated with substantial pain and suffering, disability, and even death. As a result, osteoporosis imposes a significant burden on both the individual and society. During the past two decades, a range of medications has become available for the treatment and prevention of osteoporosis. The primary aim of pharmacological therapy is to reduce the risk of osteoporotic fractures.

The objective of this report is to review and describe the current burden of osteoporosis and highlight recent advances and ongoing challenges for treatment and prevention of the disease. The report encompasses both epidemiological and health economic aspects of osteoporosis and osteoporotic fractures with a geographic focus on EU27. Projections of the future prevalence of osteoporosis and fracture incidence, the direct and total societal burden of the disease, and the consequences of different intervention strategies receive special attention. The report may serve as a basis for the formulation of healthcare policy concerning osteoporosis in general and the treatment and prevention of osteoporosis in particular. It may also provide guidance regarding the overall healthcare priority of the disease. The report is divided into five chapters:

\section{Introduction to osteoporosis}

This introductory chapter briefly reviews the way in which osteoporosis and the associated fractures are defined, describes the most common osteoporotic fractures, and the extent of the burden worldwide.

2. Medical innovation and its clinical uptake in the management of osteoporosis The second chapter reviews the measurement of bone mineral density, diagnosis of osteoporosis, methods for assessment of fracture risk, the development of interventions that reduce the risk of fractures, practice guidelines, and the cost-effectiveness of osteoporosis treatments.

\section{Epidemiology of osteoporosis}

The third chapter reviews the epidemiology and consequences of osteoporosis and fractures, as well as different approaches for setting intervention thresholds (i.e. at what fracture risk it is appropriate to initiate treatment).

\section{Burden of fractures}

The fourth chapter presents a model estimation of the burden of osteoporosis in the EU27 for 2010. The burden is described in terms of fractures, costs, and QALYs lost. Fracture burden is also projected to the year 2025 based on expected demographic changes.

\section{Uptake of osteoporosis treatments}

The fifth chapter provides a description of the current uptake of osteoporosis treatments, that is, how many patients of those eligible for treatment that actually can be treated in the EU27. International sales data from 2001 and forward were used to analyse international variations in treatment uptake. 


\section{Introduction to osteoporosis}

\section{Summary}

This introductory chapter briefly reviews the way in which osteoporosis and the associated fractures are defined, describes the most common osteoporotic fractures, and the extent of the burden worldwide.

\section{The key messages of this chapter are:}

Osteoporosis is characterized by reduced bone mass and disruption of bone microarchitecture, resulting in increased bone fragility and increased fracture risk.

In 1994 and 2008, the WHO published diagnostic criteria for osteoporosis in postmenopausal women based on the T-score for bone mineral density (BMD). Osteoporosis is defined as a value for BMD 2.5 standard deviations (SD) or more below the young female adult mean (T-score less than or equal to -2.5 SD).

Based on these diagnostic criteria, approximately $6 \%$ of men and $21 \%$ of women aged 50-84 years have osteoporosis affecting 27.6 million men and women in the EU in 2010.

The most common osteoporotic fractures are those at the hip, spine, forearm and humerus. At the age of 50 years, the remaining lifetime probability of one of these fractures is $22 \%$ and $46 \%$ in men and women, respectively.

There are very large variations in the incidence of osteoporotic fractures between and within countries for reasons that are not known, but are partly associated with economic prosperity.

Osteoporosis causes more than 8.9 million fractures annually worldwide and over one-third of all osteoporotic fractures occur in Europe.

In Europe osteoporotic fractures account for 2 million disability adjusted life years (DALYS) annually, somewhat more than are accounted for by hypertensive heart disease or rheumatoid arthritis.

The number of osteoporotic fractures is rising in many countries. Reasons for this relate in part to the increased longevity of the population. The age- and sex-specific incidence of fracture has also increased in some but not all countries.

\subsection{Introduction and aims of the report}

Osteoporosis is characterized by reduced bone mass and disruption of bone architecture, resulting in increased bone fragility and increased fracture risk [1]. The publication of a World Health Organization (WHO) report on the assessment of fracture risk and its application to screening for postmenopausal osteoporosis in 1994 provided diagnostic criteria for osteoporosis based on the measurement of bone mineral density (BMD) and recognized osteoporosis as an established and well-defined disease that affected more than 75 million people in the United States, Europe and Japan [2].

Osteoporosis represents a major non-communicable disease of today and is set to increase markedly in the future. There is underutilisation of the measures available to combat the disease and there is therefore a need for assessment of best practices in prevention and treatment, since the adoption of these across countries can potentially result in significant reductions in the burden of this disease. This report reviews country-specific information on the application of new technologies in osteoporosis, the epidemiology of fracture, future trends, and the uptake of treatments. The aim is to quantify the burden of osteoporosis in terms of prevalence, fractures, patients at risk, uptake of treatment, mortality and the societal costs in different countries using a common methodology. The countries reviewed comprise member states of the EU. An earlier report reviewed the larger populations of Europe (Spain, Italy, France, Germany and the UK) and Sweden [3]. The present review extends this outreach.

The consequences of osteoporosis reside in the fractures that arise. This introduction covers briefly the way in which osteoporosis is defined, describes the most common osteoporotic fractures, and the extent of the burden worldwide shown in current literature. Parts of the introduction have been taken from the earlier report [3] that considered the burden of osteoporosis in the five major EU countries and Sweden where relevant to the context of the present report.

\subsection{Measurement of BMD}

The description of osteoporosis captures the notion that low bone mass is an important component of the risk of fracture, but other abnormalities such as micro-architectural deterioration contribute to skeletal fragility. Ideally, clinical assessment of the skeleton should capture all these determinants of fracture risk, but at present the assessment of bone mass is the only aspect that can be readily measured in clinical practice, and forms the cornerstone for the general management of osteoporosis being used for diagnosis, risk prediction, and monitoring of patients on treatment $[2,4,5]$.

BMD is the amount of bone mass per unit volume (volumetric density, $\mathrm{g} / \mathrm{cm}^{3}$ ), or per unit area (areal density, $\mathrm{g} / \mathrm{cm}^{2}$ ), and both can be measured in vivo by densitometric techniques. For the purpose of this report BMD refers to an areal BMD unless otherwise specified. A large variety of techniques is available [2] but the most widely used techniques by far are based on x-ray absorptiometry in bone, particularly dual energy $\mathrm{x}$-ray absorptiometry (DXA). DXA is based on the absorption of $\mathrm{x}$-rays which is very sensitive to the calcium content of tissue, of which bone is the most important fraction. DXA provides a two-dimensional 
areal value rather than a volumetric density and thus is influenced by bone size as well as true density. The most commonly measured sites are the lumbar spine (L1-L4) and the proximal femur. However, in older people the accuracy of measurements in the lumbar spine may be impaired by scoliosis, vertebral deformity, osteophytes and extraskeletal calcification and the proximal femur is the reference site for diagnosis [5, 6]. Lumbar spine measurements are most widely used to monitor treatment since they are sensitive to treatmentinduced changes. DXA techniques using the lateral view of the spine rather than in the customary postero-anterior projection are increasingly used to detect vertebral fractures $[7,8]$.

\subsection{Defining osteoporosis}

The diagnostic criterion for osteoporosis is based on the measurement of BMD [9]. BMD is most often described as a T-score or Zscore, both of which are units of SD. The Z-score describes the number of SDs by which the BMD in an individual differs from the mean value expected for age and sex (Fig. 1). The T-score describes the number of SDs by which the BMD in an individual differs from the mean value expected in young healthy individuals.

The operational definition of osteoporosis is based on the T-score for BMD in women [2,9] and is defined as a value for BMD 2.5 SD or more below the young female adult mean (T-score less than or equal to $-2.5 \mathrm{SD}$ ) as shown in Figure 2. This threshold was originally developed for measurements of BMD at the spine, hip, or forearm. More recently, the operational definition of osteoporosis has been refined by WHO with the femoral neck as the standard measurement site and the use of an international reference standard for the

\section{BMD (\% healthy women)}

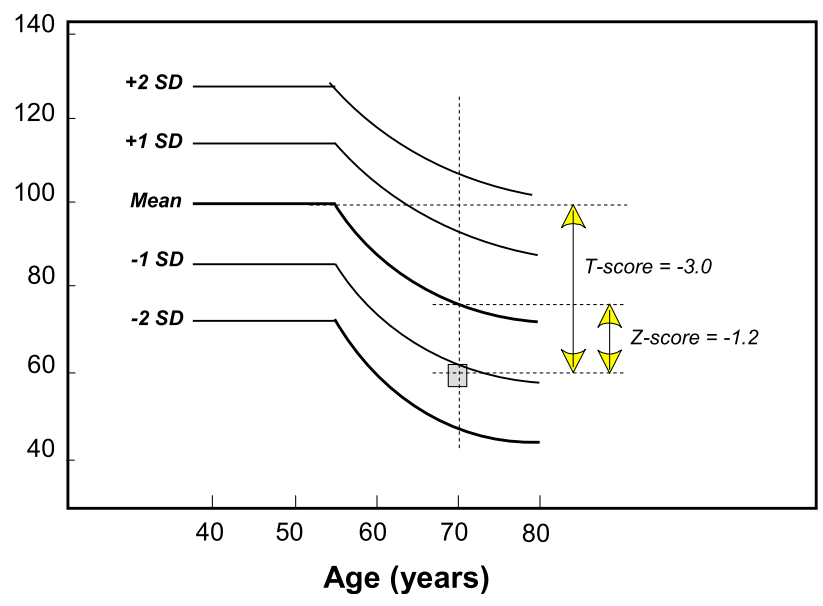

Fig. 1 Schematic diagram showing the mean BMD with SD intervals in women by age and the derivation of Z-scores and T-scores from BMD

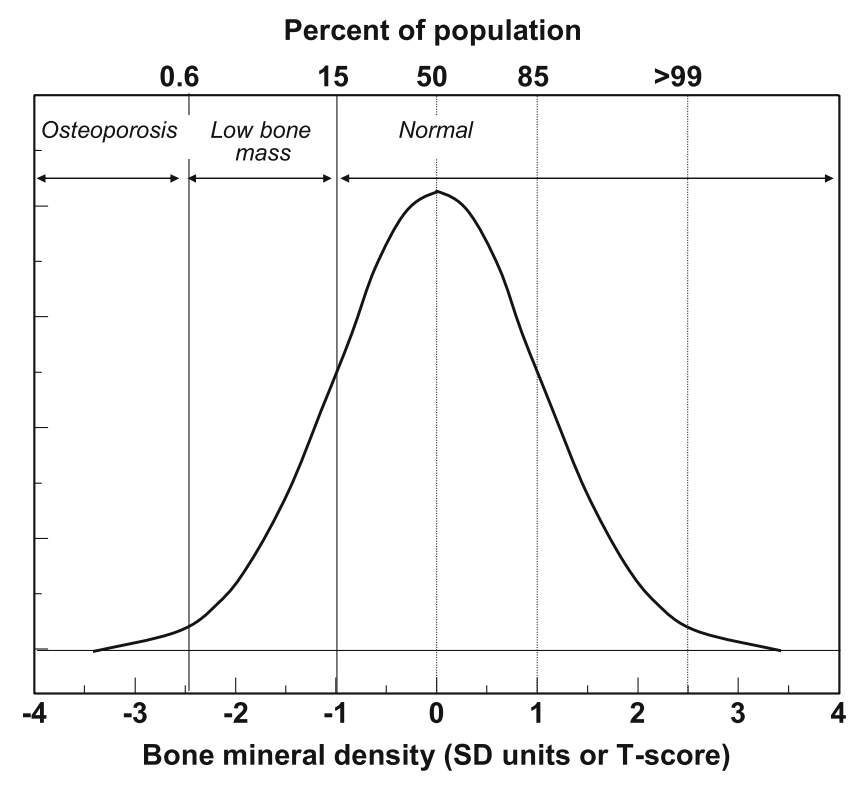

Fig. 2 The distribution of BMD in young healthy women in SD units and threshold values for osteoporosis and low bone mass

calculation of the T-score [6]. The reference population for both men and women is the mean and SD values in young women from the NHANES III study [10]. Thus the diagnostic criterion for men uses the same threshold for BMD as that for women. This arises fortuitously because for any age and BMD at the femoral neck, the risk of hip fracture or a major osteoporotic fracture is approximately the same in men and women [11-13]. Note that the use of the T-score threshold is inappropriate in children or adolescents.

For the purposes of this report, the term osteoporosis refers to the densitometric criterion outlined above. These considerations should not be taken, however, to infer that the use of other techniques or other sites do not have clinical utility for the management of patients where they have been shown to provide information on fracture risk. It is also relevant to make the distinction between the definition of osteoporosis based on BMD and a clinical diagnosis based on the occurrence of fragility fractures. Finally, it is important to recognise that the presence or absence of osteoporosis based on BMD is not synonymous with an intervention threshold which is more appropriately based on fracture risk rather than on BMD alone.

\subsection{Prevalence of osteoporosis}

Because the distribution of BMD in the young healthy population is normally distributed [14] and bone loss occurs with advancing age, the prevalence of osteoporosis increases with age. The prevalence of osteoporosis in 
Table 1 Prevalence of osteoporosis at the age intervals shown in Sweden using female-derived reference ranges at the femoral neck [15]

\begin{tabular}{|c|c|c|c|c|}
\hline \multirow[b]{2}{*}{$\begin{array}{l}\text { Age range } \\
\text { (years) }\end{array}$} & \multicolumn{2}{|c|}{ Men } & \multicolumn{2}{|c|}{ Women } \\
\hline & $\begin{array}{c}\% \text { of } \\
\text { population }\end{array}$ & $\begin{array}{c}\text { Number } \\
\text { affected (000) }\end{array}$ & $\begin{array}{c}\% \text { of } \\
\text { population }\end{array}$ & $\begin{array}{c}\text { Number } \\
\text { affected (000) }\end{array}$ \\
\hline $50-54$ & 2.5 & 7.0 & 6.3 & 17.0 \\
\hline $55-59$ & 3.5 & 7.6 & 9.6 & 21.1 \\
\hline $60-64$ & 5.8 & 11.4 & 14.3 & 30.0 \\
\hline $65-69$ & 7.4 & 14.2 & 20.2 & 43.7 \\
\hline $70-74$ & 7.8 & 14.6 & 27.9 & 63.0 \\
\hline $75-79$ & 10.3 & 13.7 & 37.5 & 68.3 \\
\hline $80-84$ & 16.6 & 14.7 & 47.2 & 67.8 \\
\hline $50-84$ & 6.3 & 83.2 & 21.2 & 310.9 \\
\hline
\end{tabular}

Sweden using the WHO criterion is shown for Swedish men and women in Table 1 [15]. Approximately $6 \%$ of men and $21 \%$ of women aged 50-84 years are classified as having osteoporosis. The prevalence of osteoporosis in women over the age of 50 years is 3-4 times greater than in men - comparable to the difference in lifetime risk of an osteoporotic fracture in men and women.

For the purposes of this report, it is assumed that the mean femoral neck BMD is similar across countries at the age of 50 years and so too is the rate of bone loss at the femoral neck with age. The same assumptions have been used elsewhere [3, 16, 17]. The assumptions are consistent with empirical observation in some $[5,18-20]$ but not all studies [21-24]. Although differences in the age-dependent BMD (and hence the prevalence of osteoporosis) have been reported between countries, the differences are relatively small $[5,22,24]$ and most studies are on limited sample sizes, subject to selection bias, undertaken on a regional rather than national basis and cross-sectional in nature. It is notable that the variations in BMD between populations are substantially less than variations in fracture risk. Indeed, age- and sex-specific risks of hip fracture differ more than 10-fold, even within Europe [25-28]. These differences are very much larger than can be accounted for by any differences in BMD between communities.

With these caveats, the prevalence of densitometric osteoporosis varies somewhat between member states according to the demography of the population. In men over the age of 50 years the prevalence of osteoporosis varies from $5.9 \%$ (Poland) to $7.2 \%$ (Luxembourg). In women, the rates vary from $19.1 \%$ (Cyprus) to $23.5 \%$ (France). Further details on a country by country basis are given in Chapter 3 and the country-specific reports published as a compendium in this issue of Archives in Osteoporosis. The prevalence of osteoporosis in the EU is estimated at 27.6 million in 2010 (Fig. 3). The extension of this report from the 5 major countries (EU5) to the EU27 increases the proportion of men and women with osteoporosis by $35 \%$.

\section{0 million women in the EU have osteoporosis}

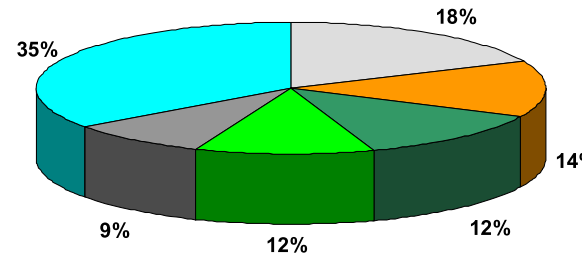

5.6 million men in the EU have osteoporosis
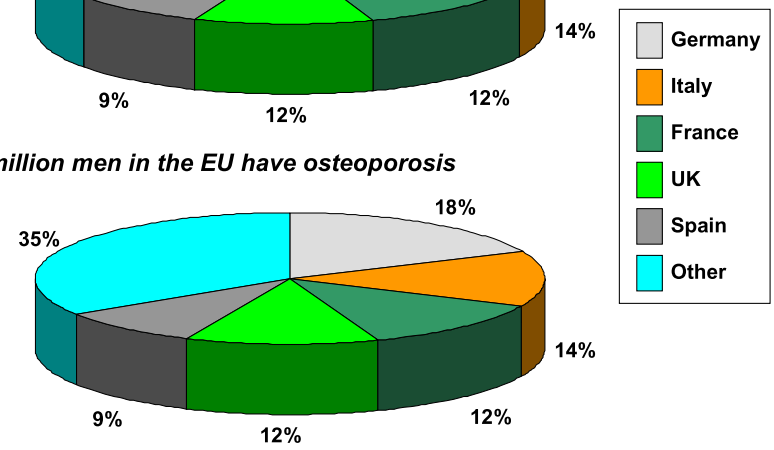

Fig. 3 The prevalence distribution of osteoporosis in the EU and the 5 countries with the highest populations in 2010 


\subsection{Defining osteoporotic fracture}

Osteoporosis is manifested by fractures but the definition of an osteoporotic fracture is not straightforward. Opinions differ concerning the inclusion or exclusion of different sites of fracture in describing osteoporotic fractures. One approach is to consider all fractures from low energy trauma as being osteoporotic. "Low energy" may variously be defined as a fall from a standing height or less, or trauma that in a healthy individual would not give rise to fracture [29]. This characterization of low trauma indicates that the vast majority of hip and forearm fractures are low energy injuries or fragility fractures $[30,31]$. The consideration of low energy has the merit of recognizing the multifactorial causation of fracture, but osteoporotic individuals are more likely to fracture than their normal counterparts following high energy injuries [31]. As might be expected, there is also an imperfect concordance between low energy fractures and those associated with reductions in BMD $[32,33]$.

The rising incidence of fractures with age does not provide direct evidence for osteoporosis, since a rising incidence of falls could also be a cause. By contrast, a lack of increasing incidence with age is reasonable presumptive evidence that a fracture type is unlikely to be osteoporosis-related. An indirect arbiter of an osteoporotic fracture is the finding of a strong association between the fracture and the risk of classical osteoporotic fractures at other sites. Vertebral fractures, for example, are a very strong risk factor for subsequent hip and vertebral fracture [34-38], whereas forearm fractures predict future vertebral and hip fractures [39].

Due to the difficulties of knowing which fractures have been caused by low energy trauma, the approach used in this report and elsewhere is to characterize fracture sites as osteoporotic when they are associated with low bone mass and their incidence rises with age after the age of 50 years [40]. The most common fractures defined in this way are those at the hip, spine and forearm, and humerus but many other fractures after the age of 50 years are related at least in part to low BMD and should be regarded as osteoporotic [32, 40-42]. These include fractures of the ribs, tibia (in women, but not including ankle fractures), pelvis and other femoral fractures (Fig. 4). Their neglect underestimates the burden of osteoporosis, particularly in younger individuals. Under this schema, the fracture sites that would be

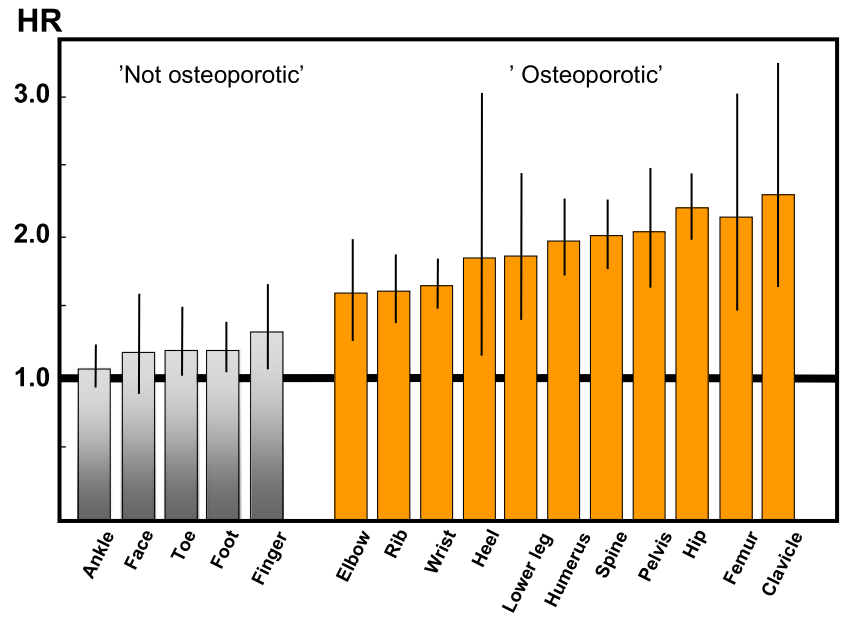

Fig. 4 Hazard ratio and $95 \%$ confidence intervals for osteoporosis as judged by BMD at the hip according to fracture site in women from France [41]

excluded are those at the ankle, hands and feet, digits, skull and face.

\subsection{Common osteoporotic fractures}

The most common osteoporotic fractures comprise vertebral fractures, fractures of the forearm (particularly Colles' fracture), hip fractures, and proximal humerus fractures [2]. In Sweden, the remaining lifetime risk at the age of 50 years of sustaining a hip fracture is $22.9 \%$ in women and $10.7 \%$ in men. The remaining lifetime risk of a major osteoporotic fracture (clinical spine, hip, forearm or humeral fracture) is $46.4 \%$ in women and $22.4 \%$ in men [43] (Table 2). The vast majority of osteoporotic fractures occur in elderly women [44]. Overall, women have about twice as high a risk of sustaining any fracture than men. However, there are variations between different fracture sites. For example women have about a 5 times higher risk of sustaining a forearm fracture than men but less than twice the risk of sustaining a spine fracture. The reasons for this relate in part to differences in bone density at maturity and in particular to the loss of bone that occurs after the menopause. In addition, women live longer than men and are exposed, therefore, for longer periods to a reduced bone density and other risk factors for osteoporosis or fracture. Men have higher rates of fracture-related mortality than women [45], possibly related to higher rates of comorbidity [46, 47]. 
Table 2 Remaining lifetime probability of fracture (\%) in men and women from Sweden at the ages shown. The risk ratio refers to the female/male probabilities [43]

\begin{tabular}{|c|c|c|c|c|c|c|}
\hline \multirow[b]{2}{*}{ Type of fracture } & \multicolumn{3}{|c|}{ At 50 years } & \multicolumn{3}{|c|}{ At 80 years } \\
\hline & Men & Women & Risk ratio & Men & Women & Risk ratio \\
\hline Forearm & 4.6 & 20.8 & 4.5 & 1.6 & 8.9 & 5.6 \\
\hline Hip & 10.7 & 22.9 & 2.1 & 9.1 & 19.3 & 2.1 \\
\hline Spine $^{a}$ & 8.3 & 15.1 & 1.8 & 4.7 & 8.7 & 1.9 \\
\hline Proximal humerus & 4.1 & 12.9 & 3.1 & 2.5 & 7.7 & 3.1 \\
\hline Any of these & 22.4 & 46.4 & 2.1 & 15.3 & 31.7 & 2.1 \\
\hline
\end{tabular}

The incidence of fragility fractures increases markedly with age, though the rate of rise with age differs for different fracture outcomes. For this reason, the proportion of fractures at any site also varies with age. This is most evident for forearm and hip fractures [48] (Fig. 5). Thus forearm fractures account for a greater proportion at younger ages than in the elderly. Conversely, hip fractures are rare at the age of 50 years but become the predominant osteoporosis fracture from the age of 75 years. In women, the median age for distal forearm fractures is around 65 years and for hip fracture, 80 years. Thus both the number of fractures and the type of fracture are critically dependent on the age of the populations at risk.

\section{Age 50-54 years}

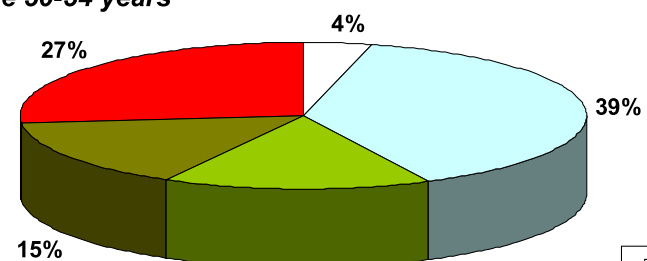

$15 \%$

Age 85-89 years

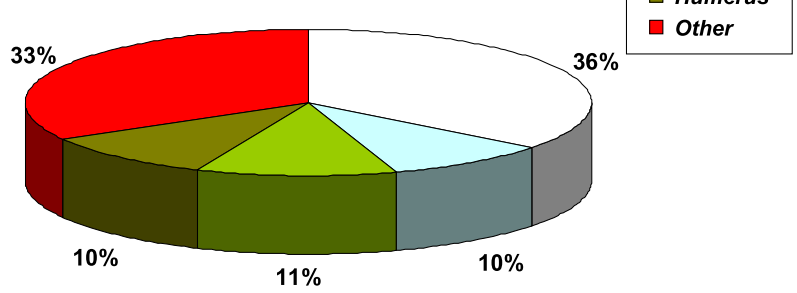

Fig. 5 The site specific pattern of osteoporotic fractures between the ages of $50-54$ and $85-89$ years in women from Sweden [48]

\subsubsection{Hip fracture}

Hip fracture is the most serious osteoporotic fracture. Most are caused by a fall from the standing position, although they sometimes occur spontaneously [49]. The risk of falling increases with age and is somewhat higher in elderly women than in elderly men. About one-third of elderly individuals fall annually, with the result that $5 \%$ will sustain a fracture and $1 \%$ will suffer a hip fracture [50]. Hip fracture is painful and nearly always necessitates hospitalisation.

A hip fracture is a fracture of the proximal femur, either through the femoral cervix (sub-capital or trans-cervical: intra-capsular fracture) or more distally through the trochanteric region (intra-trochanteric: extra-capsular fracture). Trochanteric fractures are more characteristically osteoporotic, and the increase in age-specific and sex-specific risks for hip fracture is greater for trochanteric than for cervical fractures [51]. Trochanteric fractures are also more commonly associated with a prior fragility fracture.

Displaced cervical fractures have a high incidence of malunion and osteonecrosis following internal fixation, and the prognosis is improved with hip replacement. Trochanteric hip fractures appear to heal normally after adequate surgical management. Complications may arise because of immobility. The outcome is much poorer where surgery is delayed for more than 2 days. Up to $20 \%$ of patients die in the first year following hip fracture, mostly as a result of serious underlying medical conditions $[52,53]$ and less than half of survivors regain the level of function that they had prior to hip fracture [54]. Patients with hip fracture often have significant co-morbidities, so that not all deaths associated with hip fracture are due to the hip fracture event. It is estimated that approximately $30 \%$ of deaths are 
causally related [55]. When this is taken into account, hip fracture causes more deaths than road traffic accidents in Sweden and about the same number as those caused by breast cancer (Table 3).

Compared with other fractures, a great deal of information is available on the epidemiology of hip fracture. The reason is that nearly all patients with hip fracture are admitted to hospital and appear on discharge records. In most cases information is also available from surgical records. At most other sites of fracture, a minority of patients are admitted but may attend hospital on an outpatient basis.

\subsubsection{Vertebral fracture}

The vast majority of vertebral fractures are a result of moderate or minimal trauma [56]. The incidence and morbidity of vertebral fractures are not well documented, in part related to the difficulties in defining vertebral fracture, and also because of the non-specific nature of the morbidity occasioned by the disorder (e.g., back pain). Thus, the diagnosis is made on a change in the shape of the vertebral body on x-rays. The deformities that result from osteoporotic fracture are usually classified as a crush fracture (involving compression of the entire vertebral body), a wedge fracture (in which there is anterior or posterior height loss), and biconcavity (where there is relative maintenance of the anterior and posterior heights with central compression of the end-plate regions). A number of morphometric approaches has been developed to quantify the shape of the vertebral body from radiographs of the lateral spine, and this has helped in defining the prevalence and incidence of vertebral fracture. A widely used clinical system is to classify vertebral fractures as mild (20-25\% height loss), moderate (25-40\% height loss), or severe (>40\% height loss) [57].

A further problem in describing the epidemiology of vertebral fracture is that not all fractures come to clinical attention [58-61]. Estimates for the proportion of vertebral deformities that reach primary care attention vary, however, in different countries [58, 60-62]. In register studies, the discharge rate for hospitalised vertebral fractures is closely correlated with the discharge rate for hip fracture [59]. In Sweden, approximately $23 \%$ of vertebral deformities come to clinical attention in women, and a somewhat higher proportion in men [60]. A similar proportion has been observed in the placebo wing of multinational intervention studies [63]. For the purpose of this report that deals with the burden of disease, vertebral fractures are defined as those coming to clinical attention ("clinical vertebral fractures').

Vertebral fractures may give rise to pain, loss of height and progressive curvature of the spine (kyphosis). The consequences of kyphosis include difficulties in performing daily activities and a loss of self-esteem due to the change in body shape. Severe kyphosis also gives rise to respiratory and gastrointestinal disorders. Although vertebral fractures that come to clinical attention are less costly than hip fractures, the morbidity from an acute fracture in the first year is nearly as severe as that due to a hip fracture [64] and is associated with an increase in mortality [65]. Vertebral fractures are also a very strong risk factor for a further fracture at the spine and elsewhere [34-36, 66].

\subsubsection{Distal forearm fracture}

The most common distal forearm fracture is a Colles' fracture. This fracture lies within $2.5 \mathrm{~cm}$ of the wrist joint

Table 3 Causes of death in men and women aged 45 years or more from Sweden [55]

\begin{tabular}{lcccc}
\hline & Men & Women & Total & Share of all deaths (\%) \\
\hline $\begin{array}{l}\text { Acute myocardial } \\
\text { infarction }\end{array}$ & 7,113 & 5,335 & 12,449 & 13 \\
Lung cancer & 1,761 & 1,112 & 2,873 & 3 \\
Prostate cancer & 2,480 & 0 & 2,480 & 3 \\
Breast cancer & 11 & 1,549 & 1,560 & 2 \\
Hip fracture & 566 & 854 & 1,420 & 2 \\
Transport accident & 422 & 142 & 564 & 1 \\
\hline
\end{tabular}


margin and is associated with dorsal angulation and displacement of the distal fragment of the radius. It may be accompanied by a fracture of the ulna styloid process. A Smith fracture resulting in ventral angulation usually follows a forcible flexion injury to the wrist and is relatively uncommon in the elderly.

The cause of fracture is usually a fall on the outstretched hand [54]. Although fractures of the forearm cause less morbidity than hip fractures, are rarely fatal, and seldom require hospitalisation, the consequences are often underestimated. Fractures are painful and need 4-6 weeks in plaster. Approximately $1 \%$ of patients with a forearm fracture become dependent as a result of the fracture [67], but nearly half report only fair or poor functional outcome at 6 months [68]. There is a high incidence of algodystrophy - a syndrome which gives rise to pain, tenderness, stiffness and swelling of the hand, and more rarely to frozen shoulder syndrome [69]. Moreover, the risk of other osteoporotic fractures in later life is also increased after Colles' fracture $[34,35,66]$.

\subsection{Fracture burden worldwide}

There is a marked difference in the incidence of hip fracture worldwide and probably in other osteoporotic fractures [28] (Fig. 6). Indeed, the difference in incidence between countries is much greater than the

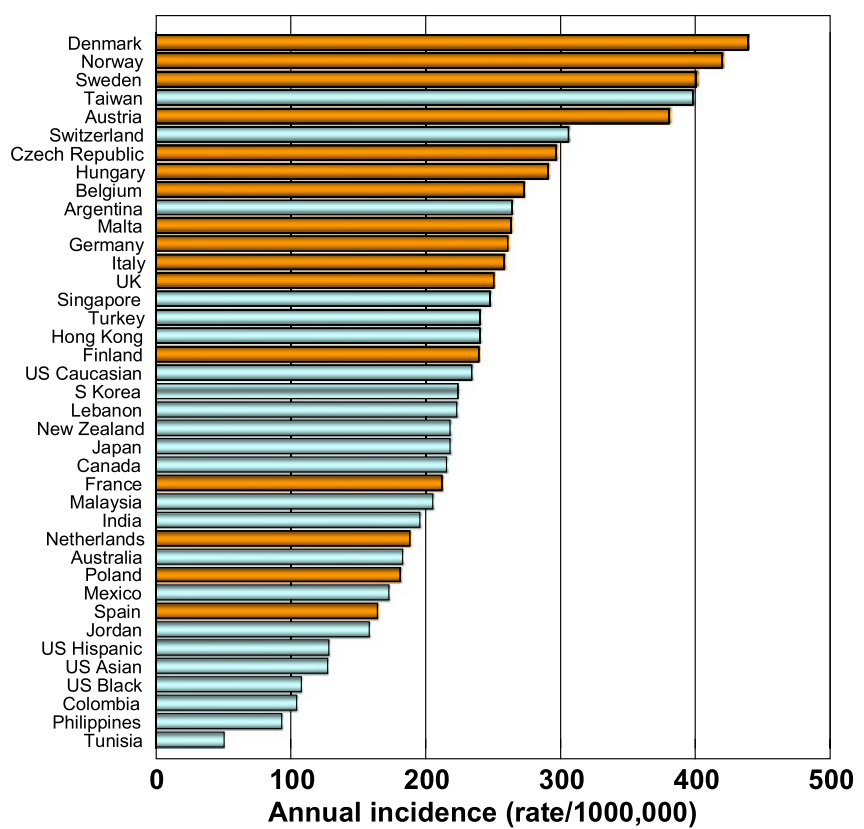

Fig. 6 Annual incidence of hip fracture in men and women from selected countries standardized to the world population for 2010 [28]. EU countries are highlighted differences in incidence between sexes within a country $[26,27]$. The EU comprises countries with some of the highest hip fracture rates which are considered in Chapter 3.

Many risk factors for osteoporosis, and in particular for hip fracture have been identified which include a low body mass index (BMI), low calcium intake, reduced sunlight exposure and early menopause. These may have important effects within communities but do not explain differences in risk between communities. The factor which best predicts this is socio-economic prosperity that in turn may be related to low levels of physical activity [70] (Fig. 7). This is plausible, but only a hypothesis. It will be important to determine whether this and other factors are truly responsible for the heterogeneity of fracture risk. If such factors can be identified and are reversible, the primordial prevention of hip fracture in those communities with presently low rates might be feasible and, conversely, primary prevention of hip fracture in communities with high rates might be undertaken.

Osteoporosis causes more than 8.9 million fractures annually worldwide (Table 4) - approximately 1,000 per hour [48]. Fracture rates are higher in the western world than in other regions so that, despite the lower population, slightly more than one-third of all osteoporotic fractures occur in Europe.

10 -year hip fracture probability (\%)

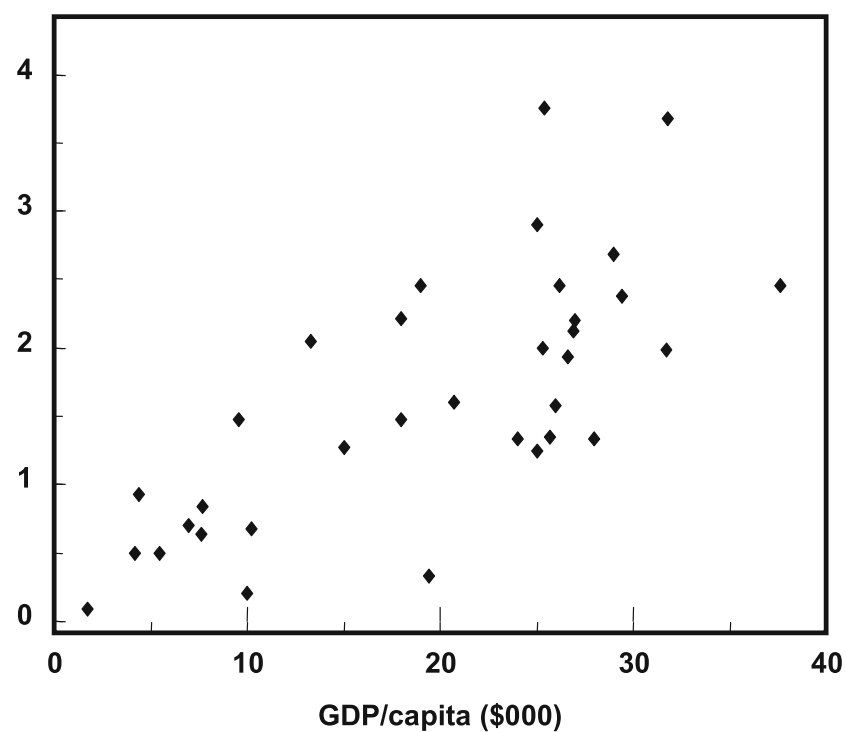

Fig. 7 Correlation between age standardized incidence of hip fracture in women in different countries and gross domestic product (GDP) per capita [70] 
Table 4 Number of osteoporotic fractures by site, in men and women aged 50 years or more in 2000, by WHO region [48]

\begin{tabular}{|c|c|c|c|c|c|c|}
\hline \multirow[b]{2}{*}{ WHO region } & \multicolumn{4}{|c|}{$\begin{array}{l}\text { Number of fractures by site } \\
\text { (thousands) }\end{array}$} & \multicolumn{2}{|c|}{$\begin{array}{l}\text { All osteoporotic } \\
\text { fractures (thousands) }\end{array}$} \\
\hline & Hip & Spine & $\begin{array}{l}\text { Proximal } \\
\text { Humerus }\end{array}$ & Forearm & No. & $\%$ \\
\hline Africa & 8 & 12 & 6 & 16 & 75 & 0.8 \\
\hline Americas & 311 & 214 & 111 & 248 & 1,406 & 15.7 \\
\hline South-East Asia & 221 & 253 & 121 & 306 & 1,562 & 17.4 \\
\hline Europe & 620 & 490 & 250 & 574 & 3,119 & 34.8 \\
\hline $\begin{array}{l}\text { Eastern } \\
\text { Mediterranean }\end{array}$ & 35 & 43 & 21 & 52 & 261 & 2.9 \\
\hline Western Pacific ${ }^{a}$ & 432 & 405 & 197 & 464 & 2,536 & 28.6 \\
\hline All regions & 1627 & 1417 & 706 & 1660 & 8,959 & \\
\hline
\end{tabular}

${ }^{a}$ Includes Australia, China, Japan, New Zealand and the Republic of Korea

The global burden of osteoporosis can be quantified by DALYs [71]. This integrates the years of life lost due to a fracture and the disability in those that survive. A year lost due to premature mortality is equal to one DALY. If the quality of life is halved by a fracture $(1=$ death; $0=$ perfect health), then a year of life disabled is equal to a DALY of 0.5 . In the year 2000 there were an estimated 9 million osteoporotic fractures world-wide of which 1.6 million were at the hip, 1.7 million at the forearm and 1.4 million were clinical vertebral fractures. The total DALYs lost was 5.8 million accounting for $0.83 \%$ of the global burden of non-communicable disease. In Europe osteoporotic fractures account for 2 million DALYs annually, somewhat more than accounted for by hypertensive heart disease and rheumatoid arthritis [48], but less than chronic obstructive pulmonary disease (Fig. 8). With the exception of lung cancer, fractures due to osteoporosis account for more combined deaths and morbidity than any cancer type (Fig. 9). Collectively, osteoporotic fractures account for approximately $1 \%$ of the DALYs attributable to non-communicable diseases in Europe.

\subsection{The future burden}

The frequency of osteoporotic fracture is rising in many countries. In some other countries such as the UK and
US, rates have stabilised or even slightly decreased $[72,73]$. Reasons for an increase relate in part to the increased longevity of the population, which is occurring both in the developed and developing world.

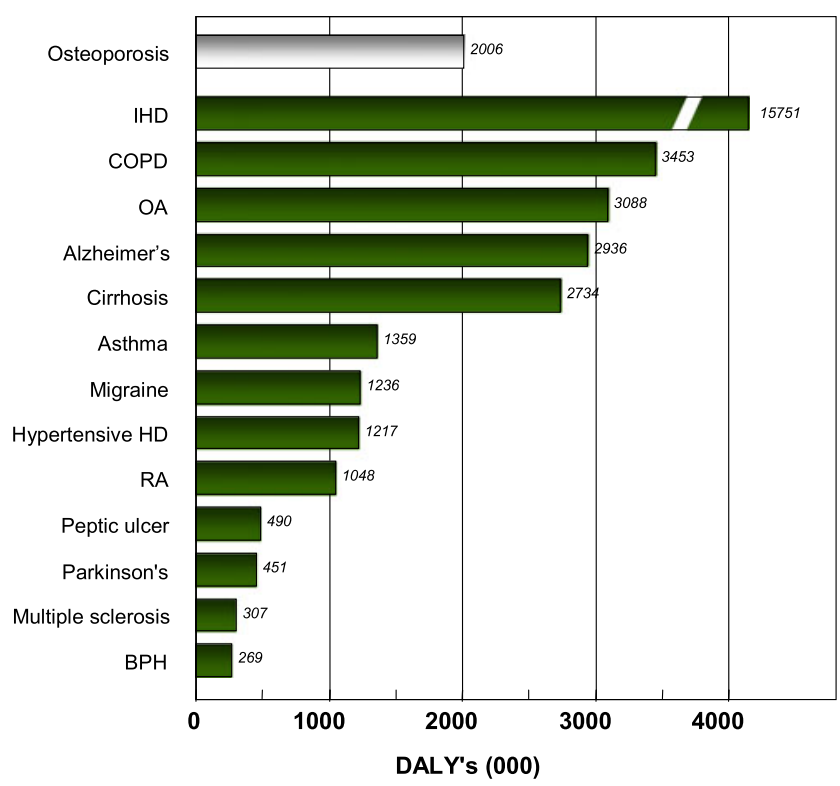

Fig. 8 Burden of diseases estimated as DALYs in 2002 in Europe for the non-communicable diseases shown [48]. IHD: Ischemic heart disease, COPD: Chronic obstructive pulmonary disease, OA: Osteoarthritis, HD: heart disease, RA: Rheumatoid arthritis, BPH: Benign prostatic hyperplasia 


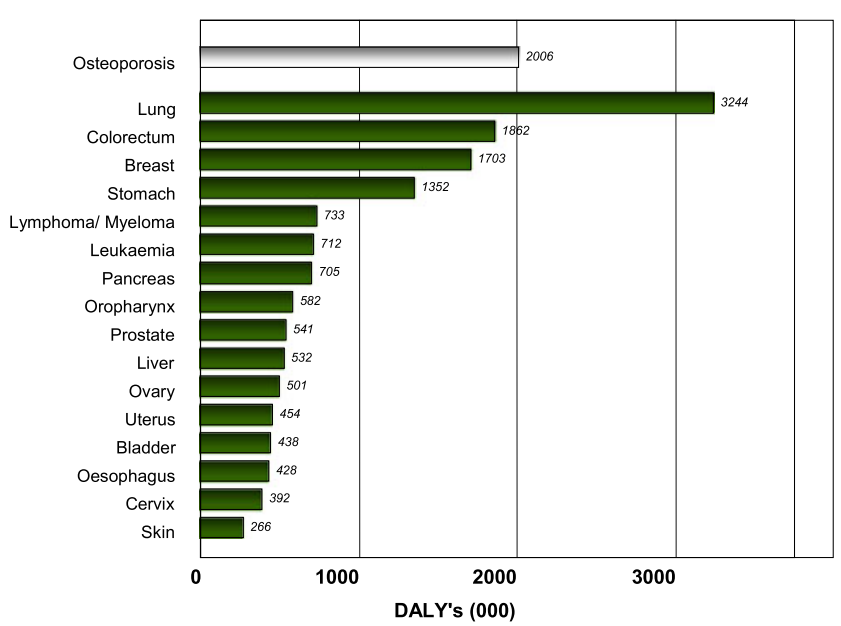

Fig. 9 Burden of diseases estimated as DALYs for osteoporosis and specific sites of cancer in 2002 in Europe [48]

Improvements in socio-economic prosperity that in turn decrease everyday levels of physical activity may be a factor associated with increasing fracture rates. In Europe, the total population will not increase markedly over the next 25 years, but the proportion accounted for by the elderly will increase by $56 \%$ in men and by $41 \%$ in women. In the developing world, the total population as well as life expectancy of the elderly will increase by more than two-fold over the next 25 years, so that osteoporotic fractures will assume even greater significance for health care planning. For the very elderly, the size of the population aged 85 years or more will increase by $129 \%$ in men and by $73 \%$ in women. These projections are relatively robust in the sense that all individuals who will be elderly in 2035 are already born.

There are important differences in demographic shifts between the EU countries. For example, the number of men and women aged 65 years or more will increase by $50.6 \%$ in the EU but the increase ranges from $10.4 \%$ in Bulgaria to $117.3 \%$ in Ireland (Fig. 10). Moreover the economic burden will increase further in the sense that the productive segment of the population to sustain this increase will decrease in size. For example, in 2010 the population aged 20-64 years was 307.3 million but will decrease by $9 \%$ to 279.8 million in 2035 [74].

The number of hip fractures has been estimated to more than double over an interval of 50 years assuming no change in age-specific risk [73, 75] but would more than quadruple with rather conservative estimates of the secular trend [73] (Table 5).

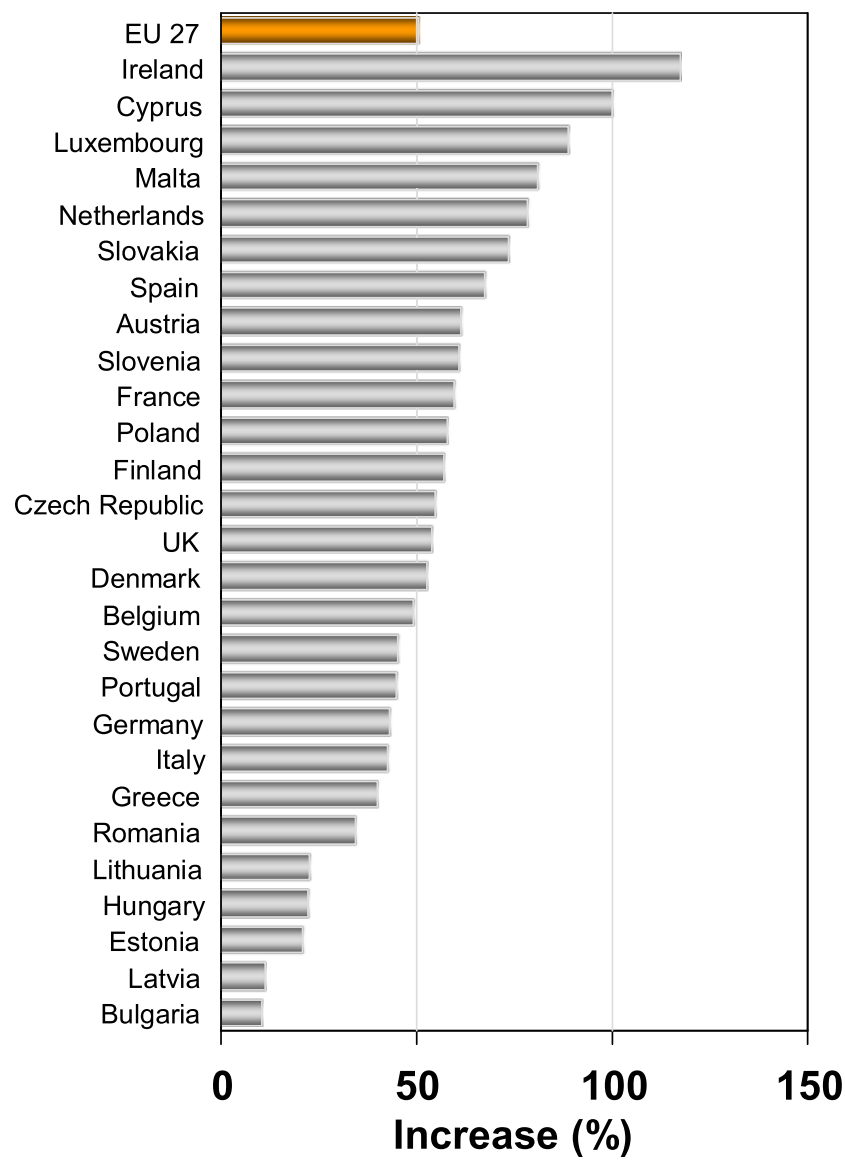

Fig. 10 Predicted increases in the population (men and women) aged 65 years or more in the EU by country [74]

Table 5 Number of hip fractures estimated worldwide for the year 2000 and those projected by demographic changes alone and those assuming additional increases in age- and sex-specific risk [73]

\begin{tabular}{llcc}
\hline Year & Scenario & $\begin{array}{c}\text { Hip fractures } \\
\text { (thousands) }\end{array}$ & Increment \\
\hline 2000 & Base case & 1,503 & 1 \\
2050 & Age effect & 4,493 & 3 \\
& 1\% secular trend & 8,162 & 5.4 \\
& 2\% (0\% Europe \& US) & 12,335 & 8.2 \\
& 3\% (0\% Europe \& US) & 21,310 & 14.2 \\
\hline
\end{tabular}




\section{References}

1. (1993) Consensus development conference: diagnosis, prophylaxis, and treatment of osteoporosis. Am J Med 94:646-650

2. WHO (1994) Assessment of fracture risk and its application to screening for postmenopausal osteoporosis. WHO Study Group. World Health Organ Tech Rep Ser 843:1-129

3. Strom O, Borgstrom F, Kanis JA, Compston J, Cooper C, McCloskey EV, Jonsson B (2011) Osteoporosis: burden, health care provision and opportunities in the EU: a report prepared in collaboration with the International Osteoporosis Foundation (IOF) and the European Federation of Pharmaceutical Industry Associations (EFPIA). Arch Osteoporos 6:59-155

4. Genant HK, Lang TF, Engelke K, Fuerst T, Gluer C, Majumdar $\mathrm{S}$, Jergas M (1996) Advances in the noninvasive assessment of bone density, quality, and structure. Calcif Tissue Int 59 Suppl 1:S10-S15

5. Kanis JA on behalf of the World Health Organization Scientific Group (2008) Assessment of osteoporosis at the primary healthcare level. Technical Report. WHO Collaborating Centre, University of Sheffield, UK. Available at: http://www.shef.ac.uk/FRAX/ pdfs/WHO_Technical_Report.pdf

6. Kanis JA, McCloskey EV, Johansson H, Oden A, Melton LJ, III, Khaltaev N (2008) A reference standard for the description of osteoporosis. Bone 42:467-475

7. McCloskey EV, Vasireddy S, Threlkeld J, Eastaugh J, Parry A, Bonnet N, Beneton M, Kanis JA, Charlesworth D (2008) Vertebral fracture assessment (VFA) with a densitometer predicts future fractures in elderly women unselected for osteoporosis. J Bone Miner Res 23:1561-1568

8. Schousboe JT, Debold CR (2006) Reliability and accuracy of vertebral fracture assessment with densitometry compared to radiography in clinical practice. Osteoporos Int 17:281289

9. Kanis JA, Melton LJ, III, Christiansen C, Johnston CC, Khaltaev N (1994) The diagnosis of osteoporosis. J Bone Miner Res 9:1137-1141

10. Looker AC, Wahner HW, Dunn WL, Calvo MS, Harris TB, Heyse SP, Johnston CC, Jr., Lindsay R (1998) Updated data on proximal femur bone mineral levels of US adults. Osteoporos Int 8:468-489

11. De Laet CE, Van Hout BA, Burger H,Weel AE, Hofman A, Pols HA (1998) Hip fracture prediction in elderly men and women: validation in the Rotterdam study. J Bone Miner Res 13:15871593

12. Johnell O, Kanis JA, Oden A, et al. (2005) Predictive value of BMD for hip and other fractures. J Bone Miner Res 20:11851194

13. Kanis JA, Bianchi G, Bilezikian JP, Kaufman JM, Khosla S, Orwoll E, Seeman E (2011) Towards a diagnostic and therapeutic consensus in male osteoporosis. Osteoporos Int 22:2789-2798

14. De Laet C, Oden A, Johansson H, Johnell O, Jonsson B, Kanis JA (2005) The impact of the use of multiple risk indicators for fracture on case-finding strategies: a mathematical approach. Osteoporos Int 16:313-318

15. Kanis JA, Johnell O, Oden A, Jonsson B, De Laet C, Dawson A (2000) Risk of hip fracture according to the World Health Organization criteria for osteopenia and osteoporosis. Bone 27:585590
16. Gauthier A, Kanis JA, Jiang Y, Martin M, Compston JE, Borgstrom F, Cooper C, McCloskey EV (2011) Epidemiological burden of postmenopausal osteoporosis in the UK from 2010 to 2021: estimations from a disease model. Arch Osteoporos $6: 179-188$

17. Gauthier A, Kanis JA, Martin M, Compston J, Borgstrom F, Cooper C, McCloskey E (2011) Development and validation of a disease model for postmenopausal osteoporosis. Osteoporos Int 22:771-780

18. Karlsson MK, Gardsell P, Johnell O, Nilsson BE, Akesson K, Obrant KJ (1993) Bone mineral normative data in Malmo, Sweden. Comparison with reference data and hip fracture incidence in other ethnic groups. Acta Orthop Scand 64:168-172

19. Lofman O, Larsson L, Ross I, Toss G, Berglund K (1997) Bone mineral density in normal Swedish women. Bone 20:167-174

20. Parr RM, Dey A, McCloskey EV, et al. (2002) Contribution of calcium and other dietary components to global variations in bone mineral density in young adults. Food Nutr Bull 23:180 184

21. Holt G, Khaw KT, Reid DM, et al. (2002) Prevalence of osteoporotic bone mineral density at the hip in Britain differs substantially from the US over 50 years of age: implications for clinical densitometry. Br J Radiol 75:736-742

22. Lunt M, Felsenberg D, Adams J, et al. (1997) Population-based geographic variations in DXA bone density in Europe: the EVOS Study. European Vertebral Osteoporosis. Osteoporos Int 7:175189

23. Noon E, Singh S, Cuzick J, et al. (2010) Significant differences in UK and US female bone density reference ranges. Osteoporos Int 21:1871-1880

24. Paggiosi MA, Glueer CC, Roux C, Reid DM, Felsenberg D, Barkmann R, Eastell R (2011) International variation in proximal femur bone mineral density. Osteoporos Int 22:721-729

25. Bacon WE, Maggi S, Looker A, et al. (1996) International comparison of hip fracture rates in 1988-89. Osteoporos Int 6:69-75

26. Elffors I, Allander E, Kanis JA, Gullberg B, Johnell O, Dequeker J, Dilsen G, Gennari C, Lopes Vaz AA, Lyritis G (1994) The variable incidence of hip fracture in southern Europe: the MEDOS Study. Osteoporos Int 4:253-263

27. Johnell O, Gullberg B, Allander E, Kanis JA (1992) The apparent incidence of hip fracture in Europe: a study of national register sources. MEDOS Study Group. Osteoporos Int 2:298-302

28. Kanis JA, Oden A, McCloskey EV, Johansson H, Wahl DA, Cooper C, IOF Working group on Epidemiology and Quality of Life (2012) A systematic review of hip fracture incidence and probability of fracture worldwide. Osteoporos Int 23:2239-2256

29. Melton LJ, III, Thamer M, Ray NF, Chan JK, Chesnut CH, III, Einhorn TA, Johnston CC, Raisz LG, Silverman SL, Siris ES (1997) Fractures attributable to osteoporosis: report from the National Osteoporosis Foundation. J Bone Miner Res 12:16-23

30. Mackey DC, Lui LY, Cawthon PM, Bauer DC, Nevitt MC, Cauley JA, Hillier TA, Lewis CE, Barrett-Connor E, Cummings SR (2007) High-trauma fractures and low bone mineral density in older women and men. JAMA 298:2381-2388

31. Sanders KM, Pasco JA, Ugoni AM, Nicholson GC, Seeman E, Martin TJ, Skoric B, Panahi S, Kotowicz MA (1998) The 
exclusion of high trauma fractures may underestimate the prevalence of bone fragility fractures in the community: the Geelong Osteoporosis Study. J Bone Miner Res 13:1337-1342

32. Seeley DG, Browner WS, Nevitt MC, Genant HK, Scott JC, Cummings SR (1991) Which fractures are associated with low appendicular bone mass in elderly women? The Study of Osteoporotic Fractures Research Group. Ann Intern Med 115:837842

33. Stone KL, Seeley DG, Lui LY, Cauley JA, Ensrud K, Browner WS, Nevitt MC, Cummings SR (2003) BMD at multiple sites and risk of fracture of multiple types: longterm results from the Study of Osteoporotic Fractures. J Bone Miner Res 18:1947-1954

34. Johnell O, Oden A, Caulin F, Kanis JA (2001) Acute and long-term increase in fracture risk after hospitalization for vertebral fracture. Osteoporos Int 12:207-214

35. Klotzbuecher CM, Ross PD, Landsman PB, Abbott TA, III, Berger M (2000) Patients with prior fractures have an increased risk of future fractures: a summary of the literature and statistical synthesis. J Bone Miner Res 15:721-739

36. Kotowicz MA, Melton LJ, III, Cooper C, Atkinson EJ, O'Fallon WM, Riggs BL (1994) Risk of hip fracture in women with vertebral fracture. J Bone Miner Res 9:599-605

37. Melton LJ, III, Atkinson EJ, Cooper C, O'Fallon WM, Riggs BL (1999) Vertebral fractures predict subsequent fractures. Osteoporos Int 10:214-221

38. Ross PD, Davis JW, Epstein RS, Wasnich RD (1991) Pre-existing fractures and bone mass predict vertebral fracture incidence in women. Ann Intern Med 114:919-923

39. Cuddihy MT, Gabriel SE, Crowson CS, O'Fallon WM, Melton LJ, III (1999) Forearm fractures as predictors of subsequent osteoporotic fractures. Osteoporos Int 9:469-475

40. Kanis JA, Oden A, Johnell O, Jonsson B, De Laet C, Dawson A (2001) The burden of osteoporotic fractures: a method for setting intervention thresholds. Osteoporos Int 12:417-427

41. Delmas PD, Marin F, Marcus R, Misurski DA, Mitlak BH (2007) Beyond hip: importance of other nonspinal fractures. Am J Med 120:381-387

42. Nguyen TV, Eisman JA, Kelly PJ, Sambrook PN (1996) Risk factors for osteoporotic fractures in elderly men. Am J Epidemiol 144:255-263

43. Kanis JA, Johnell O, Oden A, Sembo I, Redlund-Johnell I, Dawson A, De Laet C, Jonsson B (2000) Long-term risk of osteoporotic fracture in Malmo. Osteoporos Int 11:669674

44. Cummings SR, Kelsey JL, Nevitt MC, O’Dowd KJ (1985) Epidemiology of osteoporosis and osteoporotic fractures. Epidemiol Rev 7:178-208

45. Center JR, Nguyen TV, Schneider D, Sambrook PN, Eisman JA (1999) Mortality after all major types of osteoporotic fracture in men and women: an observational study. Lancet 353:878-882

46. Bliuc D, Nguyen ND, Milch VE, Nguyen TV, Eisman JA, Center JR (2009) Mortality risk associated with lowtrauma osteoporotic fracture and subsequent fracture in men and women. JAMA 301:513-521

47. Trombetti A, Herrmann F, Hoffmeyer P, Schurch MA, Bonjour JP, Rizzoli R (2002) Survival and potential years of life lost after hip fracture in men and age-matched women. Osteoporos Int $13: 731-737$
48. Johnell O, Kanis JA (2006) An estimate of the worldwide prevalence and disability associated with osteoporotic fractures. Osteoporos Int 17:1726-1733

49. Melton L.J.III. (1995) Epidemiology of fractures. In Osteoporosis: etiology, diagnosis, and management. (Ed: Riggs B.L.; Melton L.J.), Lippincott-Raven Press, Philadelphia. 2nd edition: 225-47

50. Gibson M (1987) The prevention of falls in later life. Danish Medical Bulletin 34(Suppl. 4):1-24

51. Michaelsson K, Weiderpass E, Farahmand BY, Baron JA, Persson PG, Ziden L, Zetterberg C, Ljunghall S (1999) Differences in risk factor patterns between cervical and trochanteric hip fractures. Swedish Hip Fracture Study Group. Osteoporos Int $10: 487-494$

52. Keene GS, Parker MJ, Pryor GA (1993) Mortality and morbidity after hip fractures. BMJ 307:1248- 1250

53. Poor G, Atkinson EJ, O'Fallon WM, Melton LJ, III (1995) Determinants of reduced survival following hip fractures in men. Clin Orthop 260-265

54. Melton LJ, III (2003) Adverse outcomes of osteoporotic fractures in the general population. J Bone Miner Res 18:1139-1141

55. Kanis JA, Oden A, Johnell O, De Laet C, Jonsson B, Oglesby AK (2003) The components of excess mortality after hip fracture. Bone 32:468-473

56. WHO (2003) The burden of musculoskeletal conditions at the start of the new millennium. World Health Organization Tech Rep Ser 919: i-218

57. Genant HK, Jergas M, Palermo L, Nevitt M, Valentin RS, Black D, Cummings SR (1996) Comparison of semiquantitative visual and quantitative morphometric assessment of prevalent and incident vertebral fractures in osteoporosis The Study of Osteoporotic Fractures Research Group. J Bone Miner Res 11:984-996

58. Ettinger B, Black DM, Nevitt MC, Rundle AC, Cauley JA, Cummings SR, Genant HK (1992) Contribution of vertebral deformities to chronic back pain and disability. The Study of Osteoporotic Fractures Research Group. J Bone Miner Res 7:449-456

59. Johnell O, Gullberg B, Kanis JA (1997) The hospital burden of vertebral fracture in Europe: a study of national register sources. Osteoporos Int 7:138-144

60. Kanis JA, Johnell O, Oden A, Borgstrom F, Zethraeus N, De Laet C, Jonsson B (2004) The risk and burden of vertebral fractures in Sweden. Osteoporos Int 15:20-26

61. van Staa TP, Dennison EM, Leufkens HG, Cooper C (2001) Epidemiology of fractures in England and Wales. Bone 29:517-522

62. Cooper C, Atkinson EJ, O'Fallon WM, Melton LJ, III (1992) Incidence of clinically diagnosed vertebral fractures: a population-based study in Rochester, Minnesota, 1985-1989. J Bone Miner Res 7:221-227

63. Lindsay R, Silverman SL, Cooper C, et al. (2001) Risk of new vertebral fracture in the year following a fracture. JAMA 285:320-323

64. Peasgood T, Herrmann K, Kanis JA, Brazier JE (2009) An updated systematic review of Health State Utility Values for osteoporosis related conditions. Osteoporos Int 20:853- 868

65. Kanis JA, Oden A, Johnell O, De Laet C, Jonsson B (2004) Excess mortality after hospitalisation for vertebral fracture. Osteoporos Int 15:108-112

66. Johnell O, Kanis JA, OdenA, Sernbo I, Redlund-Johnell I, Petterson C, De Laet C, Jonsson B (2004) Fracture risk following an osteoporotic fracture. Osteoporos Int 15:175-179 
67. Chrischilles EA, Butler CD, Davis CS, Wallace RB (1991) A model of lifetime osteoporosis impact. Arch Intern Med 151:2026-2032

68. Kaukonen JP, Karaharju EO, Porras M, Luthje P, Jakobsson A (1988) Functional recovery after fractures of the distal forearm. Analysis of radiographic and other factors affecting the outcome. Ann Chir Gynaecol 77:27-31

69. Bickerstaff DR, Kanis JA (1994) Algodystrophy: an under-recognized complication of minor trauma. Br J Rheumatol 33:240 248

70. Johnell O, Borgstrom F, Jonsson B, Kanis J (2007) Latitude, socioeconomic prosperity, mobile phones and hip fracture risk. Osteoporos Int 18:333-337

71. Murray C, Lopez A (1996) Global and regional descriptive epidemiology of disability. Incidence, prevalence, health expectancies and years lived with disability. In Murray C, Lopez A (eds) The global burden of disease: a comprehensive assessment of mortality and disability from diseases, injuries and risk factors in 1990 and projected to 2020. Cambridge University Press, Cambridge, pp 201-246

72. Cooper C, Cole ZA, Holroyd CR, Earl SC, Harvey NC, Dennison EM, Melton LJ, Cummings SR, Kanis JA (2011) Secular trends in the incidence of hip and other osteoporotic fractures. Osteoporos Int 22:1277-1288

73. Gullberg B, Johnell O, Kanis JA (1997) World-wide projections for hip fracture. Osteoporos Int 7:407-413

74. United Nations Department of Economic and Social Affairs Population Division (2011)World Population Prospects test. Data accessed November, 2011. http://esa.un.org/unpd/wpp/unpp/ p2k0data.asp

75. Cooper C, Campion G, Melton LJ, III (1992) Hip fractures in the elderly: a world-wide projection. Osteoporos Int 2:285-289 


\section{Medical innovation and its clinical uptake in the management of osteoporosis}

\section{Summary}

In recent years, there has been a number of advances, particularly in the measurement of BMD, diagnosis of osteoporosis, the assessment of fracture risk, the development of interventions that reduce the risk of fractures and the production of practice guidelines. This chapter describes the current state of these aspects in the field of osteoporosis. Also, the costeffectiveness of osteoporosis treatments is addressed.

\section{The key messages of this chapter are:}

BMD forms a cornerstone for the general management of osteoporosis, being used for diagnosis, fracture risk assessment, selection of patients for treatment and monitoring of patients on treatment.

There is marked heterogeneity in the availability of $D X A$ in the EU, and most countries have insufficient resources to implement practice guidelines.

There is an important distinction to be made between the use of BMD for diagnosis and for fracture risk assessment. Fracture risk assessment is improved by the concurrent consideration of risk factors that operate independently of BMD.

FRAX models integrate the weight of clinical risk factors $(C R F S)$ for fracture risk, with or without information on $B M D$ and provide estimates of the probability of fracture. Models are available for 16 member states.

Austria, Belgium Denmark, Finland, Hungary and the UK have the highest usage of FRAX. If Denmark is excluded because of exceptionally high uptake, this amounts to an average of 4,800 tests/million of the general population which is within the estimated service requirement for FRAX. The uptake of FRAX is sub-optimal in the majority of EU countries for which models are available.

Approved pharmacological interventions include bisphosphonates, strontium ranelate, raloxifene, denosumab and parathyroid hormone peptides (PTHs). These are widely available but their use is restricted by reimbursement policies. Full or near full reimbursement is available in a minority of member states. In other countries reimbursement is partial or restricted to individuals with a prior fracture or to women only. Some countries that provide reimbursement exclude PTH.

Fracture prevention with generic alendronate in women aged 50 years and older at high risk of fracture is costeffective in most Western countries. Other treatments are cost-effective alternatives to no treatment, particularly in patients that cannot take alendronate.

Compliance and persistence with treatment for osteoporosis are poor; approximately $50 \%$ of patients do not follow their prescribed treatment regimen and/or discontinue treatment within 1 year.

Measures to improve adherence will lead to more avoided fractures and are cost-effective complements to currently available treatments.

In all national treatment guidelines a case-finding approach is suggested for patient identification. However, they vary in terms of which risk factors are acknowledged, how fracture risk should be assessed and how BMD measurements should be used.

Notwithstanding the availability of guidelines, recommendations in national guidelines are not always implemented.

\subsection{Introduction}

In recent years, there has been a number of advances, particularly in the measurement of BMD, the assessment of fracture risk, the development of interventions that reduce the risk of fractures and the production of practice guidelines. These advances have been extensively reviewed in an earlier report [1] but relevant sections are summarised in the present report to give the report appropriate context. A particular focus of the chapter is to describe the manner in which these advances have been applied in member states.

\subsection{Use of BMD}

The assessment of bone mass forms a cornerstone for the general management of osteoporosis being used for diagnosis, risk prediction, selection of patients for treatment and monitoring of patients on treatment [2].

In addition to categorising individuals as having or not having osteoporosis (Chapter 1), a much more important use of bone mineral measurement is to provide prognostic information of future fracture risk $[3,4]$. A further use is as a tool to monitor changes in bone mass in a treated or untreated patient, though this remains a somewhat contentious issue [5-7].

\subsubsection{Availability of DXA}

The requirement for assessing and monitoring the treatment of osteoporosis in accordance with practice guidelines has been estimated at 10.6 DXA units per million of the general population [8]. Several surveys have indicated marked heterogeneity in the availability of DXA in the EU [8,9] and a recent survey, based on 


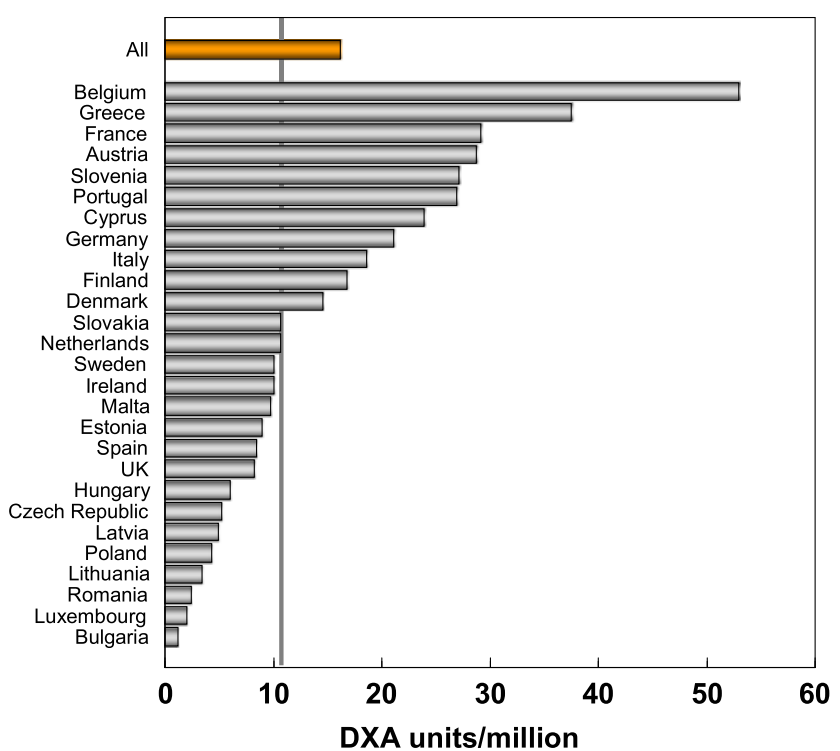

Fig. 11 DXA units/million of the general population in 2010 based on sales of DXA in the EU supplied by manufacturers (Kanis J.A. personal communication, 2011)

manufacturer sales, confirms this finding (Kanis J.A. personal communication 2011). The survey indicated that about $50 \%$ of countries in the EU had the recommended number of DXA machines for their population. It is important to note that the figures provided do not distinguish machines dedicated in part or in full to clinical research, or machines that lie idle or are underutilised because of lack of funding. It is likely, therefore, that a majority of countries are underresourced in the context of practice guidelines.

A further consideration is the uneven geographical location of equipment, which is known to be problematic in Italy, Spain and the UK. This inequity results in long waiting times or long distances to travel or, in many cases, no practical access at all. A recent audit of the IOF [10] (an update of an earlier audit [9]) reported that the average waiting time among the EU countries is 29 days but ranges from 0 to 6 months in different countries. Within countries there may also be a large range in waiting times, in some instances up to 1 year. The median waiting times are shown in Fig. 12. There is no clear relationship between waiting times and the availability of DXA. For example, the average waiting time in Italy is reported to be 83 days, though the availability is high (18.6 machines/million of the general population). Conversely, there is no waiting time in Bulgaria where the provision of DXA is low. The latter observation presumably reflects the fact that the few machines available are only used to service specialised departments and that BMD assessments are unavailable to the vast majority of the population at risk. The disparity between the availability of equipment and waiting time identifies a high heterogeneity in the use of BMD to assess osteoporosis.

Reimbursement for DXA scans varies widely between member states both in terms of the criteria required and level of reimbursement awarded but only a minority of countries (11/27) provided full reimbursement under any circumstances in 2008. Since then reimbursement policies have improved and 18 countries offered unconditional reimbursement in 2013 [10] (Table 6). In others, reimbursement or partial reimbursement is limited and usually dependent on physician referral for approved indications, sometimes restricted to criteria that do not satisfy the requirements of good clinical practice. An example is seen in Bulgaria (and incidentally in Switzerland) where reimbursement is only offered if the BMD test turns out to be positive (i.e. shows osteoporosis). The cost of DXA also varies widely (Table 6) and bears little relationship to the wealth of the nation or to the availability of DXA machines.

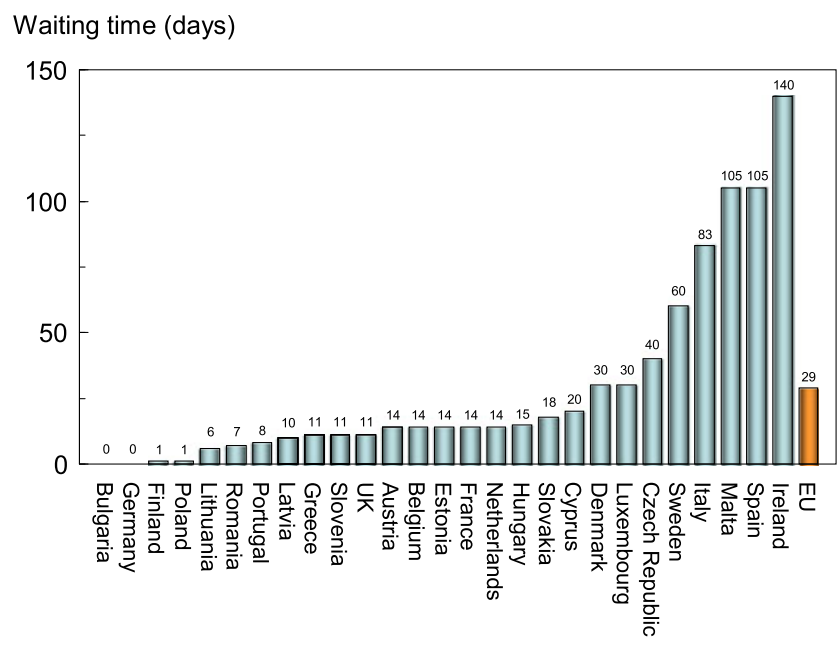

Fig. 12 Average waiting time for a DXA assessment by EU country [10] 
Table 6 The number and provision of central DXA units available in the EU27 (Data on reimbursement and waiting time [10])

\begin{tabular}{|c|c|c|c|c|}
\hline & $\begin{array}{c}\text { DXA } \\
\text { units/million }\end{array}$ & $\begin{array}{l}\text { Waiting } \\
\text { time (d) }\end{array}$ & Cost $(€)$ & Reimbursement \\
\hline Austria & 28.7 & 14 & $30[11]$ & yes \\
\hline Belgium & 53 & 14 & $34[12]$ & partial \\
\hline Bulgaria & 1.2 & 0 & $59[9]$ & none \\
\hline Cyprus & 23.9 & 20 & $75[9]$ & yes (depending on income) \\
\hline Czech Republic & 5.2 & $40^{*}$ & $32[9]$ & yes \\
\hline Denmark & 14.6 & 30 & $187[13]$ & yes \\
\hline Estonia & 8.9 & 14 & 14 [14] & yes \\
\hline Finland & 16.8 & 1 & $146[15]$ & yes \\
\hline France & 29.1 & 14 & $41[9]$ & yes (conditional) \\
\hline Germany & 21.1 & 0 & $36[9]$ & yes \\
\hline Greece & 37.5 & $11^{*}$ & 115 [9] & yes \\
\hline Hungary & 6.0 & $15^{*}$ & $7[16]$ & yes \\
\hline Ireland & 10.0 & $140^{* a}$ & 99 [17] & yes (conditional) \\
\hline Italy & 18.6 & $83^{*}$ & $81[9]$ & yes (conditional) \\
\hline Latvia & 4.9 & $10^{*}$ & $18[18]$ & yes \\
\hline Lithuania & 3.4 & $6^{*}$ & 28 [19] & no \\
\hline Luxembourg & 2.0 & 30 & $59[20]$ & yes \\
\hline Malta & 9.7 & $105^{*}$ & $184[21]$ & yes \\
\hline Netherlands & 10.7 & $14^{*}$ & $84[22]$ & yes \\
\hline Poland & 4.3 & 1 & $10[9]$ & yes (conditional) \\
\hline Portugal & 26.9 & 8 & $5[23]$ & yes \\
\hline Romania & 2.4 & 7 & $5[24]$ & yes \\
\hline Slovakia & 10.7 & $18^{*}$ & $32[9]$ & yes \\
\hline Slovenia & 27.1 & $11^{*}$ & $29[25]$ & yes (conditional) \\
\hline Spain & 8.4 & $105^{*}$ & 109 [9] & yes \\
\hline Sweden & 10.0 & 60 & $152[26]$ & yes \\
\hline UK & 8.2 & $11^{*}$ & 51 [27] & yes $^{d}$ \\
\hline All & 16.2 & 29 & & \\
\hline
\end{tabular}

* average of range; ${ }^{\mathrm{a}}$ data; ${ }^{\mathrm{d}}$ days 


\subsection{Assessment of fracture risk}

Although the diagnosis of the disease relies on the quantitative assessment of BMD, which is a major determinant of bone strength, the clinical significance of osteoporosis lies in the fractures that arise. In this respect, there are some analogies with other multifactorial chronic diseases. For example, hypertension is diagnosed on the basis of blood pressure, whereas an important clinical consequence of hypertension is stroke. Because a variety of non-skeletal factors contributes to fracture risk [4, 28], the diagnosis of osteoporosis by the use of BMD measurements is at the same time an assessment of a risk factor for the clinical outcome of fracture. For these reasons there is a distinction to be made between the use of BMD for diagnosis and for risk assessment.

\subsubsection{Assessing risk with BMD}

The use of bone mass measurements for prognosis depends upon accuracy. Accuracy in this context is the ability of the measurement to predict fracture. As reviewed previously, many prospective population studies indicate that the risk for fracture increases by a factor of 1.5 to 3.0 for each SD decrease in BMD [29]. The ability of BMD to predict fracture is comparable to the use of blood pressure to predict stroke, and significantly better than serum cholesterol to predict myocardial infarction $[3,4]$. The highest gradient of risk is found at the hip to predict hip fracture where the fracture risk increases 2.6 fold for each SD decrease in hip BMD.

Despite these performance characteristics, it should be recognised that just because BMD is normal, there is no guarantee that a fracture will not occur-only that the risk is lower. Conversely, if BMD is in the osteoporotic range, then fractures are more likely, but not invariable. The principal difficulty is that BMD alone has high specificity but low sensitivity, so that the majority of osteoporotic fractures will occur in individuals with BMD values above the osteoporosis threshold [30-34]. The low sensitivity is one of the reasons why widespread population-based screening is not recommended in women at the time of the menopause.

\subsubsection{Clinical risk factors (CRFs)}

The performance characteristics of the test can, however, be improved by the concurrent consideration of risk factors that operate independently of BMD. A good example is age. The same T-score with the same technique at any one site has a different prognostic significance at different ages [35, 36], indicating that age contributes to risk independently of BMD (Fig. 13). Thus, the consideration of age and BMD together increases the range of risk that can be identified.

There are, however, a large number of additional risk factors that provide information on fracture risk independently of both age and BMD. A caveat is that some risk factors may not identify a risk that is amenable to particular treatments, so that the relationship between absolute probability of fracture and reversibility of risk is important [37]. Liability to falls is an appropriate example where the risk of fracture is high, but treatment with agents affecting bone metabolism may have little effect [38].

Over the past few years a series of meta-analyses has been undertaken to identify internationally validated independent CRFs to be used in case finding strategies with or without the use of BMD. These are summarised in Table 7 [39] and form the input to compute fracture probability with FRAX. Detailed considerations of the CRFs used have been recently reviewed $[1,40]$.

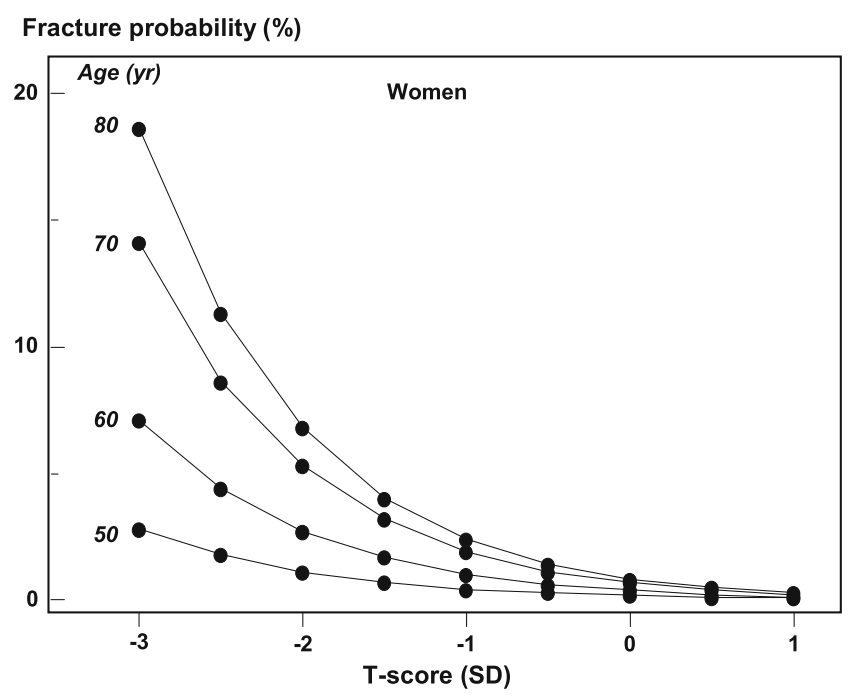

Fig. 13 The relationship between $B M D$ at the femoral neck expressed as a T-score and 10-year hip fracture probability in women from Sweden according to age. For any given T-score, the probability of fracture is higher with increasing age [36], with kind permission from Springer Science and Business Media 
Table 7 Clinical risk factors used for the assessment of fracture probability with FRAX [28]

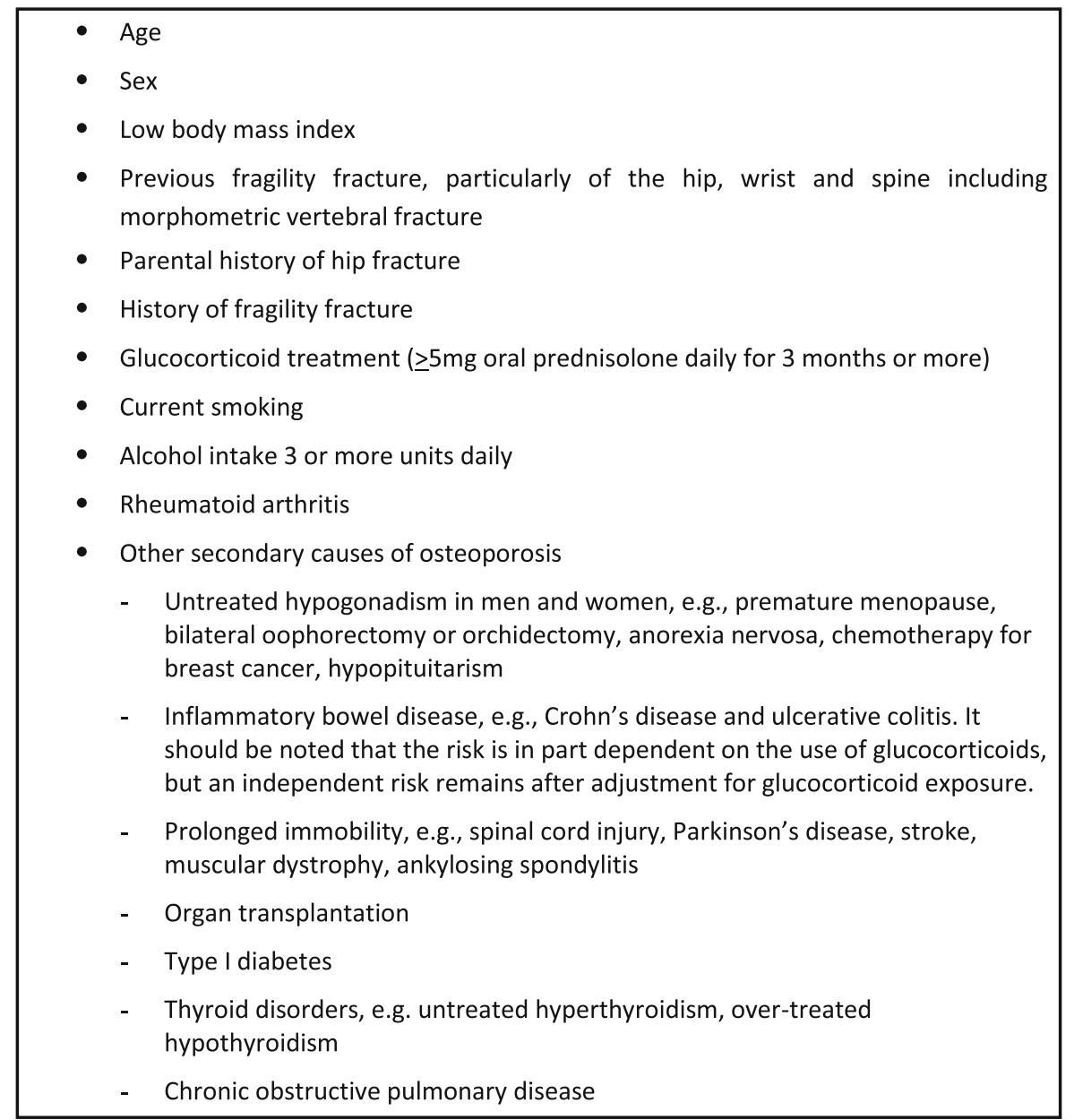

\subsection{FRAX ${ }^{\circledR}$}

FRAX models are algorithms that integrate the weight of CRFs for fracture risk, with or without information on BMD. They were developed by the WHO Collaborating Centre for Metabolic Bone Diseases at Sheffield, UK and launched in 2008 [28]. Femoral neck BMD or the T-score equivalent may be optionally input. The FRAX tool (www.shef.ac.uk/FRAX) computes the 10-year probability of hip fracture or a major osteoporotic fracture. A major osteoporotic fracture is a clinical spine, hip, forearm and humerus fracture.
FRAX computes a fracture probability. The probability of fracture depends upon age and life expectancy as well as the current relative risk. Thus, where the risk of death is high, the probability of fracture will decrease for the same fracture hazard. The Poisson regression models used in the development of the FRAX model allow the interaction between the identified CRFs, fracture, death and the time parameter to be incorporated. For example, they account for the impact of smoking or low BMI not only on fracture risk but also on the risk of death. The latter is a unique feature compared to other fracture prediction tools $[41,42]$. 
Facture risk and mortality differ markedly in different countries so that FRAX models are calibrated to the epidemiology of specific countries where appropriate information is available. In Europe, models are available for Austria, Belgium, Czech Republic, Finland, France, Germany, Hungary, Italy, Malta, Netherlands, Norway, Poland, Romania, Spain, Sweden, Switzerland and the UK. The 10-year probability of a major osteoporotic fracture for a 65 -year old man or woman with previous fracture, a femoral neck T-score of $-2.5 \mathrm{SD}$, a BMI of $25 \mathrm{~kg} / \mathrm{m}^{2}$ and no other risk factors for various European countries is shown in Fig. 14. As in the case of hip fracture, there is a marked heterogeneity of fracture probability in the different European countries. Also, where the probability is high in men, it is high in women and vice versa. Unlike fracture risk, the difference in fracture probability between men and women is not marked. This is because, in the example provided, BMD is used in the calculation of probability. In men and women of the same age and with the same BMD,

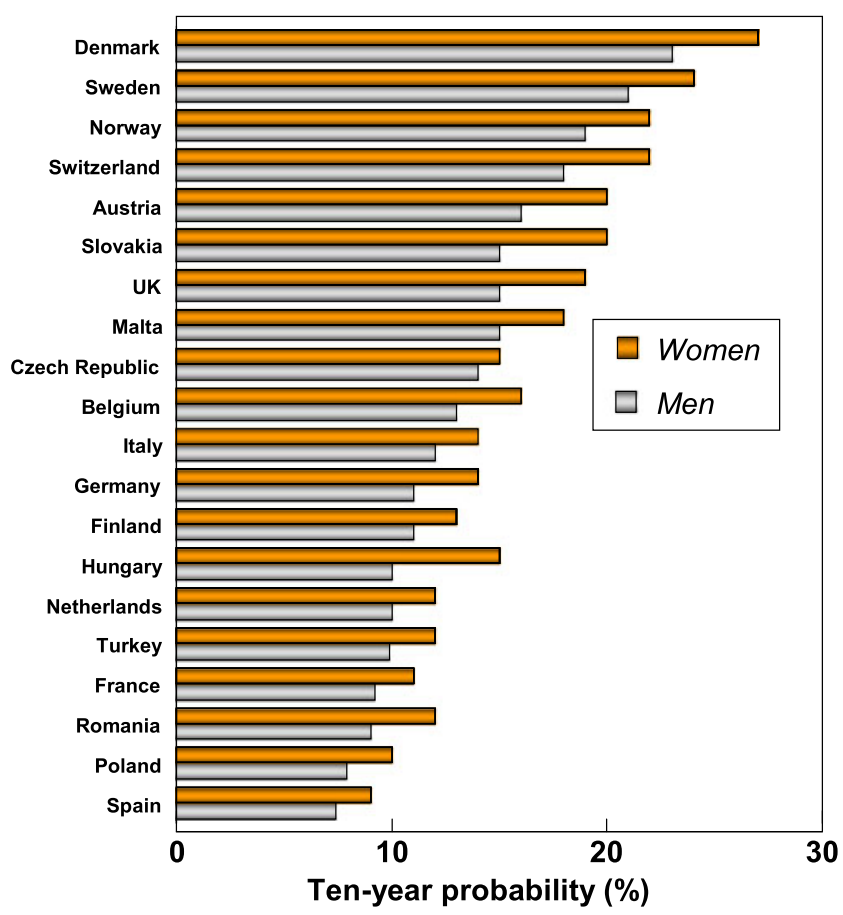

Fig. 14 Ten-year probability of a major osteoporotic fracture (\%) for a 65 -year old man or woman with previous fracture, a femoral neck Tscore of $-2.5 \mathrm{SD}$ and BMI of $25 \mathrm{~kg} / \mathrm{m}^{2}$ and no other risk factors according to FRAX in different European countries fracture risk is similar [43]. The somewhat higher probabilities in women are due to the longer life expectancy in women compared with men.

Like any algorithm, FRAX has a number of limitations. For example, several of the CRFs used take no account of dose-response, but rather represent an average dose or exposure. Thus, there is good evidence that the risk associated with smoking [44, 45], excess alcohol consumption [46], and the use of glucocorticoids [47, 48] increases with increasing exposure, as does the number of prior fractures $[40,49,50]$. On the other hand, the algorithms are easy to use and their simplicity is appropriate for primary care.

The application of FRAX to clinical practice demands a consideration of the fracture probability at which to intervene, both for treatment (an intervention threshold) and for BMD testing (assessment thresholds). Probabilitybased intervention thresholds have been developed for Europe in a generic sense [51, 52], but also for individual countries including Canada, Germany, Japan, Sweden, Switzerland, the UK and US [39, 53-56]. The potential application of the UK guidance for the identification of individuals at high risk of fracture, developed by the National Osteoporosis Guideline Group (NOGG) (www.shef.ac.uk/NOGG), to other EU countries is developed in subsequent chapters.

\subsubsection{Utilisation of FRAX}

FRAX was launched in 2008, at which time models were available for Austria, France, Germany, Italy, Spain, Sweden and the UK. Since then, nine additional models have been added so that 16 of the $27 \mathrm{EU}$ member states are serviced. More models are under development. The web based usage of the models is shown in Table 8 which shows considerable heterogeneity in uptake. Belgium, UK, Luxembourg, Sweden and Ireland have the highest usage of FRAX. These data underestimate the use of FRAX by an uncertain amount due to the availability of FRAX on bone densitometers. The FRAX calculations are not effected through the web site. In addition, hand held calculators are used in several countries, particularly in Poland. In Germany, probability based fracture risk assessment comprises a component of National guidelines, but is not FRAX based. 
Table 8 FRAX calculations by country of origin (URL) between November 2010 and December 2011 [Google Analytics]

\begin{tabular}{|c|c|c|c|c|}
\hline & Calculations/year & Population (000) & $\begin{array}{c}\text { Calculations/ } \\
\text { million/yr }\end{array}$ & FRAX model available \\
\hline Austria & 13,281 & 8,387 & 1,584 & yes \\
\hline Belgium & 51,860 & 10,698 & 4,848 & yes \\
\hline Bulgaria & 637 & 7,497 & 85 & \\
\hline Cyprus & 277 & 880 & 315 & \\
\hline Czech Republic & 1,910 & 10,411 & 366 & yes \\
\hline Denmark & 5,328 & 5,481 & 972 & yes \\
\hline Estonia & 281 & 1,339 & 210 & \\
\hline Finland & 2,385 & 5,346 & 446 & yes \\
\hline France & 19,909 & 62,637 & 318 & yes \\
\hline Germany $^{\text {a }}$ & 6,761 & 82,057 & 82 & yes \\
\hline Greece & 5,936 & 11,183 & 531 & \\
\hline Hungary & 12,362 & 9,973 & 1,240 & yes \\
\hline Ireland & 7,629 & 4,589 & 1,662 & \\
\hline Italy & 32,143 & 60,098 & 535 & yes \\
\hline Latvia & 137 & 2,240 & 61 & \\
\hline Lithuania & 97 & 3,255 & 30 & \\
\hline Luxembourg & 1,036 & 492 & 2,106 & \\
\hline Malta & 624 & 410 & 1,522 & yes \\
\hline Netherlands ${ }^{a}$ & 8,917 & 16,653 & 535 & yes \\
\hline Poland ${ }^{b}$ & 13,443 & 38,038 & 706 & yes \\
\hline Portugal & 11,601 & 10,732 & 1,081 & \\
\hline Romania & 6,211 & 21,190 & 586 & yes \\
\hline Slovakia & 1,896 & 5,412 & 350 & \\
\hline Slovenia & 2,725 & 2,025 & 1,346 & \\
\hline Spain & 46,856 & 45,317 & 1,034 & yes \\
\hline Sweden & 19,070 & 9,293 & 2,052 & yes \\
\hline UK & 144,653 & 61,899 & 2,337 & yes \\
\hline All & 417,965 & 49,7532 & 840 & $16 / 27$ \\
\hline
\end{tabular}

a Alternate model available; 'Hand held model available 
With these caveats, it is appropriate, but difficult, to compare the current uptake of FRAX with the targets that might be required for adequate service provision. In the case of DXA, the requirements for risk assessment were estimated at 3-5 DXA units/million of the general population in the year 2000 [8]. With an average of 1250 tests/unit/year this equates to a requirement of 3750 6250 tests/million of the population/year. In Belgium which has the highest uptake of FRAX in the EU, the use of FRAX on the web site amounted to $51,860 \mathrm{calcu}-$ lations in one year for a population of 10.7 million, equivalent to 473 tests/million (Fig. 15 and Table 8). Thus the usage of FRAX is less than the estimated optimal requirements for DXA by a large amount. In many practice guidelines (e.g. the UK), the use of FRAX should outstrip the use of DXA. These considerations suggest that uptake of FRAX is sub-optimal in all EU countries, including those for which models are available.

\subsection{Treatment of osteoporosis and prevention of fracture}

In recent years there have been significant advances in the management of osteoporosis, particularly with respect to the development of pharmacological interventions to reduce fracture risk. These are summarised below and more detailed accounts are given in the review of the EU5 countries
[1] and the European guidelines for glucocorticoid-induced osteoporosis [52].

\subsubsection{General management}

General management includes the avoidance of modifiable risk factors such as smoking and excessive alcohol intake. Assessment of the risk of falls and their prevention is important, especially in the elderly. An increased likelihood of falls can arise from numerous age- and disease-related factors. Some of these factors, such as impaired vision can be modified and there is good evidence that prompt treatment of cataracts reduces falls risk [57]. Other disease processes are more difficult to manage including, for example heart disease, dementia, stroke and other neurological diseases. Some medications, especially sedatives, can impair balance and are significant risk factors for fractures. Environmental factors that can precipitate a fall include slippery or uneven flooring, carpet edges and poor or inadequate footwear. Further, where possible, drugs that induce accelerated bone loss should be avoided or the minimum effective dose titrated.

Immobility is a strong risk factor for osteoporosis [58]. Maintenance of mobility is therefore important. It is not known what constitutes the optimal exercise programme to maintain skeletal mass in health or disease but exercise can also improve posture and balance to protect against both falls and fractures [59].

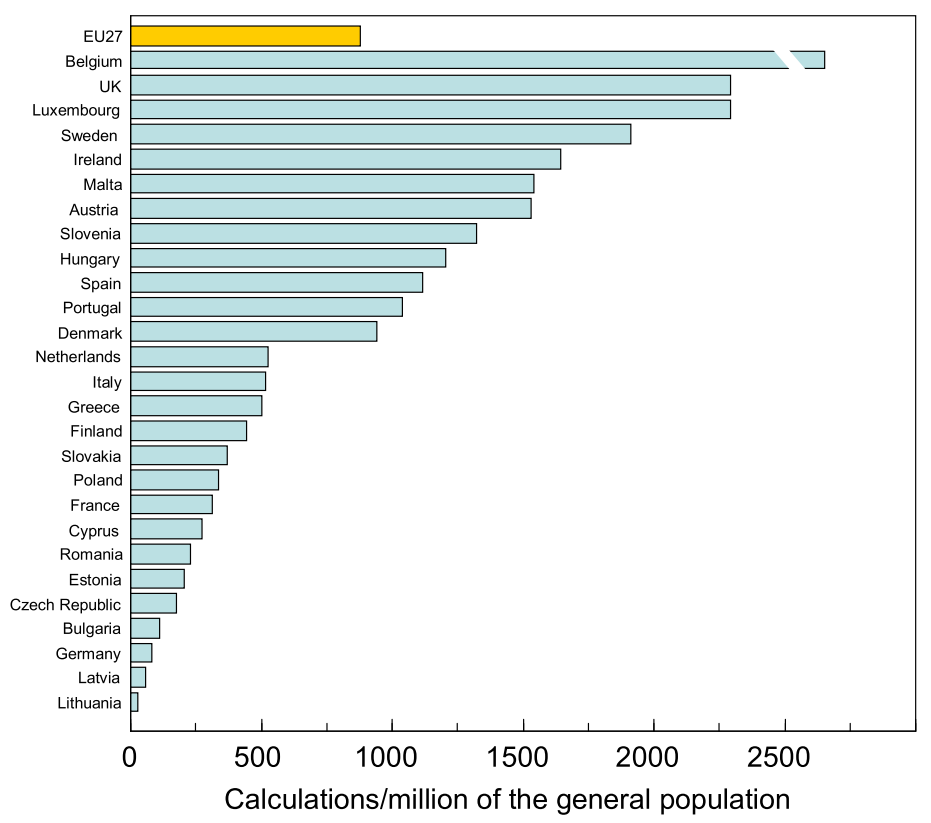

Fig. 15 FRAX calculations by URL source Nov 2010-Nov 2011 [Google Analytics] 
Correction of nutritional deficiencies, particularly of calcium, vitamin D and protein, are advised. Intakes of at least $1,000 \mathrm{mg} /$ day of calcium, $400-800 \mathrm{IU}$ of vitamin $\mathrm{D}$ and of $1 \mathrm{~g} / \mathrm{kg}$ body weight of protein are widely recommended [60, 61]. Calcium, vitamin D and the combination are commonly used in patients as a primary therapeutic agent, particularly in combination with other therapeutic agents.

Calcium supplements and vitamin D are widely available in all EU countries but guidelines regarding their use and other lifestyle advice are not universally provided. The provision of government endorsed public health programmes on nutrition and lifestyle is even lower and available in only 7 member states (Bulgaria, Finland, France, Italy, Luxembourg, Sweden and the UK) [10].

\subsubsection{Major pharmacological interventions}

Approved pharmacological interventions include bisphosphonates, strontium ranelate, raloxifene, denosumab and parathyroid hormone peptides [1]. Interventions that are approved for the prevention and treatment of osteoporosis in Europe are shown in Table 9. Most of these are approved only for the treatment of postmenopausal osteoporosis. However, alendronate, etidronate, risedronate zoledronic acid and teriparatide are also approved for the prevention and treatment of glucocorticoid-induced osteoporosis in Europe [52] and alendronate, risedronate, zoledronic acid, strontium ranelate and teriparatide are approved for the treatment of osteoporosis in men.

Table 9 Pharmacological interventions used in the EU for the prevention of osteoporotic fractures [1]

\begin{tabular}{|c|c|c|c|}
\hline Intervention & $\begin{array}{l}\text { Year of } \\
\text { market } \\
\text { approval }\end{array}$ & Dosing regimen & Route of administration \\
\hline Alendronate & 1995 & $\begin{array}{l}70 \mathrm{mg} \text { once weekly or } 5 \\
\text { or } 10 \mathrm{mg} \text { once daily }\end{array}$ & Oral \\
\hline Etidronate & 1980 & $\begin{array}{l}400 \mathrm{mg} \text { daily for } 2 \text { weeks } \\
\text { every } 3 \text { months }\end{array}$ & Oral \\
\hline Ibandronate a). & 2005 & $150 \mathrm{mg}$ once monthly & Oral \\
\hline Ibandronate b). & 2005 & $\begin{array}{l}3 \text { mg once every } 3 \\
\text { months }\end{array}$ & Intravenous injection \\
\hline Risedronate & 2000 & $\begin{array}{l}35 \text { mg once weekly or } 5 \\
\text { mg once daily }\end{array}$ & Oral \\
\hline Zoledronic acid & 2005 & $5 \mathrm{mg}$ once yearly & Intravenous infusion \\
\hline Denosumab & 2010 & 60 mg twice yearly & Subcutaneous injection \\
\hline Raloxifene & 1998 & $60 \mathrm{mg}$ once daily & Oral \\
\hline Bazedoxifene ${ }^{a}$ & 2009 & $20 \mathrm{mg}$ once daily & Oral \\
\hline $\begin{array}{l}\text { Strontium } \\
\text { ranelate }\end{array}$ & 2004 & $2 \mathrm{~g}$ once daily & Oral \\
\hline Teriparatide & 2003 & $20 \mu \mathrm{g}$ once daily & Subcutaneous injection \\
\hline $\begin{array}{l}\text { Parathyroid } \\
\text { hormone 1-84 }\end{array}$ & 2006 & $100 \mu \mathrm{g}$ once daily & Subcutaneous injection \\
\hline
\end{tabular}

\footnotetext{
${ }^{\mathrm{a}}$ Registered but not marketed widely (Germany and Spain)
} 
All these interventions have been shown to reduce the risk of vertebral fracture when given with calcium and vitamin D supplements. Some have been shown to also reduce the risk of non-vertebral fractures and some specifically, hip fractures. Of the available options, alendronate, risedronate, zoledronic acid, denosumab and strontium ranelate have been demonstrated to reduce vertebral, non-vertebral and hip fractures [38, 6272] (Table 10). Because of this broader spectrum of anti-fracture efficacy these agents are generally regarded as preferred options in the prevention of fractures in postmenopausal women. This distinction is important because once a fracture occurs, the risk of a subsequent fracture at any site is increased independent of BMD [73], and hence an intervention that covers all major fracture sites is preferable.

Since there have been no head-to-head studies with fracture as the primary outcome, direct comparison of efficacy between agents is not possible. However, the reduction in vertebral fracture rate has generally been between 50 and $70 \%$; whereas the magnitude of reduction in non-vertebral fracture, where demonstrated, has generally been smaller and in the order of 15 to $25 \%$. This difference in effect on different fracture outcomes is likely to reflect, at least in part, the importance of falls in the pathogenesis of these fractures but may also result from differences in the effects of the treatments on cortical and cancellous bone.

Reduction in fracture risk has been shown to occur within 1 year of treatment for bisphosphonates, strontium ranelate and denosumab. This is particularly important in the case of vertebral fractures, since after an incident vertebral fracture there is a $20 \%$ risk of a further fracture occurring within the next 12 months, emphasizing the importance of prompt treatment once a fracture has occurred [49, 74, 75].

Although pharmacological interventions are licensed for use, uptake within the EU is restricted, particularly with regard to reimbursement policies (Table 11) [9, 10]. Full or near full reimbursement is available in a minority of member states. There is no reimbursement in Malta. In other countries reimbursement is partial or restricted to individuals with a prior fracture (Germany) or to women only (Netherlands). Some countries with reimbursement exclude PTH (e.g. Italy, Sweden).

Table 10 Spectrum of anti-fracture efficacy of interventions approved in Europe [39]

\begin{tabular}{lccc}
\hline & \multicolumn{3}{c}{ Fracture outcome } \\
\cline { 2 - 4 } Intervention & Vertebral & Non-vertebral & Hip \\
\hline Alendronate & + & + & + \\
Ibandronate & + & $+*$ & $\mathrm{NAE}$ \\
Denosumab & + & + & + \\
Risedronate & + & + & + \\
Zoledronic acid & + & + & + \\
Raloxifene & + & $\mathrm{NAE}$ & $\mathrm{NAE}$ \\
Strontium ranelate & + & + & $+*$ \\
Teriparatide & + & + & NAE \\
PTH (1-84) & + & NAE & NAE \\
\hline
\end{tabular}

NAE: not adequately evaluated

*In subsets of patients (post-hoc analysis)

PTH: parathyroid hormone 
Table 11 Available medical interventions and reimbursement policies $[9,10]$

\begin{tabular}{|c|c|c|c|c|c|c|c|}
\hline Country & $\begin{array}{l}\text { Bisphos } \\
\text { phonates }\end{array}$ & SERMs & $\begin{array}{l}\text { Strontium } \\
\text { ranelate }\end{array}$ & Calcitonin & $\begin{array}{l}\text { PTH } \\
\text { analogues }\end{array}$ & Denosumab & $\begin{array}{l}\text { Reimbursement } \\
\text { (\%) }\end{array}$ \\
\hline Austria & + & + & + & + & + & + & 100 \\
\hline Belgium & + & + & + & - & + & + & 10 to 20 \\
\hline Bulgaria & + & - & + & - & - & + & 25 \\
\hline Cyprus & + & + & + & + & + & + & $\begin{array}{l}100 \text { depending on } \\
\text { income }\end{array}$ \\
\hline Czech Republic & + & + & + & + & + & + & $50-90^{b}$ \\
\hline Denmark & + & + & + & - & + & + & $50-90$ \\
\hline Estonia & $t^{a}$ & - & + & - & - & - & $50-90$ \\
\hline Finland & + & + & + & + & + & + & 40 \\
\hline France & + & + & + & - & + & - & 65 \\
\hline Germany & + & + & + & + & + & + & 100 \\
\hline Greece & + & + & + & - & + & + & In part \\
\hline Hungary & + & + & + & + & + & + & $70-90$ \\
\hline Ireland & + & + & + & + & + & + & $\begin{array}{l}100, \text { depending } \\
\text { on income }\end{array}$ \\
\hline Italy & $+{ }^{a}$ & + & + & - & + & + & 100 \\
\hline Latvia & + & - & + & - & + & + & 50 \\
\hline Lithuania & + & + & + & + & + & + & $50-80$ \\
\hline Luxembourg & + & + & + & - & - & + & $80-100$ \\
\hline Malta & $-{ }^{a}$ & - & - & - & - & - & 0 \\
\hline Netherlands & + & + & + & - & - & + & 100 \\
\hline Poland & $t^{a}$ & - & + & - & - & + & 30 \\
\hline Portugal & + & + & + & + & + & - & 69 \\
\hline Romania & $+{ }^{a}$ & + & + & + & - & - & 50 \\
\hline Slovakia & + & + & + & + & + & + & 90 \\
\hline Slovenia & + & + & + & - & + & + & 100 \\
\hline Spain & + & + & + & + & + & + & $\begin{array}{l}50,100 \text { for retired } \\
\text { population }\end{array}$ \\
\hline Sweden & $++^{a}$ & + & + & - & + & + & 100 \\
\hline UK & + & + & + & + & + & + & 100 \\
\hline
\end{tabular}

-Not available or not reimbursed

${ }^{a}$ Not all bisphosphonates available

${ }^{\mathrm{b}}$ Only if prescribed by a specialist

PTH: parathyroid hormone

\subsubsection{Future developments in the treatment of osteoporosis}

A number of new approaches is being explored for the prevention of fractures in postmenopausal women [76].
These include new treatment modalities including antibodies to Wnt antagonists e.g., sclerostin [77], cathepsin $\mathrm{K}$ inhibitors [78], transdermal PTH peptide formulations [79], and drugs that act on calcium 
sensing receptors [80]. In addition, there is growing interest in the use of sequential therapy, using antiresorptive drugs to maintain the benefit of anabolic agents, and using mild anti-resorptives after a period of treatment with potent anti-resorptive drugs such as denosumab.

\subsubsection{Vertebroplasty and balloon kyphoplasty}

Vertebroplasty and balloon kyphoplasty are options for the management of acute vertebral fractures [81]. Vertebroplasty consists of the transpedicular placement of bone cement into fractured vertebral bodies, whereas in balloon kyphoplasty a balloon is introduced into the fractured vertebra and inflated to restore vertebral height. Subsequently, the balloon is deflated and the space created is filled with bone cement. Both approaches have been shown to reduce pain and improve functional ability significantly when compared to non-surgical management in patients with acute symptomatic vertebral fractures [82-84]. Balloon kyphoplasty appears to be superior to vertebroplasty with respect to restoration of vertebral height and reduction of spinal deformity, although the clinical and functional significance of the relatively small differences remain to be established.

In the majority of studies, these procedures were compared to non-surgical management. However, in two recent randomized controlled studies, vertebroplasty was compared to a placebo procedure in which the various stages of vertebroplasty were mimicked but without injection of cement. Neither of these studies was able to demonstrate a beneficial effect of vertebroplasty over placebo on pain, functional ability or quality of life $[85,86]$; a recent meta-analysis of individual patient data from these studies failed to show an advantage of vertebroplasty over placebo for participants with recent onset fracture or severe pain [87]. The follow-up period of these studies was relatively short (1 month and 6 months, respectively) and it is possible that the long-acting local anaesthetic injected in the placebo group might have provided some pain relief in the placebo group. No placebo-controlled trials have been conducted for balloon kyphoplasty.
In a recent study, vertebroplasty was found to have a higher rate of procedure-related complications than balloon kyphoplasty and a higher rate of cement leakage, which may sometimes result in neurological symptoms [88]. A potential concern for both procedures is that the risk of compression fractures in vertebrae adjacent to the operated vertebra might be increased and further long-term studies are required to address this issue. The results of studies so far reported indicate a similar incidence of new vertebral fractures in women who have undergone balloon kyphoplasty or vertebroplasty when compared to non-surgical management but longer term data are required. A recent study from the US Medicare database found the relative risk of mortality for kyphoplasty patients was $23 \%$ lower than that for vertebroplasty patients (adjusted $\mathrm{HR}=0.77, p<.001$ ) [89].

\subsubsection{Fracture liaison services}

Fracture liaison services, also known as osteoporosis coordinator programmes and care manager programmes, provide a system for the routine assessment and management of postmenopausal women and older men who have sustained a low trauma fracture [90-94]. Although the importance of an incident fracture as a risk factor for further fracture is well recognised, the majority of patients presenting with a low trauma fracture do not receive appropriate assessment and treatment in the setting of standard hospital care. Fracture liaison services address this need through a systematic approach to identifying the vast majority of such individuals and assessing their risk of further fractures and the need for treatment. Most fracture liaison services are based in secondary care although models in primary care have also been described. A dedicated co-ordinator, often a nurse, working closely with the patient, primary care physician, orthopaedic and trauma department and osteoporosis and falls service is central to the development of a successful service. An example of the structure of a fracture liaison service is shown in Fig. 16.

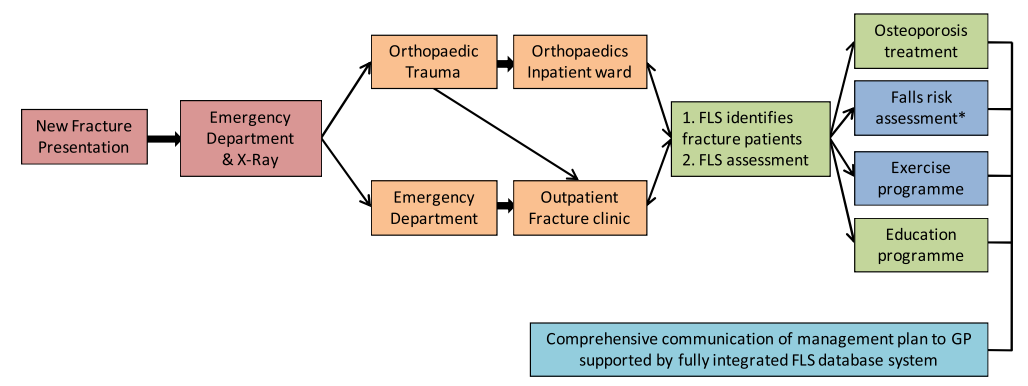

Fig. 16 Example care team: The operational structure of a UK-based Fracture Liaison Service (FLS) [95, 96] 
The clinical and cost-effectiveness of fracture liaison services has been demonstrated in several centres [97101]. In an analysis of data collected over 8 years in Glasgow it was estimated that the service prevented 18 hip fractures and saved $£ 21,000$ per 1000 patients [102]. Use of a systematic coordinator approach in the Kaiser Permanente Healthy Bones Program was associated with a $40 \%$ reduction in hip fractures [103]. The health economic analyses that have been published so far have shown that osteoporosis management programmes are a cost-effective intervention for the prevention of fractures $[101,102,104,105]$. A fracture liaison service in Sydney, Australia, reduced the risk of re-fracture of the hip by $80 \%$, improved quality of life and was associated with an incremental cost-effectiveness ratio (ICER) versus standard care of 17,291 Australian dollars per QALY gained [104].

\subsection{Cost-effectiveness of pharmaceutical interventions}

The osteoporosis market is today dominated by bisphosphonates, particularly alendronate, which has become the first-line choice in many countries given its proven efficacy and low price. Bisphosphonates are generally found to be cost-effective in women with osteoporosis, regardless of whether or not the perspective is societal and if the modelling horizon is lifetime or shorter [106].

A pan-European study from 2004 estimated the cost-effectiveness of branded alendronate in nine countries [26]. In this study alendronate was shown to be cost-saving compared with no treatment in women with osteoporosis (with and without previous vertebral fracture) from the Nordic countries (Norway, Sweden, and Denmark). The cost-effectiveness of alendronate compared to no treatment was also within acceptable ranges in Belgium, France, Germany, Italy, Spain and the UK. However, with the rapid decline in the price of the generic alendronate, analyses based on a branded drug price have become obsolete and would require an update. For example, in the above mentioned study the annual price of alendronate varied between $€ 444 /$ year (UK) to $€ 651 /$ year (Denmark). The current drug price for alendronate is less than $€ 300 /$ year in all countries and as low as €18/year in the UK. Revisiting the analysis using these prices would markedly improve the cost-effectiveness of generic alendronate.

In a more recent study from 2008 [107], the costeffectiveness of alendronate compared with no treatment using a generic price in the UK was assessed by using the FRAX algorithm for fracture risk estimation.
Table 12 Cost-effectiveness of alendronate (cost (£000)/QALY gained) in UK women with clinical risk factors according to age and T-score for femoral neck BMD [107]. A cost of less than $£ 20-30,000 /$ QALY gained is considered to be cost-effective

\begin{tabular}{|c|c|c|c|c|}
\hline \multirow[b]{2}{*}{ Age } & \multicolumn{4}{|c|}{ T-score (SD) } \\
\hline & 0 & -1 & -2 & -3 \\
\hline \multicolumn{5}{|c|}{ Prior fracture } \\
\hline 50 & 18.1 & 15.7 & 9.9 & 3.2 \\
\hline 60 & 18.4 & 15.6 & 10.5 & 2.6 \\
\hline 70 & 9.0 & 6.5 & 3.2 & c.s. \\
\hline 80 & 13.9 & 7.3 & 2.3 & c.s. \\
\hline \multicolumn{5}{|c|}{ Family history } \\
\hline 50 & 16.3 & 14.7 & 11.1 & 5.9 \\
\hline 60 & 15.7 & 14 & 10.4 & 5.9 \\
\hline 70 & 9 & 6 & 1.8 & c.s. \\
\hline 80 & 5.1 & c.s. & c.s. & c.s. \\
\hline \multicolumn{5}{|c|}{ Glucocorticoids } \\
\hline 50 & 23.3 & 19.5 & 13.3 & 4.6 \\
\hline 60 & 22.3 & 19.0 & 12.6 & 3.1 \\
\hline 70 & 10.6 & 7.5 & 2.9 & c.s. \\
\hline 80 & 15.0 & 6.4 & c.s. & c.s. \\
\hline \multicolumn{5}{|c|}{ Rheumatoid arthritis } \\
\hline 50 & 21.1 & 22.6 & 15.4 & 6.2 \\
\hline 60 & 25.1 & 21.1 & 14.4 & 6.3 \\
\hline 70 & 11.5 & 8.4 & 4.4 & c.s. \\
\hline 80 & 15.7 & 7.8 & 1.9 & c.s. \\
\hline \multicolumn{5}{|c|}{ Alcohol (>3 units/day) } \\
\hline 50 & 28.5 & 24.3 & 16.2 & 6 \\
\hline 60 & 27.1 & 22.7 & 15 & 6.1 \\
\hline 70 & 12.6 & 8.9 & 4.4 & c.s. \\
\hline 80 & 16.1 & 7.6 & 1.2 & c.s. \\
\hline \multicolumn{5}{|c|}{ Current smoking } \\
\hline 50 & 37.6 & 31.7 & 19.9 & 6.6 \\
\hline 60 & 37.7 & 31.1 & 19.5 & 6.7 \\
\hline 70 & 18.5 & 13.1 & 5.6 & c.s. \\
\hline 80 & 25.8 & 12.0 & 0.2 & c.s. \\
\hline
\end{tabular}

c.s. $=$ cost-saving

Alendronate was in this analysis priced at $£ 95 /$ year and could be considered cost-effective in most age and risk groups (Table 12).

The cost-effectiveness of a range of treatments has also been evaluated in women with a BMD value meeting or exceeding the threshold of osteoporosis. As seen in Table 13, the cost-effectiveness of alendronate compared with 
Table 13 Cost-per QALY gained ( $£$ ) of various drugs compared to no treatment in women aged 70 years in the UK [51]

\begin{tabular}{lllll}
\hline \multirow{2}{*}{ Intervention } & \multicolumn{2}{l}{ T-score $=-2.5$ SD } & & No BMD \\
\cline { 2 - 3 } Alendronate & No prior fracture & Prior fracture & & Prior fracture \\
\hline Etidronate & 3,714 & 867 & 2,119 \\
Ibandronate daily & 12,869 & 10,098 & 9,093 \\
Ibandronate intermittent & 20,956 & 14,617 & 14,694 \\
Raloxifene & 31,154 & 21,587 & 21,745 \\
Raloxifene without breast cancer & 11,184 & 10,379 & 10,808 \\
Risedronate & 34,011 & 23,544 & 23,755 \\
Strontium ranelate & 18,271 & 12,659 & 13,853 \\
Strontium ranelate, post hoc & 25,677 & 18,332 & 19,221 \\
analysis & 18,628 & 13,077 & 13,673 \\
\hline
\end{tabular}

no treatment was better than for the alternatives [107]. This is mainly driven by the drug price rather than differences in efficacy between treatments. Recent studies suggest, however, that some generic formulations are less well tolerated than the branded product which may have an adverse effect on cost-effectiveness [108]. This consideration aside, the study supports the view that alendronate should be considered as a first line intervention, at least in a UK setting. Nevertheless, cost-effective scenarios were found for treatments other than alendronate, providing credible alternative options for patients unable to take alendronate. Similar conclusions have also been reached in separate studies for most second line treatments [106, 109-114]. There are differences, however, in the spectrum of efficacy of these alternatives across different fracture sites that will determine their suitability in the clinical management of individuals.

With the advent of treatments directed to individuals at high risk it is appropriate to consider the fracture probability at which interventions become cost-effective [115]. This has been explored for the use of alendronate $[107,116]$ risedronate [114], denosumab [113], raloxifene [117] and strontium ranelate [111]. In the case of generic alendronate treatment compared to no treatment was found to be costeffective at a 10 -year probability of a major fracture of $7.5 \%$ in a UK setting (Fig. 17). The threshold probability at which treatment became cost-effective was higher with other treatments than for alendronate, related in large part to the higher cost of intervention. For example, at a WTP of $£ 20,000$ per QALY, treatment with risedronate was cost-effective at a probability threshold of $19 \%$ compared with a threshold of $7 \%$ with generic alendronate.
When considering the body of published evidence, fracture prevention with alendronate in women at elevated risk of fracture older than 50 years is cost-effective in most western countries. Cost-effectiveness improves further in patients with additional risk factors. Fracture risk at a given T-score is similar in men and women [28], the effectiveness of intervention in men is broadly similar to that in women at equivalent risk [43], and the cost and disutility of fractures is similar in men and women $[118,119]$. For these reasons the costeffectiveness of treating men is broadly the same as for women at a given absolute risk of fracture $[116,120]$.

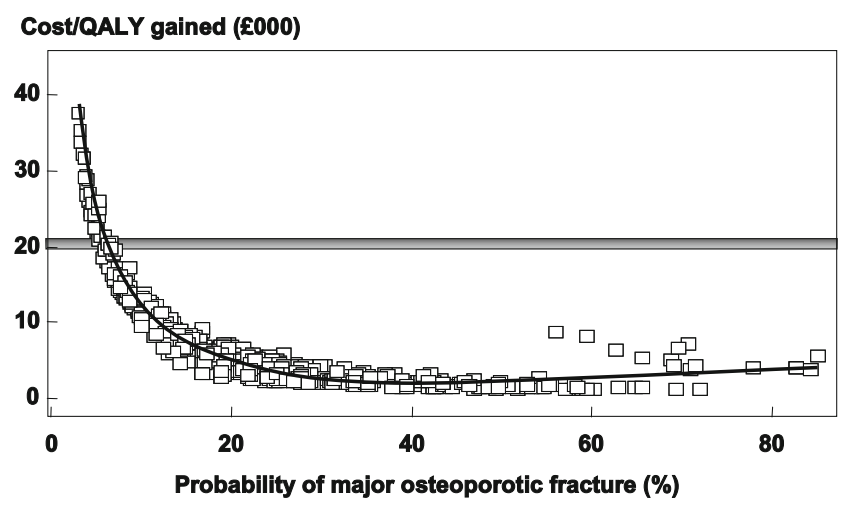

Fig. 17 Correlation between the probability of a major osteoporotic fracture and cost-effectiveness at the age of 50 years in women from the UK (BMI set to $26 \mathrm{~kg} / \mathrm{m}^{2}$ ). Each point represents a particular combination of BMD and CRFs. The horizontal line denotes the threshold for cost-effectiveness (a willingness to pay of $£ 20,000 /$ QALY gained) (Kanis et al. with permission from Elsevier [107]) 


\subsection{Adherence, compliance and persistence}

There is a wide variety of definitions for adherence in the literature. The term compliance is widely used, but it has been argued that the term implies "obedience to doctors" and that it should be termed in a way that also includes the active choice of the patient [121]. In line with this view, a number of alternative terms have been proposed: adherence, patient cooperation, therapeutic alliance or concordance, referring to the agreement between patient and physician [122-125]. For the purpose of this report the terms compliance and persistence were used to define the following of dosing instructions and the time on treatment, respectively. The term adherence was used as a general term encompassing both of these concepts.

Adherence is one of the rising challenges in osteoporosis treatment, since suboptimal adherence results in suboptimal clinical effects such as inadequate fracture prevention. Adherence is not equal in all drug administration but depends on different drug characteristics, discussed below in this section, and there are thereby factors that can be improved in the development of new drugs. Due to its impact on fracture risk, adherence should be considered in cost-effectiveness models.

\subsubsection{Measurements of adherence}

The methods available for measuring adherence are usually broken down into direct and indirect methods of measurement. Each method has advantages and disadvantages, and no method is considered the gold standard [126, 127]. Examples of direct measures of adherence include directly observed therapy, measurement of concentrations of a drug or its metabolite in blood or urine, and detection or measurement in blood of a biological marker added to the drug formulation. Indirect methods of measurement of adherence include asking the patient how easy it was to take the prescribed medication, performing pill counts, ascertaining rates of refilling prescriptions, collecting patient questionnaires, using medication event monitoring systems or asking the patient to keep a medication diary [128].

Whilst clinical trials remain the gold standard for measuring fracture reduction, the high internal validity required to demonstrate efficacy comes at the expense of external validity. The results of such trials may therefore generalize poorly to clinical practice $[124,129]$ since the benefits obtained in practice might fall short of the anticipated benefits indicated by clinical trials. Another factor important to consider when measuring adherence is that patients who know they are observed alter their behaviour, and thus prospective studies of patient cohorts can lead to overestimations of adherence. Therefore, persistence and compliance of medication is often measured retrospectively using claims data. Such data also has the advantage of including a very high number of patients so that they can be used to measure the relationship between adherence and clinical efficacy. However, the results from these studies are very general, and usually report on the number of prescriptions filled over time. Compliance in terms of how and if drugs are actually taken cannot be studied with this method. These retrospective database studies often produce two types of adherence estimates:

1) Persistence, defined as either the time to treatment discontinuation or as the proportion of patients that at a certain time point still fill prescriptions without a gap in refills longer than an allowed period of time (e.g., 30, 60 or 90 days).

2) Compliance, defined as medication possession ratio (MPR). MPR is usually defined as the number of days of medication available to the patient, divided by the number of days of observation. Estimates of MPR should be interpreted with caution since its meaning differs with the definition of days of observation. MPR measures only the frequency and length of refill gaps if the observation time is defined to be the same as a patient's total time on treatment [130]. If days of observation is a predefined time period (e.g., 24 months) [131], MPR becomes a composite estimate of persistence and compliance. Although the MPR provides insight into the availability of medication, it does not provide information on the timeliness and consistency of refilling. An MPR $>80 \%$ is often used as a threshold for high adherence, where improved clinical outcomes can be observed [131-133]. However, this threshold originates from a blood pressure control study [134] and has been criticised for being arbitrary when extrapolated to other diseases [135].

MPR can also be measured in prospective studies, where patients report their own drug consumption. These selfreported studies however more commonly report on general compliance and patients also have the possibility to report on adherence to administration protocol. It should be noted that self-reported studies often result in better compliance than parallel database studies [136, 137].

Patient education and nurse-led monitoring early in the course of treatment have been shown to improve compliance [138]. It has not been established whether monitoring by measurement of biochemical markers of bone turnover or BMD provides additional benefits $[5,6,139]$. The determinants of low persistence and compliance to treatment are not well understood. Research suggests that several factors are important, including dosing requirements and frequency, adverse events, the patient-physician relationship, and patient inability to detect 
symptomatic improvement [135, 140-143]. Retrospective studies indicate that weekly dosing regimens are associated with better persistence than daily regimens [143]. New treatments have quarterly (i.v. ibandronate), 6-monthly (denosumab), or annual (zoledronate) dosing. Theoretically, this type of administration should have potential to improve adherence. However, to what extent increased use of these drugs will improve adherence and lead to fewer fractures in clinical practice is currently not known. This will be an important issue to address in future studies when sufficient real world data become available.

\subsubsection{Adherence in a real world setting}

Compliance and persistence with treatment for osteoporosis in clinical practice are poor; approximately $50 \%$ of patients do not follow their prescribed treatment regimen and/or discontinue treatment within 1 year [144]. Adherence to anti-fracture treatment has been studied extensively. Kothawala [145] presented a meta-analysis of adherence to osteoporosis medication. This review compares results from self-reported as well as database studies and concludes that about one-third to half of all patients on osteoporosis medication do not take their medication as directed. The pooled persistence data resulted in persistence rates of $52 \%$ for treatments lasting 1-6 months, $50 \%$ for treatments lasting 7-12 months and $42 \%$ for treatments lasting 13-24 months.

\subsubsection{Adherence and anti-fracture efficacy}

Poor adherence has been shown to be associated with reduced anti-fracture efficacy when expressed both as MPR [131] and as persistence $[130,146]$. Figure 18 shows an analysis from the Swedish Adherence Register Analysis (SARA) study depicting the relation between time on treatment and fracture risk in 37,394 bisphosphonate-treated patients observed for 36 months [130]. The magnitude of effect may be overestimated since patients who fail to comply with placebo have poorer health outcomes than compliant patients [147, 148]. In the context of osteoporosis, fracture risks have been reported to be higher and BMD lower in non-persistent patients taking placebo compared with persistent patients in the placebo wing of an intervention study [149]. Because osteoporosis is an asymptomatic disease where only a fraction of the treated patients will sustain a fracture, large samples of patients are needed to detect differences in fracture rates between patients with high and low adherence to medication.

Furthermore, two systematic reviews report on the link between adherence and anti-fracture efficacy. Ross et al. report that both compliance and persistence are important factors for optimal fracture prevention [150]. Their study points to the possibility of persistence being even more important than compliance in the effect on fracture risk; the meta-analysis showed that fracture risk increases by $30 \%$ with non-adherence and by $30-40 \%$ with non-persistence. A review and meta-analysis by

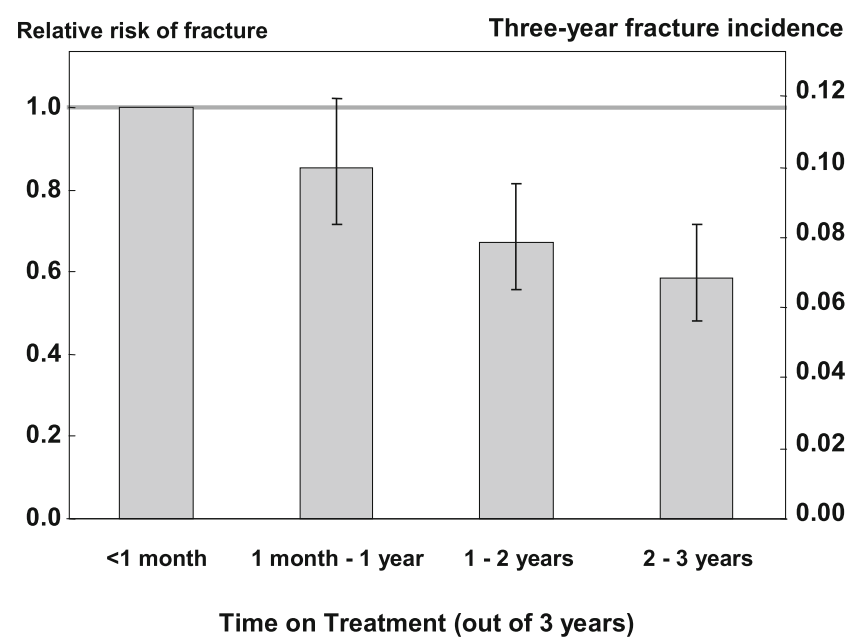

Fig. 18 Relative risk (RR) of 2-year fracture incidence (reference: $<1$ month of treatment) [130]

Imaz et al. focuses on adherence to bisphosphonates and the impact of poor compliance on fracture risk [151]. The noncompliant patients were estimated to have a $46 \%$ higher fracture risk compared to highly compliant patients. The highest impact of compliance on fracture risk was noted for vertebral fractures, and was higher than that seen for hip fractures.

\subsubsection{Cost-effectiveness and adherence}

Health economic modelling of anti-fracture therapies is a thoroughly researched area, and many publications on the topic are available. However, adherence is seldom included in the cost-effectiveness models. Poor adherence is commonly believed to have little impact on cost-effectiveness in clinical practice, since poor adherence affects cost as well as outcomes. Also of relevance is that with poor adherence fewer patients will be properly treated, and thus fewer fractures prevented, which is the principal goal of treatment. Costeffectiveness analysis is also important in this context since future improvements in fracture prevention may come not only from more efficacious treatments but also through improved drug delivery and adherence [152]. Thus the prices, costs, and cost-effectiveness of these new alternatives need to be compared with the present alternatives in clinical practice.

From a health economic perspective, high adherence is particularly important when treating high-risk populations. Cost-effectiveness of treatments that potentially confer high adherence is sensitive to assumptions regarding the relation between adherence and residual effect after stopping treatment and drug-effect reductions from poor compliance.

Modelling studies of denosumab (6-monthly dosing) [113] and zoledronate (12-monthly dosing) [153] have indicated that improving treatment adherence is likely to be cost-effective. The health benefits of improved adherence are often partially offset by increased intervention costs that are associated with the improved drug-taking behaviour. Nonetheless, adherence 
is likely to be associated with added value for the healthcare system because more fractures will be avoided $[152,154]$.

To summarise, adherence to osteoporosis treatment is suboptimal and associated with reduced anti-fracture effectiveness in clinical practice. The treatment gap in the management of osteoporosis in Europe is partly caused by insufficient case finding, but also in part by suboptimal treatment adherence. Besides improved case finding, improved adherence to treatment would increase treatment penetration in high risk populations and would likely be associated with improved outcomes in clinical practice.

Much of the data discussed above come from outside EU27 and given that data on adherence differs between regions and people with different ethnicity [155], it is important to study adherence in the European Union, and to assess inter country variation. The pattern of data availability in different countries is also of interest to identify future research needs. A systematic literature review was performed to assess the adherence to pharmaceutical treatment of osteoporosis in clinical practice in the EU27. The results are presented as an appendix to this chapter (Appendix A).

\subsection{National guidelines and reimbursement policies for the management of osteoporosis in the $\mathbf{E U}$}

National guidelines for the assessment and treatment of osteoporosis are available from the majority of member states. Details of recent guidelines for the EU5 are recently published $[1,28]$. Their scope variously covers post-menopausal women, men, glucocorticoid-induced osteoporosis and population-based screening (Table 14). With the exception of Germany and Italy, populationbased screening is not recommended. In Hungary, however BMD is offered free of charge to women aged 50 years or more, though the uptake is low. With the exception of the UK, none of the guidelines are underpinned by health economic analyses. In the UK, the guidelines of the NOGG have been validated by an economic analysis [107]. In the case of the National Institute for Health and Clinical Excellence (NICE), the guidance has been driven by cost-effectiveness [156-158].

Table 14 Scope of guidelines for the assessment and treatment of osteoporosis in the EU [10]

\begin{tabular}{|c|c|c|c|c|c|}
\hline & $\begin{array}{c}\text { Developed } \\
\text { (year) }\end{array}$ & PMW & $\begin{array}{c}\text { Scope } \\
\text { GIO }\end{array}$ & Men & Population-based screening \\
\hline Austria & 2010 & + & + & + & no \\
\hline Belgium & 2005-11 & + & + & & no \\
\hline Bulgaria & 2007 & + & + & + & yes \\
\hline Cyprus & na & & & & \\
\hline Czech Republic & 2003-10 & + & + & & no \\
\hline Denmark & 2009 & + & & & no \\
\hline Estonia & 2012 & + & + & + & yes \\
\hline Finland & 2013 & + & + & + & no \\
\hline France & 2012 & + & + & + & yes \\
\hline & & + & + & & Yes, women aged over 70 and men \\
\hline Germany & 2009 & & & + & aged over 80 years \\
\hline Greece & 2009 & + & + & + & no \\
\hline Hungary & 2011 & + & $\mathrm{nr}$ & $\mathrm{nr}$ & Yes, women aged $50+$ years \\
\hline Ireland & 2011 & + & & + & no \\
\hline Italy & 2011 & + & + & + & Women aged over 65 years \\
\hline Latvia & 2011 & + & + & + & yes \\
\hline Lithuania & 2011 & + & & & yes \\
\hline Luxembourg & 2010 & + & & & yes \\
\hline Malta & na & & & & \\
\hline Netherlands & 2011-12 & + & + & + & yes \\
\hline Poland & 2011-12 & + & + & + & yes \\
\hline Portugal & 2011 & + & & & yes \\
\hline Romania & 2011 & + & + & + & no \\
\hline Slovakia & $2006 / 09 / 10$ & + & + & & yes \\
\hline Slovenia & 2002 & + & & & no \\
\hline Spain & 2004-11 & + & + & + & yes/no \\
\hline Sweden & 2008 & + & + & + & yes \\
\hline UK (NICE) & 2008-12 & + & - & - & yes \\
\hline UK (NOGG) & 2008 & + & + & + & yes \\
\hline
\end{tabular}

PMW, postmenopausal women; GIO, glucocorticoid induced osteoporosis

nr, not recorded; na, not available 
Guidelines in 24 of the 25 countries covered the assessment of fracture risk (the exception was the Czech Republic). The most common tools for fracture risk assessment were age in 22/25 countries (exceptions were Lithuania, Slovakia and Sweden) and bone mineral density (in all countries). The use of fracture risk assessment algorithms was less consistent and noted in 18 countries. FRAX was the most widely used instrument though in Germany the DVO tool was recommended [159]. In the UK both FRAX and QFracture have been approved [160]. There are some apparent anomalies in the recommendations over the use of FRAX. In Italy and Spain, there are several guidelines from different organisations that give divergent recommendations.

Guidelines in all 25 countries covered eligibility for treatment with a general commonality of approach. Eligibility for treatment depended on prior fracture (except Denmark and Sweden), age (except Lithuania, Slovakia and Sweden) and BMD (all countries). As was the case for risk assessment tools, these provided criteria for intervention in fewer (17/25) countries (Table 15).
Several counties reported incompatibilities between recommendations for risk assessment or treatment with reimbursement policy (Table 15). For example, guidelines recommended the use of FRAX which was not provided for in reimbursement provision (Belgium, Poland, Romania and Slovakia), specific treatments were recommended but not reimbursed (Poland, Romania) and central DXA was recommended for risk assessment but other techniques (peripheral BMD and QCT) were reimbursed (Lithuania). In Luxembourg, the BMD thresholds for treatment differ from the criteria for reimbursement for DXA. In other instances, guidelines recommended the use of risk factors such as a prior fragility fractures but reimbursement was solely dependent on BMD (Lithuania, Romania). With regard to treatment, reimbursement was limited in time (18 months) but treatment recommended on a long-term basis (Lithuania). A problem inconsistently related to reimbursement was that multiple guidelines gave conflicting recommendations (Italy, Spain, and the UK).

Table 15 Summary of risk assessment and treatment criteria provided by treatment guidelines in the EU [10]

\begin{tabular}{|c|c|c|c|c|c|c|c|}
\hline & \multicolumn{3}{|c|}{ Risk assessment } & \multicolumn{3}{|c|}{ Criteria for treatment } & \multirow[b]{2}{*}{ Compatibility } \\
\hline & Age & BMD & FRAX & Age & BMD & FRAX & \\
\hline Austria & yes & yes & no & yes & yes & no & yes \\
\hline Belgium & yes & yes & yes & yes & yes & yes & no see above \\
\hline Bulgaria & yes & yes & yes & yes & yes & yes & no \\
\hline Cyprus & - & - & - & - & - & - & - \\
\hline Czech Republic & yes & yes & yes & yes & yes & yes & no \\
\hline Denmark & yes & yes & no & no & yes & no & yes \\
\hline Estonia & yes & yes & yes & yes & yes & yes & yes \\
\hline Finland & yes & yes & yes & yes & yes & yes & yes \\
\hline France & yes & yes & yes & no & yes & yes & yes \\
\hline Germany $^{a}$ & yes & yes & yes $^{a}$ & yes & yes & $y_{e s}{ }^{a}$ & no \\
\hline Greece & yes & yes & yes & yes & yes & yes & yes \\
\hline Hungary & yes & yes & yes & yes & yes & yes & yes \\
\hline Ireland & yes & yes & no & yes & yes & no & yes \\
\hline Italy & yes & yes & yes/no & yes & yes & yes/no & no \\
\hline Latvia & yes & yes & no & no & yes & yes & yes \\
\hline Lithuania & no & yes & no & no & yes & no & no \\
\hline Luxembourg & yes & yes & yes & yes & yes & yes & $\mathrm{n} / \mathrm{a}$ \\
\hline Malta & - & - & - & & - & - & - \\
\hline Netherlands & yes & yes & optional & yes & yes & no & \\
\hline Poland & yes & yes & yes & yes & yes & yes & no \\
\hline Portugal & yes & yes & yes & yes & yes & yes & yes \\
\hline Romania & yes & yes & yes & no & yes & no & no \\
\hline Slovakia & no & yes & no & no & yes & no & yes \\
\hline Slovenia & yes & yes & no & yes & yes & no & yes \\
\hline & & & yes/no/ & yes & yes & & yes \\
\hline Spain & yes & yes & optional & & & yes/no & \\
\hline Sweden & no & yes & yes & no & yes & yes & yes \\
\hline UK & yes & yes & yes & yes & yes & yes & yes \\
\hline
\end{tabular}




\subsubsection{Compliance with guidelines}

The Prospective Observational Study Investigating Bone Loss Experience in Europe (POSSIBLE EU) is a longitudinal, non-interventional cohort study with the objective to examine the use of osteoporosis medications in EU5 [161]. The POSSIBLE EU included 3,402 women that either were receiving or starting osteoporosis treatment. Information regarding demographics, bone diagnosis (e.g., DXA), risk factors, co-morbidities and concomitant medication was collected at baseline. Patients were followed up after 1 year. The data collected in POSSIBLE EU provide interesting information on how osteoporosis treatment is managed in clinical practice. An analysis of the baseline data showed that only $52 \%$ of all patients had been evaluated by DXA and $68 \%$ of these patients had osteoporosis and $32 \%$ osteopenia. $25 \%$ of all patients had no DXA and no prevalent fractures. There were also large variations between countries, for example the proportion of patients that had osteoporosis (T-score $<-2.5 \mathrm{SD}$ ), a prior fracture and/or glucocorticoid therapy was $55 \%$ in Spain and $83 \%$ in the UK.

These are interesting findings because they imply that osteoporosis is managed somewhat differently in clinical practice compared to national guidelines. It seems that even though not specifically acknowledged and recommended in several of the guidelines, physicians in clinical practice do consider other risk factors such as parental fracture, smoking and alcohol use in the treatment decision. However, it also seems that guidelines have an impact in clinical practice. For example, the UK which has more restricted recommendations (i.e., the NICE guidelines) also has a notably higher proportion of patients that fall under a more classical definition of osteoporosis and high risk of fracture based on BMD and prior fracture.

\subsubsection{Imperfect health care practice}

Notwithstanding a number of advances, particularly in the diagnosis of osteoporosis, the assessment of fracture risk, the development of interventions that reduce the risk of fractures and the production of practice guidelines, a minority of patients at high fracture risk are identified for treatment [162-165]. For example, a Canadian study of emergency department radiographs found that only $55 \%$ of vertebral fractures were mentioned in the radiology report [166]. In patients with a fragility fracture, less than $20 \%$ of individuals receive therapies to reduce future fracture within the year following fracture $[55,162,163,167-169]$. Paradoxically, the therapeutic care gap is wider in the elderly in whom the importance and impact of treatment is high; studies have shown that as few as $10 \%$ of such women with fragility fractures receive any osteoporosis therapy (oestrogens not considered) [162, 170, 171]. Furthermore, treatment rates following a fracture are lower for those individuals who reside in long term care [163]. This contrasts with myocardial infarction, which overcame a significant care gap over the past 15 years; $75 \%$ of individuals now receive beta blockers to help prevent recurrent myocardial infarction [172].

\section{References}

1. Strom O, Borgstrom F, Kanis JA, Compston J, Cooper C, McCloskey EV, Jonsson B (2011) Osteoporosis: burden, health care provision and opportunities in the EU: a report prepared in collaboration with the International Osteoporosis Foundation (IOF) and the European Federation of Pharmaceutical Industry Associations (EFPIA). Arch Osteoporos 6:59-155

2. Kanis JA, Gluer CC (2000) An update on the diagnosis and assessment of osteoporosis with densitometry. Committee of Scientific Advisors, International Osteoporosis Foundation. Osteoporos Int 11:192-202

3. Marshall D, Johnell O, Wedel H (1996) Meta-analysis of how well measures of bone mineral density predict occurrence of osteoporotic fractures. Br Med J 312:1254-1259

4. WHO (1994) Assessment of fracture risk and its application to screening for postmenopausal osteoporosis. WHO Study Group. World Health Organ Tech Rep Ser 843:1-129

5. Bell KJ, Hayen A, Macaskill P, Irwig L, Craig JC, Ensrud K, Bauer DC (2009) Value of routine monitoring of bone mineral density after starting bisphosphonate treatment: secondary analysis of trial data. BMJ 338:b2266

6. Compston J (2009) Monitoring bone mineral density during antiresorptive treatment for osteoporosis. BMJ 338:b1276

7. Watts NB, Lewiecki EM, Bonnick SL, et al. (2009) Clinical value of monitoring BMD in patients treated with bisphosphonates for osteoporosis. J Bone Miner Res 24:16431646

8. Kanis JA, Johnell O (2005) Requirements for DXA for the management of osteoporosis in Europe. Osteoporos Int 16:229-238

9. International Osteoporosis Foundation (IOF) (2011) Osteoporosis in the European Union in 2008: 10 years of progress and ongoing challenges. IOF, Nyon. Available at: http://www.iofbonehealth.org/ osteoporosis-europe an-unionten-years-progress-and-ongoingchallenges

10. International Osteoporosis Foundation (IOF) (2013) Osteoporosis Advisory Panel. Scorecard questionnaire for SCOPE: a scorecard for osteoporosis in Europe. Data on file

11. NÖ Gebeitskrankenkasse (2011) Zusatzvereinbarung Honorarordning 2009. Accessed June 2011, www.noegkk.at

12. INAMI-RIZIV Institut nationale d'assurance maladie invalidité (2011) Accessed June 2011. http://www.inami.fgov.be/insurer/fr/ rate/pdf/last/doctors/rx20110601 fr.pdf

13. The Danish Ministry of Health (2000) Takstsystem 2011 ISBN 978-87-7601304-2:

14. Estonian Health Insurance Fund (2011) Available at Riigi Teataja. www.riigiteataja.ee/akt/121062011024\#para 121062011017 
15. The Social Insurance Institution of Finland (2011) Accessed July 2011. http://kela.fi/

16. Hungarian National Health Insurance Fund (OEP) (2011) Personal communication with Petra Freyler and www.oep.hu

17. Irish Osteoprosis Society (2011) www.irishosteoporosis.ie and personal communication with Michele O'Brien August 2011

18. Health Payment Center in Latvia (VNC) (2011) Personal communication with Toms Noviks August, 2011 and http:// www.vnc.gov.lv/

19. Health RoL-Mo (2011) Lithuanian National Health Insurance Fund under the Ministry of Health. www.vlk.lt

20. Caisse Nationale de Santé Luxembourg (2011) www.cns.lu

21. Ministry for Health (2011) Elderly and Community Care, Malta. In Mater Dei Hospital price. pp www.sahha.gov.mt,

22. The Dutch Healthcare Authority (NZa) (2011) Accessed August 2011 www.nza.nl

23. Portal da Saudé Portugal (2011) Accessed in July www. portaldasaude.pt

24. Casa de Asagurari de Sanatate a Municipiului Bucuresti (2011) Accessed August, 2011. p http://www.casmb.ro/

25. Health Insurance Institute of Slovenia (ZZZS) (2011) Personal communication with Maja Tomši and www.zzzs.si

26. Strom O, Borgstrom F, Sen SS, Boonen S, Haentjens P, Johnell O, Kanis JA (2007) Cost-effectiveness of alendronate in the treatment of postmenopausal women in 9 European countries - an economic evaluation based on the fracture intervention trial. Osteoporos Int 18:1047-1061

27. Stevenson M, Davis S (2006) Analyses of the cost effectiveness of pooled alendronate and risedronate, compared with strontium ranelate, raloxifene, etidronate and teriparatide. http:// wwwniceorguk/pageaspx?o=370643.

28. Kanis JA on behalf of the World Health Organization Scientific Group (2008) Assessment of osteoporosis at the primary healthcare level. Technical Report. World Health Organization Collaborating Centre for Metabolic Bone Diseases, University of Sheffield, UK. 2007: University of Sheffield. Available at: http:// www.shef.ac.uk/FRAX/pdfs/WHO Technical Report.pdf

29. Johnell O, Kanis JA, Oden A, et al. (2005) Predictive value of BMD for hip and other fractures. J Bone Miner Res 20:11851194

30. Kanis JA, Johnell O, Oden A, De Laet C, Jonsson B, Dawson A (2002) Ten-year risk of osteoporotic fracture and the effect of risk factors on screening strategies. Bone 30:251-258

31. Langsetmo L, Goltzman D, Kovacs CS, Adachi JD, Hanley DA, Kreiger N, Josse R, Papaioannou A, Olszynski WP, Jamal SA (2009) Repeat low-trauma fractures occur frequently among men and women who have osteopenic BMD. J Bone Miner Res 24:1515-1522

32. Schuit SC, van der Klift M, Weel AE, De Laet CE, Burger H, Seeman E, Hofman A, Uitterlinden AG, van Leeuwen JP, Pols HA (2004) Fracture incidence and association with bone mineral density in elderly men and women: the Rotterdam Study. Bone 34:195-202

33. Siris ES, Brenneman SK, Miller PD, Barrett-Connor E, Chen YT, Sherwood LM, Abbott TA (2004) Predictive value of low BMD for 1-year fracture outcomes is similar for postmenopausal women ages 50-64 and 65 and Older: results from the National Osteoporosis Risk Assessment (NORA). J Bone Miner Res 19:1215-1220

34. Stone KL, Seeley DG, Lui LY, Cauley JA, Ensrud K, Browner WS, Nevitt MC, Cummings SR (2003) BMD at multiple sites and risk of fracture of multiple types: longterm results from the Study of Osteoporotic Fractures. J Bone Miner Res 18:1947-1954

35. Hui SL, Slemenda CW, Johnston CC, Jr. (1988) Age and bone mass as predictors of fracture in a prospective study. J Clin Invest 81:1804-1809

36. Kanis JA, Johnell O, Oden A, Dawson A, De Laet C, Jonsson B (2001) Ten year probabilities of osteoporotic fractures according to BMD and diagnostic thresholds. Osteoporos Int 12:989-995

37. Kanis JA, McCloskey E, Johansson H, Oden A, Leslie WD (2012) FRAX((R)) with and without bone mineral density. Calcif Tissue Int 90:1-13

38. McClung MR, Geusens P, Miller PD, et al. (2001) Effect of risedronate on the risk of hip fracture in elderly women. Hip Intervention Program Study Group. N Engl J Med 344:333-340

39. Compston J, Cooper A, Cooper C, Francis R, Kanis JA, Marsh D, McCloskey EV, Reid DM, Selby P, Wilkins M (2009) Guidelines for the diagnosis and management of osteoporosis in postmenopausal women and men from the age of 50 years in the UK. Maturitas 62:105-108

40. Kanis JA, Hans D, Cooper C, et al. (2011) Interpretation and use of FRAX in clinical practice. Osteoporos Int 22:2395-2411

41. Hippisley-Cox J, Coupland C (2009) Predicting risk of osteoporotic fracture in men and women in England and Wales: prospective derivation and validation of QFractureScores. BMJ 339:b4229

42. Nguyen ND, Frost SA, Center JR, Eisman JA, Nguyen TV (2008) Development of prognostic nomograms for individualizing 5-year and 10-year fracture risks. Osteoporos Int 19:1431-1444

43. Kanis JA, Bianchi G, Bilezikian JP, Kaufman JM, Khosla S, Orwoll E, Seeman E (2011) Towards a diagnostic and therapeutic consensus in male osteoporosis. Osteoporos Int 22:2789-2798

44. Kanis JA, Johnell O, Oden A, et al. (2005) Smoking and fracture risk: a meta-analysis. Osteoporos Int 16:155-162

45. Law MR, Hackshaw AK (1997) A meta-analysis of cigarette smoking, bone mineral density and risk of hip fracture: recognition of a major effect. BMJ 315:841-846

46. Kanis JA, Johansson H, Johnell O, Oden A, De Laet C, Eisman JA, Pols H, Tenenhouse A (2005) Alcohol intake as a risk factor for fracture. Osteoporos Int 16:737-742

47. van Staa TP, Dennison EM, Leufkens HG, Cooper C (2001) Epidemiology of fractures in England and Wales. Bone 29:517-522

48. van Staa TP, Leufkens HG, Cooper C (2002) The epidemiology of corticosteroid-induced osteoporosis: a meta-analysis. Osteoporos Int 13:777-787

49. Lindsay R, Silverman SL, Cooper C, et al. (2001) Risk of new vertebral fracture in the year following a fracture. JAMA 285:320-323

50. Lunt M, O'Neill TW, Felsenberg D, Reeve J, Kanis JA, Cooper C, Silman AJ (2003) Characteristics of a prevalent vertebral deformity predict subsequent vertebral fracture: results from the European Prospective Osteoporosis Study (EPOS). Bone 33:505-513

51. Kanis JA, Burlet N, Cooper C, Delmas PD, Reginster JY, Borgstrom F, Rizzoli R (2008) European guidance for the diagnosis and management of osteoporosis in postmenopausal women. Osteoporos Int 19:399-428

52. Lekamwasam S, Adachi JD, Agnusdei D, et al. (2012) A framework for the development of guidelines for the management of glucocorticoid-induced osteoporosis. Osteoporos Int 23:22572276 
53. The National Board of Health and Welfare (Socialstyrelsen) [Accessed: 2010-08-01]. http://wwwsocialstyrelsense/Lists/ Artikelkatalog/Attachments/18665/2012-5-1pdf

54. Dawson-Hughes B, Tosteson AN, Melton LJ, 3rd, Baim S, Favus MJ, Khosla S, Lindsay RL, National Osteoporosis Foundation Guide C (2008) Implications of absolute fracture risk assessment for osteoporosis practice guidelines in the USA. Osteoporos Int 19:449-458

55. Papaioannou A, Giangregorio L, Kvern B, Boulos P, Ioannidis G, Adachi JD (2004) The osteoporosis care gap in Canada. BMC Musculoskelet Disord 5:11

56. ASCO (2010) Association Suisse contre l'Ostéoporose: Recommendations ASCO 2010. http://wwwsvgoch/content/documents/ ASCO_Recommandation2010 V19avril2010pdf

57. Harwood RH, Foss AJ, Osborn F, Gregson RM, Zaman A, Masud $\mathrm{T}$ (2005) Falls and health status in elderly women following first eye cataract surgery: a randomised controlled trial. $\mathrm{Br} \mathrm{J}$ Ophthalmol 89:53-59

58. Cooper C, Wickham C, Coggon D (1990) Sedentary work in middle life and fracture of the proximal femur. $\mathrm{Br} \mathrm{J}$ Ind Med 47:69-70

59. Sherrington C, Whitney JC, Lord SR, Herbert RD, Cumming RG, Close JC (2008) Effective exercise for the prevention of falls: a systematic review and meta-analysis. J Am Geriatr Soc 56:2234-2243

60. Holick MF, Binkley NC, Bischoff-Ferrari HA, Gordon CM, Hanley DA, Heaney RP, Murad MH, Weaver CM, Endocrine S (2011) Evaluation, treatment, and prevention of vitamin D deficiency: an Endocrine Society clinical practice guideline. J Clin Endocrinol Metab 96:1911-1930

61. Ross AC (2011) The 2011 report on dietary reference intakes for calcium and vitamin D. Public Health Nutr 14:938-939

62. Black DM, Cummings SR, Karpf DB, et al. (1996) Randomised trial of effect of alendronate on risk of fracture in women with existing vertebral fractures. Fracture Intervention Trial Research Group. Lancet 348:1535-1541

63. Cummings SR, San Martin J, McClung MR, et al. (2009) Denosumab for prevention of fractures in postmenopausal women with osteoporosis. N Engl J Med 361:756- 765

64. Delmas PD (2008) Clinical potential of RANKL inhibition for the management of postmenopausal osteoporosis and other metabolic bone diseases. J Clin Densitom 11:325-338

65. Delmas PD, Recker RR, Chesnut CH, 3rd, Skag A, Stakkestad JA, Emkey R, Gilbride J, Schimmer RC, Christiansen C (2004) Daily and intermittent oral ibandronate normalize bone turnover and provide significant reduction in vertebral fracture risk: results from the BONE study. Osteoporos Int 15:792-798

66. Ettinger B, Black DM, Mitlak BH, et al. (1999) Reduction of vertebral fracture risk in postmenopausal women with osteoporosis treated with raloxifene: results from a 3-year randomized clinical trial. Multiple Outcomes of Raloxifene Evaluation (MORE) Investigators. JAMA 282:637-645

67. Greenspan SL, Bone HG, Ettinger MP, Hanley DA, Lindsay R, Zanchetta JR, Blosch CM, Mathisen AL, Morris SA, Marriott TB (2007) Effect of recombinant human parathyroid hormone (1-84) on vertebral fracture and bone mineral density in postmenopausal women with osteoporosis: a randomized trial. Ann Intern Med 146:326-339
68. Harris ST,Watts NB, Genant HK, et al. (1999) Effects of risedronate treatment on vertebral and nonvertebral fractures in women with postmenopausal osteoporosis: a randomized controlled trial. Vertebral Efficacy With Risedronate Therapy (VERT) Study Group. JAMA 282:1344-1352

69. Meunier PJ, Roux C, Seeman E, et al. (2004) The effects of strontium ranelate on the risk of vertebral fracture in women with postmenopausal osteoporosis. N Engl J Med 350:459-468

70. Neer RM, Arnaud CD, Zanchetta JR, et al. (2001) Effect of parathyroid hormone (1-34) on fractures and bone mineral density in postmenopausal women with osteoporosis. N Engl J Med 344:1434-1441

71. Reginster J, Minne HW, Sorensen OH, et al. (2000) Randomized trial of the effects of risedronate on vertebral fractures in women with established postmenopausal osteoporosis. Vertebral Efficacy with Risedronate Therapy (VERT) Study Group. Osteoporos Int 11:83-91

72. Reginster JY, Seeman E, De Vernejoul MC, et al. (2005) Strontium Ranelate Reduces the Risk of Nonvertebral Fractures in Postmenopausal Women with Osteoporosis: Treatment of Peripheral Osteoporosis (TROPOS) Study. J Clin Endocrinol Metab 90:2816-2822

73. Kanis JA, Johnell O, De Laet C, et al. (2004) A metaanalysis of previous fracture and subsequent fracture risk. Bone 35:375-382

74. Johnell O, Kanis JA, OdenA, Sernbo I, Redlund-Johnell I, Petterson C, De Laet C, Jonsson B (2004) Fracture risk following an osteoporotic fracture. Osteoporos Int 15:175-179

75. Johnell O, Oden A, Caulin F, Kanis JA (2001) Acute and long-term increase in fracture risk after hospitalization for vertebral fracture. Osteoporos Int 12:207-214

76. Canalis E (2010) New treatment modalities in osteoporosis. Endocr Pract 16:855-863

77. Hoeppner LH, Secreto FJ, Westendorf JJ (2009) Wnt signaling as a therapeutic target for bone diseases. Expert Opin Ther Targets 13:485-496

78. Stoch SA, Zajic S, Stone J, et al. (2009) Effect of the cathepsin $\mathrm{K}$ inhibitor odanacatib on bone resorption biomarkers in healthy postmenopausal women: two doubleblind, randomized, placebo-controlled phase I studies. Clin Pharmacol Ther 86:175-182

79. Cosman F, Lane NE, Bolognese MA, Zanchetta JR, GarciaHernandez PA, Sees K, Matriano JA, Gaumer K, Daddona PE (2010) Effect of transdermal teriparatide administration on bone mineral density in postmenopausal women. J Clin Endocrinol Metab 95:151-158

80. Kumar S, Matheny CJ, Hoffman SJ, et al. (2010) An orally active calcium-sensing receptor antagonist that transiently increases plasma concentrations of PTH and stimulates bone formation. Bone 46:534-542

81. Boonen S, Wahl DA, Nauroy L, et al. (2011) Balloon kyphoplasty and vertebroplasty in the management of vertebral compression fractures. Osteoporos Int 22:2915-2934

82. Bouza C, Lopez T, Magro A, Navalpotro L, Amate JM (2006) Efficacy and safety of balloon kyphoplasty in the treatment of vertebral compression fractures: a systematic review. Eur Spine J 15:1050-1067

83. Taylor RS, Taylor RJ, Fritzell P (2006) Balloon kyphoplasty and vertebroplasty for vertebral compression fractures: a comparative systematic review of efficacy and safety. Spine 31:2747-2755 
84. Wardlaw D, Cummings SR, Van Meirhaeghe J, Bastian L, Tillman JB, Ranstam J, Eastell R, Shabe P, Talmadge K, Boonen S (2009) Efficacy and safety of balloon kyphoplasty compared with non-surgical care for vertebral compression fracture (FREE): a randomised controlled trial. Lancet 373:1016-1024

85. Buchbinder R, Osborne RH, Ebeling PR, Wark JD, Mitchell P, Wriedt C, Graves S, Staples MP, Murphy B (2009) A randomized trial of vertebroplasty for painful osteoporotic vertebral fractures. N Engl J Med 361:557- 568

86. Kallmes DF, Comstock BA, Gray LA, Heagerty PJ, Hollingworth W, Turner JA, Stout L, Jarvik JG (2009) Baseline pain and disability in the Investigational Vertebroplasty Efficacy and Safety Trial. Am J Neuroradiol 30:1203-1205

87. Staples MP, Kallmes DF, Comstock BA, Jarvik JG, Osborne RH, Heagerty PJ, Buchbinder R (2011) Effectiveness of vertebroplasty using individual patient data from two randomised placebo controlled trials: meta-analysis. BMJ 343:d3952

88. Lee MJ, Dumonski M, Cahill P, Stanley T, Park D, Singh K (2009) Percutaneous treatment of vertebral compression fractures: a meta-analysis of complications. Spine 34:12281232

89. Edidin AA, Ong K, Lau E, Kurtz SM (2009) Mortality Risk for Operated and Non-Operated Vertebral Fracture Patients in the Medicare Population. American Academy of Orthopaedic Surgeons, Annual Meeting (podium presentation abstract) http:// www3.aaos.org/education/anmeet/anmt2009/podium/ podium.cfm?Pevent=312:

90. Eisman JA, Bogoch ER, Dell R, et al. (2012) Making the first fracture the last fracture: ASBMR task force report on secondary fracture prevention. J Bone Miner Res 27:2039-2046

91. Ganda K, Puech M, Chen JS, Speerin R, Bleasel J, Center JR, Eisman JA, March L, Seibel MJ (2013) Models of care for the secondary prevention of osteoporotic fractures: a systematic review and meta-analysis. Osteoporos Int 24:393-406

92. McLellan AR, Gallacher SJ, Fraser M, McQuillian C (2003) The fracture liaison service: success of a program for the evaluation and management of patients with osteoporotic fracture. Osteoporos Int 14:1028-1034

93. Mitchell PJ (2011) Fracture Liaison Services: the UK experience. Osteoporos Int 22 Suppl 3:487-494

94. Sale JE, Beaton D, Posen J, Elliot-Gibson V, Bogoch E (2011) Systematic review on interventions to improve osteoporosis investigation and treatment in fragility fracture patients. Osteoporos Int 22:2067-2082

95. British Orthopaedic Association (2007) The care of patients with fragility fracture

96. McLaughlin MA, Orosz GM, Magaziner J, Hannan EL, McGinn T, Morrison RS, Hochman T, Koval K, Gilbert M, Siu AL (2006) Preoperative status and risk of complications in patients with hip fracture. J Gen Intern Med 21:219-225

97. Davis JC, Guy P, Ashe MC, Liu-Ambrose T, Khan K (2007) HipWatch: osteoporosis investigation and treatment after a hip fracture: a 6-month randomized controlled trial. J Gerontol A Biol Sci Med Sci 62:888-891

98. Gardner MJ, Flik KR, Mooar P, Lane JM (2002) Improvement in the undertreatment of osteoporosis following hip fracture. J Bone Joint Surg Am 84-A:1342-1348

99. Majumdar SR, Beaupre LA, Harley CH, Hanley DA, Lier DA, Juby AG, Maksymowych WP, Cinats JG, Bell NR, Morrish DW (2007) Use of a case manager to improve osteoporosis treatment after hip fracture: results of a randomized controlled trial. Arch Intern Med 167:2110-2115
100. Majumdar SR, Johnson JA, McAlister FA, Bellerose D, Russell AS, Hanley DA, Morrish DW, Maksymowych WP, Rowe BH (2008) Multifaceted intervention to improve diagnosis and treatment of osteoporosis in patients with recent wrist fracture: a randomized controlled trial. CMAJ 178:569-575

101. Majumdar SR, Lier DA, Rowe BH, Russell AS, McAlister FA, Maksymowych WP, Hanley DA, Morrish DW, Johnson JA (2011) Cost-effectiveness of a multifaceted intervention to improve quality of osteoporosis care after wrist fracture. Osteoporos Int 22:1799-1808

102. McLellan AR, Wolowacz SE, Zimovetz EA, Beard SM, Lock S, McCrink L, Adekunle F, Roberts D (2011) Fracture liaison services for the evaluation and management of patients with osteoporotic fracture: a cost-effectiveness evaluation based on data collected over 8 years of service provision. Osteoporos Int 22:2083-2098

103. Dell R (2011) Fracture prevention in Kaiser Permanente Southern California. Osteoporos Int 22 Suppl 3:457-460

104. Cooper MS, Palmer AJ, Seibel MJ (2012) Costeffectiveness of the Concord Minimal Trauma Fracture Liaison service, a prospective, controlled fracture prevention study. Osteoporos Int 23:97-107

105. Dell RM, Greene D, Anderson D, Williams K (2009) Osteoporosis disease management: What every orthopaedic surgeon should know. J Bone Joint Surg Am 91 Suppl 6:79- 86

106. Zethraeus N, Borgstrom F, Strom O, Kanis JA, Jonsson B (2007) Cost-effectiveness of the treatment and prevention of osteoporosis - a review of the literature and a reference model. Osteoporos Int 18:9-23

107. Kanis JA, Adams J, Borgstrom F, Cooper C, Jonsson B, Preedy D, Selby P, Compston J (2008) The costeffectiveness of alendronate in the management of osteoporosis. Bone 42:4-15

108. Kanis JA, Reginster JY, Kaufman JM, Ringe JD, Adachi JD, Hiligsmann M, Rizzoli R, Cooper C (2012) A reappraisal of generic bisphosphonates in osteoporosis. Osteoporos Int 23:213-221

109. Borgstrom F, Johnell O, Kanis JA, Oden A, Sykes D, Jonsson B (2004) Cost effectiveness of raloxifene in the treatment of osteoporosis in Sweden: an economic evaluation based on the MORE study. Pharmacoeconomics 22:1153-1165

110. Borgstrom F, Jonsson B, Strom O, Kanis JA (2006) An economic evaluation of strontium ranelate in the treatment of osteoporosis in a Swedish setting: Based on the results of the SOTI and TROPOS trials. Osteoporos Int 17:1781-1793

111. Borgstrom F, Strom O, Coelho J, Johansson H, Oden A, McCloskey E, Kanis JA (2010) The cost-effectiveness of strontium ranelate in the UK for the management of osteoporosis. Osteoporos Int 21:339-349

112. Fleurence RL, Iglesias CP, Johnson JM (2007) The cost effectiveness of bisphosphonates for the prevention and treatment of osteoporosis: a structured review of the literature. Pharmacoeconomics 25:913-933

113. Jonsson B, Strom O, Eisman JA, Papaioannou A, Siris ES, Tosteson A, Kanis JA (2011) Cost-effectiveness of Denosumab for the treatment of postmenopausal osteoporosis. Osteoporos Int 22: $967-82$

114. Kanis JA, Borgstrom F, Johnell O, Jonsson B (2004) Costeffectiveness of risedronate for the treatment of osteoporosis and prevention of fractures in postmenopausal women. Osteoporos Int 5: 862-71

115. Borgstrom F, Strom O, Kleman M, McCloskey E, Johansson H, Oden A, Kanis JA (2010) Cost-effectiveness of bazedoxifene incorporating the FRAX(R) algorithm in a European perspective. Osteoporos Int 22: 955-65 
116. Lippuner K, Johansson H, Borgstrom F, Kanis JA, Rizzoli R (2012) Cost-effective intervention thresholds against osteoporotic fractures based on FRAX(R) in Switzerland. Osteoporos Int 23:2579-2589

117. Ivergard M, Strom O, Borgstrom F, Burge RT, Tosteson AN, Kanis J (2010) Identifying cost-effective treatment with raloxifene in postmenopausal women using risk algorithms for fractures and invasive breast cancer. Bone 47:966-974

118. Borgstrom F, Zethraeus N, Johnell O, et al. (2006) Costs and quality of life associated with osteoporosisrelated fractures in Sweden. Osteoporos Int 17:637-650

119. Strom O, Borgstrom F, Zethraeus N, et al. (2008) Longterm cost and effect on quality of life of osteoporosis-related fractures in Sweden. Acta Orthop 79:269-280

120. Tosteson AN, Melton LJ, III, wson-Hughes B, Baim S, Favus MJ, Khosla S, Lindsay RL (2008) Cost-effective osteoporosis treatment thresholds: the United States perspective. Osteoporos Int 19:437-447

121. Donovan JL (1995) Patient decision making. The missing ingredient in compliance research. Int J Technol Assess Health Care 11:443-455

122. Henneman EA, Lee JL, Cohen JI (1995) Collaboration: a concept analysis. J Adv Nurs 21:103-109

123. Lutfey KE, Wishner WJ (1999) Beyond "compliance" is "adherence". Improving the prospect of diabetes care. Diabetes Care 22:635-639

124. Madden BP (1990) The hybrid model for concept development: its value for the study of therapeutic alliance. Adv Nurs Sci 12:75-87

125. Mullen PD (1997) Compliance becomes concordance. BMJ 314:691-692

126. Alcoba M, Cuevas MJ, Perez-Simon MR, et al. (2003) Assessment of adherence to triple antiretroviral treatment including indinavir: role of the determination of plasma levels of indinavir. J Acquir Immune Defic Syndr 33:253258

127. Paes AH, Bakker A, Soe-Agnie CJ (1998) Measurement of patient compliance. Pharm World Sci 20:73-77

128. Osterberg L, Blaschke T (2005) Adherence to medication. N Engl J Med 353:487-497

129. Fayers PM, Hand DJ (1997) Generalisation from phase III clinical trials: survival, quality of life, and health economics. Lancet 350:1025-1027

130. Landfeldt E, Strom O, Robbins S, Borgstrom F (2011) Adherence to treatment of primary osteoporosis and its association to fractures-the Swedish Adherence Register Analysis (SARA). Osteoporos Int 23: 433-43

131. Siris ES, Harris ST, Rosen CJ, Barr CE, Arvesen JN, Abbott TA, Silverman S (2006) Adherence to bisphosphonate therapy and fracture rates in osteoporotic women: relationship to vertebral and nonvertebral fractures from 2 US claims databases. Mayo Clin Proc 81:1013-1022

132. Caro JJ, Ishak KJ, Huybrechts KF, Raggio G, Naujoks C (2004) The impact of compliance with osteoporosis therapy on fracture rates in actual practice. Osteoporos Int 15:1003-1008

133. Huybrechts KF, Ishak KJ, Caro JJ (2006) Assessment of compliance with osteoporosis treatment and its consequences in a managed care population. Bone 38:922-928

134. Haynes RB, Ackloo E, Sahota N, McDonald HP, Yao X (2008) Interventions for enhancing medication adherence. Cochrane Database Syst Rev CD000011
135. Claxton AJ, Cramer J, Pierce C (2001) A systematic review of the associations between dose regimens and medication compliance. Clin Ther 23:1296-1310

136. Ziller V, Wetzel K, Kyvernitakis I, Seker-Pektas B, Hadji P (2011) Adherence and persistence in patients with postmenopausal osteoporosis treated with raloxifene. Climacteric $14: 228-235$

137. Ziller V, Zimmermann SP, Kalder M, Ziller M, Seker- Pektas B, Hellmeyer L, Hadji P (2010) Adherence and persistence in patients with severe osteoporosis treated with teriparatide. Curr Med Res Opin 26:675-681

138. Clowes JA, Peel NF, Eastell R (2004) The impact of monitoring on adherence and persistence with antiresorptive treatment for postmenopausal osteoporosis: a randomized controlled trial. J Clin Endocrinol Metab 89:1117-1123

139. Delmas PD, Vrijens B, Eastell R, Roux C, Pols HA, Ringe JD, Grauer A, Cahall D, Watts NB (2007) Effect of monitoring bone turnover markers on persistence with risedronate treatment of postmenopausal osteoporosis. J Clin Endocrinol Metab 92:1296-1304

140. Cramer JA (1995) Relationship between medication compliance and medical outcomes. Am J Health Syst Pharm 52:S27-S29

141. Eraker SA, Kirscht JP, Becker MH (1984) Understanding and improving patient compliance. Ann Intern Med 100:258-268

142. Lamberg L (2000) Patient-physician relationship critical even during brief "medication checks". JAMA 284:29-31

143. Silverman SL, Gold DT (2008) Compliance and persistence with osteoporosis therapies. Curr Rheumatol Rep 10:118122

144. Compston JE, Seeman E (2006) Compliance with osteoporosis therapy is the weakest link. Lancet 368:973-974

145. Kothawala P, Badamgarav E, Ryu S, Miller RM, Halbert RJ (2007) Systematic review and meta-analysis of realworld adherence to drug therapy for osteoporosis. Mayo Clin Proc 82:1493-1501

146. Weycker D, Macarios D, Edelsberg J, Oster G (2006) Compliance with drug therapy for postmenopausal osteoporosis. Osteoporos Int 17:1645-1652

147. Granger BB, Swedberg K, Ekman I, Granger CB, Olofsson B, McMurray JJ, Yusuf S, Michelson EL, Pfeffer MA, investigators $\mathrm{C}$ (2005) Adherence to candesartan and placebo and outcomes in chronic heart failure in the CHARM programme: double-blind, randomised, controlled clinical trial. Lancet 366:2005-2011

148. Irvine J, Baker B, Smith J, Jandciu S, Paquette M, Cairns J, Connolly S, Roberts R, Gent M, Dorian P (1999) Poor adherence to placebo or amiodarone therapy predicts mortality: results from the CAMIAT study. Canadian Amiodarone Myocardial Infarction Arrhythmia Trial. Psychosom Med 61:566-575

149. McCloskey EV, De Takats D, Orgee J, Aropinn S (2005) Characteristics associated with non-persitence during daily therapy. Experience from the placebo wing in a community based clinical trial. J Bone Miner Res 20:S282

150. Ross S, Samuels E, Gairy K, Iqbal S, Badamgarav E, Siris E (2011) A meta-analysis of osteoporotic fracture risk with medication nonadherence. Value Health 14:571-581

151. Imaz I, Zegarra P, Gonzalez-Enriquez J, Rubio B, Alcazar R, Amate JM (2010) Poor bisphosphonate adherence for treatment of osteoporosis increases fracture risk: systematic review and meta-analysis. Osteoporos Int 21:1943-1951 
152. Ström O, Borgström F, Kleman M, McCloskey E, Odén A, Johansson H, Kanis JA (2010) FRAX ${ }^{\circledR}$ and its applications in health economics - Cost-effectiveness and intervention thresholds using bazedoxifene in a Swedish setting as an example. Bone. 2010 47:430-7

153. Cotte FE, Fardellone P, Mercier F, Gaudin AF, Roux C (2010) Adherence to monthly and weekly oral bisphosphonates in women with osteoporosis. Osteoporos Int 21:145-155

154. Hiligsmann M, Rabenda V, Gathon HJ, Ethgen O, Reginster JY (2010) Potential clinical and economic impact of nonadherence with osteoporosis medications. Calcif Tissue Int 86:202-210

155. Egede LE, Gebregziabher M, Hunt KJ, Axon RN, Echols C, Gilbert GE, Mauldin PD (2013) Regional, Geographic, and Ethnic Differences in Medication Adherence Among Adults with Type 2 Diabetes (February). Ann Pharmacother. Epub ahead of print 8 Feb 2011

156. National Institute for Health and Clinical Excellence (NICE) (2010) Alendronate, etidronate, risedronate, raloxifene and strontium ranelate for the primary prevention of osteoporotic fragility fractures in postmenopausal women. Technology appraisal TA 160. www.nice.org.uk/guidance/ TA160

157. National Institute for Health and Clinical Excellence (NICE) (2010) Denosumab for the prevention of osteoporotic fractures in postmenopausal women. Technology appraisal TA 204. www.nice.org.uk/guidance/TA204

158. National Institute for Health and Clinical Excellence (NICE) (2011) Alendronate, etidronate, risedronate, raloxifene, strontium ranelate and teriparatide for the secondary prevention of osteoporotic fragility fractures in postmenopausal women. Technology appraisal TA 161. www.nice.org.uk/guidance/TA161

159. Osteologie D (2011) DVO guideline 2009 for prevention, diagnosis and therapy of osteoporosis in adults. Osteologie 20:5574

160. NICE (2012) Osteoporosis: assessing the risk of fragility fracture. Clinical guideline 146

161. Roux C, Cooper C, Diez-Perez A, Martinez L, Ortolani S, Gitlin M, Moller G, Shepherd S, Freemantle N (2011) Prevalence of osteoporosis and fractures among women prescribed osteoporosis medication in five European countries: the POSSIBLE EU((R)) study. Osteoporos Int 22: $1227-36$
162. Freedman KB, Kaplan FS, Bilker WB, Strom BL, Lowe RA (2000) Treatment of osteoporosis: are physicians missing an opportunity? J Bone Joint Surg Am 82-A:1063- 1070

163. Giangregorio L, Papaioannou A, Cranney A, Zytaruk N, Adachi JD (2006) Fragility fractures and the osteoporosis care gap: an international phenomenon. Semin Arthritis Rheum 35:293-305

164. Nayak S, Roberts MS, Greenspan SL (2009) Factors associated with diagnosis and treatment of osteoporosis in older adults. Osteoporos Int 20:1963-1967

165. Vaile J, Sullivan L, Bennett C, Bleasel J (2007) First Fracture Project: addressing the osteoporosis care gap. Intern Med J 37:717-720

166. Majumdar SR, Kim N, Colman I, Chahal AM, Raymond G, Jen H, Siminoski KG, Hanley DA, Rowe BH (2005) Incidental vertebral fractures discovered with chest radiography in the emergency department: prevalence, recognition, and osteoporosis management in a cohort of elderly patients. Arch Intern Med 165:905-909

167. Bessette L, Ste-Marie LG, Jean S, Davison KS, Beaulieu M, Baranci M, Bessant J, Brown JP (2008) Recognizing osteoporosis and its consequences in Quebec (ROCQ): background, rationale, and methods of an antifracture patient health-management programme. Contemp Clin Trials 29:194-210

168. Elliot-Gibson V, Bogoch ER, Jamal SA, Beaton DE (2004) Practice patterns in the diagnosis and treatment of osteoporosis after a fragility fracture: a systematic review. Osteoporos Int 15:767-778

169. Haaland DA, Cohen DR, Kennedy CC, Khalidi NA, Adachi JD, Papaioannou A (2009) Closing the osteoporosis care gap: increased osteoporosis awareness among geriatrics and rehabilitation teams. BMC Geriatr 9:28

170. Swedish National Board of Health and Welfare (2009) Quality and Efficiency in Swedish Health Care. In. Swedish Association of Local Authorities and Regions Swedish National Board of Health and Welfare, Stockholm

171. Borgstrom F, Johnell O, Kanis JA, Jonsson B, Rehnberg C (2006) At what hip fracture risk is it cost- effective to treat? International intervention thresholds for the treatment of osteoporosis. Osteoporos Int 17:1459- 1471

172. Austin P, Tu J, Ko D, Alter D (2008) Factors associated with the use of evidence-based therapies fter discharge among elderly patients with myocardial infarction. Canadian Medical Association Journal 179:901-908 


\section{Appendix A.}

\section{Literature review of recent adherence literature in the $E U$}

In order to assess adherence to pharmaceutical pharmacological therapies for osteoporosis in clinical practice in the EU27, a systematic literature review with the following objective was performed: i) to identify and describe recently published studies on adherence to osteoporosis medication in the EU27; and ii) if possible, synthesise the findings.

\section{Methods}

Pubmed was searched for relevant articles published from January 12006 to June 1 2011. Fixed search terms were used to identify the relevant studies, both using free text and Mesh terms: osteoporosis [Mesh], adherence [Mesh], adherence, persistence, medication possession ratio, compliance and drug schedule. Only articles in the English language were considered.

Articles investigating adherence to pharmacological treatment for primary osteoporosis in the EU 27 were included in the review. Relevant treatments were defined as bisphosphonates, hormone replacement treatment (HRT), selective estrogen receptor modulators (SERMs), parathyroid hormone (PTH) peptides, strontium ranelate and calcitonin. Articles were excluded if: i) calcium and/or Vitamin D were the primary treatments of interest; ii) the study had an interventional design; iii) data were obtained from a non EU 27 country; iv) adherence, persistence or compliance were not outcomes v) the article did not contain original data. Articles were first screened based on their title and then the abstract. Subsequently, the remaining articles were reviewed in full text.

On the basis of these explicit criteria, search results were independently reviewed by two reviewers trained in health service research and differences in inclusion/exclusion of articles were resolved through consensus agreement.

The definitions of compliance, persistence and adherence vary among publications. Therefore, to ensure consistency, we categorised reported measures according to pre-set definitions rather than using the definitions in the article. We considered compliance as the correctness of drug intake in terms of dose and frequency. Persistence was considered as the time on treatment as well as the proportion of patients being considered persistent at a specific time point (e.g. at 1 year).

\section{Results}

The initial search resulted in 547 unique hits. The title review excluded 241, leaving 306 articles for abstract review. This process resulted in 75 articles to be studied in full text. According to the pre-set definitions, 25 articles were accepted for data abstraction (Fig. 19).

\subsection{Study characteristics}

Of the 25 studies, nine focused solely on persistence, six focused solely on compliance, and ten assessed both outcomes. The studies on persistence were more frequently based on database derived data $(n=15)$ than patient reported data $(n=3)$, with one study using both methodologies. The studies on compliance showed a more even distribution of database derived $(n=6)$ and self-reported data $(n=8)$ with two studies using both methodologies (Table 16).

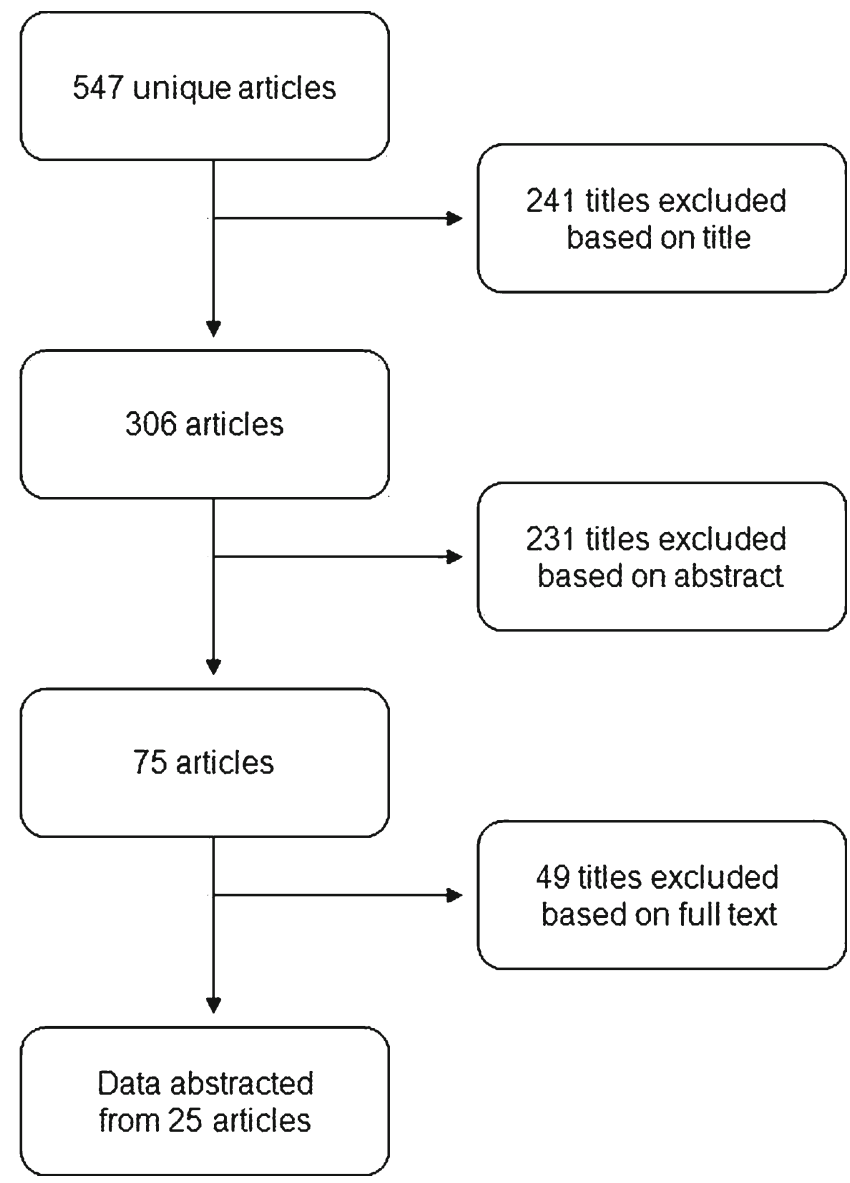

Fig. 19 Review process of articles on adherence to osteoporosis treatment 
Table 16 Characteristics of the 25 articles included for data extraction

\begin{tabular}{|c|c|c|c|c|c|c|}
\hline \multirow{2}{*}{ Country } & \multicolumn{2}{|c|}{ Persistence } & \multicolumn{2}{|c|}{ Compliance } & \multirow{2}{*}{-Drug type } & \multirow[b]{2}{*}{ Ref } \\
\hline & $\begin{array}{c}\text { Self- } \\
\text { reported }\end{array}$ & $\begin{array}{c}\text { Database } \\
\text { derived }\end{array}$ & $\begin{array}{c}\text { Self- } \\
\text { reported }\end{array}$ & $\begin{array}{c}\text { Database } \\
\text { derived }\end{array}$ & & \\
\hline Belgium & & $x$ & & $x$ & $\mathrm{BP}$ & [1] \\
\hline Belgium & & $x$ & & $x$ & $\mathrm{BP}$ & [2] \\
\hline Czech Republic & & & $x$ & & $\mathrm{BP}+\mathrm{SERM}+$ calcitonin & [3] \\
\hline France & & & $x$ & & $\mathrm{BP}+\mathrm{SERM}$ & [4] \\
\hline France & & $\mathrm{x}$ & & $\mathrm{x}$ & $\mathrm{BP}$ & [5] \\
\hline France & & $x$ & & & $\mathrm{BP}$ & [6] \\
\hline France & & $x$ & & $x$ & $\mathrm{BP}+\mathrm{SERM}+\mathrm{Str}$ & [7] \\
\hline France, UK & & $x$ & & $x$ & $\mathrm{BP}$ & [8] \\
\hline France & & & $x$ & & $\mathrm{BP}+\mathrm{SERM}+\mathrm{Str}$ & [9] \\
\hline Germany & $x$ & & & & $\mathrm{BP}$ & [10] \\
\hline Germany & $x$ & $x$ & $x$ & $x$ & SERM & [11] \\
\hline Germany & & $x$ & $x$ & $x$ & Teriparatide & [12] \\
\hline Italy & & & $x$ & & $\mathrm{BP}+\mathrm{SERM}$ & [13] \\
\hline Italy & & & $x$ & & $\mathrm{BP}+\mathrm{SERM}$ & [14] \\
\hline Italy & $x$ & & $x$ & & $\mathrm{BP}+\mathrm{SERM}+\mathrm{HRT}$ & [15] \\
\hline Netherlands & & $x$ & & & $\mathrm{BP}$ & [16] \\
\hline Netherlands & & $x$ & & & $\mathrm{BP}$ & [17] \\
\hline Netherlands & & $x$ & & & $\mathrm{BP}$ & [18] \\
\hline Netherlands & & $x$ & & & $\mathrm{BP}$ & [19] \\
\hline Spain & & & $x$ & & SERM & [20] \\
\hline UK & & $x$ & & & Teriparatide & [21] \\
\hline UK & & $x$ & & $x$ & $\mathrm{BP}$ & [22] \\
\hline UK & $x$ & & $x$ & & $\mathrm{BP}$ & [23] \\
\hline UK & & $x$ & & & $\mathrm{BP}$ & [24] \\
\hline UK & & $x$ & & & $\mathrm{BP}$ & [25] \\
\hline
\end{tabular}

$\mathrm{BP}=$ bisphosphonates; SERM = selective estrogen receptor modulator; $\mathrm{Str}=$ Strontium Ranelate; HRT $=$ Hormone replacement treatment

The most commonly studied drugs were bisphosphonates, which were included in 21 out of 25 studies. Alendronate, a bisphosphonate, was also the most common individual drug reported on. Raloxifene, a SERM, was included in nine studies; strontium ranelate and teriparatide were included in two studies while HRT and calcitonin were included in one study each. The number of studies on specific classes and individual treatments may reflect the prescription pattern and time of availability of the different drugs in the EU.

\subsection{Persistence}

Persistence was measured in 19 of the 25 articles. According to our definition both time to treatment discontinuation and proportion of patients still on treatment at a predefined time from treatment initiation were regarded as measures of persistence.

The definition of time to treatment discontinuation differed among the studies. Four studies presented only median time to discontinuation $[1,2,5,21]$; two studies presented only mean time to discontinuation $[8,22]$; and one study presented both outcomes [24]. It is notable that mean time to discontinuation (231 days) differed from the median time to discontinuation
(267 days) in the study estimating both outcomes. Furthermore, the length of the permissible treatment gap differed between the studies, ranging from 30 days to 45 days. Partially reflecting these methodological differences, time to treatment discontinuation ranged from 155 days in French women prescribed daily alendronate or risedronate to 282 days in Belgian women prescribed daily or weekly alendronate (Table 17).

Similarly, the definition of patients still on treatment at a specified time point differed among studies. Five studies defined patients still on treatment as patients that renewed their prescription within a predefined gap from their last prescription; three studies defined patients still on treatment as patients having a medication possession ratio (MPR) at or above $80 \%$; and one study presented estimates for both definitions. It is notable that the estimate resulting from the first definition $(40 \%)$ differed from the estimate resulting from the second definition (49\%) in the article assessing both methods. Furthermore, in the studies estimating the proportion still on treatment using the predefined gap method, the permissible gap ranged from 30 days to 3 months, with one study using a dynamic method with the permissible gap defined as half of the dispensing time. Whilst the time points at which the 
Table 17 Results from articles presenting database derived persistence results

\begin{tabular}{|c|c|c|c|c|c|c|c|c|c|}
\hline Country & Measure & MPR & Mean or & Patients & Permissible & Result & Treatment & Other & Ref \\
\hline \multirow[t]{3}{*}{ Belgium } & TTD & & Median & 54,807 & $35 d$ & $250 d$ & Aln & $\begin{array}{l}\text { Daily and weekly } \\
\text { dosing }\end{array}$ & {$[1]$} \\
\hline & P6m & & & & & $58 \%$ & & & \\
\hline & $\mathrm{P} 12 \mathrm{~m}$ & & & & & $40 \%$ & & & \\
\hline \multirow[t]{4}{*}{ Belgium } & TTD & & Median & 726 & $35 d$ & $282 d$ & Aln & $\begin{array}{l}\text { Daily and weekly } \\
\text { dosing }\end{array}$ & {$[2]$} \\
\hline & P6m & & & & & $60 \%$ & & & \\
\hline & P12m & & & & & $40 \%$ & & & \\
\hline & P12m & $\mathrm{MPR}>80 \%$ & & & & $49 \%$ & & & \\
\hline \multirow[t]{6}{*}{ France } & TTD & & Median & 1,989 & $30 d$ & $169 d$ & Aln, Ris & Weekly dosing & {$[5]$} \\
\hline & P6m & & & & & $46 \%$ & & & \\
\hline & P12m & & & & & $30 \%$ & & & \\
\hline & TTD & & & 1,001 & $45 d$ & $265 d$ & Iba & Monthly dosing & \\
\hline & P6m & & & & & $57 \%$ & & & \\
\hline & $\mathrm{P} 12 \mathrm{~m}$ & & & & & $48 \%$ & & & \\
\hline \multirow[t]{6}{*}{ France } & P6m & & & $1,129,392$ & $30 d$ & $63 \%$ & $\mathrm{BP}$ & Daily dosing & {$[6]$} \\
\hline & P12m & & & & & $44 \%$ & & & \\
\hline & $\mathrm{P} 24 \mathrm{~m}$ & & & & & $32 \%$ & & & \\
\hline & P6m & & & $1,129,392$ & $30 d$ & $67 \%$ & BP & Weekly dosing & \\
\hline & $\mathrm{P} 12 \mathrm{~m}$ & & & & & $51 \%$ & & & \\
\hline & $\mathrm{P} 24 \mathrm{~m}$ & & & & & $41 \%$ & & & \\
\hline \multirow[t]{2}{*}{ France } & P12m & & & 390 & $30 d$ & $34 \%$ & $\begin{array}{l}\text { Aln, Ris, Eti, } \\
\quad \text { Rlx, Str }\end{array}$ & $\begin{array}{l}\text { Fracture cases; } \\
\text { switching ok }\end{array}$ & [7] \\
\hline & P12m & & & 2,078 & & $41 \%$ & & $\begin{array}{l}\text { Matched } \\
\text { controls }\end{array}$ & \\
\hline \multirow[t]{3}{*}{ UK } & TTD & & Mean & 7,567 & $30 d$ & $243 d$ & Aln, Ris & $\begin{array}{l}\text { Daily and weekly } \\
\text { dosing }\end{array}$ & {$[8]$} \\
\hline & TTD & & & 6,463 & & $208 d$ & Aln, Ris & Daily & \\
\hline & TTD & & & 1,104 & & $249 d$ & Aln, Ris & Weekly dosing & \\
\hline \multirow[t]{3}{*}{ France } & TTD & & Mean & 5,332 & & $173 d$ & Aln, Ris & $\begin{array}{l}\text { Daily and weekly } \\
\text { dosing }\end{array}$ & {$[8]$} \\
\hline & TTD & & & 3,969 & & $155 d$ & Aln, Ris & Daily dosing & \\
\hline & TTD & & & 1363 & & $179 d$ & Aln, Ris & Weekly dosing & \\
\hline \multirow[t]{4}{*}{ Netherlands } & P6m & $\mathrm{MPR}>80 \%$ & & 8,822 & & $66 \%$ & Aln, Ris & $\begin{array}{l}\text { Daily and weekly } \\
\text { dosing }\end{array}$ & [16] \\
\hline & P12m & & & & & $58 \%$ & & & \\
\hline & $\mathrm{P} 24 \mathrm{~m}$ & & & & & $49 \%$ & & & \\
\hline & P36m & & & & & $40 \%$ & & & \\
\hline Netherlands & P12m & $M P R>80 \%$ & & 8,822 & & $53 \%$ & Aln, Ris & $\begin{array}{l}\text { Daily and Weekly } \\
\text { dosing }\end{array}$ & [17] \\
\hline
\end{tabular}

proportion of persistent patients was estimated ranged from 3 months to 5 years, all nine studies estimated the proportion of patients persistent at 12 months, with estimates ranging from $30 \%$ in French women prescribed weekly alendronate or risedronate to $58 \%$ in Dutch women prescribed daily or weekly alendronate or risedronate (Table 17). However, these estimates may not be directly comparable reflecting the aforementioned differences in definitions and methodology. 
Table 17 (continued)

\begin{tabular}{|c|c|c|c|c|c|c|c|c|c|}
\hline Country & Measure & MPR & Mean or & Patients & Permissible & Result & Treatment & Other & Ref \\
\hline & P3m & & & 1,639 & & $71 \%$ & Aln, Ris & $\begin{array}{l}\text { Daily dosing; } \\
\text { Start < 2000-07 }\end{array}$ & \\
\hline & P6m & & & & & $58 \%$ & & & \\
\hline & $\mathrm{P} 12 \mathrm{~m}$ & & & & & $48 \%$ & & & \\
\hline & P3m & & & 2,583 & & $74 \%$ & Aln, Ris & $\begin{array}{l}\text { Daily dosing; } \\
\text { Start > 2000-07 }\end{array}$ & \\
\hline & P6m & & & & & $62 \%$ & & & \\
\hline & $\mathrm{P} 12 \mathrm{~m}$ & & & & & $52 \%$ & & & \\
\hline & P3m & & & 4,600 & & $80 \%$ & Aln, Ris & Weekly dosing & \\
\hline & P6m & & & & & $71 \%$ & & & \\
\hline & $\mathrm{P} 12 \mathrm{~m}$ & & & & & $64 \%$ & & & \\
\hline \multirow[t]{12}{*}{ Netherlands } & $\mathrm{P} 12 \mathrm{~m}$ & & & 14,760 & $\begin{array}{c}1 / 2 \\
\text { dispensing } \\
\text { time }\end{array}$ & $434 \%$ & Aln, Ris, Eti & & [19] \\
\hline & $\mathrm{P} 24 \mathrm{~m}$ & & & 11,359 & & $27 \%$ & & & \\
\hline & $\mathrm{P} 12 \mathrm{~m}$ & & & 4,981 & & $33 \%$ & Aln & Daily dosing & \\
\hline & $\mathrm{P} 24 \mathrm{~m}$ & & & 4,549 & & $18 \%$ & & & \\
\hline & P12m & & & 3,589 & & $48 \%$ & Aln & Weekly dosing & \\
\hline & $\mathrm{P} 24 \mathrm{~m}$ & & & 1,981 & & $35 \%$ & & & \\
\hline & P12m & & & 611 & & $33 \%$ & Ris & Daily dosing & \\
\hline & $\mathrm{P} 24 \mathrm{~m}$ & & & 512 & & $17 \%$ & & & \\
\hline & $\mathrm{P} 12 \mathrm{~m}$ & & & 1,171 & & $47 \%$ & Ris & Weekly dosing & \\
\hline & $\mathrm{P} 24 \mathrm{~m}$ & & & 263 & & $26 \%$ & & & \\
\hline & P12m & & & 4,408 & & $40 \%$ & Eti & Daily dosing & \\
\hline & $\mathrm{P} 24 \mathrm{~m}$ & & & 4,054 & & $22 \%$ & & & \\
\hline UK & TTD & & Median & 1,104 & & $252 d$ & Ter & & [21] \\
\hline \multirow[t]{4}{*}{ UK } & TTD & & Mean & 15,330 & $30 d$ & $234 d$ & Aln, Ris & $\begin{array}{l}\text { Daily and weekly } \\
\text { dosing }\end{array}$ & [22] \\
\hline & TTD & & & 7,567 & & $243 d$ & & GPRD Database & \\
\hline & TTD & & & 5,962 & & $222 d$ & & $\begin{array}{l}\text { MEDIPLUS } \\
\text { database }\end{array}$ & \\
\hline & TTD & & & 1,801 & & $233 d$ & & $\begin{array}{l}\text { DIN_LINK } \\
\text { database }\end{array}$ & \\
\hline \multirow[t]{5}{*}{ UK } & TTD & & Mean & 1,286 & & $231 d$ & Aln, Ris & Weekly dosing & [24] \\
\hline & & & Median & & & $267 d$ & & & \\
\hline & P12m & $M P R>80 \%$ & & & & $48 \%$ & Aln, Ris & Weekly dosing & \\
\hline & P12m & & & & & $47 \%$ & Aln & Weekly dosing & \\
\hline & $\mathrm{P} 12 \mathrm{~m}$ & & & & & $41 \%$ & Ris & Weekly dosing & \\
\hline \multirow[t]{2}{*}{ UK } & P1y & & & 44,531 & $3 m$ & $58 \%$ & Aln, Ris & & [25] \\
\hline & P5y & & & & & $24 \%$ & & & \\
\hline
\end{tabular}

$\mathrm{MPR}=$ medication possession ratio; TTD = time to treatment discontinuation; P3m, P6m, P12m, P24m, P1y, P5y = persistent patients at 3 months, 6 months, 12 months, 24 months, 1 year, 5 years; BP = Bisphosphonates; Aln = Alendronate; Ris = Risedronate; Iba = Ibandronate; Eti = Etidronate; $\mathrm{Rlx}=$ Raloxifene; $\mathrm{Str}=$ strontium ranelate; Ter $=$ teriparatide; $\mathrm{d}=\mathrm{day} ; \mathrm{m}=$ month 
Table 18 Results from articles presenting self-reported persistence results

\begin{tabular}{|c|c|c|c|c|c|c|}
\hline Country & Measure & Mean or & Patients & Results & Treatment & Ref \\
\hline \multirow[t]{3}{*}{ Germany } & TTD & & 62 & $9.5 \mathrm{~m}$ & Generic Aln & [10] \\
\hline & & & 62 & $11.0 \mathrm{~m}$ & Aln & \\
\hline & & & 62 & $11.6 \mathrm{~m}$ & Ris & \\
\hline \multirow[t]{5}{*}{ Germany } & TTD & mean & 300 & $19 m$ & $\mathrm{R} \mid \mathrm{x}$ & [11] \\
\hline & P6m & & & $84 \%$ & & \\
\hline & $\mathrm{P} 12 \mathrm{~m}$ & & & $81 \%$ & & \\
\hline & $\mathrm{P} 24 \mathrm{~m}$ & & & $78 \%$ & & \\
\hline & P36m & & & $77 \%$ & & \\
\hline \multirow[t]{21}{*}{ Italy } & $\%$ disc. $<6 \mathrm{~m}$ & & 9,851 & $10.3 \%$ & All therapies* & [15] \\
\hline & $\%$ disc. $6-12 m$ & & & $4.8 \%$ & & \\
\hline & $\%$ disc. $>12 \mathrm{~m}$ & & & $3.1 \%$ & & \\
\hline & $\%$ disc. $<6 \mathrm{~m}$ & & 795 & $7.0 \%$ & HRT & \\
\hline & $\%$ disc. $6-12 m$ & & & $3.4 \%$ & & \\
\hline & $\%$ disc. $>12 \mathrm{~m}$ & & & $12.6 \%$ & & \\
\hline & $\%$ disc. $<6 \mathrm{~m}$ & & 778 & $9.1 \%$ & Rlx & \\
\hline & $\%$ disc. $6-12 m$ & & & $5.3 \%$ & & \\
\hline & $\%$ disc. $>12 \mathrm{~m}$ & & & $1.9 \%$ & & \\
\hline & $\%$ disc. $<6 \mathrm{~m}$ & & 1,740 & $13.6 \%$ & Cld & \\
\hline & $\%$ disc. $6-12 m$ & & & $8.2 \%$ & & \\
\hline & $\%$ disc. $>12 \mathrm{~m}$ & & & $14.2 \%$ & & \\
\hline & $\%$ disc. $<6 \mathrm{~m}$ & & 1,706 & $9.8 \%$ & daily Aln & \\
\hline & $\%$ disc. $6-12 m$ & & & $6.6 \%$ & & \\
\hline & $\%$ disc. $>12 \mathrm{~m}$ & & & $4.5 \%$ & & \\
\hline & $\%$ disc. $<6 \mathrm{~m}$ & & 2,220 & $5.9 \%$ & weekly Aln & \\
\hline & $\%$ disc. $6-12 m$ & & & $0.9 \%$ & & \\
\hline & $\%$ disc. $>12 \mathrm{~m}$ & & & $0.1 \%$ & & \\
\hline & $\%$ disc. $<6 \mathrm{~m}$ & & 9,32 & $11.8 \%$ & Ris & \\
\hline & $\%$ disc. $6-12 m$ & & & $4.7 \%$ & & \\
\hline & $\%$ disc. $>12 m$ & & & $2.5 \%$ & & \\
\hline UK & TTD & median & 334 & $24 m$ & $\mathrm{BP}$ & [23] \\
\hline
\end{tabular}

TTD = time to treatment discontinuation; P3m, P6m = persistent patients at 3 months, 6 months, etc; Aln = alendronate; HRT = hormone replacement treatment; $\mathrm{Rlx}=$ raloxifene; $\mathrm{Cld}=$ clodronate; $\mathrm{Ris}=$ risedronate; $\mathrm{BP}=$ bisphosphonates; disc $=$ discontinued; $* \mathrm{HRT}, \mathrm{Rlx}, \mathrm{Cld}, \mathrm{Aln}, \mathrm{Ris}$, and calcium+vitamin $\mathrm{D}$

Self-reported persistence was presented in four studies (Table 18). Among these, time to treatment discontinuation was the most frequent outcome, presented in three articles; two studies estimated mean time to discontinuation and one estimated median time to discontinuation, with estimate of mean/median time to discontinuation ranging from 9.5 months in German women prescribed generic alendronate [10] to 24 months in UK women prescribed bisphosphonates [23]. As can be seen in the study by Rossini et al. [15], patients appeared to discontinue treatment at a higher rate during the first 6 months of treatment than subsequently.

Self-reported and database derived persistence estimates were combined to produce estimates of persistence at 6 and 12 months by Ziller et al. [11]. The results are presented in Table 19.

Table 19 Results from articles presenting combined database derived and self-reported persistence results

\begin{tabular}{lcccccc}
\hline Country & Measure & Patients & Results & $\begin{array}{c}\text { Permissible } \\
\text { gap }\end{array}$ & Treatment & Ref \\
\hline Germany & P6m & 300 & $67 \%$ & $90 \mathrm{~d}$ & Rlx & {$[11]$} \\
& P12m & & $56 \%$ & & & \\
& P24m & & $48 \%$ & & & \\
& P36m & & $35 \%$ & & & \\
\end{tabular}

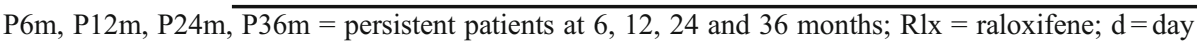




\subsection{Compliance}

Compliance was measured in 16 of the 25 studies. Compared to persistence, the studies of compliance were more evenly distributed between databases and patient reports (six database derived studies, eight patient reported studies, and two studies using both approaches).

Database derived compliance was primarily measured as medication possession ratio (MPR). Five of six studies report point estimates of mean MPR $[1,2,5,7,8]$ whereas one used a cut-off point of MPR of $80 \%$ to determine the proportion compliant patients [11]. Among the studies reporting point estimates of MPR, three reported MPR at 12 months $[1,2,8]$ arguably producing a composite estimate of persistence and compliance rather than an estimate of compliance.

The point estimates of MPR ranged from $53 \%$ for French women prescribed daily bisphosphonates [8] to $85 \%$ for French patients prescribed monthly ibandronate [5] (Table 20). However, given the differences in methodology among studies, the estimates may not be directly comparable.

The characteristics and results of the studies presenting self-reported compliance estimates are summarized in Table 21. Since compliance encompasses many aspects of drug intake, such as number of doses actually taken, correctness of timing of drug intake and intake of drug according to specific instructions (e.g. before a meal etc.), self-reported compliance reports may be more informative than the database derived estimates. However, the methodology for deriving selfreported compliance estimates appeared less standardised than for database-derived estimates, rendering comparisons of estimates of self-reported compliance more challenging. Two studies used a validated instrument designed to determine compliance-the Morisky questionnaire-which gives the result as the Morisky score $[9,20]$. Blotman et al. used a test developed in France [4] and Carr et al. performed a national survey based on three validated questionnaires [23]. The

Table 20 Results from articles presenting database derived compliance results

\begin{tabular}{|c|c|c|c|c|c|c|c|}
\hline Country & Measure & $\begin{array}{c}\text { Mean or } \\
\text { median MPR }\end{array}$ & Patients & Results & Treatment & Other information & Ref \\
\hline \multirow[t]{3}{*}{ Belgium } & MPR $12 \mathrm{~m}$ & Mean & 2,9157 & $65 \%$ & Aln & $\begin{array}{l}\text { Daily and weekly } \\
\text { dosing }\end{array}$ & [1] \\
\hline & & & 14,136 & $59 \%$ & Aln & Daily dosing & \\
\hline & & & 15,021 & $71 \%$ & Aln & Weekly dosing & \\
\hline \multirow[t]{3}{*}{ Belgium } & MPR $12 \mathrm{~m}$ & Mean & 306 & $67 \%$ & Aln & $\begin{array}{l}\text { Daily and weekly } \\
\text { dosing }\end{array}$ & {$[2]$} \\
\hline & & & 124 & $66 \%$ & Aln & Daily dosing & \\
\hline & & & 182 & $68 \%$ & Aln & Weekly dosing & \\
\hline \multirow[t]{2}{*}{ France } & MPR & Mean & 1,989 & $79 \%$ & Aln, Ris & Weekly dosing & {$[5]$} \\
\hline & & & 1001 & $85 \%$ & Iba & Monthly & \\
\hline \multirow[t]{2}{*}{ France } & MPR & Mean & 390 & $59 \%$ & Aln, Ris, Eti, & fracture cases & [7] \\
\hline & & & 2,078 & $72 \%$ & Rix, st & Controls & \\
\hline \multirow[t]{6}{*}{$\begin{array}{l}\text { France, } \\
\text { UK }\end{array}$} & MPR $12 \mathrm{~m}$ & Mean & 7,567 & $74 \%$ & Aln, Ris & $\begin{array}{l}\text { UK, Daily and } \\
\text { weekly dosing }\end{array}$ & [8] \\
\hline & & & 6,463 & $64 \%$ & Alln, Ris & UK, Daily dosing & \\
\hline & & & 1,104 & $76 \%$ & Aln, Ris & UK, Weekly dosing & \\
\hline & & & 5,332 & $58 \%$ & Aln, Ris & $\begin{array}{l}\text { France, Daily and } \\
\text { weekly dosing }\end{array}$ & \\
\hline & & & 3,969 & $53 \%$ & Aln, Ris & $\begin{array}{l}\text { France, Daily } \\
\text { dosing }\end{array}$ & \\
\hline & & & 1,363 & $59 \%$ & Aln, Ris & $\begin{array}{l}\text { France, Weekly } \\
\text { dosing }\end{array}$ & \\
\hline Germany & MPR $>80 \%$ & & 300 & $38 \%$ & Rlx & & {$[11]$} \\
\hline
\end{tabular}

$\mathrm{MPR}=$ medication possession ratio; $\mathrm{Aln}=$ alendronate; $\mathrm{Str}=$ strontium ranelate; Ris = risedronate; $\mathrm{Iba}=$ ibandronate; Eti = etidronate; $\mathrm{Rlx}=$ raloxifene; $\mathrm{m}=$ month 
remaining studies presented self-reported MPR: one study presented MPR as a point estimate [3] whereas the four remaining studies presented the proportion of patients above MPR cut-off points; among those the cut-off points were set at $75 \%$ in two studies $[13,14]$ and $80 \%$ in three studies $[11,12,15]$.

The estimates of compliant patients derived using questionnaires ranged from $48 \%$ in UK for women prescribed bisphosphonates [23] to $66 \%$ in French women prescribed bisphosphonates, raloxifene or strontium ranelate. The proportion of patients who reported an MPR above 75 or $80 \%$-indicating high compliance-ranged from $61 \%$ in Italian women prescribed clodronate [15] to $93 \%$ in Italian women prescribed alendronate, risedronate or raloxifene [13]. In the study reporting the point estimate of MPR, MPR was reported at $93 \%$ for women prescribed, alendronate, risedronate, raloxifene or calcitonin [3].

The studies by Ziller et al. presented self-reported and database derived compliance estimates which suggested that patients overestimate their compliance $[11,12]$. The results from the self-reported part of the study were that $75 \%$ and

Table 21 Results from articles presenting self-reported compliance results

\begin{tabular}{|c|c|c|c|c|c|c|c|}
\hline Country & Measure & $\begin{array}{l}\text { Mean or } \\
\text { median }\end{array}$ & Patients & Result & Treatment & $\begin{array}{c}\text { Other } \\
\text { information }\end{array}$ & Ref \\
\hline \multirow[t]{4}{*}{ Czech Republic } & MPR & Mean & 200 & $93 \%$ & Aln, Ris, Rlx, Ctn & & [3] \\
\hline & & & 138 & $94 \%$ & Aln, Ris & & \\
\hline & & & 36 & $93 \%$ & Rlx & & \\
\hline & & & 26 & $87 \%$ & Ctn & & \\
\hline \multirow[t]{4}{*}{ France } & TEO & & 1019 & & Aln, Ris, Rlx & & [4] \\
\hline & High compliance & & & $61 \%$ & & & \\
\hline & Adequate compliance & & & $35 \%$ & & & \\
\hline & Low compliance & & & $4 \%$ & & & \\
\hline \multirow[t]{2}{*}{ France } & Morisky score & Mean & 785 & 3.3 & BP, Rlx, Str & & [9] \\
\hline & Morisky score $=4$ & & & $66 \%$ & & $\begin{array}{c}\text { Morisky score }<4 \text { is } \\
\text { non-compliant }\end{array}$ & \\
\hline Germany & MPR $>80 \% 39 m$ & & 300 & $75 \%$ & Rlx & & [11] \\
\hline Germany & $M P R>80 \% 12 m$ & & 50 & $91 \%$ & Ter & & {$[12]$} \\
\hline Italy & MPR $>75 \%$ & & 880 & $93 \%$ & Aln, Ris, Rlx & $\begin{array}{c}\text { MPR }>75 \% \text { is } \\
\text { compliant }\end{array}$ & {$[13]$} \\
\hline Italy & MPR $>75 \%$ & & & $91 \%$ & Aln, Ris, Rlx & $\begin{array}{c}\text { MPR }>75 \% \text { is } \\
\text { compliant }\end{array}$ & [14] \\
\hline \multirow[t]{9}{*}{ Italy } & MPR<30\% & & 795 & $1 \%$ & HRT & & [15] \\
\hline & MPR $30-50 \%$ & & & $1 \%$ & & & \\
\hline & MPR $50-80 \%$ & & & $20 \%$ & & & \\
\hline & MPR $>80 \%$ & & & $71 \%$ & & & \\
\hline & MPR<30\% & & 778 & $2 \%$ & Rlx & & \\
\hline & MPR $30-50 \%$ & & & $1 \%$ & & & \\
\hline & MPR 50-80\% & & & $8 \%$ & & & \\
\hline & MPR $>80 \%$ & & & $90 \%$ & & & \\
\hline & MPR<30\% & & 1740 & $4 \%$ & Cld & & \\
\hline
\end{tabular}


Table 21 (continued)

\begin{tabular}{|c|c|c|c|c|c|c|c|}
\hline Country & Measure & $\begin{array}{l}\text { Mean or } \\
\text { median }\end{array}$ & Patients & Result & Treatment & $\begin{array}{c}\text { Other } \\
\text { information }\end{array}$ & Ref \\
\hline & MPR 30-50\% & & & $9 \%$ & & & \\
\hline & MPR $50-80 \%$ & & & $27 \%$ & & & \\
\hline & MPR $>80 \%$ & & & $61 \%$ & & & \\
\hline & MPR $<30 \%$ & & 1706 & $3 \%$ & Daily Aln & & \\
\hline & MPR 30-50\% & & & $7 \%$ & & & \\
\hline & MPR $50-80 \%$ & & & $22 \%$ & & & \\
\hline & $M P R>80 \%$ & & & $69 \%$ & & & \\
\hline & $M P R<30 \%$ & & 2220 & $1 \%$ & Weekly Aln & & \\
\hline & MPR $30-50 \%$ & & & $2 \%$ & & & \\
\hline & MPR $50-80 \%$ & & & $13 \%$ & & & \\
\hline & $M P R>80 \%$ & & & $84 \%$ & & & \\
\hline & MPR<30\% & & 932 & $2 \%$ & Ris & & \\
\hline & MPR $30-50 \%$ & & & $5 \%$ & & & \\
\hline & MPR $50-80 \%$ & & & $19 \%$ & & & \\
\hline & MPR $>80 \%$ & & & $74 \%$ & & & \\
\hline \multirow[t]{2}{*}{ Spain } & Morisky test $=4$ at $3 \mathrm{~m}$ & & 379 & $63 \%$ & RIx & $\begin{array}{l}\text { Morisky test=4 is } \\
\text { high compliance }\end{array}$ & {$[20]$} \\
\hline & Morisky test $=4$ at $12 \mathrm{~m}$ & & & $53 \%$ & & & \\
\hline UK & $\begin{array}{c}\text { Proportion compliant } \\
\text { patients* }\end{array}$ & & & $48 \%$ & BP & & [23] \\
\hline
\end{tabular}

MPR = medication possession ratio; $\mathrm{BP}=$ bisphosphonate; $\mathrm{Aln}=$ alendronate; $\mathrm{Ris}=$ risedronate; $\mathrm{Rlx}=$ raloxifene; $\mathrm{Ctn}=$ calcitonin; $\mathrm{Str}=$ strontium ranelate; $\mathrm{Ter}=$ teriparatide; $\mathrm{HRT}=$ hormone replacement treatment; $\mathrm{Cld}=$ clodronate; $\mathrm{TEO}=$ Test d'Evalution de l'Observance; *According to questionnaire

$91 \%$ of the German women participating in the study had an MPR over $80 \%$ for raloxifene and teriparatide, respectively. When combined with the database derived estimates of MPR, the estimates were modified to $32 \%$ for raloxifene and $80 \%$ for teriparatide (Table 22).

\subsection{Data synthesis}

In order to produce meaningful estimates of persistence and compliance in the EU27, the studies eligible for metaanalysis should have a sufficient geographic spread. Having assessed the methodologies used in the studies identified in the review, we concluded that neither studies of persistence nor compliance could be pooled to provide meaningful estimates from an EU27 perspective.

To pool the estimates of persistence or compliance in meta-analysis, the methodologies used in the selected studies must be sufficiently similar. Consequently, pooling database derived and self-reported estimates would not be appropriate in view of the different methodology used in data collection.

For the studies estimating database derived persistence, the seven studies presenting time to discontinuation cannot be pooled with the studies presenting persistence at a specified time point given that the outcomes differ. When assessing the studies presenting

Table 22 Results from articles presenting combined database derived and self-reported persistence results

$\mathrm{MPR}=$ medication possession ratio; $\mathrm{m}=$ month

\begin{tabular}{lccccc}
\hline Country & Measure & Patients & Result & Treatment & Ref \\
\hline Germany & MPR $>80 \% 39 \mathrm{~m}$ & 300 & $32 \%$ & raloxifene & {$[11]$} \\
Germany & MPR $>80 \% 12 \mathrm{~m}$ & 50 & $80 \%$ & teriparatide & {$[12]$} \\
\hline session ratio $m=$ month & & & &
\end{tabular}


time to discontinuation with respect to outcome (mean or median) and permissible gap (number of days) a maximum of three studies were eligible for pooling. Similarly when assessing the studies reporting the proportion of patients still on treatment at 12 months (the most frequently reported time point) with respect to outcome (MPR $>80 \%$ or patients refilling medication within a pre-specified period) and length of permissible gap, a maximum of four studies was eligible for pooling.

Estimates of self-reported persistence were presented as time to discontinuation in three studies and as either the proportion of patients still on treatment or patients having discontinued treatment in two studies, resulting in a maximum of three studies eligible for pooling.

For the studies estimating database derived compliance, the six studies presenting a point estimate of MPR cannot be pooled with the study reporting the proportion of patients above a cut-off point $(80 \%)$ for compliance, given that the outcomes differ. When assessing the studies presenting a point estimate of MPR with respect to outcome (MPR at 12 months or MPR during entire period the patient remained on treatment) a maximum of three studies were eligible for pooling.

Estimates of self-reported compliance were either reported using questionnaires (four studies, three different questionnaires), cut-off point for MPR (four studies, two different cut-off points) or point estimate of MPR (one study). Consequently, a maximum of two studies was eligible for pooling, rendering analysis representative for the EU-27 unfeasible.

\subsection{Determinants and outcomes of adherence in reported studies}

The articles included in this review not only reported on persistence and compliance. Some also reported on the patient characteristics that could predict or correlate with adherence behaviour. Carr et al. [23] described factors associated with compliance and persistence to bisphosphonate therapy. Adherence was better in patients with previous fractures and a longer history of osteoporosis. Low persistence was correlated to concerns about side effects of treatment. Side effects of the gastro-intestinal (GI) tract with oral bisphosphonate treatment was shown to be of considerable importance for both compliance and persistence [17, 18]. Among bisphosphonates, less frequent dosing was frequently shown to associated with higher compliance and persistence $[1,4-6,8,9,15,17-19,22,23,25]$. Weekly administration was shown to outperform daily, and monthly being better than weekly. None of the articles indicate that less frequent dosing was associated with increased adherence. However, the absolute numbers for the respective outcomes differ substantially.

A number of articles also describe the consequence of suboptimal adherence: lost clinical effect. Gallagher et al. [25] reported a $22 \%$ lower risk of hip and femur fractures in current bisphosphonate users compared to past users. Similar numbers are reported by van den Boogaard et al. [19] when comparing fracture risk in patients who are persistent with treatment for 1 year or not; they show that persistent use resulted in a $26 \%$ lower fracture rate. In a study of Dutch women starting bisphosphonate treatment, Penningvan Beest et al. [16] compared fracture risk in noncompliant patients, defined as those patients having an MPR $<80 \%$. It was found that noncompliant use was associated with a $45 \%$ increased fracture risk compared to compliant use. In a study of Belgian women, also treated with bisphosphonates, each decrease of MPR with $1 \%$ was correlated to an increase in fracture risk by $0.4 \%$ [1].

\section{Discussion}

This study reviewed articles reporting on several outcome measures of adherence with medical treatments (except for calcium and vitamin D only). There are different strengths and drawbacks with different methods to assess these different outcomes. Database derived approaches to adherence results in a limited choice of outcomes, but can on the other hand provide a higher degree of comparability and enables studies of larger populations. The availability of databases that register drug use is naturally a prerequisite for database derived adherence estimates. These kinds of databases are more widely available than is suggested by the publications identified. E.g. Sweden, Denmark, Finland, Italy and Spain all have databases enabling this kind of research. The countries for which data are included in this literature review are shown in Fig. 20. Furthermore, a number of publications on adherence to pharmacological therapies for osteoporosis in clinical practice have recently been published from Scandinavia [26-31]. These were not captured by the literature review, due to the date limits imposed on the search. Thus, data from Eastern and North Europe were scarce using the defined inclusion criteria. In general, more information was available from the larger countries, e.g. data were abstracted from all EU5 countries. 


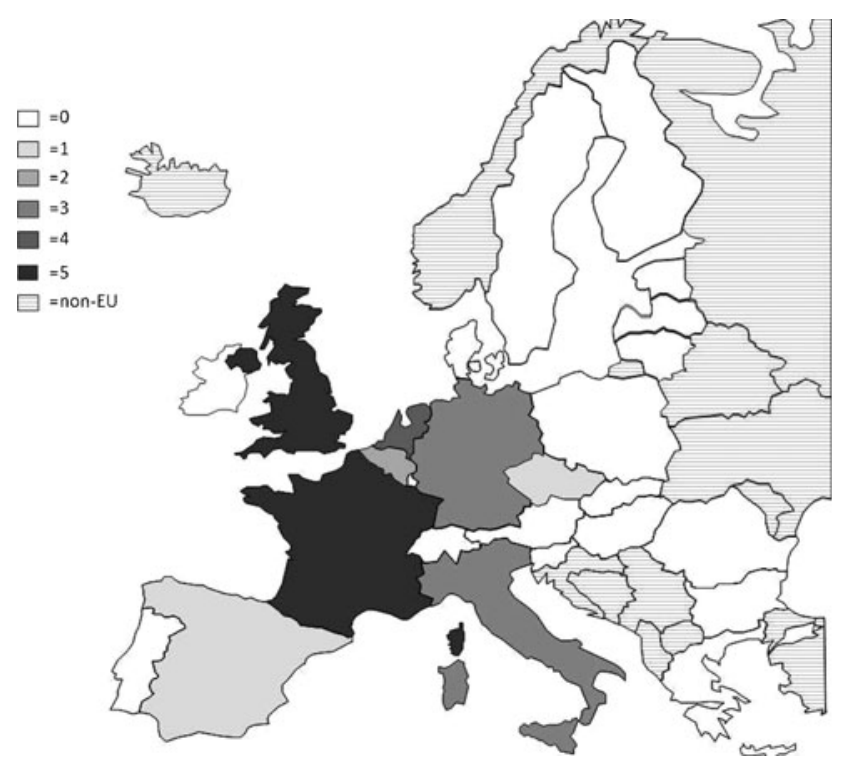

Fig. 20 Number of papers included in literature review for the respective countries in EU27

Adherence, as measured by persistence and compliance, was suboptimal in all studies included in this literature review. Of major importance is that it is also correlated with a decreased clinical effect. Nonpersistence is associated with side effects and other factors that could be modified in clinical practice through education, information as well as in research aiming for refined drug tolerability. Also, the frequency of dosing should be kept in mind when aiming for improved outcomes through increased adherence.

\section{References}

1. Rabenda V, Mertens R, Fabri V, Vanoverloop J, Sumkay F, Vannecke C, Deswaef A, Verpooten GA, Reginster JY (2008) Adherence to bisphosphonates therapy and hip fracture risk in osteoporotic women. Osteoporos Int 19:811-818

2. Rabenda V, Vanoverloop J, Fabri V, Mertens R, Sumkay F, Vannecke C, Deswaef A, Verpooten GA, Reginster JY (2008) Low incidence of anti-osteoporosis treatment after hip fracture. J Bone Joint Surg Am 90:2142-2148

3. Vytrisalova M, Blazkova S, Palicka V, Vlcek J, Cejkova M, Hala T, Pavelka K, Koblihova H (2008) Self-reported compliance with osteoporosis medication-qualitative aspects and correlates. Maturitas 60:223-229

4. Blotman F, Cortet B, Hilliquin P, Avouac B, Allaert FA, Pouchain D, Gaudin AF, Cotte FE, El Hasnaoui A (2007) Characterisation of patients with postmenopausal osteoporosis in French primary healthcare. Drugs Aging 24:603-614

5. Cotte FE, Fardellone P, Mercier F, Gaudin AF, Roux C (2010) Adherence to monthly and weekly oral bisphosphonates in women with osteoporosis. Osteoporos Int 21:145-155
6. Cotte FE, Cortet B, Lafuma A, Avouac B, Hasnaoui AE, Fardellone P, Pouchain D, Roux C, Gaudin AF (2008) A model of the public health impact of improved treatment persistence in post-menopausal osteoporosis in France. Joint Bone Spine 75:201-208

7. Cotte FE, Mercier F, De PG (2008) Relationship between compliance and persistence with osteoporosis medications and fracture risk in primary health care in France: a retrospective case-control analysis. Clin Ther 30:2410-2422

8. Cramer JA, Lynch NO, Gaudin AF, Walker M, Cowell W (2006) The effect of dosing frequency on compliance and persistence with bisphosphonate therapy in postmenopausal women: a comparison of studies in the United States, the United Kingdom, and France. Clin Ther 28:1686-1694

9. Huas D, Debiais F, Blotman F, Cortet B, Mercier F, Rousseaux C, Berger V, Gaudin AF, Cotte FE (2010) Compliance and treatment satisfaction of post menopausal women treated for osteoporosis. Compliance with osteoporosis treatment. BMC Womens Health 10:26

10. Ringe JD, Moller G (2009) Differences in persistence, safety and efficacy of generic and original branded once weekly bisphosphonates in patients with postmenopausal osteoporosis: 1 -year results of a retrospective patient chart review analysis. Rheumatology Int 30:213-221

11. Ziller V, Wetzel K, Kyvernitakis I, Seker-Pektas B, Hadji P (2011) Adherence and persistence in patients with postmenopausal osteoporosis treated with raloxifene. Climacteric 14:228-235

12. Ziller V, Zimmermann SP, Kalder M, Ziller M, Seker-Pektas B, Hellmeyer L, Hadji P (2010) Adherence and persistence in patients with severe osteoporosis treated with teriparatide. Curr Med Res Opin 26:675-681

13. Adami S, Isaia G, Luisetto G, Minisola S, Sinigaglia L, Gentilella R, Agnusdei D, Iori N, Nuti R (2006) Fracture incidence and characterization in patients on osteoporosis treatment: the ICARO study. J Bone Miner Res 21:1565-1570

14. Adami S, Isaia G, Luisetto G, Minisola S, Sinigaglia L, Silvestri S, Agnusdei D, Gentilella R, Nuti R (2008) Osteoporosis treatment and fracture incidence: the ICARO longitudinal study. Osteoporos Int 19:1219-1223

15. Rossini M, Bianchi G, Di MO, Giannini S, Minisola S, Sinigaglia L, Adami S (2006) Determinants of adherence to osteoporosis treatment in clinical practice. Osteoporos Int 17:914-921

16. Penning-van Beest FJ, Erkens JA, Olson M, Herings RM (2008) Loss of treatment benefit due to low compliance with bisphosphonate therapy. Osteoporos Int 19: 511-517

17. Penning-van Beest FJ, Erkens JA, Olson M, Herings RM (2008) Determinants of non-compliance with bisphosphonates in women with postmenopausal osteoporosis. Curr Med Res Opin 24:13371344

18. Penning-van Beest FJ, Goettsch WG, Erkens JA, Herings RM (2006) Determinants of persistence with bisphosphonates: a study in women with postmenopausal osteoporosis. Clin Ther 28:236-242

19. van den Boogaard CH, Breekveldt-Postma NS, Borggreve SE, Goettsch WG, Herings RM (2006) Persistent bisphosphonate use and the risk of osteoporotic fractures in clinical practice: a database analysis study. Curr Med Res Opin 22:1757-1764

20. Guilera M, Fuentes M, Grifols M, Ferrer J, Badia X (2006) Does an educational leaflet improve self-reported adherence to therapy in osteoporosis? The OPTIMA study. Osteoporos Int 17:664-671

21. Arden NK, Earl S, Fisher DJ, Cooper C, Carruthers S, Goater M (2006) Persistence with teriparatide in patients with osteoporosis: the UK experience. Osteoporos Int 17:1626-1629 
22. Brankin E, Walker M, Lynch N, Aspray T, Lis Y, Cowell W (2006) The impact of dosing frequency on compliance and persistence with bisphosphonates among postmenopausal women in the UK: evidence from three databases. Curr Med Res Opin 22:1249-1256

23. Carr AJ, Thompson PW, Cooper C (2006) Factors associated with adherence and persistence to bisphosphonate therapy in osteoporosis: a cross-sectional survey. Osteoporos Int 17:1638-1644

24. de Lusignan S, van Vlymen J, Hague N, Dhoul N (2006) Using computers to identify non-compliant people at increased risk of osteoporotic fractures in general practice: a cross-sectional study. Osteoporos Int 17:1808-1814

25. Gallagher AM, Rietbrock S, Olson M, van Staa TP (2008) Fracture outcomes related to persistence and compliance with oral bisphosphonates. J Bone Miner Res 23:1569-1575

26. Abrahamsen B (2013) Are long-term bisphosphonate users a reality? Dose years for current bisphosphonate users assessed using the danish national prescription database. Osteoporos Int 24:369-372
27. Hansen C, Pedersen BD, Konradsen H, Abrahamsen B (2012) Anti-osteoporotic therapy in Denmark-predictors and demographics of poor refill compliance and poor persistence. Osteoporos Int [Epub ahead of print] 2012

28. Landfeldt E, Strom O, Robbins S, Borgstrom F (2012) Adherence to treatment of primary osteoporosis and its association to fractures - the Swedish Adherence Register Analysis (SARA). Osteoporos Int 23:433-443

29. Nielsen DS, Langdahl BL, Sorensen OH, Sorensen HA, Brixen KT (2010) Persistence to medical treatment of osteoporosis in women at three different clinical settings - a historical cohort study. Scand J Public Health 38:502-507

30. Roerholt C, Eiken P, Abrahamsen B (2009) Initiation of antiosteoporotic therapy in patients with recent fractures: a nationwide analysis of prescription rates and persistence. Osteoporos Int 20:299-307

31. Strom O, Landfeldt E (2012) The association between automatic generic substitution and treatment persistence with oral bisphosphonates. Osteoporos Int 23:2201-2209 


\section{Epidemiology of osteoporosis}

\section{Summary}

The objective of this chapter is to describe the epidemiology of osteoporosis and its consequences in the countries of the European Union in 2010. The information presented here forms the basis for the estimation of burden of osteoporosis presented in Chapter 4.

\section{The key messages of this chapter are:}

In 2010, it is estimated that 22 million women and 5.5 million men in the EU had osteoporosis using the diagnostic criterion of the $\mathrm{WHO}$.

Incidence rates of hip fractures were available for most, but not all, countries of the EU whereas information on countryspecific incidence rates of forearm, clinical vertebral fractures and other osteoporotic fractures was scarce.

The number of new fractures in 2010 in the EU was estimated at 3.5 million, comprising approximately 620,000 hip fractures, 520,000 vertebral fractures, 560,000 forearm fractures and 1,800,000 other fractures (1.e. pelvis, rib, humerus, tibia, fibula, clavicle, scapula, sternum, and other femoral fractures).

Two thirds of all incident fractures occurred in women.

Among people aged 50 years or more who were still alive in 2010, 3.3 million individuals had sustained a hip fracture (prevalence of prior hip fracture). The corresponding number of men and women with prior clinical vertebral fractures was estimated at 3.5 million men and women.

In 2010, the number of deaths causally related to fractures was estimated at 43,000. Approximately $50 \%$ of fracture related deaths in women were due to hip fractures, $28 \%$ to clinical vertebral and $22 \%$ to other fractures. Corresponding proportions for men were $47 \%, 39 \%$ and $14 \%$, respectively.

\subsection{Epidemiology of osteoporosis and fracture}

The primary objective of this chapter is to map the epidemiology of osteoporosis and its consequences in the 27 member countries of the European Union-Austria, Belgium, Bulgaria, Cyprus, Czech Republic, Denmark, Estonia, Finland, France, Germany, Greece, Hungary, Ireland, Italy, Latvia, Lithuania, Luxembourg, Malta, Netherlands, Poland, Portugal, Romania, Slovakia, Slovenia, Spain, Sweden, and the UK-collectively referred to as EU27. The information provided in this chapter forms the basis for estimating the burden of osteoporosis, presented in Chapter 4.

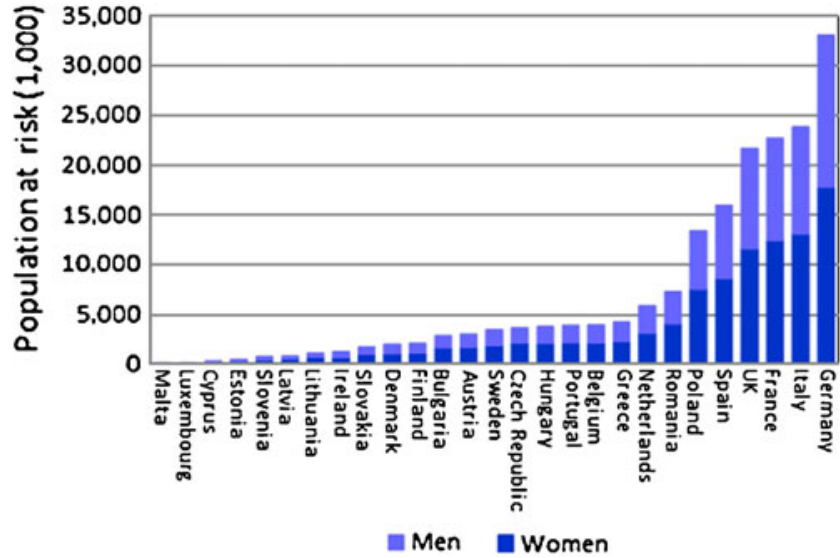

Fig. 21 Population at risk: men and women over the age of 50 in respective country in thousands, 2010 [1]

\subsection{Population at risk}

Osteoporosis is a disease most common in the elderly population. Very few fragility fractures occur before the age of 50 years, and the incidence of these fractures increases progressively with age after 50 years. For the purpose of this report, we consider the populations at risk to include men and women from the age of 50 years. The population at risk in the EU for 2010 is shown by country in Fig. 21. Collectively, there were 183 million persons aged 50 years and above in the EU. Germany had the most (33 million) and Malta the least $(152,000)$ inhabitants at risk in 2010 [1].

Of the population aged above 50 years in the EU27, $77 \%$ were below 75 years. Out of the total population above 50 years in the European Union, $54 \%$ were women and $46 \%$ were men. The total population in the EU27 stratified by five-year age intervals is shown in Fig. 22. Going forward, the large middle-aged population combined with a comparatively small young population is likely to result in a high absolute number of elderly individuals and an increasing proportion of elderly to middle-aged individuals.

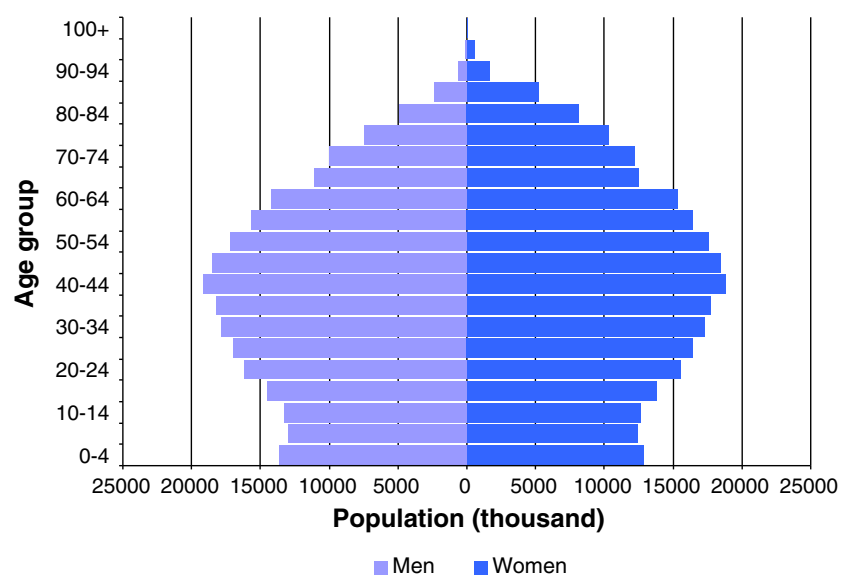

Fig. 22 Population in EU (in thousands) in 5-year age groups, 2010 [1] 


\subsection{Prevalence of osteoporosis}

Osteoporosis is diagnosed using dual-energy X-ray absorptiometry (DXA), which measures bone mineral density (BMD). BMD can be measured at various sites, but the diagnostic reference site is the femoral neck using the NHANES III reference data [2-4]. According to the criterion set by a WHO Study Group, osteoporosis is diagnosed when the BMD at the femoral neck is 2.5 standard deviations or more below the average BMD of the young white female population [2-4] (see Chapter 1).

Accurate estimates of the prevalence of osteoporosis require country specific data on the distribution of femoral neck BMD. As outlined in Chapter 1, large populationbased reference data are lacking in the EU27 countries. For the purposes of this report, it is assumed that the mean femoral neck BMD is similar across countries at the age of 50 years as is the rate of bone loss at the femoral neck with age. The same assumptions have been used elsewhere [5-7]. On this basis, the prevalence of osteoporosis can be calculated from the age- and sex-specific prevalence of osteoporosis in the NHANES III study as given for Sweden in Chapter 1. These prevalence estimates are then applied to the population demography in each EU country. Approximately 5,500,000 osteoporotic men and 22,100,000 osteoporotic women resided in the EU27 in 2010, i.e. there were four times as many women with osteoporosis as there were men. Of all countries in the EU27, Germany was estimated to have the highest number of individuals with osteoporosis with approximately 1 million osteoporotic men and 4 million osteoporotic women. Overall the prevalence of osteoporosis was $6.6 \%$ and $22.1 \%$ in men and women aged 50 years or more and $5.5 \%$ in the general population (Table $23)$. In men aged 50 years or more, the prevalence of osteoporosis varied from $5.7 \%$ in Slovakia to $6.9 \%$ in Greece, Italy and Sweden. The corresponding data for women were $19.3 \%$ for Bulgaria and $23.4 \%$ for Italy (Table 24 ).

The prevalence of osteoporosis increases progressively with age, though the absolute number of individuals with

Table 23 Estimated number of men and women with osteoporosis (defined as a T-score of $-2.5 \mathrm{SD}$ or less at the femoral neck), prevalence in men and in women over 50 years, and prevalence in the total population, 2010

\begin{tabular}{|c|c|c|c|c|c|c|}
\hline Country & $\begin{array}{c}\text { Men with } \\
\text { osteoporosis }\end{array}$ & $\begin{array}{l}\text { Women with } \\
\text { osteoporosis }\end{array}$ & $\begin{array}{c}\text { Men and } \\
\text { women with } \\
\text { osteoporosis }\end{array}$ & $\begin{array}{c}\text { Prevalance in } \\
\text { male } \\
\text { population } \\
\text { aged } 50 \text { or } \\
\text { more (\%) }\end{array}$ & $\begin{array}{l}\text { Prevalance } \\
\text { in female } \\
\text { population } \\
\text { aged } 50 \text { or } \\
\text { more }(\%)\end{array}$ & $\begin{array}{c}\text { Prevalance in } \\
\text { total } \\
\text { population } \\
(\%)\end{array}$ \\
\hline Austria & 89862 & 368685 & 458547 & 6.5 & 22.2 & 5.5 \\
\hline Belgium & 120695 & 476875 & 597570 & 6.6 & 22.4 & 5.6 \\
\hline Bulgaria & 81482 & 336425 & 417907 & 6.4 & 20.9 & 5.6 \\
\hline Cyprus & 9263 & 31032 & 40295 & 6.2 & 19.3 & 3.7 \\
\hline Czech Republic & 103114 & 425944 & 529058 & 6.0 & 20.4 & 5.0 \\
\hline Denmark & 61456 & 221912 & 283368 & 6.5 & 21.1 & 5.1 \\
\hline Estonia & 11642 & 65789 & 77431 & 6.2 & 22.2 & 5.8 \\
\hline Finland & 61054 & 243399 & 304453 & 6.4 & 21.5 & 5.7 \\
\hline France & 691112 & 2784198 & 3475310 & 6.7 & 22.5 & 5.5 \\
\hline Germany & 1006652 & 4017260 & 5023912 & 6.6 & 22.6 & 6.1 \\
\hline Greece & 135202 & 507505 & 642707 & 6.9 & 22.3 & 5.7 \\
\hline Hungary & 94949 & 452158 & 547107 & 6.2 & 21.1 & 5.5 \\
\hline Ireland & 37127 & 129309 & 166436 & 6.2 & 20.0 & 3.7 \\
\hline Italy & 749237 & 3042794 & 3792031 & 6.9 & 23.4 & 6.3 \\
\hline Latvia & 19210 & 111236 & 130446 & 6.1 & 22.3 & 5.8 \\
\hline Lithuania & 27136 & 148375 & 175511 & 6.1 & 21.7 & 5.3 \\
\hline Luxembourg & 4541 & 17422 & 21963 & 6.1 & 21.0 & 4.3 \\
\hline Malta & 4190 & 16074 & 20264 & 5.9 & 19.8 & 4.9 \\
\hline Netherlands & 175244 & 643258 & 818502 & 6.3 & 20.8 & 4.9 \\
\hline Poland & 338756 & 1509772 & 1848528 & 5.8 & 20.1 & 4.8 \\
\hline Portugal & 117738 & 475882 & 593620 & 6.7 & 22.0 & 5.6 \\
\hline Romania & 198065 & 835885 & 1033950 & 6.2 & 20.5 & 4.8 \\
\hline Slovakia & 42726 & 188911 & 231637 & 5.7 & 19.4 & 4.2 \\
\hline Slovenia & 20543 & 89489 & 110032 & 6.0 & 21.5 & 5.4 \\
\hline Spain & 496368 & 1952987 & 2449355 & 6.8 & 22.6 & 5.4 \\
\hline Sweden & 113722 & 409373 & 523095 & 6.9 & 22.4 & 5.6 \\
\hline UK & 679424 & 2527331 & 3206755 & 6.7 & 21.9 & 5.2 \\
\hline EU27 & 5490510 & 22029280 & 27519790 & 6.6 & 22.1 & 5.5 \\
\hline
\end{tabular}


Table 24 Estimated number of men and women with osteoporosis (defined as a T-score of -2.5 SD or less at the femoral neck) and prevalence in the population aged over 50 years in the EU27, 2010

\begin{tabular}{lrrrrrrrrc}
\hline $\begin{array}{l}\text { Age } \\
\text { group } \\
\text { (years) }\end{array}$ & \multicolumn{3}{c}{$\begin{array}{c}\text { Subjects with osteoporosis } \\
\text { (000) }\end{array}$} & \multicolumn{3}{c}{ Population at risk (000) } & \multicolumn{3}{c}{ Prevalence (\%) } \\
\cline { 2 - 11 } & Women & \multicolumn{1}{c}{ Men } & Total & Women & Men & Total & Women & Men & Total \\
\hline $50-54$ & 1106 & 429 & 1535 & 17556 & 17152 & 34708 & 6.3 & 2.5 & 4.4 \\
$55-59$ & 1578 & 547 & 2125 & 16434 & 15637 & 32071 & 9.6 & 3.5 & 6.6 \\
$60-64$ & 2188 & 826 & 3014 & 15302 & 14242 & 29544 & 14.3 & 5.8 & 10.2 \\
$65-69$ & 2523 & 818 & 3341 & 12489 & 11054 & 23543 & 20.2 & 7.4 & 14.2 \\
$70-74$ & 3409 & 777 & 4186 & 12217 & 9967 & 22184 & 27.9 & 7.8 & 18.9 \\
$75-79$ & 3876 & 768 & 4644 & 10335 & 7459 & 17794 & 37.5 & 10.3 & 26.1 \\
$80+$ & 7350 & 1325 & 8675 & 15573 & 7980 & 23553 & 47.2 & 16.6 & 36.8 \\
$50+$ & 22029 & 5491 & 27520 & 99906 & 83491 & 183397 & 22.1 & 6.6 & 15.0 \\
\hline
\end{tabular}

osteoporosis increases less markedly (Table 24). When stratifying the population between 50 and 80 years in fiveyear age groups, the highest number of women with osteoporosis (approximately 3,900,000) was observed in the 75-79 year age group. However, for men the highest estimated number of individuals with osteoporosis was found in 60-64 year age group (approximately 800,000). The number of men and women with osteoporosis and prevalence of osteoporosis stratified by five-year age groups are given in Table 24.

\subsection{Incidence of fractures}

The clinical significance of osteoporosis lies in the fractures that occur as a consequence of increased bone fragility. Information on the incidence of fragility fractures varies between the countries of the EU27. In general, reports on hip fracture incidence are more commonly available than fractures at other sites. This arises because a very high proportion of hip fractures are treated in hospitals on an inpatient basis, so that the data are captured through hospital statistics. Other fractures are to a significant extent treated in an outpatient setting and are thus more difficult to monitor in a community. The fractures of interest in this section are fractures of the hip, spine and forearm as well as fractures at other sites characteristic of osteoporosis, termed 'other fractures'.

Incidences of fractures were obtained from a literature review in which Medline was searched for articles using the keywords "Country" and "Fracture" and "Incidence". Titles and abstracts identified by the search were screened and potentially relevant articles retrieved in full text. Furthermore, all abstracts presented at the IOF and ECCEO conferences since 2000 were screened for additional data. For the EU5, the incidence used in Strom et al. was used, except for Italian data on hip fracture incidence [8], which were updated consistent with a revision of the FRAX model.

For hip fractures, where available, data used to populate FRAX models were chosen since these provide most recent data and have been evaluated as high quality [9]. For the remaining countries, national data were preferred over regional estimates. For the countries where hip fracture incidence was not available (or only available for the female population), incidence was imputed from the nearest country with hip fracture incidence available. Where the incidence of fractures other than the hip was not available, the incidence was imputed from the hip fracture incidence in the relevant country, using the relationship between hip fracture incidence and incidence of fracture in other sites in Sweden [10]. This assumes that the ratios between age and sex specific incidence of hip fracture and fractures of other sites found in Sweden are similar in other countries. This assumption, which is also used in some FRAX models, has been shown to hold true for the countries where this has been tested [11, 12]. Examples are given in Fig. 23. Age-specific incidence was linearly interpolated between the age intervals, and the value shown for each interval was set for the age in the middle of the interval (e.g., the incidence rate for women 70-74 was used for a 72-year old woman).

\subsection{Incidence of hip fracture}

In order to compare fracture rates we standardised fracture rates to the EU population for 2010. The comparison assumes

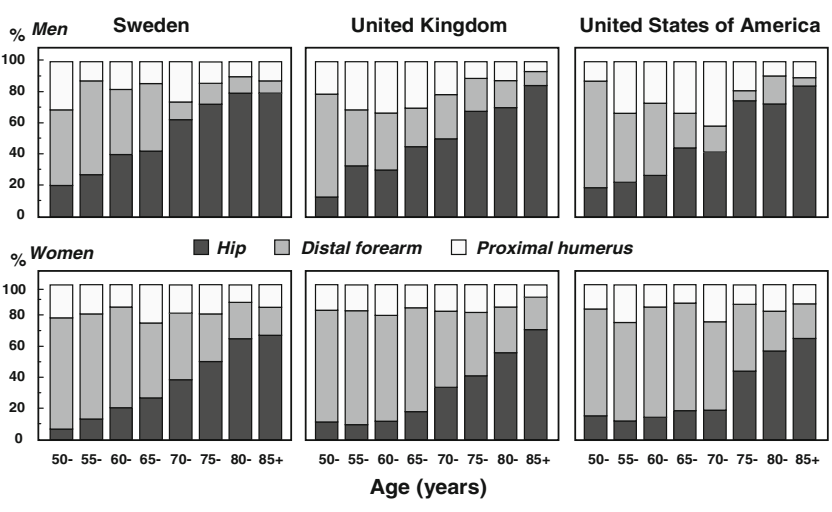

Fig. 23 Pattern of common fractures expressed as a proportion (\%) of the total in the US, Sweden and the UK [12] 
that the age- and sex-specific rates have remained unchanged between the year of ascertainment and 2010. EU standardized (2010) hip fracture rates and associated information on the source of the data for all member countries are shown in Table 25 . Where available, country specific age-stratified incidence rates are provided in the country specific reports published concurrently with this report.

There was a marked heterogeneity in hip fracture risk between countries. In women, the lowest annual incidences were found in Romania and Poland with the highest rates observed in Denmark and Sweden. There was an approximately 3-fold range in hip fracture incidence. The heterogeneity in hip fracture risk is less than that observed on a worldwide basis (a ten-fold range) but nevertheless substantial. The incidence of hip fracture in men was approximately half that noted in women (visualised in Fig. 24). Thus where higher rates were observed in women, higher rates were found in men and vice versa. There was a significant correlation between the rates in men and women $(r=0.86 ; p<0.001)$.

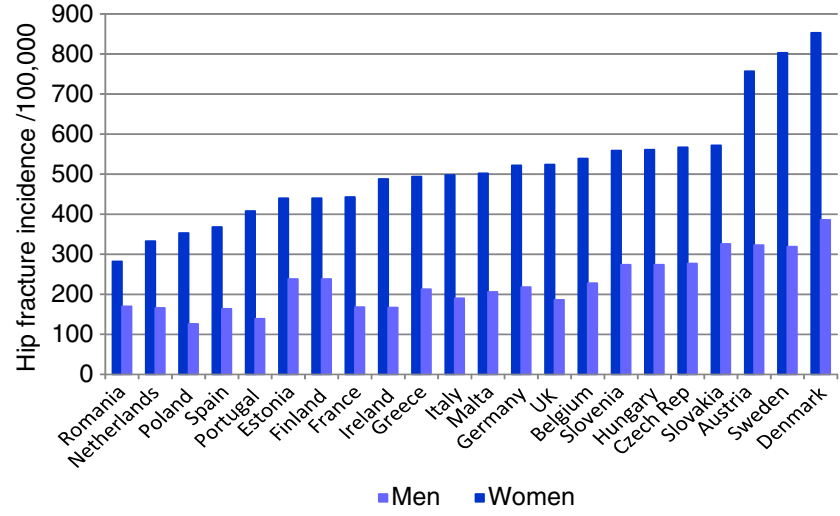

Fig. 24 Hip fracture incidence/100,000 in men and women above 50 years standardized to the EU27 population

The differences in fracture rates between men and women are largely explained by differences in femoral

Table 25 Information available on hip fracture incidence and EU standardised (2010) hip fracture rates (per 100,000 per year)

\begin{tabular}{|c|c|c|c|c|c|c|c|c|c|c|}
\hline \multirow[b]{2}{*}{ Country } & \multicolumn{4}{|c|}{ Source } & \multicolumn{3}{|c|}{$\begin{array}{l}\text { Incidence in the total } \\
\text { population }\end{array}$} & \multicolumn{3}{|c|}{$\begin{array}{c}\text { Incidence in population } \\
\text { above } 50 \text { years }\end{array}$} \\
\hline & Year & Quality $^{\mathrm{a}}$ & Sample $^{b}$ & Ref & Women & Men & $\begin{array}{c}\text { Men } \\
\text { and } \\
\text { women }\end{array}$ & Women & Men & $\begin{array}{c}\text { Men } \\
\text { and } \\
\text { women }\end{array}$ \\
\hline Austria & $2001-5$ & G & $\mathrm{N}$ & [13] & 295 & 110 & 205 & 757 & 323 & 559 \\
\hline $\begin{array}{l}\text { Belgium } \\
\text { Bulgaria }\end{array}$ & $2005-7$ & G & $\mathrm{N}$ & $\begin{array}{c}{[14]} \\
c\end{array}$ & 210 & 78 & 146 & 539 & 228 & 397 \\
\hline Cyprus & & & & d & & & & & & \\
\hline Czech Rep & $2008-9$ & G & $\mathrm{N}$ & [15] & 221 & 95 & 159 & 567 & 277 & 435 \\
\hline Denmark & 2004 & G & $N$ & $\mathrm{i}$ & 333 & 132 & 235 & 853 & 386 & 640 \\
\hline Estonia & 1991-4 & $P$ & $\mathrm{R}$ & [16] & 172 & 81 & 128 & 440 & 238 & 348 \\
\hline Finland & $2000-5$ & G & $\mathrm{N}$ & $j$ & 172 & 81 & 128 & 440 & 238 & 348 \\
\hline France & 2004 & G & $N$ & [17] & 173 & 57 & 116 & 443 & 168 & 318 \\
\hline Germany & 2003-4 & G & $\mathrm{N}$ & [18] & 204 & 74 & 141 & 522 & 218 & 384 \\
\hline Greece & 1986-92 & $P / F / G$ & $\mathrm{RN}$ & [19] & 193 & 73 & 134 & 494 & 213 & 366 \\
\hline Hungary & 1999-03 & G & $N$ & [20] & 219 & 94 & 158 & 561 & 274 & 430 \\
\hline Ireland & $2008-10$ & G & $\mathrm{N}$ & [21] & 191 & 57 & 125 & 488 & 167 & 342 \\
\hline $\begin{array}{l}\text { Italy } \\
\text { Latvia }\end{array}$ & 2007 & G & $\mathrm{N}$ & $\begin{array}{c}{[8]} \\
\mathrm{e}\end{array}$ & 195 & 65 & 131 & 498 & 190 & 358 \\
\hline $\begin{array}{l}\text { Lithuania } \\
\text { Luxembourg }\end{array}$ & 2010 & $\mathrm{~F}$ & $\mathrm{~N}$ & $\begin{array}{c}{[22]} \\
f\end{array}$ & & & & & & \\
\hline Malta & 2003-7 & G & $N$ & k & 196 & 70 & 135 & 502 & 206 & 368 \\
\hline Netherlands & 2005 & G & $\mathrm{N}$ & [23] & 144 & 56 & 101 & 368 & 164 & 275 \\
\hline Poland & 2008 & $\mathrm{~F}$ & $\mathrm{R}$ & 1 & 130 & 57 & 94 & 333 & 166 & 257 \\
\hline Portugal & $2000-2$ & G & $N$ & [24] & 159 & 47 & 105 & 408 & 139 & 286 \\
\hline Romania & $2005-9$ & G & $\mathrm{N}$ & [25] & 110 & 58 & 85 & 282 & 170 & 231 \\
\hline Slovakia & 2007 & G & $N$ & [26] & 223 & 111 & 168 & 572 & 326 & 460 \\
\hline Slovenia & 2003 & $\mathrm{~F}$ & $N$ & {$[27]^{g}$} & 218 & 93 & 157 & 559 & 274 & 429 \\
\hline Spain & 1984-91 & $F / G$ & $\mathrm{R}$ & {$[28-30]^{h}$} & 138 & 43 & 91 & 353 & 126 & 250 \\
\hline Sweden & 1991 & G & $\mathrm{R}$ & [10] & 314 & 109 & 213 & 803 & 319 & 582 \\
\hline UK & 1992-3 & G & $\mathrm{R}$ & [31] & 205 & 63 & 136 & 524 & 186 & 370 \\
\hline
\end{tabular}

${ }^{\mathrm{a}}$ Quality: G good; F fair; P poor [9], ${ }^{\mathrm{b}}$ Catchment: N national; R regional, ${ }^{\mathrm{c}}$ Data not available and incidence from Poland used as a surrogate.,

${ }^{\mathrm{d}}$ Data not available and incidence from Greece used. ${ }^{\mathrm{e}}$ Data not available and incidence from Finland used. ${ }^{\mathrm{f}}$ Data not available and incidence from Belgium used. ${ }^{\mathrm{g}}$ Data only available for female population, ${ }^{\mathrm{h}}$ Mean value of five regions described in three studies, i Abrahamsen, B., personal communication, 2011; j Kroger, H and Sund R., personal communication, 2011; k Schrembi, A., personal communication, 2011; 1 Czerwinski, E. and Lorenc, R., personal communication, 2011. 
neck BMD. Indeed the incidence of hip fracture in men at any given age is similar to that of women at the same age if both have the same BMD $[32,33]$. The reason for the variation in hip fracture rates between countries is not known. Many risk factors for osteoporosis, and in particular for hip fracture have been identified which include a low body mass index, low $\mathrm{BMD}$, low calcium intake, reduced sunlight exposure, early menopause, smoking, high alcohol consumption, low physical activity levels and migration status. These may have important effects within communities but do not explain differences in risk between communities [29]. The factor which is most closely associated with the variability is socio-economic prosperity, in that higher hip fracture rates are observed in those countries with the higher GDP [34]. This in turn, may be related to low levels of physical activity or an increased probability of falling on hard surfaces. This is plausible, but only a hypothesis. Paradoxically, socioeconomic prosperity may protect against hip fractures within countries [35]. The contrast between ecological and population risk factors is not uncommon and in the context of hip fracture, for example, is also noted with calcium nutrition where countries with higher calcium intakes have the greater hip fracture risk $[36,37]$.

\subsection{Incidence of vertebral fractures}

Vertebral fractures may be defined in several ways. Morphometric vertebral fractures are identified as radiographic deformities which may be either symptomatic or clinically silent. Thus, not all morphometric vertebral fractures come to clinical attention and the proportion that does, varies between studies and between countries [38-40]. Several studies indicate that the ratio of clinical to morphometric fractures is approximately 1 in 5 in women and 2 in 5 in men [39-41]. Morphometrically diagnosed fractures are associated with morbidity and increased risk of future fractures. It should however be noted that they also include the fractures that come to clinical attention, which makes the burden attributable to purely sub-clinical fractures difficult to assess. In the context of this report, the incidence of clinically relevant vertebral fractures was estimated, since individuals affected by these are most likely to be identified for treatment. Clinical vertebral fractures are also more readily linked to cost and Health Related Quality of Life (HRQoL) consequences. Undoubtedly however, this leads to an underestimation of the

Table 26 Estimated incidence (per 100,000) in the male and female population over 50 years of clinical vertebral fractures adjusted to the age-distribution in the EU27 in 2010

\begin{tabular}{lccc}
\hline Country & Men & Women & Men and women \\
\hline Austria & 311 & 453 & 387 \\
Belgium & 206 & 323 & 268 \\
Bulgaria & 214 & 213 & 213 \\
Cyprus & 222 & 392 & 313 \\
Czech Republic & 271 & 340 & 308 \\
Denmark & 374 & 555 & 471 \\
Estonia & 229 & 271 & 251 \\
Finland & 229 & 271 & 251 \\
France & 153 & 256 & 208 \\
Germany & 234 & 371 & 307 \\
Greece & 222 & 392 & 313 \\
Hungary & 259 & 329 & 296 \\
Ireland & 156 & 310 & 238 \\
Italy & 169 & 316 & 248 \\
Latvia & 229 & 271 & 251 \\
Lithuania & 185 & 206 & 196 \\
Luxembourg & 206 & 323 & 268 \\
Malta & 218 & 400 & 316 \\
Netherlands & 147 & 241 & 197 \\
Poland & 185 & 206 & 196 \\
Portugal & 121 & 240 & 185 \\
Romania & 214 & 213 & 213 \\
Slovakia & 373 & 388 & 381 \\
Slovenia & 259 & 329 & 296 \\
Spain & 114 & 199 & 159 \\
Sweden & 318 & 503 & 417 \\
UK & 217 & 322 & 273 \\
\hline & & & \\
\hline & 29 & 13 & 13 \\
\hline
\end{tabular}

Note: All incidences (except for Sweden), are estimated using Swedish ratios between hip and vertebral fractures and the country-specific hip fracture incidence. (Swedish fracture incidences are from Malmö, Sweden [10].) 
burden of vertebral fractures. Data on the incidence of clinical vertebral fractures, capturing fractures treated in both inpatient and outpatient settings, are lacking in most of the countries in the EU, the exceptions being Sweden and UK. In the UK, the incidence of clinically identified fractures has been studied within the General Practice Research Database (GPRD) [40]. The incidence is, however, very low and it is likely that the majority of fractures were not coded [42]. Indeed, reported rates of vertebral fracture vary by more than 10 -fold in general practice in the UK [43]. The ratio of clinical fractures identified in the GPRD to those identified by morphometry in the UK is unrealistically low compared with other countries [44], supporting the view that the GPRD database significantly under-reported clinical vertebral fracture.

For this reason, vertebral fracture rates were imputed for all countries except Sweden, where high quality data reporting the incidences of hip and vertebral fractures that come to clinical attention were available from Malmö [10]. It was assumed for each age and sex that the ratio of the incidence of vertebral fracture to hip fractures in Malmö, Sweden would be comparable to the ratio of vertebral fracture incidence to hip fracture incidence in each EU country. The estimated incidence of clinical vertebral fractures standardised to the age-distribution in the population above the age of 50 years in the EU27 is shown in Table 26. The country-specific variations in clinical vertebral fracture incidence correspond to that seen for hip fracture incidence due to the method of imputation. In women, the standardised incidence ranged from 206 in Poland and Lithuania to 555 per 100,000 in Denmark whereas in men it ranged from 91 to 374 in UK and Denmark. The incidence of clinical vertebral fractures in both men and women above the age of 50 years ranged from 172 in Spain to 471 in Denmark. Further details on the incidence of clinical vertebral fracture for ages 50-80 years are presented in the country specific reports published concurrently with this report.

\subsection{Incidence of forearm and other osteoporotic fractures}

The forearm (distal forearm, distal radius, wrist) is a common site of osteoporotic fractures. The incidence of forearm fractures increases with age, although not as steeply as that of hip fracture. The majority of forearm fractures are treated in hospital out-patient departments. There are reports from EU27 countries on the incidence of forearm fractures leading to hospitalisation, e.g. from France [45]. There are also studies published from Slovenia [27] and Italy [46] which present the incidence of forearm fractures treated in inpatient and/or outpatient care. However, the Slovenian study only reports fractures occurring in women, and the Italian study lacks age stratification of data within the elderly population.
Forearm fracture incidence presented in a form suitable for this study was only available for Hungary [20], the UK [31] and Sweden [10]. For other countries, forearm fracture incidence was imputed from the hip fracture incidence in the relevant country, using the relationship between hip fracture incidence and forearm fracture incidence in Sweden.

In addition to hip, spine and forearm fractures, fractures at several other sites are considered to be causally related to osteoporosis in that their respective incidence increases with age and they are associated with low BMD (see Chapter 1). Fractures of the femur, pelvis, humerus, rib, clavicle, scapula and sternum are in this report grouped as "other fractures". Their incidence is only available in complete form for Sweden, and therefore incidence is imputed for other countries using the same method as for vertebral and forearm fractures described above.

\subsection{Number of incident fractures}

The number of fragility fractures occurring in the EU27 in 2010 was estimated using age- and sex-specific incidence rates and age- and sex specific population data. The majority of the fractures sustained (Table 27) were "other fractures" (approximately $1,800,000)$ followed by hip $(600,000)$, forearm $(600,000)$ and clinical vertebral fractures $(500,000)$. Individuals 80 years of age or more sustained the majority of hip fractures whilst most of the forearm fractures were found in younger age groups. The highest number of vertebral fractures occurred in individuals between 70 and 75 years of age.

Whilst incidence rates of fractures increased with age, the increase in the absolute number of fractures levels off in the older age groups, reflecting a decrease in the population at risk with age. When stratifying the population between the ages of 50 and 95 years in 5 year age groups, the highest estimated numbers of women with hip (approximately 110, 000), and "other" fractures $(210,000)$ were observed in the 85-90 year age group whereas the highest numbers of vertebral $(55,000)$ and forearm fractures $(70,000)$ were observed in the $80-84$ and 70-74 year age groups, respectively. For men the highest number of hip (approximately 36,000), vertebral $(31,000)$, forearm $(18,000)$ and other fractures $(113,000)$ were found in the $80-84,70-74,60-64$ and $80-84$ year age groups respectively. Overall, the highest number of fractures was found in men and women aged 80-84 years.

The number of incident fractures per site and country is shown in Table 28. Germany had the highest number of fractures for all fracture types in both men and womenapproximately 725,000 incident fractures in totalpredominately reflecting a large population size and comparatively high fracture incidence. Malta and Luxembourg had the lowest number of fractures for all types - (approximately 3,000 incident fractures in total in each country), reflecting 
Table 27 Estimated number of incident fractures stratified by age and fracture type in the EU27, 2010

\begin{tabular}{|c|c|c|c|c|c|c|}
\hline Age group (years) & Hip & Vertebral & Forearm & Other & Total & $\begin{array}{c}\text { Population } \\
\text { at risk }\end{array}$ \\
\hline & \multicolumn{6}{|c|}{ Women } \\
\hline $50-54$ & 5032 & 13290 & 36413 & 41566 & 96301 & 17556000 \\
\hline $55-59$ & 8898 & 21978 & 62014 & 69231 & 162120 & 16434000 \\
\hline $60-64$ & 14135 & 22222 & 51092 & 51983 & 139432 & 15302000 \\
\hline $65-69$ & 22324 & 31422 & 55684 & 85452 & 194881 & 12489000 \\
\hline $70-74$ & 41064 & 51355 & 69828 & 115263 & 277510 & 12217000 \\
\hline $75-79$ & 67253 & 53766 & 61136 & 150026 & 332180 & 10335000 \\
\hline $80-84$ & 103117 & 55247 & 61248 & 188015 & 407627 & 8170000 \\
\hline $85-89$ & 110164 & 48304 & 44851 & 210095 & 413414 & 5184000 \\
\hline $90-94$ & 51930 & 21058 & 15967 & 101304 & 190259 & 1632000 \\
\hline $95+$ & 22891 & 8755 & 6039 & 46370 & 84056 & 587000 \\
\hline \multirow[t]{2}{*}{ Total } & 446806 & 327398 & 464272 & 1059304 & 2297780 & 99906000 \\
\hline & \multicolumn{6}{|c|}{ Men } \\
\hline $50-54$ & 6969 & 15380 & 10167 & 50406 & 82922 & 17152000 \\
\hline $55-59$ & 9647 & 16304 & 17689 & 104264 & 147904 & 15637000 \\
\hline $60-64$ & 10599 & 26631 & 18414 & 88906 & 144551 & 14242000 \\
\hline $65-69$ & 13795 & 18965 & 16427 & 87014 & 136200 & 11054000 \\
\hline $70-74$ & 20803 & 30971 & 9351 & 95400 & 156525 & 9967000 \\
\hline $75-79$ & 27929 & 26227 & 8296 & 72704 & 135156 & 7459000 \\
\hline $80-84$ & 36332 & 23484 & 7146 & 113011 & 179974 & 4886000 \\
\hline $85-89$ & 28988 & 20298 & 5904 & 88146 & 143336 & 2366000 \\
\hline $90-94$ & 10299 & 7969 & 2199 & 31134 & 51602 & 585000 \\
\hline $95+$ & 3149 & 2640 & 715 & 9604 & 16108 & 143000 \\
\hline \multirow[t]{2}{*}{ Total } & 168509 & 188868 & 96309 & 740591 & 1194277 & 83491000 \\
\hline & \multicolumn{6}{|c|}{ Men and women } \\
\hline $50-54$ & 12001 & 28670 & 46580 & 91972 & 179223 & 34708000 \\
\hline $55-59$ & 18545 & 38281 & 79703 & 173495 & 310024 & 32071000 \\
\hline $60-64$ & 24734 & 48854 & 69507 & 140889 & 283982 & 29544000 \\
\hline $65-69$ & 36118 & 50387 & 72111 & 172465 & 331081 & 23543000 \\
\hline $70-74$ & 61867 & 82326 & 79179 & 210663 & 434035 & 22184000 \\
\hline $75-79$ & 95181 & 79993 & 69432 & 222730 & 467336 & 17794000 \\
\hline $80-84$ & 139449 & 78731 & 68394 & 301027 & 587601 & 13056000 \\
\hline $85-89$ & 139151 & 68602 & 50755 & 298242 & 556750 & 7550000 \\
\hline $90-94$ & 62229 & 29027 & 18166 & 132438 & 241860 & 2217000 \\
\hline $95+$ & 26040 & 11395 & 6754 & 55975 & 100164 & 730000 \\
\hline Total & 615316 & 516266 & 560581 & 1799895 & 3492058 & 183397000 \\
\hline
\end{tabular}

small population sizes. The sum of all incident fractures was estimated at approximately $3,490,000$ in the EU in 2010. This equates to 9,556 new fractures per day (390 per hour).

Almost twice as many fractures occurred in women compared to men. Hip, vertebral, forearm and "other fractures" accounted for $18 \%, 15 \%, 16 \%$ and $51 \%$ of all fractures respectively (Fig. 25).

\subsection{Prior fractures}

In assessing the burden of osteoporosis, it is important to consider the number of fractures that occurred in the population before the index year, in this case 2010. Fracture at some sites are associated with morbidity that extends beyond 1 year, and estimating the number of prior fractures permits estimation of long-term suffering as a consequence of fracture. This is particularly true for hip fracture but also
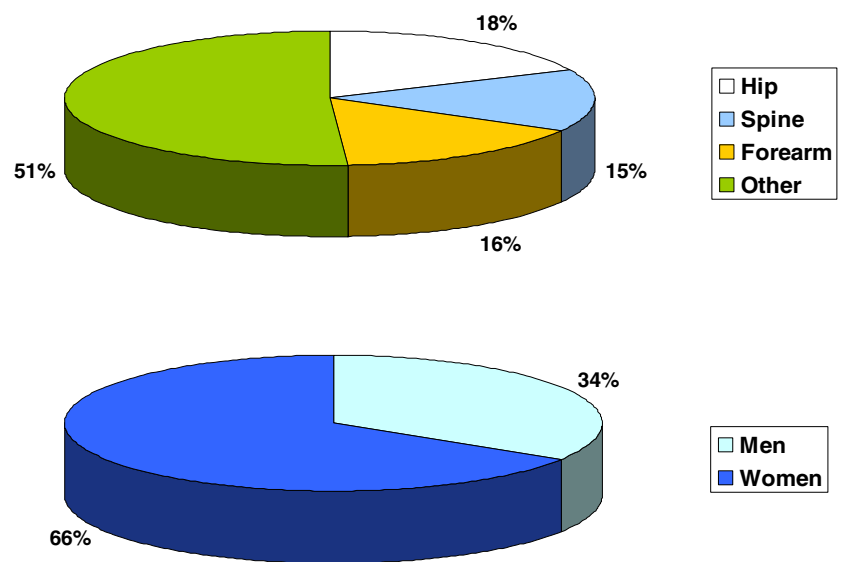

$\square$ Men $\square$ Women

Fig. 25 Proportion of incident fractures in 2010 by site (top) and sex (bottom) 
Table 28 Estimated number of incident fractures by type and country, 2010

\begin{tabular}{|c|c|c|c|c|c|c|c|c|}
\hline \multirow[b]{2}{*}{ Country } & \multicolumn{2}{|c|}{ Hip fractures } & \multicolumn{2}{|c|}{ Vertebral fractures } & \multicolumn{2}{|c|}{ Forearm fractures } & \multicolumn{2}{|c|}{ Other fractures } \\
\hline & Women & Men & Women & Men & Women & Men & Women & Men \\
\hline Austria & 11835 & 4254 & 8280 & 4822 & 11049 & 2373 & 26029 & 17894 \\
\hline Belgium & 10761 & 4199 & 7566 & 4480 & 10263 & 2095 & 23809 & 16720 \\
\hline Bulgaria & 3857 & 2061 & 3558 & 2805 & 4914 & 1579 & 9147 & 10277 \\
\hline Cyprus & 494 & 282 & 446 & 326 & 786 & 165 & 1408 & 1222 \\
\hline Czech Republic & 8330 & 3761 & 6406 & 4623 & 9364 & 2550 & 19642 & 17519 \\
\hline Denmark & 8488 & 3553 & 6221 & 4018 & 8299 & 2004 & 18886 & 14889 \\
\hline Estonia & 1229 & 384 & 942 & 451 & 1186 & 222 & 2628 & 1646 \\
\hline Finland & 4484 & 2064 & 3269 & 2385 & 4334 & 1202 & 9818 & 8849 \\
\hline France & 54935 & 18695 & 36069 & 19556 & 47131 & 8969 & 117952 & 73467 \\
\hline Germany & 95672 & 34178 & 74336 & 39291 & 99112 & 19342 & 215271 & 147572 \\
\hline Greece & 9942 & 4741 & 8248 & 5061 & 12309 & 2268 & 24483 & 18466 \\
\hline Hungary & 9704 & 3698 & 7144 & 4224 & 29832 & 9356 & 22084 & 16415 \\
\hline Ireland & 2294 & 892 & 1677 & 996 & 2519 & 482 & 5530 & 3695 \\
\hline Italy & 67595 & 22944 & 47921 & 23540 & 61523 & 10156 & 145243 & 86478 \\
\hline Latvia & 2022 & 613 & 1558 & 728 & 1985 & 367 & 4368 & 2664 \\
\hline Lithuania & 1986 & 646 & 1584 & 835 & 2087 & 456 & 4385 & 3095 \\
\hline Luxembourg & 340 & 127 & 254 & 151 & 378 & 79 & 808 & 563 \\
\hline Malta & 331 & 117 & 283 & 144 & 403 & 70 & 790 & 503 \\
\hline Netherlands & 9367 & 4028 & 7169 & 4455 & 10318 & 2152 & 21944 & 16514 \\
\hline Poland & 19665 & 7981 & 15835 & 10609 & 22211 & 6018 & 45124 & 40221 \\
\hline Portugal & 7358 & 2502 & 5232 & 2573 & 7053 & 1120 & 16501 & 9482 \\
\hline Romania & 9332 & 4975 & 8768 & 6901 & 12375 & 3880 & 22638 & 25413 \\
\hline Slovakia & 3899 & 1927 & 3395 & 2683 & 5147 & 1606 & 9655 & 10322 \\
\hline Slovenia & 2032 & 748 & 1451 & 890 & 1977 & 483 & 4502 & 3427 \\
\hline Spain & 30030 & 10442 & 19155 & 10534 & 25155 & 4563 & 65079 & 39193 \\
\hline Sweden & 14688 & 5592 & 10509 & 5983 & 13556 & 2837 & 31650 & 22231 \\
\hline UK & 56136 & 23107 & 40121 & 25803 & 59007 & 9913 & 189933 & 131853 \\
\hline EU27 & 446806 & 168509 & 327398 & 188868 & 464272 & 96309 & 1059304 & 740591 \\
\hline
\end{tabular}

applies to other fracture sites [39]. In this study, the long term effects of hip and vertebral fractures are taken into account, thus the prevalence of prior fractures at these sites has been estimated.

An additional clinical significance of a prior fracture is that it is a significant risk factor for a further fracture. A prior fracture leads to an approximately two-fold increase in fracture risk [47] and this risk factor is largely independent of BMD [48-50]. A prior history of a fragility fracture is one of the major risk factors used in the assessment of fracture risk and is incorporated into the FRAX algorithms. As might be expected, the prevalence of a prior fracture increases with age [51] but the absolute prevalence depends critically on the construct of the question used. For example, the frequency of a positive history will differ if fractures are sought from the age of 40 years or 50 years.

For the purposes of this report, a prior fracture was defined as a fracture in an individual who was alive during the index year (i.e. 2010), which had occurred after the age of 50 years and before 2010. The unit was the individual so that multiple fractures at the same site in one individual were only counted as one prior fracture of that site. The number of prior fractures is not as easily accessible as the number of incident fractures, and must instead be simulated. A micro-simulation model, programmed in TreeAge, was used to simulate the prevalence of prior hip and vertebral fractures from incidence data. The micro-simulation model was populated with the hip and clinical vertebral fracture incidence data described above, normal population mortality $[52,53]$, and Swedish relative risks of post-fracture mortality [54]. Age-specific prevalences of prior hip and prior clinical vertebral fracture were multiplied by the agespecific population in each country [1] to derive the number of prior fractures present in 2010.

The estimated number of individuals with a prior fracture varied considerably by age and the majority were found in the elderly (Table 29). The number of individuals with a prior hip fracture peaked in age group 80-84 and 85-89 for men and women, respectively. Vertebral fractures were more common in younger age groups (70-74 for men and 80-84 for women), due to a less steep incidence increase by age combined with increased mortality after fracture. The 
Table 29 Number of individuals in the EU27 2010 with a prior hip or clinical vertebral fracture occurring before 2010 stratified by age group

\begin{tabular}{|c|c|c|c|c|c|}
\hline \multirow[b]{2}{*}{ Age group (years) } & \multicolumn{2}{|c|}{ Prior hip fractures } & \multicolumn{2}{|c|}{ Prior vertebral fractures } & \multirow{2}{*}{$\begin{array}{c}\text { Total number } \\
\text { of prior } \\
\text { fractures }\end{array}$} \\
\hline & Individuals & $\begin{array}{c}\text { Proportion of } \\
\text { population (\%) }\end{array}$ & Individuals & $\begin{array}{c}\text { Proportion of } \\
\text { population (\%) }\end{array}$ & \\
\hline \multicolumn{6}{|c|}{ Women } \\
\hline 50-54 & 8120 & 0.0 & 21509 & 0.1 & 29629 \\
\hline $55-59$ & 34316 & 0.2 & 94205 & 0.6 & 128522 \\
\hline $60-64$ & 74774 & 0.5 & 164728 & 1.1 & 239501 \\
\hline $65-69$ & 125696 & 1.0 & 216637 & 1.7 & 342334 \\
\hline $70-74$ & 228669 & 1.9 & 345668 & 2.8 & 574337 \\
\hline $75-79$ & 349991 & 3.4 & 431958 & 4.2 & 781949 \\
\hline $80-84$ & 514700 & 6.3 & 479298 & 5.9 & 993998 \\
\hline $85-89$ & 590271 & 11.4 & 430309 & 8.3 & 1020579 \\
\hline $90-94$ & 290196 & 17.8 & 190145 & 11.7 & 480341 \\
\hline $95+$ & 142933 & 24.3 & 88037 & 15.0 & 230970 \\
\hline Total & 2359667 & 2.4 & 2462494 & 2.5 & 4822161 \\
\hline \multicolumn{6}{|c|}{ Men } \\
\hline $50-54$ & 11738 & 0.1 & 27546 & 0.2 & 39284 \\
\hline $55-59$ & 44259 & 0.3 & 76804 & 0.5 & 121063 \\
\hline $60-64$ & 72392 & 0.5 & 125371 & 0.9 & 197763 \\
\hline $65-69$ & 88958 & 0.8 & 141870 & 1.3 & 230828 \\
\hline $70-74$ & 125067 & 1.3 & 173329 & 1.7 & 298396 \\
\hline $75-79$ & 148122 & 2.0 & 172010 & 2.3 & 320132 \\
\hline $80-84$ & 168768 & 3.5 & 146390 & 3.0 & 315158 \\
\hline $85-89$ & 153058 & 6.5 & 111694 & 4.7 & 264752 \\
\hline $90-94$ & 61962 & 10.6 & 47706 & 8.2 & 109668 \\
\hline $95+$ & 20949 & 14.6 & 17886 & 12.5 & 38835 \\
\hline Total & 895272 & 1.1 & 1040607 & 1.2 & 1935879 \\
\hline \multicolumn{6}{|c|}{ Women and Men } \\
\hline $50-54$ & 19857 & 0.1 & 49055 & 0.1 & 68913 \\
\hline $55-59$ & 78576 & 0.3 & 171009 & 0.5 & 249585 \\
\hline $60-64$ & 147165 & 0.5 & 290099 & 1.0 & 437265 \\
\hline $65-69$ & 214655 & 0.9 & 358507 & 1.5 & 573162 \\
\hline $70-74$ & 353736 & 1.6 & 518997 & 2.3 & 872733 \\
\hline $75-79$ & 498113 & 2.8 & 603968 & 3.4 & 1102081 \\
\hline $80-84$ & 683468 & 5.2 & 625688 & 4.8 & 1309156 \\
\hline $85-89$ & 743329 & 9.9 & 542003 & 7.2 & 1285331 \\
\hline $90-94$ & 352158 & 15.9 & 237851 & 10.7 & 590009 \\
\hline $95+$ & 163882 & 22.5 & 105923 & 14.5 & 269805 \\
\hline Total & 3254939 & 1.8 & 3503101 & 1.9 & 6758040 \\
\hline
\end{tabular}

proportion of prior fractures that engendered disability in 2010 is unknown but likely depends on fracture site, the time since fracture and the individual's age.

The majority of individuals with a prior fracture were women $(4,800,000$ women compared to $1,900,000$ men) (Table 29).

The estimated proportion of subjects with prior hip and vertebral fractures increased monotonically with age in men and women, from below $1 \%$ in individuals younger than 60 years to $24.3 \%$ (women) and $14.6 \%$ (men) for hip fractures and $15.0 \%$ (women) and $12.5 \%$ (men) for vertebral fractures (Table 29) in individuals older than 95 years. The reason the proportion of subjects with prior fractures increased monotonically with age whereas the absolute number of prior fractures did not, reflects that the population at risk (denominator in the calculation of the proportion) decreases with age.

The estimated number of men and women with a prior hip or vertebral fracture is shown in Table 30. The total number of prior fractures was estimated at approximately 6.8 million in the EU27 in 2010, comprising 3.3 million men and women with a prior hip fracture and 3.5 million with a prior clinical vertebral fracture. 
Table 30 Estimated number of men and women aged above 50 years with a prior hip or vertebral fracture by country, 2010

\begin{tabular}{|c|c|c|c|c|c|c|}
\hline \multirow{2}{*}{ Country } & \multicolumn{3}{|c|}{ Hip fracture } & \multicolumn{3}{|c|}{ Clinical vertebral fracture } \\
\hline & Men & Women & Total & Men & Women & Total \\
\hline Austria & 21653 & 52617 & 74270 & 25679 & 57944 & 83623 \\
\hline Belgium & 20749 & 53737 & 74485 & 23582 & 57124 & 80706 \\
\hline Bulgaria & 11349 & 20021 & 31370 & 11856 & 20924 & 32780 \\
\hline Cyprus & 1535 & 3387 & 4921 & 1931 & 4219 & 6150 \\
\hline Czech Republic & 17956 & 41023 & 58979 & 21313 & 43027 & 64340 \\
\hline Denmark & 15783 & 33963 & 49746 & 19652 & 38921 & 58573 \\
\hline Estonia & 1625 & 5725 & 7350 & 1707 & 5779 & 7486 \\
\hline Finland & 10821 & 23360 & 34181 & 12521 & 24671 & 37192 \\
\hline France & 106009 & 328664 & 434674 & 124564 & 310943 & 435507 \\
\hline Germany & 180264 & 489535 & 669799 & 219930 & 555599 & 775529 \\
\hline Greece & 25510 & 61902 & 87413 & 29625 & 72135 & 101760 \\
\hline Hungary & 14808 & 42416 & 57225 & 15692 & 44902 & 60594 \\
\hline Ireland & 4370 & 12877 & 17247 & 5284 & 13458 & 18742 \\
\hline Italy & 132596 & 384530 & 517126 & 151438 & 387597 & 539036 \\
\hline Latvia & 2430 & 9433 & 11862 & 2425 & 9150 & 11575 \\
\hline Lithuania & 3075 & 9971 & 13046 & 3096 & 9686 & 12782 \\
\hline Luxembourg & 669 & 1777 & 2446 & 829 & 1960 & 2790 \\
\hline Malta & 465 & 1509 & 1974 & 619 & 1697 & 2316 \\
\hline Netherlands & 20412 & 54182 & 74594 & 24566 & 57639 & 82206 \\
\hline Poland & 40516 & 98696 & 139212 & 45106 & 99757 & 144863 \\
\hline Portugal & 12295 & 39811 & 52106 & 12864 & 40789 & 53653 \\
\hline Romania & 26023 & 46001 & 72024 & 30046 & 52782 & 82829 \\
\hline Slovakia & 9236 & 18830 & 28065 & 11224 & 21263 & 32488 \\
\hline Slovenia & 3388 & 9041 & 12429 & 4229 & 10077 & 14306 \\
\hline Spain & 53523 & 157037 & 210560 & 58501 & 153927 & 212428 \\
\hline Sweden & 32425 & 66527 & 98952 & 36919 & 74428 & 111348 \\
\hline UK & 125786 & 293095 & 418881 & 145406 & 292093 & 437499 \\
\hline EU27 & 895272 & 2359667 & 3254939 & 1040607 & 2462494 & 3503101 \\
\hline
\end{tabular}

The estimated proportion of individuals (aged 50 years or more) with a prior hip fracture in the EU27 in 2010 amounted to $2.4 \%$ in women (ranging from $1.1 \%$ in Romania to $3.6 \%$ in Sweden) and $1.1 \%$ in men (ranging from $0.7 \%$ in Ireland, Malta, Netherlands, Poland, Portugal and Spain to $2.0 \%$ in Sweden). For clinical vertebral fractures the corresponding estimates were $2.5 \%$ (ranging from $1.3 \%$ in Bulgaria, Poland and Romania to $4.1 \%$ in Sweden) and $1.2 \%$ (ranging from $0.7 \%$ in e.g. Portugal and Lithuania to $2.2 \%$ in Sweden). The female to male ratio for both hip and vertebral fractures was approximately 2 . The proportion of individuals with a prior fracture by country is presented in Table 31.

It is relevant to note that the estimates above relate to a prior hip or vertebral fracture, which underestimates the prevalence of any prior fragility fracture. Using a different approach, the prevalence of a prior fracture has been estimated for Spain, France, UK, Germany, Italy and Sweden.

Table 32 summarises the data for these countries which show the prevalence of all prior fractures in 2010 undertaken with a more complete assessment compared with the estimates above. The estimation of prior vertebral + prior hip fracture appears to capture approximately $30 \%$ of prior fractures.

\subsection{Mortality due to fracture}

Independently of fracture status, low bone mineral density is associated with an increase in mortality [58-61]. Over and above this excess mortality, some specific fracture sites are associated with increased mortality $[59,62,63]$. Although the mortality after a fracture has been reported to be higher for men compared to women [62], the mortality hazard in the general population is higher in men than in women. Thus, the difference in mortality between men and women is less marked when relating the mortality to that of the general population of the same sex [63-66]. Several studies have shown that mortality is highest in the immediate fracture period and then decreases with time. However, it remains higher than that of the general population $[62,67-70]$. The pattern of mortality after fracture has been well characterised in Sweden [65, 69]. 
Table 31 Estimated proportion of men and women above 50 years with a prior hip or vertebral fracture by country, 2010

\begin{tabular}{lcccccc}
\hline & \multicolumn{3}{c}{ Hip fractures (\%) } & \multicolumn{3}{c}{ Vertebral fractures (\%) } \\
\cline { 2 - 7 } Country & Women & Men & Total & Women & Men & Total \\
\hline Austria & 3.2 & 1.6 & 2.4 & 3.5 & 1.9 & 2.7 \\
Belgium & 2.5 & 1.1 & 1.9 & 2.7 & 1.3 & 2.0 \\
Bulgaria & 1.2 & 0.9 & 1.1 & 1.3 & 0.9 & 1.1 \\
Cyprus & 2.1 & 1.0 & 1.6 & 2.6 & 1.3 & 2.0 \\
Czech Republic & 2.0 & 1.1 & 1.6 & 2.1 & 1.2 & 1.7 \\
Denmark & 3.2 & 1.7 & 2.5 & 3.7 & 2.1 & 2.9 \\
Estonia & 1.9 & 0.9 & 1.5 & 1.9 & 0.9 & 1.5 \\
Finland & 2.1 & 1.1 & 1.6 & 2.2 & 1.3 & 1.8 \\
France & 2.7 & 1.0 & 1.9 & 2.5 & 1.2 & 1.9 \\
Germany & 2.8 & 1.2 & 2.0 & 3.1 & 1.4 & 2.3 \\
Greece & 2.7 & 1.3 & 2.1 & 3.2 & 1.5 & 2.4 \\
Hungary & 2.0 & 1.0 & 1.6 & 2.1 & 1.0 & 1.6 \\
Ireland & 2.0 & 0.7 & 1.4 & 2.1 & 0.9 & 1.5 \\
Italy & 3.0 & 1.2 & 2.2 & 3.0 & 1.4 & 2.3 \\
Latvia & 1.9 & 0.8 & 1.5 & 1.8 & 0.8 & 1.4 \\
Lithuania & 1.5 & 0.7 & 1.2 & 1.4 & 0.7 & 1.1 \\
Luxembourg & 2.1 & 0.9 & 1.5 & 2.4 & 1.1 & 1.8 \\
Malta & 1.9 & 0.7 & 1.3 & 2.1 & 0.9 & 1.5 \\
Netherlands & 1.8 & 0.7 & 1.3 & 1.9 & 0.9 & 1.4 \\
Poland & 1.0 & 0.7 & 1.0 & 1.3 & 0.8 & 1.1 \\
Portugal & 1.8 & 0.7 & 1.3 & 1.9 & 0.7 & 1.4 \\
Romania & 1.1 & 0.8 & 1.0 & 1.3 & 0.9 & 1.1 \\
Slovakia & 1.9 & 1.2 & 1.6 & 2.2 & 1.5 & 1.9 \\
Slovenia & 2.2 & 1.0 & 1.6 & 2.4 & 1.2 & 1.9 \\
Spain & 1.8 & 0.7 & 1.3 & 1.8 & 0.8 & 1.3 \\
Sweden & 3.6 & 2.0 & 2.8 & 4.1 & 2.2 & 3.2 \\
UK & 2.5 & 1.2 & 1.9 & 2.5 & 1.4 & 2.0 \\
EU27 & 2.4 & 1.1 & 1.8 & 2.5 & 1.2 & 1.9 \\
\hline
\end{tabular}

In order to compute the mortality after fracture, we used the age- and country specific mortality rates for men and for women $[52,53]$. To these data, we applied the relative risks of death documented for Sweden to estimate the country-specific mortality rates after a fracture. The calculation assumes that the relative risk of death after fracture is similar to that of Sweden in all EU countries. The adequacy of this assumption is unknown but it is likely that death rates are higher in those countries with poorer health care facilities. Thus the estimates provided are likely to be conservative.

Table 32 Estimates of the prevalence of prior hip and clinical vertebral fracture (the present study) and the prevalence of all fragility fractures

\begin{tabular}{lllll}
\hline Country & Reference & Comparator (A) & This study (B) & B/A (\%) \\
\hline Spain & $\begin{array}{l}\text { Gauthier et al 2012 (unpublished } \\
\text { data) }\end{array}$ & 8.9 & 2.6 & 29 \\
France & Cawston et al 2012 [55] & 11.2 & 3.8 & 34 \\
UK & Gauthier et al 2011 [56] & 10.3 & 3.9 & 39 \\
Germany & Gauthier et al 2012 [57] & 14.1 & 4.3 & 30 \\
Italy & Piscitelli et al 2012 (unpublished & 16.2 & 4.5 & 28 \\
Sweden & Gata) & 22.6 & 6.0 & 27 \\
Average & & & & 30 \\
\hline
\end{tabular}


Table 33 Relative risk of death in the first year after fracture [69]

\begin{tabular}{lcccc}
\hline \multirow{2}{*}{$\begin{array}{l}\text { Age } \\
\text { (years) }\end{array}$} & Wip fracture & $\begin{array}{c}\text { Clinical vertebral } \\
\text { fracture }\end{array}$ & Hip fracture & $\begin{array}{c}\text { Clinical vertebral } \\
\text { fracture }\end{array}$ \\
\cline { 2 - 5 } & 9.52 & 12.07 & 15.03 & 17.82 \\
50 & 8.44 & 10.15 & 11.72 & 13.18 \\
60 & 7.92 & 9.04 & 9.13 & 9.74 \\
65 & 6.86 & 7.43 & 7.13 & 7.22 \\
70 & 5.83 & 5.98 & 5.88 & 5.64 \\
75 & 4.51 & 4.39 & 4.71 & 4.29 \\
80 & 2.97 & 2.75 & 3.62 & 3.13 \\
85 & 2.26 & 1.98 & 3.04 & 2.49 \\
90 & 1.63 & 1.36 & 2.76 & 2.14 \\
\hline
\end{tabular}

Age differentiated mortality in the first year after a vertebral or hip fracture relative to the age- specific mortality of the Swedish population is shown in Table 33 [69]. The relative risk of death decreases with age, even though the absolute mortality increases. We assumed no excess mortality after a fracture of the forearm, in accordance with the published literature $[62,67,69,71]$. For other fractures, a relative excess mortality of 1.22 was assumed for all ages $[12,72,73]$.

The increase in mortality seen after a fracture cannot be entirely attributed to the incident fracture itself because of the high levels of co-morbidity, particularly in patients with hip and vertebral fracture [59, 74, 75]. In health economic studies of osteoporosis, it is the excess mortality

Table 34 Number of deaths after fracture and deaths directly attributed to fractures within the first year, after adjusting for co-morbidities, 2010

\begin{tabular}{|c|c|c|c|c|c|c|}
\hline \multirow[b]{2}{*}{ Country } & \multicolumn{3}{|c|}{ Deaths after fracture } & \multicolumn{3}{|c|}{ Deaths directly attributed to fracture } \\
\hline & Men & Women & Total & Men & Women & Total \\
\hline Austria & 1523 & 1871 & 3393 & 457 & 561 & 1018 \\
\hline Belgium & 1590 & 1673 & 3263 & 477 & 502 & 979 \\
\hline Bulgaria & 1151 & 1006 & 2157 & 345 & 302 & 647 \\
\hline Cyprus & 96 & 82 & 178 & 29 & 25 & 53 \\
\hline Czech Republic & 1725 & 1723 & 3448 & 518 & 517 & 1034 \\
\hline Denmark & 1416 & 1513 & 2930 & 425 & 454 & 879 \\
\hline Estonia & 205 & 240 & 445 & 62 & 72 & 134 \\
\hline Finland & 755 & 662 & 1417 & 226 & 199 & 425 \\
\hline France & 6853 & 7258 & 14111 & 2056 & 2178 & 4233 \\
\hline Germany & 12642 & 16614 & 29256 & 3793 & 4984 & 8777 \\
\hline Greece & 1749 & 2013 & 3761 & 525 & 604 & 1128 \\
\hline Hungary & 2023 & 2113 & 4136 & 607 & 634 & 1241 \\
\hline Ireland & 327 & 371 & 698 & 98 & 111 & 209 \\
\hline Italy & 8522 & 9731 & 18253 & 2557 & 2919 & 5476 \\
\hline Latvia & 356 & 446 & 802 & 107 & 134 & 241 \\
\hline Lithuania & 387 & 427 & 815 & 116 & 128 & 244 \\
\hline Luxembourg & 41 & 52 & 93 & 12 & 16 & 28 \\
\hline Malta & 43 & 56 & 99 & 13 & 17 & 30 \\
\hline Netherlands & 1452 & 1449 & 2902 & 436 & 435 & 870 \\
\hline Poland & 3964 & 3845 & 7809 & 1189 & 1154 & 2343 \\
\hline Portugal & 989 & 1226 & 2215 & 297 & 368 & 665 \\
\hline Romania & 2866 & 2497 & 5363 & 860 & 749 & 1609 \\
\hline Slovakia & 1021 & 891 & 1912 & 306 & 267 & 574 \\
\hline Slovenia & 295 & 347 & 641 & 88 & 104 & 192 \\
\hline Spain & 3985 & 4515 & 8500 & 1196 & 1354 & 2550 \\
\hline Sweden & 1799 & 2105 & 3904 & 540 & 631 & 1171 \\
\hline UK & 9235 & 10962 & 20197 & 2770 & 3289 & 6059 \\
\hline EU27 & 67010 & 75687 & 142697 & 20103 & 22706 & 42809 \\
\hline
\end{tabular}


that would be avoided in the absence of a fracture that is important to consider. A common assumption [76-79] is that $30 \%$ of the excess mortality is directly caused by the fracture, which is supported by studies by Parker and Anand [80], Tosteson et al. [81] and Kanis et al. [82, 83]. In this report, it was assumed that $30 \%$ of the excess mortality during the first year was attributable to the fracture itself and that excess mortality related to the fracture was only present during the first year.

\subsection{Deaths due to fracture}

When combining the country- and age-specific estimates of incidence and post-fracture mortality, the total number of deaths occurring in the first year after fracture was estimated at 143,000. After adjusting for co-morbidities, the numbers of deaths in 2010 during the first year after fracture attributable only to the fracture were estimated at approximately 20,100 and 22,700 in men and women, respectively. Most deaths occurred in Germany, followed by the UK, whilst countries with small populations such as
Malta and Luxembourg had the lowest number of deaths. The number of deaths after fracture and deaths causally related to fractures in the countries of the European Union are shown in Table 34.

In total in the EU27, hip, vertebral and other fractures were estimated to result in approximately 11,000 , 6,000 and 5,000 deaths in women, directly attributable to fracture. The corresponding numbers for men were estimated at approximately 9,000, 8,000 and 3,000 deaths for hip, vertebral and other fractures, respectively (Table 35). Most notably, vertebral fractures caused somewhat more deaths in men than in women during the first year (8,000 in men and 6,000 in women), although approximately $75 \%$ more fractures occurred in women than men (Table 28). This is due to a higher relative mortality (Table 33) as well as a higher general mortality at higher ages in men. The majority of fracture related deaths occurred in hip fracture patients. Among men and women who experienced premature mortality due to a fracture, $47 \%$ and $50 \%$ respectively were attributable to hip fracture (Fig. 26).

Table 35 Number of deaths in 2010 directly attributable to fractures within the first year, after adjusting for co-morbidities in women and men aged $50+$ years by fracture site

\begin{tabular}{lcccccccc}
\hline & \multicolumn{2}{c}{ Hip fractures } & \multicolumn{2}{c}{ Vertebral fractures } & \multicolumn{2}{c}{ Other fractures } & \multicolumn{2}{c}{ All fractures } \\
\cline { 2 - 9 } Country & Women & Men & Women & Men & Women & Men & Women & Men \\
\hline Austria & 288 & 217 & 145 & 172 & 128 & 67 & 561 & 457 \\
Belgium & 259 & 233 & 137 & 173 & 106 & 71 & 502 & 477 \\
Bulgaria & 151 & 143 & 114 & 168 & 36 & 34 & 302 & 345 \\
Cyprus & 13 & 14 & 8 & 11 & 4 & 4 & 25 & 29 \\
Czech Republic & 268 & 233 & 159 & 221 & 90 & 63 & 517 & 518 \\
Denmark & 224 & 203 & 133 & 161 & 97 & 61 & 454 & 425 \\
Estonia & 37 & 27 & 23 & 27 & 12 & 7 & 72 & 62 \\
Finland & 103 & 106 & 55 & 89 & 41 & 31 & 199 & 226 \\
France & 1103 & 994 & 527 & 729 & 547 & 333 & 2178 & 2056 \\
Germany & 2503 & 1782 & 1439 & 1526 & 1042 & 484 & 4984 & 3793 \\
Greece & 310 & 256 & 160 & 192 & 133 & 77 & 604 & 525 \\
Hungary & 321 & 270 & 199 & 262 & 114 & 75 & 634 & 607 \\
Ireland & 56 & 47 & 31 & 36 & 24 & 15 & 111 & 98 \\
Italy & 1507 & 1271 & 784 & 875 & 628 & 411 & 2919 & 2557 \\
Latvia & 69 & 47 & 44 & 48 & 22 & 11 & 134 & 107 \\
Lithuania & 66 & 49 & 42 & 56 & 20 & 12 & 128 & 116 \\
Luxembourg & 8 & 6 & 5 & 5 & 3 & 1 & 16 & 12 \\
Malta & 9 & 6 & 6 & 5 & 3 & 2 & 17 & 13 \\
Netherlands & 219 & 212 & 126 & 159 & 90 & 65 & 435 & 436 \\
Poland & 586 & 497 & 377 & 564 & 191 & 128 & 1154 & 1189 \\
Portugal & 190 & 146 & 99 & 105 & 79 & 45 & 368 & 297 \\
Romania & 372 & 351 & 286 & 426 & 91 & 83 & 749 & 860 \\
Slovakia & 136 & 126 & 93 & 149 & 39 & 32 & 267 & 306 \\
Slovenia & 55 & 41 & 29 & 37 & 20 & 11 & 104 & 88 \\
Spain & 699 & 590 & 308 & 411 & 348 & 194 & 1354 & 1196 \\
Sweden & 321 & 268 & 170 & 192 & 140 & 79 & 631 & 540 \\
UK & 1487 & 1277 & 817 & 978 & 984 & 516 & 3289 & 2770 \\
EU27 & $\mathbf{1 1 3 5 8}$ & $\mathbf{9 4 1 3}$ & $\mathbf{6 3 1 3}$ & $\mathbf{7 7 7 9}$ & $\mathbf{5 0 3 4}$ & $\mathbf{2 9 1 1}$ & $\mathbf{2 2 ~ 7 0 6}$ & $\mathbf{2 0 1 0 3}$ \\
\hline & & & & & & & & \\
\hline
\end{tabular}




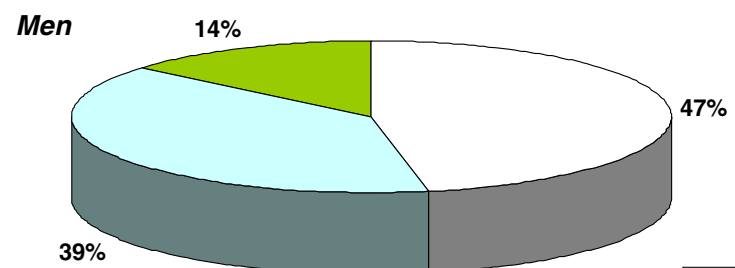

Women

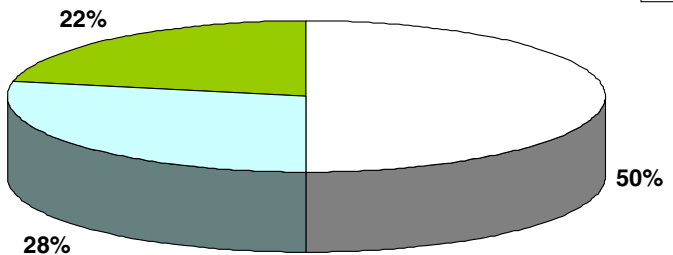

Fig. 26 Proportion of deaths due to fracture by site in men (top) and women (bottom)
The number of deaths directly attributable to fracture in the EU27 in 2010 was estimated at 24 per 100,000 people at risk (aged 50 years or more) and ranged by a factor of approximately 3 -fold in both women (from 14 in Netherlands to 43 in Denmark) and men (from 16 in Netherlands to 45 in Denmark) (Table 36). The intercountry variation predominately reflects differences in fracture incidence.

Similar to the estimated number of fractures, the number of deaths attributable to fracture decreased in higher age groups in both men and women (Table 37). The decrease is a result of fewer people at risk with age (Table 27) combined with decreasing relative risks of mortality after hip and vertebral fractures (Table 33). However, in both men and women, almost half of the deaths were incurred in ages $80-89$ years.

Table 36 Incidence (per 100,000 inhabitants aged 50+ years) of deaths directly attributable to fractures within the first year, after adjusting for comorbidities by fracture site in 2010

\begin{tabular}{|c|c|c|c|c|c|c|c|c|}
\hline \multirow[b]{2}{*}{ Country } & \multicolumn{2}{|c|}{ Hip fractures } & \multicolumn{2}{|c|}{ Vertebral fractures } & \multicolumn{2}{|c|}{ Other fractures } & \multicolumn{2}{|c|}{ All fractures } \\
\hline & Women & Men & Women & Men & Women & Men & Women & Men \\
\hline Austria & 17 & 16 & 9 & 12 & 8 & 5 & 34 & 33 \\
\hline Belgium & 12 & 13 & 6 & 9 & 5 & 4 & 24 & 26 \\
\hline Bulgaria & 9 & 11 & 7 & 13 & 2 & 3 & 19 & 27 \\
\hline Cyprus & 8 & 9 & 5 & 7 & 3 & 3 & 15 & 19 \\
\hline Czech Republic & 13 & 14 & 8 & 13 & 4 & 4 & 25 & 30 \\
\hline Denmark & 21 & 21 & 13 & 17 & 9 & 6 & 43 & 45 \\
\hline Estonia & 12 & 15 & 8 & 14 & 4 & 4 & 24 & 33 \\
\hline Finland & 9 & 11 & 5 & 9 & 4 & 3 & 18 & 24 \\
\hline France & 9 & 10 & 4 & 7 & 4 & 3 & 18 & 20 \\
\hline Germany & 14 & 12 & 8 & 10 & 6 & 3 & 28 & 25 \\
\hline Greece & 14 & 13 & 7 & 10 & 6 & 4 & 27 & 27 \\
\hline Hungary & 15 & 18 & 9 & 17 & 5 & 5 & 30 & 39 \\
\hline Ireland & 9 & 8 & 5 & 6 & 4 & 2 & 17 & 16 \\
\hline Italy & 12 & 12 & 6 & 8 & 5 & 4 & 22 & 24 \\
\hline Latvia & 14 & 15 & 9 & 15 & 4 & 4 & 27 & 34 \\
\hline Lithuania & 10 & 11 & 6 & 13 & 3 & 3 & 19 & 26 \\
\hline Luxembourg & 10 & 8 & 6 & 7 & 3 & 2 & 19 & 16 \\
\hline Malta & 11 & 9 & 7 & 7 & 3 & 2 & 21 & 18 \\
\hline Netherlands & 7 & 8 & 4 & 6 & 3 & 2 & 14 & 16 \\
\hline Poland & 8 & 9 & 5 & 10 & 3 & 2 & 15 & 20 \\
\hline Portugal & 9 & 8 & 5 & 6 & 4 & 3 & 17 & 17 \\
\hline Romania & 9 & 11 & 7 & 13 & 2 & 3 & 18 & 27 \\
\hline Slovakia & 14 & 17 & 10 & 20 & 4 & 4 & 27 & 41 \\
\hline Slovenia & 13 & 12 & 7 & 11 & 5 & 3 & 25 & 26 \\
\hline Spain & 8 & 8 & 4 & 6 & 4 & 3 & 16 & 16 \\
\hline Sweden & 18 & 16 & 9 & 12 & 8 & 5 & 35 & 33 \\
\hline UK & 13 & 13 & 7 & 10 & 9 & 5 & 29 & 27 \\
\hline EU27 & 11 & 11 & 6 & 9 & 5 & 3 & 23 & 24 \\
\hline
\end{tabular}


Table 37 Age distribution of causally related deaths in the EU in 2010

\begin{tabular}{|c|c|c|c|c|}
\hline Age group (years) & $\begin{array}{l}\text { Deaths caused by } \\
\text { hip fractures }\end{array}$ & $\begin{array}{l}\text { Deaths caused by } \\
\text { vertebral fractures }\end{array}$ & $\begin{array}{l}\text { Deaths caused by } \\
\text { other fractures }\end{array}$ & $\begin{array}{c}\text { Deaths caused by } \\
\text { fractures of all sites }\end{array}$ \\
\hline \multicolumn{5}{|c|}{ Women } \\
\hline $50-54$ & 43 & 142 & 8 & 193 \\
\hline $55-59$ & 98 & 285 & 20 & 403 \\
\hline $60-64$ & 185 & 329 & 23 & 537 \\
\hline $65-69$ & 371 & 556 & 57 & 984 \\
\hline $70-74$ & 849 & 1062 & 131 & 2042 \\
\hline $75-79$ & 1749 & 1306 & 313 & 3369 \\
\hline $80-84$ & 2900 & 1308 & 741 & 4949 \\
\hline $85-89$ & 3275 & 1010 & 1522 & 5807 \\
\hline $90-94$ & 1566 & 297 & 1274 & 3138 \\
\hline $95+$ & 322 & 17 & 944 & 1284 \\
\hline Total & 11358 & 6313 & 5034 & 22706 \\
\hline \multicolumn{5}{|c|}{ Men } \\
\hline $50-54$ & 174 & 447 & 22 & 644 \\
\hline $55-59$ & 283 & 536 & 69 & 889 \\
\hline $60-64$ & 350 & 927 & 86 & 1362 \\
\hline $65-69$ & 504 & 683 & 120 & 1307 \\
\hline $70-74$ & 889 & 1223 & 200 & 2312 \\
\hline $75-79$ & 1429 & 1140 & 256 & 2825 \\
\hline $80-84$ & 2284 & 1149 & 656 & 4090 \\
\hline $85-89$ & 2262 & 1103 & 822 & 4187 \\
\hline $90-94$ & 1021 & 477 & 463 & 1961 \\
\hline $95+$ & 216 & 95 & 217 & 527 \\
\hline Total & 9413 & 7779 & 2911 & 20103 \\
\hline \multicolumn{5}{|c|}{ Men and women } \\
\hline $50-54$ & 217 & 589 & 31 & 836 \\
\hline $55-59$ & 381 & 821 & 90 & 1292 \\
\hline $60-64$ & 535 & 1256 & 109 & 1899 \\
\hline $65-69$ & 875 & 1239 & 177 & 2291 \\
\hline $70-74$ & 1738 & 2284 & 331 & 4354 \\
\hline $75-79$ & 3179 & 2446 & 569 & 6194 \\
\hline $80-84$ & 5184 & 2457 & 1398 & 9038 \\
\hline $85-89$ & 5537 & 2113 & 2344 & 9994 \\
\hline $90-94$ & 2588 & 774 & 1737 & 5098 \\
\hline $95+$ & 538 & 112 & 1162 & 1811 \\
\hline Total & 20772 & 14092 & 7945 & 42809 \\
\hline
\end{tabular}

\section{References}

1. United Nations Department of Economic and Social Affairs Population Division (2011) World Population Prospects test. Data retrieved in November, 2011. http://esa.un.org/unpd/wpp/ unpp/p2k0data.asp

2. Kanis JA, McCloskey EV, Johansson H, Oden A, Melton LJ, III, Khaltaev N (2008) A reference standard for the description of osteoporosis. Bone 42:467-475

3. Kanis JA, Melton LJ, III, Christiansen C, Johnston CC, Khaltaev N (1994) The diagnosis of osteoporosis. J Bone Miner Res 9:1137-1141

4. Looker AC, Wahner HW, Dunn WL, Calvo MS, Harris TB, Heyse SP, Johnston CC, Jr., Lindsay R (1998) Updated data on proximal femur bone mineral levels of US adults. Osteoporos Int 8:468-489

5. Gauthier A, Kanis JA, Jiang Y, Martin M, Compston JE, Borgstrom F, Cooper C, McCloskey EV (2011) Epidemiological burden of postmenopausal osteoporosis in the UK from 2010 to 2021: estimations from a disease model. Arch Osteoporos 6:179-188
6. Gauthier A, Kanis JA, Martin M, Compston J, Borgstrom F, Cooper C, McCloskey E (2011) Development and validation of a disease model for postmenopausal osteoporosis. Osteoporos Int 22:771-780

7. Strom O, Borgstrom F, Kanis JA, Compston J, Cooper C, McCloskey EV, Jonsson B (2011) Osteoporosis: burden, health care provision and opportunities in the EU: a report prepared in collaboration with the International Osteoporosis Foundation (IOF) and the European Federation of Pharmaceutical Industry Associations (EFPIA). Arch Osteoporos 6:59-155

8. Piscitelli P, Chitano G, Johannson H, Brandi ML, Kanis JA, Black DM (2013) Updated fracture incidence rates for the Italian version of FRAX(R). Osteoporos Int 24: 859-66

9. Cauley JA, El-Hajj FG, Arabi A, et al. (2011) Official Positions for FRAX(R) clinical regarding international differences from Joint Official Positions Development Conference of the International Society for Clinical Densitometry and International Osteoporosis Foundation on $\operatorname{FRAX(R).~J~}$ Clin Densitom 14:240-262

10. Kanis JA, Johnell O, Oden A, Sembo I, Redlund-Johnell I, Dawson A, De Laet C, Jonsson B (2000) Long-term risk 
of osteoporotic fracture in Malmo. Osteoporos Int 11:669674

11. Kanis JA, Hans D, Cooper C, et al. (2011) Interpretation and use of FRAX in clinical practice. Osteoporos Int 22:2395-2411

12. Kanis JA, Oden A, Johnell O, Jonsson B, De Laet C, Dawson A (2001) The burden of osteoporotic fractures: a method for setting intervention thresholds. Osteoporos Int 12:417-427

13. Dimai HP, Svedbom A, Fahrleitner-Pammer A, Pieber $\mathrm{T}$, Resch H, Zwettler E, Chandran M, Borgstrom F (2011) Epidemiology of hip fractures in Austria: evidence for a change in the secular trend. Osteoporos Int 22:685-692

14. Hiligsmann $M$, Bruyere $O$, Roberfroid D, Dubois C, Parmentier Y, Carton J, Detilleux J, Gillet P, Reginster JY (2012) Trends in hip fracture incidence and in the prescription of antiosteoporosis medications during the same time period in Belgium (2000-2007). Arthritis Care Res (Hoboken) 64:744-750

15. Stepan JJ, Vaculik J, Pavelka K, Zofka J, Johansson H, Kanis JA (2012) Hip fracture incidence from 1981 to 2009 in the Czech Republic as a basis of the country-specific FRAX model. Calcif Tissue Int 90:365-372

16. Haviko T, Maasalu K, Seeder J (1996) The incidence of osteoporotic fractures at the University Hospital of Tartu, Estonia. Scand J Rheumatol Suppl 103:13-15

17. Couris CM, Chapurlat RD, Kanis JA, Johansson H, Burlet N, Delmas PD, Schott AM (2012) FRAX(R) probabilities and risk of major osteoporotic fracture in France. Osteoporos Int 23:2321-2327

18. Icks A, Haastert B, Wildner M, Becker C, Meyer G (2008) Trend of hip fracture incidence in Germany 1995-2004: a population-based study. Osteoporos Int 19:1139-1145

19. Paspati I, Galanos A, Lyritis GP (1998) Hip fracture epidemiology in Greece during 1977-1992. Calcif Tissue Int 62:542-547

20. Pentek M, Horvath C, Boncz I, Falusi Z, Toth E, Sebestyen A, Majer I, Brodszky V, Gulacsi L (2008) Epidemiology of osteoporosis related fractures in Hungary from the nationwide health insurance database, 1999-2003. Osteoporos Int 19:243-249

21. Dodds MK, Codd MB, Looney A, Mulhall KJ (2009) Incidence of hip fracture in the Republic of Ireland and future projections: a population-based study. Osteoporos Int 20:2105-2110

22. Tamulaitiene M, Alekna V (2012) Incidence and direct hospitalisation costs of hip fractures in Vilnius, capital of Lithuania, in 2010. BMC Public Health 12:495

23. Lalmohamed A, Welsing PM, Lems WF, Jacobs JW, Kanis JA, Johansson H, De BA, De VF (2012) Calibration of FRAX (R) 3.1 to the Dutch population with data on the epidemiology of hip fractures. Osteoporos Int 23:861-869

24. de Pina MF, Alves SM, Barbosa M, Barros H (2008) Hip fractures cluster in space: an epidemiological analysis in Portugal. Osteoporos Int 19:1797-1804

25. Grigorie D, Sucaliuc A, Johansson H, Kanis JA, McCloskey E (2013) Incidence of hip fracture in Romania and the development of a Romanian FRAX model Calcif Tissue Int 92:429-436

26. Masaryk P (2012) Hodnotenie rizika osteoporotických zlomenín v primárnej praxi (Fracture risk assessment in primary care). Rheumatologia, 26:127-133

27. Dzajkovska B, Wertheimer AI, Mrhar A (2007) The burden-ofillness study on osteoporosis in the Slovenian female population. Pharm World Sci 29:404-411
28. Diez A, Puig J, Martinez MT, Diez JL, Aubia J, Vivancos J (1989) Epidemiology of fractures of the proximal femur associated with osteoporosis in Barcelona, Spain. Calcif Tissue Int 44:382-386

29. Elffors I, Allander E, Kanis JA, Gullberg B, Johnell O, Dequeker J, Dilsen G, Gennari C, Lopes Vaz AA, Lyritis G (1994) The variable incidence of hip fracture in southern Europe: the MEDOS Study. Osteoporos Int 4:253-263

30. Izquierdo SM, Ochoa SC, Sanchez B, I, Hidalgo Prieto MC, Lozano d, V, Martin GT (1997) [Epidemiology of osteoporotic hip fractures in the province of Zamora (1993)]. Rev Esp Salud Publica 71:357-367

31. Singer BR, McLauchlan GJ, Robinson CM, Christie J (1998) Epidemiology of fractures in 15,000 adults: the influence of age and gender. J Bone Joint Surg Br 80:243-248

32. De Laet CE, Van Hout BA, Burger H, Weel AE, Hofman A, Pols HA (1998) Hip fracture prediction in elderly men and women: validation in the Rotterdam study. J Bone Miner Res 13:15871593

33. Johnell O, Kanis JA, Oden A, et al. (2005) Predictive value of BMD for hip and other fractures. J Bone Miner Res 20:11851194

34. Johnell O, Borgstrom F, Jonsson B, Kanis J (2007) Latitude, socioeconomic prosperity, mobile phones and hip fracture risk. Osteoporos Int 18:333-337

35. Bacon WE, Hadden WC (2000) Occurrence of hip fractures and socioeconomic position. J Aging Health 12:193-203

36. Kanis JA, Passmore R (1989) Calcium supplementation of the diet-II. BMJ 298:205-208

37. Kanis JA, Passmore R (1989) Calcium supplementation of the diet-I. BMJ 298:137-140

38. Cooper C, O'Neill T, Silman A (1993) The epidemiology of vertebral fractures. European Vertebral Osteoporosis Study Group. Bone 14 Suppl 1:S89-S97

39. Kanis JA, Johnell O, Oden A, Borgstrom F, Zethraeus N, De Laet C, Jonsson B (2004) The risk and burden of vertebral fractures in Sweden. Osteoporos Int 15:20-26

40. van Staa TP, Dennison EM, Leufkens HG, Cooper C (2001) Epidemiology of fractures in England and Wales. Bone 29:517-522

41. Lindsay R, Silverman SL, Cooper C, et al. (2001) Risk of new vertebral fracture in the year following a fracture. JAMA 285:320-323

42. van Staa TP, Abenhaim L, Cooper C, Zhang B, Leufkens HG (2000) The use of a large pharmacoepidemiological database to study exposure to oral corticosteroids and risk of fractures: validation of study population and results. Pharmacoepidemiol Drug Saf 9:359-366

43. de Lusignan S, Valentin T, Chan T, Hague N, Wood O, van Vlymen J, Dhoul N (2004) Problems with primary care data quality: osteoporosis as an exemplar. Inform Prim Care 12:147-156

44. Felsenberg D, Silman A, Lunt M, Ambrecht G, Ismail A (2002) Incidence of Vertebral Fracture in Europe: Results from the European Prospective Osteoporosis Study (EPOS). J Bone Miner Res 17:716-724

45. Maravic M, Taupin P, Landais P, Roux C (2010) Hospitalized wrist fractures in France: Incidence and burden trend changes. Orthop Traumatol Surg Res 96:662-666

46. Tarantino U, Capone A, Planta M, et al. (2010) The incidence of hip, forearm, humeral, ankle, and vertebral fragility fractures in Italy: results from a 3-year multicenter study. Arthritis Res Ther 12:R226

47. Klotzbuecher CM, Ross PD, Landsman PB, Abbott TA, III, Berger M (2000) Patients with prior fractures have an increased risk of future 
fractures: a summary of the literature and statistical synthesis. J Bone Miner Res 15:721-739

48. Burger H, van Daele PL, Algra D, Hofman A, Grobbee DE, Schutte HE, Birkenhager JC, Pols HA (1994) Vertebral deformities as predictors of non-vertebral fractures. BMJ 309:991-992

49. Kanis JA, Johnell O, De Laet C, et al. (2004) A metaanalysis of previous fracture and subsequent fracture risk. Bone 35:375-382

50. Nevitt MC, Ross PD, Palermo L, Musliner T, Genant HK, Thompson DE (1999) Association of prevalent vertebral fractures, bone density, and alendronate treatment with incident vertebral fractures: effect of number and spinal location of fractures. The Fracture Intervention Trial Research Group. Bone 25:613-619

51. O'Neill TW, Felsenberg D, Varlow J, Cooper C, Kanis JA, Silman AJ (1996) The prevalence of vertebral deformity in european men and women: the European Vertebral Osteoporosis Study. J Bone Miner Res 11:1010-1018

52. Human Mortality Database (2010) University of California, Berkeley (USA) and Max Planck Institute for Demographic Research (Germany)

53. Eurostat (2011) Statistics database. Data retreived in November, 2011. http://epp.eurostat.ec.europa.eu,

54. Jonsson B, Strom O, Eisman JA, Papaioannou A, Siris ES, Tosteson A, Kanis JA (2011) Cost-effectiveness of Denosumab for the treatment of postmenopausal osteoporosis. Osteoporos Int 22:967-982

55. Cawston H, Maravic M, Fardellone P, Gauthier A, Kanis JA, Compston J, Borgstrom F, Cooper C, McCloskey E (2012) Epidemiological burden of postmenopausal osteoporosis in France from 2010 to 2020: estimations from a disease model. Arch Osteoporos. 7:237-246

56. Gauthier A, Kanis JA, Jiang Y, Martin M, Compston J, Borgstrom F, Cooper C, McCloskey E (2011) Epidemiological burden of postmenopausal osteoporosis in the UK from 2010 to 2021: Estimations from a disease model. Archives of Osteoporosis 6:179-188

57. Gauthier A, Kanis JA, Jiang Y, Dreinhofer K, Martin M, Compston J, Borgstrom F, Cooper C, McCloskey E (2012) Burden of postmenopausal osteoporosis in Germany: estimations from a disease model. Arch Osteoporos 7:209-218

58. Browner WS, Seeley DG, Vogt TM, Cummings SR (1991) Nontrauma mortality in elderly women with low bone mineral density. Study of Osteoporotic Fractures Research Group. Lancet 338:355-358

59. Jalava T, Sarna S, Pylkkanen L, et al. (2003) Association between vertebral fracture and increased mortality in osteoporotic patients. J Bone Miner Res 18:1254-1260

60. Mussolino ME, Looker AC, Madans JH, Langlois JA, Orwoll ES (1998) Risk factors for hip fracture in white men: the NHANES I Epidemiologic Follow-up Study. J Bone Miner Res 13:918-924

61. Trivedi DP, Khaw KT (2001) Bone mineral density at the hip predicts mortality in elderly men. Osteoporos Int 12:259-265

62. Center JR, Nguyen TV, Schneider D, Sambrook PN, Eisman JA (1999) Mortality after all major types of osteoporotic fracture in men and women: an observational study. Lancet 353:878-882

63. Johnell O, Kanis JA, Oden A, Sernbo I, Redlund-Johnell I, Petterson C, De Laet C, Jonsson B (2004) Fracture risk following an osteoporotic fracture. Osteoporos Int 15:175-179

64. Bliuc D, Nguyen ND, Milch VE, Nguyen TV, Eisman JA, Center JR (2009) Mortality risk associated with low-trauma osteoporotic fracture and subsequent fracture in men and women. JAMA 301:513-521
65. Oden A, Dawson A, Dere W, Johnell O, Jonsson B, Kanis JA (1998) Lifetime risk of hip fractures is underestimated. Osteoporos Int 8:599-603

66. Trombetti A, Herrmann F, Hoffmeyer P, Schurch MA, Bonjour JP, Rizzoli R (2002) Survival and potential years of life lost after hip fracture in men and age-matched women. Osteoporos Int 13:731-737

67. Cooper C, Atkinson EJ, Jacobsen SJ, O'Fallon WM, Melton LJ, III (1993) Population-based study of survival after osteoporotic fractures. Am J Epidemiol 137:1001-1005

68. Forsen L, Sogaard AJ, Meyer HE, Edna T, Kopjar B (1999) Survival after hip fracture: short- and long-term excess mortality according to age and gender. Osteoporos Int 10:73-78

69. Johnell O, Kanis JA, Oden A, Sernbo I, Redlund-Johnell I, Petterson C, De Laet C, Jonsson B (2004) Mortality after osteoporotic fractures. Osteoporos Int 15:38-42

70. Roberts SE, Goldacre MJ (2003) Time trends and demography of mortality after fractured neck of femur in an English population, 1968-98: database study. BMJ 327:771-775

71. Cauley JA, Thompson DE, Ensrud KC, Scott JC, Black D (2000) Risk of mortality following clinical fractures. Osteoporos Int 11:556-561

72. Barrett JA, Baron JA, Beach ML (2003) Mortality and pulmonary embolism after fracture in the elderly. Osteoporos Int 14:889-894

73. Jonsson B, Strom O, Eisman JA, Papaioannou A, Siris ES, Tosteson A, Kanis JA (2010) Cost-effectiveness of denosumab for the treatment of postmenopausal osteoporosis. Osteoporos Int 22: $967-82$

74. Meyer HE, Tverdal A, Falch JA, Pedersen JI (2000) Factors associated with mortality after hip fracture. Osteoporos Int 11:228-232

75. Poor G, Atkinson EJ, O'Fallon WM, Melton LJ, III (1995) Determinants of reduced survival following hip fractures in men. Clin Orthop 260-265

76. Borgstrom F, Carlsson A, Sintonen H, Boonen S, Haentjens P, Burge R, Johnell O, Jonsson B, Kanis JA (2006) The cost-effectiveness of risedronate in the treatment of osteoporosis: an international perspective. Osteoporos Int 17:9961007

77. Borgstrom F, Jonsson B, Strom O, Kanis JA (2006) An economic evaluation of strontium ranelate in the treatment of osteoporosis in a Swedish setting: Based on the results of the SOTI and TROPOS trials. Osteoporos Int 17:17811793

78. NICE (2008) Osteoporosis - secondary prevention including strontium ranelate: Appraisal consultation document. www.nice.org.uk

79. Strom O, Borgstrom F, Sen SS, Boonen S, Haentjens P, Johnell O, Kanis JA (2007) Cost-effectiveness of alendronate in the treatment of postmenopausal women in 9 European countries - an economic evaluation based on the fracture intervention trial. Osteoporos Int 18:10471061

80. Parker MJ, Anand JK (1991) What is the true mortality of hip fractures? Public Health 105:443-446

81. Tosteson AN, Gottlieb DJ, Radley DC, Fisher ES, Melton LJ, III (2007) Excess mortality following hip fracture: the role of underlying health status. Osteoporos Int 18:1463-1472

82. Kanis JA, Oden A, Johnell O, De Laet C, Jonsson B (2004) Excess mortality after hospitalisation for vertebral fracture. Osteoporos Int 15:108-112

83. Kanis JA, Oden A, Johnell O, De Laet C, Jonsson B, Oglesby AK (2003) The components of excess mortality after hip fracture. Bone 32:468-473 


\section{Burden of fractures}

\section{Summary}

The objective of this chapter is to estimate the burden of osteoporosis in terms of QALYs lost and total costs in the countries of the European Union in 2010. Fracture burden is also projected to year 2025 based on expected demographic changes.

\section{Key messages of this chapter are:}

The cost of osteoporosis, including pharmacological intervention in the EU in 2010 was estimated at $€ 37$ billion. Costs of treating incident fractures represented $66 \%$ of this cost, pharmacological prevention $5 \%$ and long-term fracture care $29 \%$.

Excluding cost of pharmacological prevention, hip fractures represented $54 \%$ of the costs, "other fractures" represented $39 \%$, and vertebral and forearm fractures represented $5 \%$ and $1 \%$, respectively.

The estimated number of life-years lost in the EU due to incident fractures was approximately 26,300 in 2010.

The total health burden, measured in terms of lost QALYs, was estimated at 1,180,000 QALYs for the EU. Twice as many $Q A L Y s$ were lost in women compared to men.

The majority of the QALYs lost were a consequence of prior fractures.

Assigning a $Q A L Y$ the value of $2 x G D P$, the total value of QALYs lost in 2010 was estimated at $€ 60.4$ billion.

Due to changes in population demography the number of men and women with osteoporosis, using the diagnostic criterion of the WHO, will rise from 27.5 million in 2010 to 33.9 million in 2025, corresponding to an increase of $23 \%$.

The annual number of fractures will rise from 3.5 million in 2010 to 4.5 million in 2025, corresponding to an increase of $28 \%$.

The number of QALYs lost annually due to fractures will increase from 1.2 million in 2010 to 1.4 million in 2025, corresponding to an increase of $20 \%$.

The total cost including values of $Q A L Y$ s lost (valued at $2 \times$ GDP per capita) in the EU27 will rise from $€ 98$ billion in 2010 to $€ 121$ billion in 2025, corresponding to an increase of $22 \%$.

\subsection{Introduction}

Disease burden is the impact of a health problem measured by mortality, morbidity, financial cost or other measures. In the case of osteoporosis, burden can inter alia be quantified as the number of fractures, the number of people suffering the consequences of a fracture, or life years lost due to fracture. Cost of illness is a measure of burden quantified in monetary terms. Costs are generally classified as direct, indirect and intangible. Direct costs constitute healthcare and non-healthcare costs, indirect costs arise from productivity losses, and intangible costs constitute the monetary value of reduced health $[1,2]$.

Cost of illness studies provide no direct guidance on how resources should be allocated, but may provide relevant information concerning the consequences of a disease that may inform policy. Such studies may aid decisions concerning societal resource allocation for research, development, and funding of new treatments. Results from cost of illness studies can also be utilised to assess the long term consequences and value of medical progress.

The main objective of this chapter is to estimate the current cost of osteoporosis in the countries of the European Union and to estimate the projected cost of osteoporosis in the European Union up to 2025.

\subsection{Methods and materials}

A cost of illness study can take a healthcare payer perspective (includes all costs carried by the health care system) or a societal perspective (includes all cost carried by society). The present study included costs from a societal perspective as far as possible and the costs of osteoporosis were estimated from the cost consequences of incident and prior fractures, costs associated with pharmacological fracture prevention, and a monetary value of QALYs lost. The cost of osteoporosis is presented with and without intangible costs (i.e., the monetary value of QALYs lost).

Costs of fracture-related productivity losses were not included in the study given that they are only incurred in patients below the retirement age-median age 60 years in Europe - and have previously been estimated to be limited in osteoporosis. For example, productivity losses were estimated to account for less than $5 \%$ of the cost of osteoporosis in Australia [3], 2.8\% of the cost of osteoporosis in Austria [4] and less than $1 \%$ of hip fracture cost in Sweden [5]. Omitting costs of productivity loss underestimates the economic burden of fractures. This is especially true for fractures with a higher incidence at younger ages such as forearm fractures.

A model previously used to estimate the cost of osteoporosis in Sweden and the EU5 [6, 7] was adapted to include the countries in the present study. A literature search was performed to identify the best available health utility, epidemiological, and economic data with which to populate the model. The epidemiological data used in the model are described in Chapter 3.

The three most common sites of fragility fracture (hip, vertebral and forearm) were included in the model as well as 
a combination of other fragility fractures (pelvis, rib, humerus, tibia, fibula, clavicle, scapula, sternum, and lower femur).

Once growth has ceased, skeletal mass is relatively constant until the age of 50 years [5], so that the prevalence of osteoporosis-as defined by the WHO diagnostic criterion - and the risk of fractures are low below the age of 50 years $[5,8,9]$. Given the low number of fragility fractures in patients under 50 years and the dearth of cost and health utility implications of fractures in this population, the model was run on a population aged 50 years or above. Whilst it is difficult to assess the impact of the restriction based on the available data, it is likely to be small given the low risk of fragility fractures under the age of 50 years.

\subsubsection{Model design}

The model employs a prevalence-based bottom-up approach [10] that uses the number of cases within a defined period of time multiplied by the corresponding disease-related consequences. Fractures often lead to increased costs and morbidity for several years after the fracture occurs. The consequences related to fracture can therefore be divided into an acute or incident phase and a long-term disability phase. In the acute phase (in this report defined as the first year after fracture), costs are higher and health effects worse than in the following long term phase (defined as the period beyond the first year after fracture). Therefore, the relevant fracture related costs and health effects were captured within a defined time period for both incident fractures (i.e., fractures that occur within the year of analysis) and prior fractures (i.e., fractures that occurred in previous years but still have an impact on costs and quality of life during the study period). The same method was applied by Ström et al., reporting the economic burden of osteoporosis estimation in the EU5 and Sweden [7].

In short, the calculation of the costs and QALYs lost due to osteoporosis in 2010 was performed in the following way: the number of acute fractures was estimated from fracture incidence and population data for each country (described in Chapter 3). Subsequently, country-specific costs and generic health utility multipliers (described below) were assigned to the number of fractures to derive the cost and health utility implications for acute fractures. Given that 1 year costs and health utility implications were applied to all fractures in 2010, the resulting estimates can be interpreted as the one-year burden of incident fractures in 2010. The number of prior fractures in people above the age of 50 years was simulated under the assumption of constant population size and age- and sex distribution, fracture incidence, general population mortality and excess mortality after fractures. Please see Chapter 3 for further details on number of incident and prior fractures. Subsequently, countryspecific costs and generic health utility multipliers (described below) were assigned to the number of prior fractures to derive the cost and health utility implications of those fractures. Further details on the method for calculating the burden of fractures can be found in Ström et al. [7] and Borgström et al. [6].

\subsubsection{Cost of fracture and imputations methods}

First-year costs after fracture were obtained from a literature review where Medline was searched for articles using the keywords "[Country]" and "Fracture" and "Cost". Titles and abstracts identified by the search were screened and potentially relevant articles retrieved in full text. Furthermore, all abstracts presented at the IOF and ECCEO conferences since 2000 were screened for additional data. Where costs of fractures were not available, those were imputed as described below. Table 38 provides a summary of references and imputation methods by fracture type and country.

For hip fractures, cost estimates were available for Belgium [11], Czech Republic [12], Denmark [13, 14], Finland [15], Germany, Italy [16], the Netherlands [17], Slovenia [18], Sweden [19] and the UK, [20, 21]. Where only hospital costs of hip fracture were found (Austria [22], Czech Republic [23], Ireland [24], and Portugal [25]), the ratio between hospital cost and the total direct costs for hip fractures observed in the Swedish KOFOR study was used to obtain estimates of the first-year cost. For countries where fracture costs were not found, the costs were imputed from the nearest country available by adjusting for differences in healthcare price levels between the relevant countries [26]. Following the completion of this report, we were forwarded data on fracture costs from Slovakia [27]. These are used as a sensitivity analysis in the country specific report published in the same issue of Archives in Osteoporosis

For vertebral fractures, studies reporting on costs of treating fractures in both inpatient and outpatient settings were available for Denmark, Germany [28], Slovenia [18], Sweden and the UK [20]. For countries where only hospitalised clinical fractures costs were found, as for countries without cost estimates, the costs were derived via morbidity equivalents as estimated by Kanis et al. [29]. Morbidity equivalents can roughly be described as the morbidity a fracture type confers compared to that of a hip fracture, and costs were assumed to follow the same pattern. This assumption has been shown to be appropriate, at least in a US setting [30].

For forearm fractures, inpatient and outpatient cost estimates were available for Denmark [13], Slovenia [18], Sweden [19] and the UK [21]. For countries where forearm fractures costs were not found, costs were derived via morbidity equivalents as described for vertebral fractures above.

When calculating the Swedish cost of fractures grouped as "other fractures" (pelvis, rib, humerus, tibia, fibula, clavicle, scapula, sternum, and lower femur), it was assumed that lower 
Table 38 Cost of fracture and imputation methods

\begin{tabular}{|c|c|c|c|c|c|c|}
\hline \multirow{2}{*}{$\begin{array}{l}\text { Country } \\
\text { Austria }\end{array}$} & \multicolumn{2}{|c|}{ Hip } & \multicolumn{2}{|c|}{ Vertebral } & \multicolumn{2}{|c|}{ Forearm } \\
\hline & O & [22] & 0 & {$[22]$} & O & {$[22]^{g}$} \\
\hline Belgium & - & [11] & 0 & [11] & 0 & {$[11]^{\mathrm{g}}$} \\
\hline Bulgaria & - & {$[18]^{\mathrm{a}}$} & $\bullet$ & {$[18]^{\mathrm{a}}$} & ○ & {$[18]^{a, g}$} \\
\hline Cyprus & - & {$[16]^{\mathrm{b}}$} & - & {$[16]^{\mathrm{b}}$} & - & {$[16]^{b, g}$} \\
\hline Czech Republic & - & [12] & ○ & [12] & - & {$[12]^{\mathrm{g}}$} \\
\hline Denmark & $\bullet$ & {$[13,14]$} & $\bullet$ & [13] & - & [13] \\
\hline Estonia & - & {$[15]^{c}$} & ○ & {$[15]^{c}$} & - & {$[15]^{c, 8}$} \\
\hline Finland & - & [15] & 0 & [15] & - & {$[15]^{\mathrm{g}}$} \\
\hline France & $\circ$ & {$[20,21]^{\mathrm{d}}$} & - & {$[20,21]^{\mathrm{d}}$} & 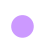 & {$[20,21]^{\mathrm{d}, \mathrm{g}}$} \\
\hline Germany & - & [28] & $\bullet$ & [31] & - & {$[28]^{\mathrm{g}}$} \\
\hline Greece & - & {$[16]^{b}$} & $\bullet$ & {$[16]^{b}$} & - & {$[16]^{b, g}$} \\
\hline Hungary & - & {$[18]^{\mathrm{a}}$} & ○ & {$[18]^{a}$} & - & {$[18]^{\mathrm{a}, \mathrm{g}}$} \\
\hline Ireland & - & [24] & 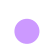 & [24] & ○ & {$[24]^{\mathrm{g}}$} \\
\hline Italy & - & [16] & ○ & [16] & 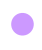 & {$[16]^{\mathrm{g}}$} \\
\hline Latvia & - & {$[15]^{c}$} & $\bullet$ & {$[15]^{c}$} & - & {$[15]^{\mathrm{c}, \mathrm{g}}$} \\
\hline Lithuania & - & {$[15]^{c}$} & ○ & {$[15]^{c}$} & - & {$[15]^{\mathrm{c}, \mathrm{g}}$} \\
\hline Luxembourg & - & {$[11]^{\mathrm{e}}$} & 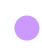 & {$[11]^{\mathrm{e}}$} & ○ & {$[11]^{e, g}$} \\
\hline Malta & - & {$[16]^{b}$} & - & {$[16]^{b}$} & 0 & {$[16]^{b, g}$} \\
\hline Netherlands & - & [17] & 0 & [17] & 0 & {$[17]^{\mathrm{g}}$} \\
\hline Poland & - & {$[12]^{f}$} & ○ & {$[12]^{\dagger}$} & - & {$[12]^{\mathrm{fg}}$} \\
\hline Portugal & - & [25] & 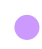 & [25] & - & {$[25]^{\mathrm{g}}$} \\
\hline Romania & ○ & {$[18]^{\mathrm{a}}$} & 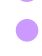 & {$[18]^{\mathrm{a}}$} & - & {$[18]^{a, g}$} \\
\hline Slovakia & - & {$[12]^{f}$} & 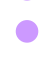 & {$[12]^{f}$} & - & {$[12]^{f, g}$} \\
\hline Slovenia & - & [18] & $\bullet$ & [18] & $\bullet$ & {$[18]^{\mathrm{g}}$} \\
\hline Spain & - & {$[20,21]^{d}$} & ○ & {$[20,21]^{d}$} & - & {$[20,21]^{d, g}$} \\
\hline Sweden & - & [19] & $\bullet$ & [19] & - & {$[19]^{\mathrm{g}}$} \\
\hline UK & 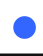 & {$[20,21]$} & - & {$[20,21]$} & - & {$[20,21]^{\mathrm{g}}$} \\
\hline
\end{tabular}

- country specific data

$=$ no country specific data

${ }^{\mathrm{a}}$ Imputed from Slovenian data by adjusting for differences in health care price levels, ${ }^{\mathrm{b}}$ Imputed from Italian data by adjusting for differences in health care price levels, ${ }^{\mathrm{c}}$ Imputed from Finnish data by adjusting for differences in health care price levels, ${ }^{\mathrm{d}}$ Imputed from the UK data by adjusting for differences in health care price levels, ${ }^{\mathrm{e}}$ Imputed from Belgian data by adjusting for differences in health care price levels, ${ }^{\mathrm{f}}$ Imputed from Czech Republic data by adjusting for differences in health care price levels, ${ }^{g}$ Imputed from hip fracture costs via morbidity equivalents as estimated by Kanis et al. [29]

leg and pelvic fractures were equivalent to hip fractures; humerus fractures were assumed to be equivalent to vertebral fractures; and fractures of the rib, clavicle, scapula, and sternum were assumed to be equivalent to forearm fractures [19]. Costs were then adjusted to represent the age distribution of these fractures. For other countries, the costs of "other fractures" were calculated as a share of the first-year hip fracture costs by assuming the same ratio of first-year hip fracture costs and "other fracture" costs observed in Sweden. Swedish costs were stratified by age, and therefore the imputed costs of other fractures also differed by age group.

Acute hip fracture costs in Europe ranged from approximately $€ 2,000$ in Bulgaria (estimated from Slovenian cost using PPP) to about $€ 25,000$ in Denmark. As a consequence of imputation, Bulgaria also had the lowest costs for vertebral fractures (€404), forearm (€112) and other fractures (€929). The lowest cost of hip fracture for a country with an original reference was Slovenia $(€ 5,306)$. The highest costs for vertebral and forearm fractures were found in Sweden at $€ 11,413$ and $€ 2,401$ respectively whereas the highest costs for "other fractures" were found in Denmark $(€ 12,749)$. Where applicable, costs were inflated to 2010 year prices using the consumer price index (CPI) [32]. First year fracture costs for all fracture types are shown in Table 39.

There are currently no published estimates of long-term fracture costs based on empirical patient samples. For the purposes of this report, we conservatively assumed that fractures other than those at the hip did not incur any long-term costs. Hip fracture costs in the second and following years after the event are usually based on the proportion of patients that become institutionalised for the long-term [33, 34]. With increasing age, an increasing proportion of patients transition from independent living to long-term care 1 year after fracture [35]. Patients who at the time of fracture already resided in long- 
Table 39 First year cost of hip, vertebral, forearm and other fractures (€, 2010). References are shown in Table 40

\begin{tabular}{lcccc}
\hline Country & Hip fracture & $\begin{array}{c}\text { Clinical vertebral } \\
\text { fracture }\end{array}$ & Forearm fracture & Other fractures \\
\hline Austria & 13,527 & 2,992 & 827 & 6,841 \\
Belgium & 11,426 & 2,527 & 698 & 5,726 \\
Bulgaria & 1,826 & 404 & 112 & 929 \\
Cyprus & 14,821 & 3,278 & 906 & 7,673 \\
Czech Republic & 5,169 & 1,143 & 316 & 2,588 \\
Denmark & 25,117 & 1,311 & 1,138 & 12,752 \\
Estonia & 5,580 & 1,234 & 341 & 2,885 \\
Finland & 16,066 & 3,554 & 982 & 8,113 \\
France & 12,030 & 2,999 & 1,374 & 8,826 \\
Germany & 19,218 & 5,585 & 1,173 & 9,989 \\
Greece & 12,550 & 2,776 & 767 & 6,624 \\
Hungary & 3,594 & 795 & 220 & 1,805 \\
Ireland & 15,230 & 3,369 & 931 & 7,756 \\
Italy & 19,602 & 4,336 & 1,197 & 10,027 \\
Latvia & 4,522 & 1,000 & 276 & 2,356 \\
Lithuania & 4,810 & 1,064 & 294 & 2,448 \\
Luxembourg & 12,616 & 2,791 & 771 & 6,350 \\
Malta & 9,084 & 2,009 & 555 & 4,810 \\
Netherlands & 10,458 & 2,313 & 639 & 5,289 \\
Poland & 4,881 & 1,080 & 298 & 2,387 \\
Portugal & 12,031 & 2,661 & 735 & 6,315 \\
Romania & 2,168 & 480 & 132 & 1,099 \\
Slovakia & 4,690 & 1,037 & 287 & 2,270 \\
Slovenia & 5,306 & 810 & 161 & 2,662 \\
Spain & 9,421 & 2,349 & 1,076 & 7,112 \\
Sweden & $15,021^{\mathrm{a}}$ & $11,413^{\mathrm{b}}$ & 2,401 & 7,910 \\
UK & 11,055 & 2,756 & 1,263 & $\mathbf{7}, 652$ \\
EU27 & $\mathbf{1 3 , 8 1 6}$ & $\mathbf{3 , 3 8 0}$ & 989 & \\
\hline
\end{tabular}

${ }^{\mathrm{a}}$ Cost ranged with age from $€ 12,870$ to $€ 19,667,{ }^{\mathrm{b}}$ Cost ranged with age from $€ 2,048$ to $€ 14,219$,

term care were assumed not to have any additional long-term fracture related costs and the rates were down-adjusted accordingly. Moreover, the proportion admitted to long-term care 1 year after fracture was also down-adjusted to account for the risk of being admitted due to causes not related to the hip fracture itself. The annual risk of being institutionalised in long-term care in the general population in Sweden is approximately $0.1 \%, 0.5 \%$, and $2 \%$ for $65-$, 75- and 85-year old individuals, respectively [36]. When individuals transitioned from independent living to long-term care, it was assumed that they remained dependent until death. Data on the proportion of patients who transition to nursing home after a hip fracture and on the probability of transition to nursing homes in the general population are scarce, and Swedish data were therefore used for all countries. This is a reasonable proxy for countries in Northern Europe, e.g., Scotland [37], but may be an overestimate for countries in other parts of Europe, where long-term care to a larger extent is provided by informal care givers (e.g., a spouse or child). Informal care is however also associated with societal costs such as productivity losses, lost leisure time, and out-of-pocket expenses. In this report, we assumed that the costs of long-term care of hip fractures are similar irrespective of whether they are incurred by informal or formal care. Swedish risks of transitioning to nursing homes are thus used as a proxy for the risk of being disabled in the long-term after a hip fracture.

The annual hip fracture cost beyond the first year after fracture was obtained by multiplying the yearly cost of residing in a nursing home with the simulated number of prior fractures transferring to nursing homes adjusted for proportions described above. For countries where yearly cost of residing in a nursing home was not found, costs were imputed from the nearest country available by adjusting for differences in healthcare price levels between the relevant countries [36]. Table 40 lists the costs, references and imputation methods by country.

\subsubsection{Costs of pharmacological prevention of fracture}

In addition to the first and subsequent year costs of fracture detailed above, patients with established osteoporosis may be prescribed bone protective treatment. The number of prescribed daily doses per country (2010) for each relevant pharmaceutical intervention (alendronate, risedronate, etidronate, ibandronate, raloxifene, zoledronic acid, strontium ranelate, teriparatide and PTH) were obtained from IMS Health and multiplied by the unit costs for respective drug in each country [52]. In addition to costs for pharmaceuticals, patients on 
Table 40 Annual nursing home costs $(€, 2010)$

\begin{tabular}{lcclcc}
\hline Country & Annual Cost & Reference & Country & Annual Cost & Reference \\
\hline Austria & 33,317 & {$[38]$} & Latvia & 6,169 & {$[39]$} \\
Belgium & 22,608 & {$[40]$} & Lithuania & 10,691 & {$[41]$} \\
Bulgaria & 4,044 & {$[42]$} & Luxembourg & 19,787 & {$[40]^{\mathrm{e}}$} \\
Cyprus & 15,261 & {$[42]^{\mathrm{a}}$} & Malta & 23,265 & {$[16]^{\mathrm{f}}$} \\
Czech Republic & 10,614 & {$[12]$} & Netherlands & 63,685 & {$[43]$} \\
Denmark & 64,831 & {$[44]$} & Poland & 13,242 & {$[45]^{\mathrm{g}}$} \\
Estonia & 10,483 & {$[46]^{\mathrm{b}}$} & Portugal & 54,140 & {$[47]^{\mathrm{h}}$} \\
Finland & 32,930 & {$[46]$} & Romania & 5,756 & {$[48]$} \\
France & 31,512 & {$[21]^{\mathrm{c}}$} & Slovakia & 8,030 & {$[49]$} \\
Germany & 34,534 & {$[45]^{\mathrm{d}}$} & Slovenia & 11,308 & {$[50]$} \\
Greece & 13,271 & {$[42]^{\mathrm{a}}$} & Spain & 51,786 & {$[47]$} \\
Hungary & 5,789 & {$[51]$} & Sweden & 57,247 & {$[14]$} \\
Ireland & 39,073 & {$[21]^{\mathrm{c}}$} & UK & 33,756 & {$[21]$} \\
Italy & 50,202 & {$[16]$} & & & \\
\hline
\end{tabular}

a Approximated by adjusting the Bulgarian cost for health adjusted price levels, ${ }^{\mathrm{b}}$ Approximated by adjusting the Finnish cost for health adjusted price levels, ${ }^{\mathrm{c}}$ Approximated by adjusting the UK cost for health adjusted price levels, ${ }^{\mathrm{d}}$ Average of four nursing home facilities, ${ }^{\mathrm{e}}$ Approximated by adjusting Belgian cost for health adjusted price levels, ${ }^{\mathrm{f}}$ Approximated by adjusting Italian cost for health adjusted price levels, ${ }^{\mathrm{g}}$ Approximated by adjusting the German cost for health adjusted price levels, ${ }^{\mathrm{h}}$ Approximated by adjusting the Spanish cost for health adjusted price levels

therapy were assumed to incur costs for an annual physician visit and a BMD measurement every second year. The cost of DXA was taken from two IOF audits [53] [54]. Furthermore, there may also be other costs related to pharmacological treatment of osteoporosis such as costs for medication to treat side effects. However, those were not included in the analysis.

Costs for first and second line treatment per year (weighted on price and market share in each country) are presented in Table 41 together with unit costs for BMD measurement and physician visits.

\subsubsection{Health utility and QALY implications of fracture}

The health burden of osteoporosis can be measured in terms QALYs lost. The QALY is a multi-dimensional outcome measure frequently employed in health economic analysis that incorporates both the quality (health related) and quantity (length) of life. QALYs are derived by multiplying the duration of life (years) with a health utility between 0 (death) and 1 (perfect health) [96]. For example, a person who lives for 5 years with a health utility of 0.8 would accrue four QALYs during those 5 years.

Health utility can be measured using the EQ-5D instrument, which rates health status grouped by physical, social and mental aspects in five dimensions (mobility, self-care, usual activities, pain/discomfort, and anxiety/depression) with a three level answer for each dimension, resulting in a total of $243\left(3^{5}\right)$ possible EQ-5D health states. Each EQ-5D health state may be converted to health utility by applying a formula that attaches weights to each of the levels in each dimension. This formula is based on the valuations of the health states from general population samples. Whilst a pan-Europe EQ-5D has been developed using a visual analogue scale, preference based valuation sets are preferable in economic studies and these have only been derived for the UK, Denmark, Germany, the Netherlands, Spain and Sweden, with the UK valuation set having been deemed the most robust [97]. Consequently, the preference based UK valuation set and normal population health utility were used for all countries.

Fracture can result in loss of health in all EQ-5D dimensions. Effects on the physical dimensions include factors such as increased pain, loss of mobility and capability of self-care. The perception of social role and impact on activities can also be affected in the social dimension. There is also a mental dimension which can be affected by, for example, depression, anxiety or loss of self-esteem [98]. Consequently, fractures result in reduced health utility and reductions differ substantially among the fracture types, and likely between countries [99]. Hip and vertebral fractures have the greatest impact on health utility whereas forearm fractures are associated with less health utility loss over a shorter period of time; most patients return to their pre-fracture utility after 12 months [99]. The loss of health utility is greatest for all fractures in the first year and decreases in subsequent years [98].

The health utility in the first year after hip, clinical vertebral and forearm fracture relative to the age-specific health utility in the normal population has been estimated at $0.70,0.59$ and 0.96 , respectively [100]. Other fractures were assigned $85 \%$ of the age specific health utility. Age-specific health utilities after fracture were derived by multiplying the health utility of the general population of the relevant age by the health utility multipliers for fracture. For example, a 75 year old man (average health utility of in men aged 75 years is 0.72 ) who sustains a hip fracture has a health utility loss of 0.216 $(=0.72 \times(1-0.70))$ in the first year after fracture, resulting in a loss of 0.216 QALYs $(=1 \times 0.216)$.

The health effects of fractures may extend beyond the first year after fracture. Hip and vertebral fractures have been shown 
Table 41 Unit costs for treatment and management in $(€, 2010)$

\begin{tabular}{|c|c|c|c|c|}
\hline Country & BMD measurement & Physician visit & $\begin{array}{c}\text { Generic } \\
\text { alendronate (р.а.) }\end{array}$ & 2nd line (p.a.) \\
\hline Austria & $30[55]$ & $30[55]$ & $174[56]$ & $257[56]$ \\
\hline Belgium & 34 [57] & $19[57]$ & $123[57]$ & $160[57]$ \\
\hline Bulgaria & $59[53]$ & $2[58]$ & 80 [59] & $179[59]$ \\
\hline Cyprus & $75[53]$ & $14[60]$ & $327[60]$ & $640[60]$ \\
\hline Czech Republic & $32[53]$ & $18^{a}$ & 15 [61] & $359[61]$ \\
\hline Denmark & $187[62]$ & $160[62]$ & $126[63]$ & $1,269[63]$ \\
\hline Estonia & $14[64]$ & 12 [64] & $171[65]$ & $232[65]$ \\
\hline Finland & $146[66]$ & $17[66]$ & $40[66]$ & $205[66]$ \\
\hline France & $41[53]$ & 50 [67] & $209[68]$ & $412[68]$ \\
\hline Germany & $36[53]$ & 38 [69] & $245[70]$ & $619[70]$ \\
\hline Greece & $115[53]$ & $8[71]$ & 239 [72] & $391[72]$ \\
\hline Hungary & $7[73]$ & $43^{b}$ & $43[74]$ & $354[74]$ \\
\hline Ireland & $99[75]$ & $46[76]$ & $240[74]$ & $570[74]$ \\
\hline Italy & $81[53]$ & $50[77]$ & 294 [78] & $619[78]$ \\
\hline Latvia & 18 [79] & 9 [79] & $85[74]$ & $308[74]$ \\
\hline Lithuania & $28[80]$ & $3[80]$ & $146[74]$ & $409[74]$ \\
\hline Luxembourg & $59[81]$ & $30[81]$ & $109[81]$ & $336[81]$ \\
\hline Malta & $184[82]$ & $23^{c}$ & $23[83]$ & $545[83]$ \\
\hline Netherlands & $84[84]$ & $23[84]$ & $4[85]$ & 226 [85] \\
\hline Poland & $10[53]$ & $17[86]$ & 245 [74] & $581[74]$ \\
\hline Portugal & 5 [87] & $3[88]$ & 16 [89] & 313 [89] \\
\hline Romania & $5[90]$ & 26 [90] & 53 [91] & 173 [91] \\
\hline Slovakia & 32 [53] & $16^{d}$ & 16 [74] & 401 [74] \\
\hline Slovenia & $29[50]$ & $15[50]$ & $161[74]$ & 234 [74] \\
\hline Spain & 109 [53] & 79 [14] & 201 [92] & 478 [92] \\
\hline Sweden & 152 [14] & 130 [14] & 27 [93] & 667 [93] \\
\hline UK & $51[21]$ & $50[94]$ & 13 [95] & 226 [95] \\
\hline
\end{tabular}

${ }^{\mathrm{a}}$ Approximated by adjusting Polish cost for health adjusted price levels [26 ${ }^{\mathrm{b}}$ Approximated by adjusting Romanian cost for health adjusted price levels [26], ${ }^{\mathrm{c}}$ Approximated by adjusting Italian cost for health adjusted price levels [26], ${ }^{\mathrm{d}}$ Approximated by adjusting Polish cost for health adjusted price levels [26].

to have long-lasting effects on health and were modelled to reduce health utility to $80 \%$ [100] and $94 \%$ [101] of that of non-fractured individuals beyond the first year after fracture. Conservatively, neither forearm, nor "other fractures" were modelled to have long-term effects on health utility.

Hip and vertebral fractures are also associated with increased mortality and studies suggest that approximately $30 \%$ of the excess mortality observed after fracture may be directly attributable to the fracture event [102-104]. "Other fractures" have also been associated with increased mortality directly attributable to the fracture and were modelled to increase risk of mortality by $12 \%$ [105]. Because deaths attributable to fracture may not occur immediately after the fracture, they do not result in one whole life year lost in the index year (2010). Based on data from the Swedish Inpatient and Cause of Death Registries presented in Borgström et al. [6], we modelled that deaths attributable to fracture occurred 140 days after fracture, resulting in approximately $2 / 3$ life years lost in 2010. QALYs lost to due post-fracture mortality are fewer than life years lost due to post-fracture mortality reflecting that individuals with fracture are not in perfect health. Life years lost resulting from deaths attributable to fractures occurring prior to 2010 were not incorporated into the model.
Similar to the methodology used to estimate costs described above, the estimate of total QALYs lost comprised QALYs lost due to incident fracture (i.e., QALYs lost due to fractures in the index year (2010)) and QALYs lost due to prior fracture (i.e. QALYs lost due fractures incurred prior to the index year, but which resulted in health utility loss in 2010). This prevalence model only account for QALYs lost due to death in the incident year, and thus substantially underestimates QALYs lost compared to an incidence model. The latter should account for all life years lost in the case of fracture compared to no fracture.

\subsubsection{Societal value of QALYS}

The value of a QALY may differ between and within countries due to a number of factors including degree of prosperity, cultural attitudes and the opportunity costs of resources devoted to obtain a marginal QALY [106].

There are two methods to elicit the value of a QALY: stated preferences and implicit valuation. In the stated preference approach, people are directly asked for their preferences whereas in implicit valuation preferences are elicited from actual choices, e.g., the premium wage a job with an increased risk of mortality or morbidity commands [106]. 
Valuing health as a function of GDP allows for variations in ability to pay for health between countries and the WHO Commission on Macroeconomics and Health has suggested that one averted DALY can be valued at three times GDP per capita [107]. This criterion has been used in health economics studies. For example, Murray et al. [108] classified treatments based on the cost per healthy life year gained as very cost-effective at $\leq 1 \times$ GDP per capita and as cost-effective at $\leq 3 \times$ GDP per capita. Whereas DALYs and QALYs are conceptually similar, they are based on different methodologies and are therefore not directly comparable [109]. However, a comparison of available estimates for different disease areas for the two outcome measures does not suggest a substantial difference in terms of GDP per capita valuation [106-108]. Consequently, we followed the approach of Borgström et al. [6] and Strom et al. [7] and set the value of a QALY at $2 \times$ GDP per capita.

\subsection{Results}

\subsubsection{Costs of osteoporosis excluding values of QALYs lost}

Several factors affect the cost of osteoporosis excluding the value of QALYs lost in a country, including age specific fracture risks, population size, age and sex distribution, fracture-related costs and the cost of pharmacological intervention. Three cost components are included in the model: cost first year after fracture, cost subsequent years after fracture, and cost of pharmacological fracture prevention including administration and monitoring costs.

The cost of osteoporosis, excluding value of QALYs lost in the EU27, amounted to $€ 37.4$ billion in 2010. First year, subsequent year, and pharmacological costs accounted for $66 \%, 29 \%$ and $6 \%$ of the costs, respectively. Whilst the proportion of costs for pharmacological prevention to total costs was low on average, some inter-country variation was observed: the lowest proportion of costs attributable to pharmacological intervention was observed in Sweden $(2 \%)$ and the highest costs in Cyprus (22\%). The high cost share in Cyprus might be explained by Cyprus having the highest number of doses of anti-osteoporosis drugs sold per person. In addition, the highest price of alendronate in the EU27 was observed in Cyprus. The cost of osteoporosis stratified by the three cost categories for each EU27 country in 2010 is presented in Table 42 below.

Hip fractures were estimated to account for $54 \%$ of the total costs, other fractures $39 \%$, vertebral fractures $5 \%$, and forearm fractures $2 \%$ (Fig. 27). The estimate

Table 42 Cost of osteoporosis (excluding value of QALYs lost) in EU27 in 2010 ( $€$ million, 2010)

\begin{tabular}{|c|c|c|c|c|}
\hline Country & $\begin{array}{c}\text { Pharmacological } \\
\text { fracture prevention }\end{array}$ & $\begin{array}{c}\text { Cost of incident } \\
\text { fractures }\end{array}$ & $\begin{array}{c}\text { Cost of long-term } \\
\text { disability }\end{array}$ & Total \\
\hline Austria & 30 & 540 & 229 & 799 \\
\hline Belgium & 29 & 419 & 157 & 606 \\
\hline Bulgaria & 1 & 30 & 11 & 42 \\
\hline Cyprus & 12 & 34 & 7 & 52 \\
\hline Czech Republic & 53 & 165 & 56 & 273 \\
\hline Denmark & 37 & 718 & 300 & 1,055 \\
\hline Estonia & 1 & 22 & 7 & 30 \\
\hline Finland & 10 & 269 & 104 & 383 \\
\hline France & 346 & 3,179 & 1,329 & 4,853 \\
\hline Germany & 336 & 6,617 & 2,055 & 9,008 \\
\hline Greece & 91 & 488 & 102 & 680 \\
\hline Hungary & 40 & 127 & 30 & 197 \\
\hline Ireland & 35 & 125 & 62 & 223 \\
\hline Italy & 361 & 4,269 & 2,402 & 7,032 \\
\hline Latvia & 2 & 29 & 7 & 38 \\
\hline Lithuania & 3 & 32 & 12 & 47 \\
\hline Luxembourg & 2 & 15 & 4 & 22 \\
\hline Malta & 2 & 11 & 4 & 17 \\
\hline Netherlands & 29 & 360 & 434 & 824 \\
\hline Poland & 76 & 355 & 162 & 593 \\
\hline Portugal & 20 & 293 & 264 & 577 \\
\hline Romania & 7 & 88 & 35 & 129 \\
\hline Slovakia & 11 & 76 & 19 & 107 \\
\hline Slovenia & 7 & 36 & 13 & 56 \\
\hline Spain & 414 & 1,372 & 1,055 & 2,842 \\
\hline Sweden & 29 & 927 & 529 & 1,486 \\
\hline UK & 103 & 3,977 & 1,328 & 5,408 \\
\hline EU27 & 2,087 & 24,574 & 10,718 & 37,378 \\
\hline
\end{tabular}




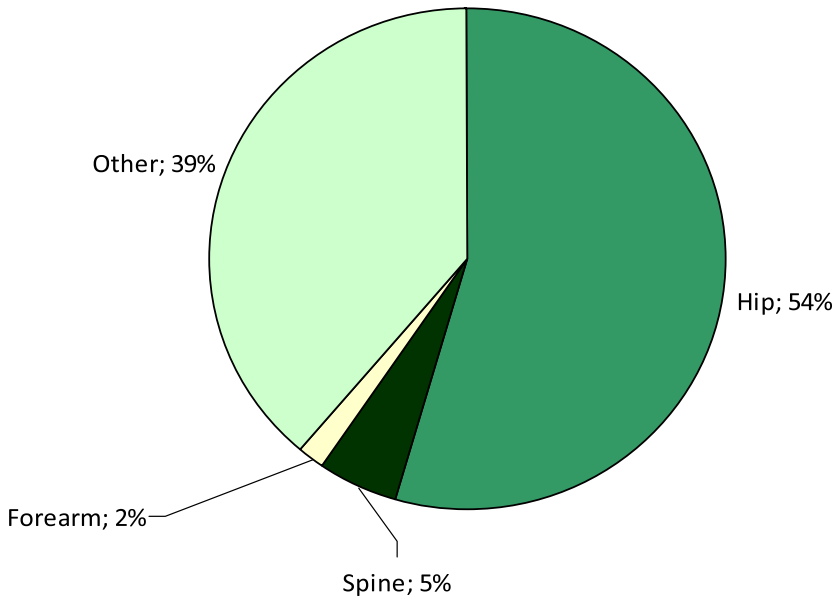

Fig. 27 Share (\%) of 2010 cost of osteoporosis in EU27 (excluding value of QALYs lost and cost of pharmacological intervention) by fracture site

of $39 \%$ for other fractures may be perceived as a high figure given that most health economic evaluations of fracture prevention mainly focus on hip and vertebral fractures [14, 110-112]. However, such studies usually evaluate treatment in elderly women where the risks of hip and vertebral fractures are greater than that of the risk of "other fractures". By contrast, the current study captured all fractures in all patients aged 50 years or more. Note that costs attributable to fractures in Fig. 27 do not incorporate costs of pharmaceutical intervention.

The highest costs were incurred by fractures occurring in individuals aged $80-89$ years. Hip and "other" fracture costs peaked in this age group, while costs for forearm and vertebral fractures peaked in individuals aged 70-79 years. Fracture costs by site and age are given in Table 43.

The total costs for osteoporosis (excluding the value of QALYs lost) were compared to total healthcare spending in the respective country (Table 44). Healthcare spending varied markedly between countries, ranging from $€ 500$ million in Malta to $€ 281$ billion in Germany. The total spend on healthcare in the European Union amounted to $€ 1,260$ billion, with the cost of osteoporotic fractures representing $3 \%$. The share varied across countries, and the extremes were represented by Cyprus where fracture burden represented approximately $5 \%$ of the total healthcare spending and Luxembourg where the corresponding number was approximately $1 \%$. It should be noted; however, that not all fracture related costs come from the healthcare budgets of the countries (e.g., long-term care).

The cost of osteoporosis per capita, shown in Table 45 is in part related to the incidence of fracture $(r=0.67, p=0.001)$ and the healthcare spend per capita $(r=0.63, p=0.004)$. Denmark has the highest cost of osteoporosis per capita with $€ 190$ per year, whereas Romania and Bulgaria had the lowest cost per capita at approximately $€ 6$ per year.

\subsubsection{Life-years lost due to fracture}

As mentioned, hip, vertebral, and other fractures are associated with increased mortality and approximately $30 \%$ of the excess mortality may be attributable directly to the fracture with each death resulting in approximately $2 / 3$ life years lost.

The total number of deaths after fracture in the EU27 in 2010 was estimated at about 143,000 , with 43,000 $(30 \%)$ directly attributable to the fracture, resulting in 26,000 life years lost (i.e., 2/3 of the 43,000 attributable deaths). The number of deaths after fracture, deaths directly attributable to fracture, and resulting life years lost are shown in Table 45.

\subsubsection{QALYs lost due to osteoporosis}

QALYs lost due to osteoporosis incorporate both the HRQoL and life years lost due to fracture (downwards adjusted to reflect the average health utility at the age in which the death attributable to fracture occurred). The number of QALYs lost in 2010 was derived by applying the health utility weights for incident and prior fractures to the number of incident and prior fractures. Thereafter, the health utility weighted life years lost were added.

Approximately 1,165,000 QALYs were lost due to osteoporosis in the EU27 in 2010. Women and men suffered approximately 781,000 and 384,000 QALYs lost,

Table 43 Cost of osteoporosis (excluding value of QALYs lost and costs of pharmacological intervention) in EU27 by fracture site and age ( $€$ million, 2010)

\begin{tabular}{lccccc}
\hline Age & Hip fractures & $\begin{array}{l}\text { Vertebral } \\
\text { fractures }\end{array}$ & $\begin{array}{c}\text { Forearm } \\
\text { fractures }\end{array}$ & Other fractures & Total \\
\hline $50-59$ years & 556 & 197 & 118 & 1,122 & 1,993 \\
60-69 years & 1,551 & 324 & 138 & 2,255 & 4,268 \\
70-79 years & 4,350 & 584 & 148 & 3,833 & 8,916 \\
80-89 years & 9,248 & 510 & 123 & 5,055 & 14,935 \\
90+ years & 3,515 & 130 & 28 & 1,507 & 5,180 \\
All ages & $\mathbf{1 9 , 2 1 9}$ & $\mathbf{1 , 7 4 5}$ & $\mathbf{5 5 4}$ & $\mathbf{1 3 , 7 7 3}$ & $\mathbf{3 5 , 2 9 2}$ \\
\hline
\end{tabular}


Table 44 Cost of osteoporosis in relation to population and healthcare spending (2010)

\begin{tabular}{|c|c|c|c|c|c|c|}
\hline Country & $\begin{array}{l}\text { Population } \\
\text { (thousands) }\end{array}$ & $\begin{array}{l}\text { Healthcare } \\
\text { spending } \\
\text { (million€) }\end{array}$ & $\begin{array}{l}\text { Healthcare } \\
\text { spending/ } \\
\text { capita } \\
\text { (€/capita) } \\
\end{array}$ & $\begin{array}{c}\text { Fracture cost } \\
\text { as } \% \\
\text { healthcare } \\
\text { spending } \\
\end{array}$ & $\begin{array}{l}\text { Fracture cost } \\
\text { per capita }(€)\end{array}$ & $\begin{array}{c}\text { Fracture cost } \\
\text { (million€) }\end{array}$ \\
\hline Austria & 8,392 & 31,000 & 3,741 & 2.5 & 95 & 799 \\
\hline Belgium & 10,712 & 42,000 & 3,903 & 1.4 & 57 & 606 \\
\hline Bulgaria & 7,493 & 2,700 & 354 & 1.6 & 6 & 42 \\
\hline Cyprus & 1,103 & 1,000 & 937 & 5.0 & 47 & 52 \\
\hline Czech Republic & 10,493 & 11,000 & 1,087 & 2.4 & 26 & 273 \\
\hline Denmark & 5,551 & 26,000 & 4,759 & 4.0 & 190 & 1,055 \\
\hline Estonia & 1,339 & 1,000 & 747 & 3.0 & 22 & 30 \\
\hline Finland & 5,365 & 18,000 & 3,263 & 2.2 & 71 & 383 \\
\hline France & 62,634 & 227,000 & 3,617 & 2.1 & 77 & 4,853 \\
\hline Germany & 82,056 & 281,000 & 3,418 & 3.2 & 110 & 9,008 \\
\hline Greece & 11,358 & 24,000 & 2,126 & 2.8 & 60 & 680 \\
\hline Hungary & 9,985 & 7,000 & 709 & 2.8 & 20 & 197 \\
\hline Ireland & 4,470 & 15,000 & 3,399 & 1.5 & 50 & 223 \\
\hline Italy & 60,098 & 148,000 & 2,461 & 4.8 & 117 & 7,032 \\
\hline Latvia & 2,252 & 1,000 & 520 & 3.2 & 17 & 38 \\
\hline Lithuania & 3,325 & 2,000 & 546 & 2.6 & 14 & 47 \\
\hline Luxembourg & 506 & 3,000 & 6,235 & 0.7 & 43 & 22 \\
\hline Malta & 416 & 500 & 1,108 & 3.7 & 41 & 17 \\
\hline the Netherlands & 16,610 & 64,000 & 3,829 & 1.3 & 50 & 824 \\
\hline Poland & 38,276 & 25,000 & 660 & 2.3 & 16 & 593 \\
\hline Portugal & 10,676 & 19,000 & 1,826 & 3.0 & 54 & 577 \\
\hline Romania & 21,486 & 7,000 & 309 & 2.0 & 6 & 129 \\
\hline Slovakia & 5,463 & 3,000 & 1,092 & 3.6 & 20 & 107 \\
\hline Slovenia & 2,028 & 6,000 & 1,485 & 0.9 & 28 & 56 \\
\hline Spain & 45,317 & 102,000 & 2,247 & 2.8 & 63 & 2,842 \\
\hline Sweden & 9,294 & 34,000 & 3,709 & 4.3 & 160 & 1,486 \\
\hline the UK & 61,899 & 159,000 & 2,564 & 3.4 & 87 & 5,408 \\
\hline EU27 & 498,597 & $1,260,000$ & 2,528 & 3.0 & 75 & 37,378 \\
\hline
\end{tabular}

respectively. Prior fractures were the main driver of QALYs lost, accounting for approximately $58 \%$ and $50 \%$ of the loss in women and men respectively. The higher proportion of QALYs lost due to prior fractures in women than in men reflects higher absolute mortality after fracture in men, a

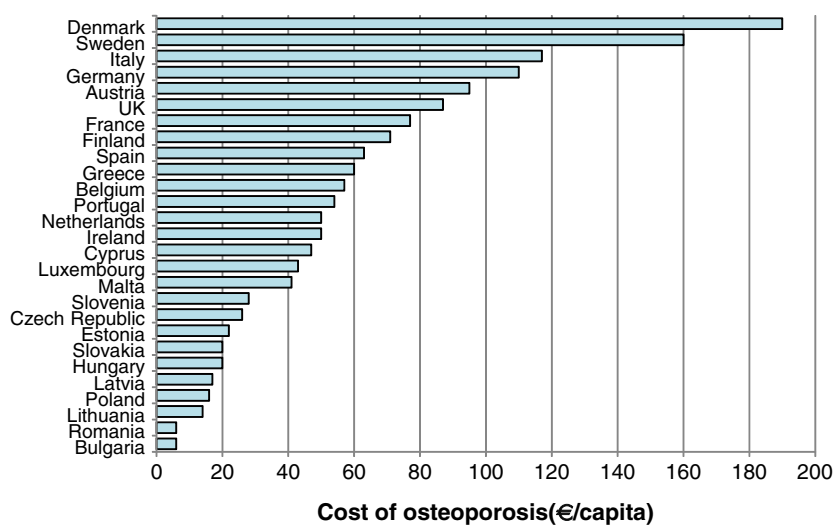

Fig. 28 Estimated cost of osteporosis (excluding values of QALYs lost) per capita $(€, 2010)$ pattern also observed in the number of prior fractures described in Chapter 3. Germany was the individual country where most QALYs were lost in both men and women, followed by Italy for women and the UK for men. The number of QALYs lost due to incident (including QALYs lost due to deaths directly attributable to fracture) and prior fractures for women and men in each of the EU27 countries is shown in Table 46.

Hip fractures, vertebral, forearm and "other fractures" incurred approximately 600,000, 344,000, 19,000, and 202,000 QALYs lost, respectively. For hip and vertebral fractures, approximately $79 \%$ and $59 \%$ of the QALYs lost were incurred by prior fractures. Given that no long-term health utility loss was assumed for forearm and other fracture, all QALYs lost for these fracture types resulted from incident fractures. The greatest number of QALYs lost in the EU27 in 2010 was incurred in people aged 80 to 90 years with 426,000 QALYS lost representing $37 \%$ of the total. In this group, the fracture type incurring highest number of QALYs lost was prior hip fractures. The number of QALYs lost stratified by age and fracture type is presented in Table 47. 
Table 45 Estimated number of deaths after fracture, deaths attributable to fracture, and life years lost due to attributable deaths in men and women and (2010)

\begin{tabular}{|c|c|c|c|c|c|c|c|c|c|}
\hline \multirow[t]{2}{*}{ Country } & \multicolumn{3}{|c|}{ Deaths after fracture } & \multicolumn{3}{|c|}{$\begin{array}{c}\text { Deaths directly attributable to } \\
\text { fracture }\end{array}$} & \multicolumn{3}{|c|}{ Life-years lost due to fracture } \\
\hline & Men & Women & Total & Men & Women & Total & Men & Women & Total \\
\hline Austria & 1,523 & 1,871 & 3,393 & 457 & 561 & 1,018 & 282 & 346 & 628 \\
\hline Belgium & 1,590 & 1,673 & 3,263 & 477 & 502 & 979 & 294 & 309 & 603 \\
\hline Bulgaria & 1,151 & 1,006 & 2,157 & 345 & 302 & 647 & 213 & 186 & 399 \\
\hline Cyprus & 96 & 82 & 178 & 29 & 25 & 53 & 18 & 15 & 33 \\
\hline Czech Republic & 1,725 & 1,723 & 3,448 & 518 & 517 & 1,034 & 319 & 319 & 638 \\
\hline Denmark & 1,416 & 1,513 & 2,930 & 425 & 454 & 879 & 262 & 280 & 542 \\
\hline Estonia & 205 & 240 & 445 & 62 & 72 & 134 & 38 & 44 & 82 \\
\hline Finland & 755 & 662 & 1,417 & 226 & 199 & 425 & 140 & 122 & 262 \\
\hline France & 6,853 & 7,258 & 14,111 & 2,056 & 2,178 & 4,233 & 1,267 & 1,342 & 2,610 \\
\hline Germany & 12,642 & 16,614 & 29,256 & 3,793 & 4,984 & 8,777 & 2,338 & 3,072 & 5,410 \\
\hline Greece & 1,749 & 2,013 & 3,761 & 525 & 604 & 1,128 & 323 & 372 & 696 \\
\hline Hungary & 2,023 & 2,113 & 4,136 & 607 & 634 & 1,241 & 374 & 391 & 765 \\
\hline Ireland & 327 & 371 & 698 & 98 & 111 & 209 & 61 & 69 & 129 \\
\hline Italy & 8,522 & 9,731 & 18,253 & 2,557 & 2,919 & 5,476 & 1,576 & 1,800 & 3,376 \\
\hline Latvia & 356 & 446 & 802 & 107 & 134 & 241 & 66 & 83 & 148 \\
\hline Lithuania & 387 & 427 & 815 & 116 & 128 & 244 & 72 & 79 & 151 \\
\hline Luxembourg & 41 & 52 & 93 & 12 & 16 & 28 & 8 & 10 & 17 \\
\hline Malta & 43 & 56 & 99 & 13 & 17 & 30 & 8 & 10 & 18 \\
\hline Netherlands & 1,452 & 1,449 & 2,902 & 436 & 435 & 870 & 269 & 268 & 537 \\
\hline Poland & 3,964 & 3,845 & 7,809 & 1,189 & 1,154 & 2,343 & 733 & 711 & 1,444 \\
\hline Portugal & 989 & 1,226 & 2,215 & 297 & 368 & 665 & 183 & 227 & 410 \\
\hline Romania & 2,866 & 2,497 & 5,363 & 860 & 749 & 1,609 & 530 & 462 & 992 \\
\hline Slovakia & 1,021 & 891 & 1,912 & 306 & 267 & 574 & 189 & 165 & 354 \\
\hline Slovenia & 295 & 347 & 641 & 88 & 104 & 192 & 54 & 64 & 119 \\
\hline Spain & 3,985 & 4,515 & 8,500 & 1,196 & 1,354 & 2,550 & 737 & 835 & 1,572 \\
\hline Sweden & 1,799 & 2,105 & 3,904 & 540 & 631 & 1,171 & 333 & 389 & 722 \\
\hline UK & 9,235 & 10,962 & 20,197 & 2,770 & 3,289 & 6,059 & 1,708 & 2,027 & 3,735 \\
\hline EU27 & 67,010 & 75,687 & 142,697 & 20,103 & 22,706 & 42,809 & 12,392 & 13,997 & 26,389 \\
\hline
\end{tabular}

QALYs lost from fracture related deaths were included in the estimate for incident fractures, reflecting that increased mortality is accounted for within the first year after fracture. These deaths amounted to approximately 26,000 life-years lost which corresponded to a loss of about 13,000 QALYs, representing approximately $2.5 \%$ of the QALYs lost due to incident fractures and $1 \%$ of all QALYs lost.

Even though common, forearm fractures only represented a marginal share $(1 \%)$ of the estimated fracture-related QALYs lost. The negligible impact of forearm fracture on QALYs lost in the total population is due to its relatively small impact on health utility during the first year after fracture, no associated mortality and the complete longterm recuperation after fracture assumed in the model. The proportion of QALYs lost by incident and prior fracture are shown in Fig. 29.

\subsubsection{Value of QALYs lost due to osteoporosis}

Valuing a QALY at $2 \times \mathrm{GDP} /$ capita resulted in a value of QALYs lost due to osteoporotic fractures in 2010 of $€ 60$ billion. Country specific estimates of value of QALYs lost ranged from $€ 24$ million in Malta to $€ 15$ billion in Germany (Table 48).

Valuing a QALY at $2 \times \mathrm{GDP} /$ capita resulted in an estimated cost of $€ 121$ for QALYs lost per capita in the EU27 in 2010. Country specific estimates ranged from $€ 16$ in Romania and Bulgaria to $€ 307$ in Denmark (Fig. 30).

\subsubsection{Cost of osteoporosis including value of QALYS lost}

When the cost of osteoporosis was combined with the value for QALYs lost, valued at $2 \times$ GDP, the cost of osteoporosis amounted to $€ 98$ billion in the EU27 in 2010 . The cost ranged from $€ 41$ million in Malta to $€ 24$ billion in Germany.

QALYs lost accounted for $62 \%$ of the total cost of osteoporosis including values of QALYs lost in the EU27 in 2010, ranging from $50 \%$ in Portugal to $87 \%$ in Luxembourg. Incident fractures, prior fractures and pharmacological intervention accounted for $25 \%, 11 \%$ and $2 \%$, respectively, of the cost of osteoporosis including values of QALYs lost. The cost 
Table 46 Estimated number of QALYs lost due to fractures (2010)

\begin{tabular}{|c|c|c|c|c|c|c|c|c|c|}
\hline \multirow[b]{2}{*}{ Country } & \multicolumn{3}{|c|}{ Men } & \multicolumn{3}{|c|}{ Women } & \multicolumn{3}{|c|}{ Total } \\
\hline & $\begin{array}{l}\text { Incident } \\
\text { fracture }\end{array}$ & $\begin{array}{c}\text { Prior } \\
\text { fracture }\end{array}$ & Total & $\begin{array}{l}\text { Incident } \\
\text { fracture }\end{array}$ & $\begin{array}{l}\text { Prior } \\
\text { fracture }\end{array}$ & Total & $\begin{array}{l}\text { Incident } \\
\text { fracture }\end{array}$ & $\begin{array}{c}\text { Prior } \\
\text { fracture }\end{array}$ & Total \\
\hline Austria & 4,767 & 4,674 & 9,441 & 8,230 & 10,226 & 18,456 & 12,997 & 14,900 & 27,897 \\
\hline Belgium & 4,487 & 4,405 & 8,892 & 7,535 & 10,337 & 17,872 & 12,022 & 14,741 & 26,763 \\
\hline Bulgaria & 2,734 & 2,381 & 5,115 & 3,219 & 3,978 & 7,197 & 5,954 & 6,358 & 12,312 \\
\hline Cyprus & 323 & 337 & 660 & 438 & 705 & 1,143 & 761 & 1,042 & 1,803 \\
\hline Czech Republic & 4,605 & 3,900 & 8,505 & 6,317 & 8,008 & 14,324 & 10,922 & 11,907 & 22,829 \\
\hline Denmark & 3,978 & 3,452 & 7,430 & 6,060 & 6,699 & 12,758 & 10,038 & 10,150 & 20,188 \\
\hline Estonia & 447 & 340 & 787 & 889 & 1,098 & 1,987 & 1,336 & 1,438 & 2,774 \\
\hline Finland & 2,352 & 2,317 & 4,669 & 3,176 & 4,486 & 7,661 & 5,528 & 6,803 & 12,330 \\
\hline France & 19,653 & 22,650 & 42,303 & 36,558 & 60,557 & 97,115 & 56,210 & 83,208 & 139,418 \\
\hline Germany & 39,154 & 39,310 & 78,464 & 70,667 & 97,196 & 167,864 & 109,821 & 136,506 & 246,327 \\
\hline Greece & 5,017 & 5,440 & 10,457 & 7,937 & 12,558 & 20,495 & 12,954 & 17,998 & 30,952 \\
\hline Hungary & 4,572 & 3,087 & 7,659 & 7,758 & 8,250 & 16,008 & 12,330 & 11,337 & 23,667 \\
\hline Ireland & 986 & 945 & 1,931 & 1,697 & 2,469 & 4,167 & 2,683 & 3,414 & 6,097 \\
\hline Italy & 23,512 & 28,099 & 51,611 & 46,792 & 72,900 & 119,692 & 70,303 & 100,999 & 171,303 \\
\hline Latvia & 726 & 501 & 1,227 & 1,477 & 1,794 & 3,271 & 2,203 & 2,295 & 4,498 \\
\hline Lithuania & 828 & 638 & 1,466 & 1,490 & 1,916 & 3,405 & 2,318 & 2,554 & 4,872 \\
\hline Luxembourg & 149 & 147 & 296 & 254 & 350 & 604 & 402 & 498 & 900 \\
\hline Malta & 137 & 105 & 242 & 264 & 302 & 566 & 401 & 407 & 808 \\
\hline Netherlands & 4,414 & 4,416 & 8,830 & 6,992 & 10,490 & 17,482 & 11,407 & 14,905 & 26,312 \\
\hline Poland & 10,507 & 8,644 & 19,150 & 15,029 & 19,092 & 34,121 & 25,536 & 27,736 & 53,272 \\
\hline Portugal & 2,577 & 2,537 & 5,114 & 5,207 & 7,594 & 12,802 & 7,785 & 10,131 & 17,915 \\
\hline Romania & 6,740 & 5,638 & 12,378 & 7,937 & 9,406 & 17,343 & 14,677 & 15,044 & 29,721 \\
\hline Slovakia & 2,668 & 2,032 & 4,700 & 3,214 & 3,799 & 7,012 & 5,881 & 5,831 & 11,712 \\
\hline Slovenia & 893 & 745 & 1,638 & 1,439 & 1,780 & 3,220 & 2,332 & 2,526 & 4,858 \\
\hline Spain & 10,594 & 11,139 & 21,733 & 19,836 & 29,237 & 49,073 & 30,430 & 40,376 & 70,806 \\
\hline Sweden & 5,966 & 6,885 & 12,851 & 10,203 & 12,971 & 23,174 & 16,169 & 19,856 & 36,025 \\
\hline UK & 29,717 & 26,824 & 56,541 & 46,961 & 55,224 & 102,185 & 76,678 & 82,048 & 158,726 \\
\hline EU27 & 192,503 & 191,587 & 384,090 & 327,575 & 453,422 & 780,997 & 520,078 & 645,009 & $1,165,087$ \\
\hline
\end{tabular}

of osteoporosis including the value of QALYs lost and the proportion attributable to the different cost categories are presented in Table 49.

\subsubsection{Cost of osteoporosis compared to other diseases}

The estimated cost of osteoporosis may be compared to the cost of other diseases. However, given that the EU27 is a relatively new construct, few directly comparable studies exist. Furthermore, methodological differences may render studies difficult to compare. However, a few studies conducted on a similar geographic area with comparable methodology exist.
In a report issued by the European Brain Council, the yearly societal costs for a number of brain disorders in the EU27 were estimated at $€ 105$ billion for dementia, $€ 43.5$ billion for headache, $€ 14.6$ billion for multiple sclerosis, and $€ 13.9$ billion for Parkinson's disease [14, 111-113].

The cost of coronary heart disease and cerebrovascular disease in the European Union (25 countries) has been estimated at approximately $€ 45$ billion and $€ 34$ billion, respectively, at 2003 prices [114]. For coronary heart disease, healthcare costs, productivity losses, and informal care comprised $51 \%, 34 \%$ and $15 \%$, respectively. Costs for pharmacological treatment accounted for $12 \%$ of the total

Table 47 Number of QALYs lost due to fractures at different sites in respective age group in EU27 (2010)

\begin{tabular}{lcccccc}
\hline & \multicolumn{7}{c}{ Age (years) } \\
\cline { 2 - 7 } & $50-59$ & $60-69$ & $70-79$ & $80-89$ & $90+$ & All ages \\
\cline { 2 - 6 } Incident hip fractures & 7,675 & 14,797 & 36,663 & 60,566 & 17,481 & 137,182 \\
Incident vertebral fractures & 23,031 & 32,906 & 51,761 & 43,511 & 10,911 & 162,120 \\
Incident forearm fractures & 4,580 & 4,936 & 4,916 & 3,607 & 691 & 18,730 \\
Incident "other" fractures & 32,544 & 37,073 & 49,370 & 64,077 & 18,981 & 202,045 \\
Prior hip fractures & 15,969 & 57,002 & 127,881 & 197,050 & 65,176 & 463,078 \\
Prior vertebral fractures & 12,721 & 36,328 & 59,968 & 57,419 & 15,496 & 181,931 \\
All & $\mathbf{9 6 , 5 2 0}$ & $\mathbf{1 8 3 , 0 4 3}$ & $\mathbf{3 3 0 , 5 5 9}$ & $\mathbf{4 2 6 , 2 3 0}$ & $\mathbf{1 2 8 , 7 3 5}$ & $\mathbf{1 , 1 6 5 , 0 8 7}$ \\
\hline
\end{tabular}




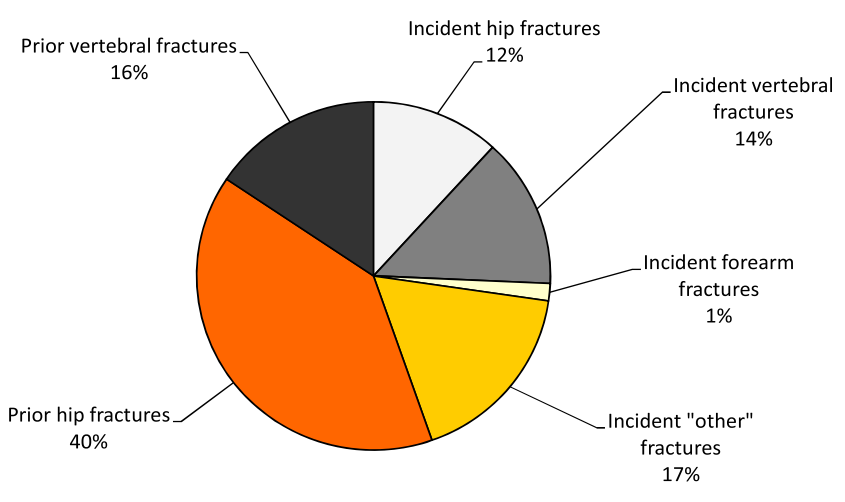

Fig. 29 Proportion of QALYs lost by incident and prior fracture in the EU27 2010

costs, substantially higher than for osteoporosis. For cerebrovascular disease, healthcare costs, productivity losses, and informal care comprised $61 \%, 18 \%$ and $21 \%$ respectively. Costs for pharmacological treatment accounted for $3 \%$ of the total costs for cerebrovascular disease [114], somewhat lower than for osteoporosis.

The cost of epilepsy in the European Union (25 countries) has been estimated at $€ 15.5$ billion at 2004 prices.
Healthcare costs comprised $18 \%$ of costs, whereas direct medical costs and productivity losses represented $27 \%$ and $55 \%$, respectively [115].

Thus, in relation to other common non-communicable diseases osteoporosis has major economic consequences for society.

Osteoporosis shares some features of dementia, in that it is a disease of the elderly population and is expected to take an increasing share of healthcare spending when taking into account the demographic changes expected with an ageing population [116]. However, while large amounts of money are being spent on research and development of new drugs to treat dementia, there has been small or little success in introducing new drugs to the market [117]. The availability of affordable and efficient pharmacological treatment, as well as non-pharmacological fracture risk prevention, provides an opportunity to take immediate action to reduce the future number of osteoporotic fractures

\subsection{Burden of osteoporosis up to 2025}

Osteoporosis is a disease primarily affecting the elderly; the prevalence of osteoporosis as judged by BMD criteria

Table 48 Value of QALYs lost due to osteoporotic fractures (valued at 2×2010 GDP/capita per QALY; million $€$ )

\begin{tabular}{|c|c|c|c|c|c|c|}
\hline Country & $\mathrm{GDP}(€ \mathrm{~m})$ & $\begin{array}{c}\text { Population } \\
(1,000)\end{array}$ & $\begin{array}{l}\text { 2xGDP per } \\
\text { capita }\end{array}$ & QALYs lost & $\begin{array}{c}\text { Value of } \\
\text { QALYs lost } \\
(€ \mathrm{~m})\end{array}$ & $\begin{array}{c}€ \text { lost per } \\
\text { capita }\end{array}$ \\
\hline Austria & 286,197 & 8,392 & 68,200 & 27,897 & 1,903 & 227 \\
\hline Belgium & 354,378 & 10,712 & 64,800 & 26,763 & 1,734 & 162 \\
\hline Bulgaria & 36,034 & 7,493 & 9,600 & 12,312 & 118 & 16 \\
\hline Cyprus & 17,334 & 1,103 & 43,400 & 1,803 & 78 & 71 \\
\hline Czech Republic & 149,313 & 10,493 & 27,600 & 22,829 & 630 & 60 \\
\hline Denmark & 235,609 & 5,551 & 84,400 & 20,188 & 1,704 & 307 \\
\hline Estonia & 14,305 & 1,339 & 21,400 & 2,774 & 59 & 44 \\
\hline Finland & 180,253 & 5,365 & 67,200 & 12,330 & 829 & 154 \\
\hline France & $1,932,802$ & 62,634 & 59,600 & 139,418 & 8,309 & 133 \\
\hline Germany & $2,476,800$ & 82,056 & 60,600 & 246,327 & 14,927 & 182 \\
\hline Greece & 227,318 & 11,358 & 40,800 & 30,952 & 1,263 & 111 \\
\hline Hungary & 97,095 & 9,985 & 19,600 & 23,667 & 464 & 46 \\
\hline Ireland & 155,992 & 4,470 & 69,800 & 6,097 & 426 & 95 \\
\hline Italy & $1,556,029$ & 60,098 & 51,200 & 171,303 & 8,771 & 146 \\
\hline Latvia & 17,975 & 2,252 & 16,000 & 4,498 & 72 & 32 \\
\hline Lithuania & 27,535 & 3,325 & 16,600 & 4,872 & 81 & 24 \\
\hline Luxembourg & 40,267 & 506 & 164,200 & 900 & 148 & 292 \\
\hline Malta & 6,164 & 416 & 29,600 & 808 & 24 & 57 \\
\hline Netherlands & 588,414 & 16,610 & 70,800 & 26,312 & 1,863 & 112 \\
\hline Poland & 354,310 & 38,276 & 18,600 & 53,272 & 991 & 26 \\
\hline Portugal & 172,799 & 10,676 & 32,400 & 17,915 & 580 & 54 \\
\hline Romania & 121,941 & 21,486 & 11,400 & 29,721 & 339 & 16 \\
\hline Slovakia & 65,887 & 5,463 & 24,200 & 11,712 & 283 & 52 \\
\hline Slovenia & 35,416 & 2,028 & 34,600 & 4,858 & 168 & 83 \\
\hline Spain & $1,051,342$ & 45,317 & 46,200 & 70,806 & 3,271 & 72 \\
\hline Sweden & 346,855 & 9,294 & 74,000 & 36,025 & 2,666 & 287 \\
\hline UK & $1,700,145$ & 61,899 & 54,800 & 158,726 & 8,698 & 141 \\
\hline EU27 & $12,248,507$ & 498,597 & 49,132 & $1,165,087$ & 60,339 & 121 \\
\hline
\end{tabular}




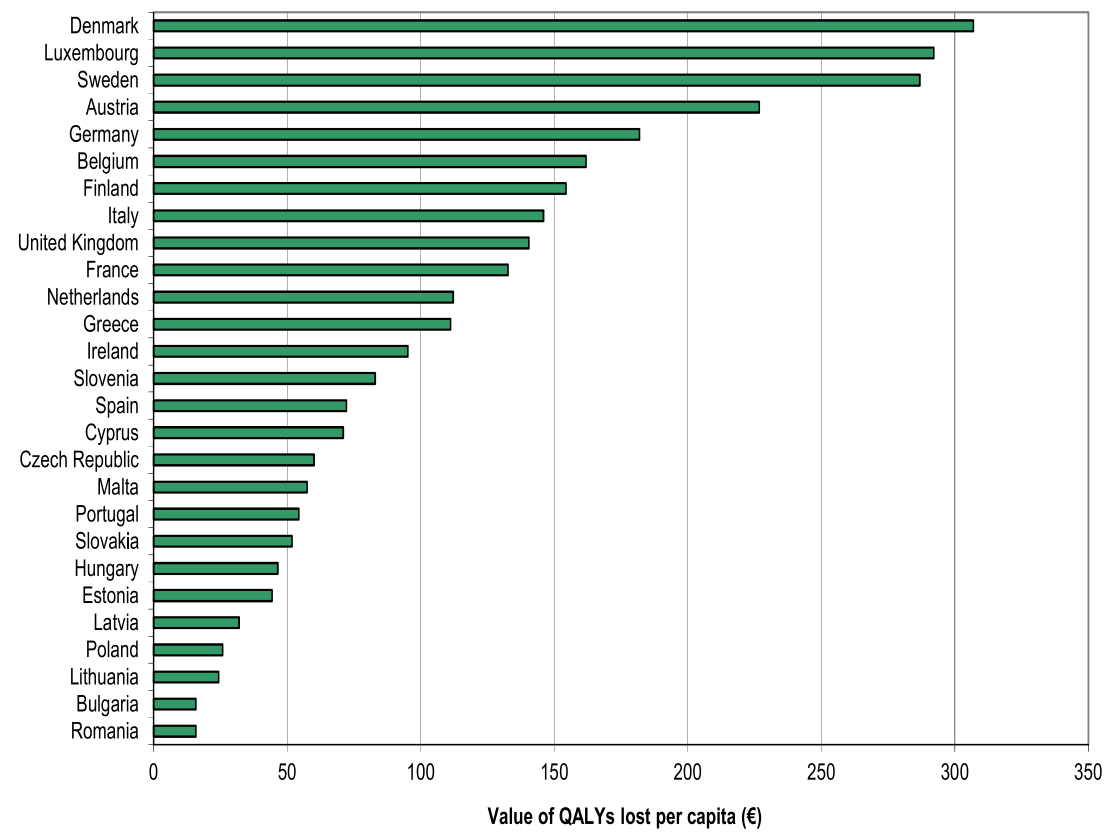

Fig. 30 Value of QALYs lost (valued at $2 \times 2010 \mathrm{GDP} /$ capita per QALY) per capita $(€)$

Table 49 Total cost of osteoporosis including the value of QALYs lost (valued at $2 \times 2010 \mathrm{GDP} /$ capita per QALY) in million $€$ and proportion of costs attributable to different categories

\begin{tabular}{|c|c|c|c|c|c|}
\hline \multirow[b]{2}{*}{ Country } & \multicolumn{5}{|c|}{ Cost (\%) due to } \\
\hline & $\begin{array}{l}\text { Cost including values of } \\
\text { QALYs lost }(€ 000,000)\end{array}$ & $\begin{array}{l}\text { Incident } \\
\text { fracture }\end{array}$ & Prior fracture & $\begin{array}{c}\text { Pharmacological } \\
\text { fracture } \\
\text { prevention } \\
\end{array}$ & $\begin{array}{l}\text { \% Value } \\
\text { QALYs lost }\end{array}$ \\
\hline Austria & 2,701 & 20 & 8 & 1 & 70 \\
\hline Belgium & 2,340 & 18 & 7 & 1 & 74 \\
\hline Bulgaria & 160 & 19 & 7 & 1 & 74 \\
\hline Cyprus & 130 & 26 & 5 & 9 & 60 \\
\hline Czech Republic & 903 & 18 & 6 & 6 & 70 \\
\hline Denmark & 2,759 & 26 & 11 & 1 & 62 \\
\hline Estonia & 89 & 25 & 8 & 1 & 66 \\
\hline Finland & 1,211 & 22 & 9 & 1 & 68 \\
\hline France & 13,162 & 24 & 10 & 3 & 63 \\
\hline Germany & 23,935 & 28 & 9 & 1 & 62 \\
\hline Greece & 1,943 & 25 & 5 & 5 & 65 \\
\hline Hungary & 661 & 19 & 5 & 6 & 70 \\
\hline Ireland & 649 & 19 & 10 & 5 & 66 \\
\hline Italy & 15,803 & 27 & 15 & 2 & 56 \\
\hline Latvia & 110 & 27 & 6 & 2 & 66 \\
\hline Lithuania & 128 & 25 & 9 & 2 & 63 \\
\hline Luxembourg & 169 & 9 & 3 & 1 & 87 \\
\hline Malta & 41 & 27 & 10 & 5 & 58 \\
\hline Netherlands & 2,686 & 13 & 16 & 1 & 69 \\
\hline Poland & 1,584 & 22 & 10 & 5 & 63 \\
\hline Portugal & 1,157 & 25 & 23 & 2 & 50 \\
\hline Romania & 468 & 19 & 7 & 1 & 72 \\
\hline Slovakia & 390 & 20 & 5 & 3 & 73 \\
\hline Slovenia & 224 & 16 & 6 & 3 & 75 \\
\hline Spain & 6,113 & 22 & 17 & 7 & 54 \\
\hline Sweden & 4,152 & 22 & 13 & 1 & 64 \\
\hline UK & 14,106 & 28 & 9 & 1 & 62 \\
\hline EU27 & 97,778 & 25 & 11 & 2 & 62 \\
\hline
\end{tabular}


increases markedly with age. As described in Chapter 3, $6 \%$ of women aged 50-54 years have osteoporosis, and the prevalence increases with age. Among women aged 80 years or older $47 \%$ have a BMD value in the osteoporosis range. The determinants of the future burden of osteoporosis depend on several factors in society, including changes in population, age-specific fracture risk and measures to reduce the risk of fracture. This section presents the projected burden of osteoporosis in the European Union up to 2025 with regard to the expected demographic changes.

\subsubsection{Secular trends}

Incidence rates can be followed over time using agestandardized incidence rates. Age- and sex- specific risk of fracture has been most completely studied in the case of hip fractures. In general, age- and sex-adjusted hip fracture incidence increased until the mid or end of the 20th century, with a subsequent plateau or even decrease [118]. In Europe, this tendency is best documented for Northern Europe. For example, whilst Swedish crude hip fracture incidence has increased, age-adjusted incidence (independent of demographic trends) remained stable between 1967 and 2001. Palvanen et al. [119] also described this phenomenon for humeral fractures and report a clear rise in the fracture rate in Finnish women 60 years of age and older from 1970 until the late 1990s followed by stabilisation and even decreased fracture rates in later years. For the UK, hip fracture rates have been reported to stabilise over the period 1989-1998 [120]. The trend has been further confirmed in Germany [121], the Netherlands [122], Hungary [123] and Austria [124]. There are fewer studies available from Southern Europe. A Spanish study reported that the number of hip fractures increased between 1988 and 2002, but no significant change was observed in age-adjusted incidence rates among men or women over this period [125].

The precise reasons for secular changes are unknown, and both skeletal and non-skeletal mechanisms have been suggested. An example of a non-skeletal factor is a cohort effect towards improved functionality among older women and actions and interventions in preventing and reducing falls. The importance of functionality is exemplified by a recent German study where 256 nursing homes were included in an intervention programme aimed at reducing the risk of residents falling. This was done through measures such as strength and balance training. Compared to control nursing homes, the intervention led to a relative risk of femoral fracture of 0.82 (95\% CI 0.72-0.93) [126]. An example of a risk factor for skeletal health that changes over time is the effect on maternal vitamin D status on offspring bone mass [127, 128].

The increasing use of drugs targeting osteoporosis could also contribute to the decrease in incidence. However, since incidence rates stabilized before treatment uptake rose significantly [7], increased drug access is unlikely to be the main reason for the secular trends observed.

For the purpose of this report we assume that incidence rates have reached a plateau and will remain stable until 2025 consistent with the findings described above.

\subsubsection{Demography up to 2025}

The demographic projection in the European Union for the years up to 2025 will translate into an increase in the number of fractures, as age is an important risk factor for fractures and the elderly population is projected to increase in almost all countries. Estimates are based on the UN World Population Projections using the medium variant [129]. In the European Union, the population over 50 years is expected to increase from 183 million in 2010 to 219 million in 2025, corresponding to a rise of approximately $20 \%$, with the male to female ratio increasing from $84 \%$ to $87 \%$. When stratifying the population by age groups, the highest growth is forecast for the population aged 80 years or more ( $32 \%$ increase). Given a greater increase in life expectancy in men than in women, the ratio of men to women in the population over 80 years is forecast to increase from $51 \%$ to $60 \%$ over the period. UN World Population Projections for the EU-27 are shown in Table 50.

The estimated demographic changes differ for the individual countries (Figs. 31 and 32). In Bulgaria for example, the male population above 50 years is expected to decrease by $1 \%$, whereas for all other countries the male population is expected to increase in all age groups. In women aged 50 74 years, the changes range from a $3 \%$ decrease in Bulgaria to a $43 \%$ increase in Luxembourg. In women aged 75 years and above, the corresponding numbers are a $7 \%$ increase in Latvia to a $63 \%$ increase in Cyprus. Spain and Malta are projected to have the highest increase in men aged 50-74 years and 75+ years, respectively. The projections expressed in relative change for countries with very small populations are uncertain given that numbers are presented in 1000s by the UN.

Although the total population increases between 2010 and 2025 , the population below 50 years is projected to decrease by $7 \%$ during the time period and the population under 65 years is forecast to decrease by approximately $3 \%$ (Table 50). As a consequence, the projected increase in costs of osteoporosis is forecast to be carried by a decreasing population at productive ages.

\subsubsection{Prevalence of osteoporosis as defined using the WHO diagnostic criteria up to 2025}

Assuming that the prevalence of osteoporosis (described in Chapter 3), defined using the WHO diagnostic criterion, remains constant until 2025, the demographic changes are expected to result in an increase in the number of individuals with osteoporosis from 28 million in 2010 to 34 million in 2025, 
Table 50 Population in thousands by age and sex [129]

\begin{tabular}{|c|c|c|c|c|c|c|c|c|}
\hline & All ages & $50-64$ & $65-79$ & $80+$ & $0-49$ & $50+$ & $\% 50+$ & $\% 65+$ \\
\hline & \multicolumn{8}{|c|}{2010} \\
\hline Men & 244,697 & 47,031 & 28,480 & 7,980 & 161,206 & 83,491 & 34 & 15 \\
\hline Women & 255,727 & 49,292 & 35,041 & 15,573 & 155,821 & 99,906 & 38 & 20 \\
\hline \multirow[t]{2}{*}{ Total } & 500,424 & 96,323 & 63,521 & 23,553 & 317,027 & 183,397 & 36 & 18 \\
\hline & \multicolumn{8}{|c|}{2015} \\
\hline Men & 248,173 & 49,646 & 31,281 & 9,349 & 157,897 & 90,276 & 36 & 16 \\
\hline Women & 258,141 & 51,711 & 37,495 & 17,102 & 151,833 & 106,308 & 41 & 21 \\
\hline \multirow[t]{2}{*}{ Total } & 506,314 & 101,357 & 68,776 & 26,451 & 309,730 & 196,584 & 39 & 19 \\
\hline & \multicolumn{8}{|c|}{2020} \\
\hline Men & 250,929 & 52,263 & 33,914 & 10,743 & 154,009 & 96,920 & 39 & 18 \\
\hline Women & 260,017 & 53,702 & 40,150 & 18,599 & 147,566 & 112,451 & 43 & 23 \\
\hline \multirow[t]{2}{*}{ Total } & 510,946 & 105,965 & 74,064 & 29,342 & 301,575 & 209,371 & 41 & 20 \\
\hline & \multicolumn{8}{|c|}{2025} \\
\hline Men & 252,861 & 53,105 & 37,344 & 11,650 & 150,762 & 102,099 & 40 & 19 \\
\hline Women & 261,272 & 53,898 & 43,915 & 19,406 & 144,053 & 117,219 & 45 & 24 \\
\hline Total & 514,133 & 107,003 & 81,259 & 31,056 & 294,815 & 219,318 & 43 & 22 \\
\hline
\end{tabular}

corresponding to an increase of $23 \%$. The increase is estimated to be higher in men than in women ( $29 \%$ vs. $22 \%)$. In the population aged 80 years and over, the overall increase is estimated at $28 \%$ with an even larger difference between men and women (46\% vs. $25 \%$ ). The number of people with osteoporosis stratified by five-year age groups is shown in Table 51.

\subsubsection{Number of incident fractures up to 2025}

Assuming that the incidence rates of fractures (see Chapter 3 ) remain constant until 2025, the demographic changes are

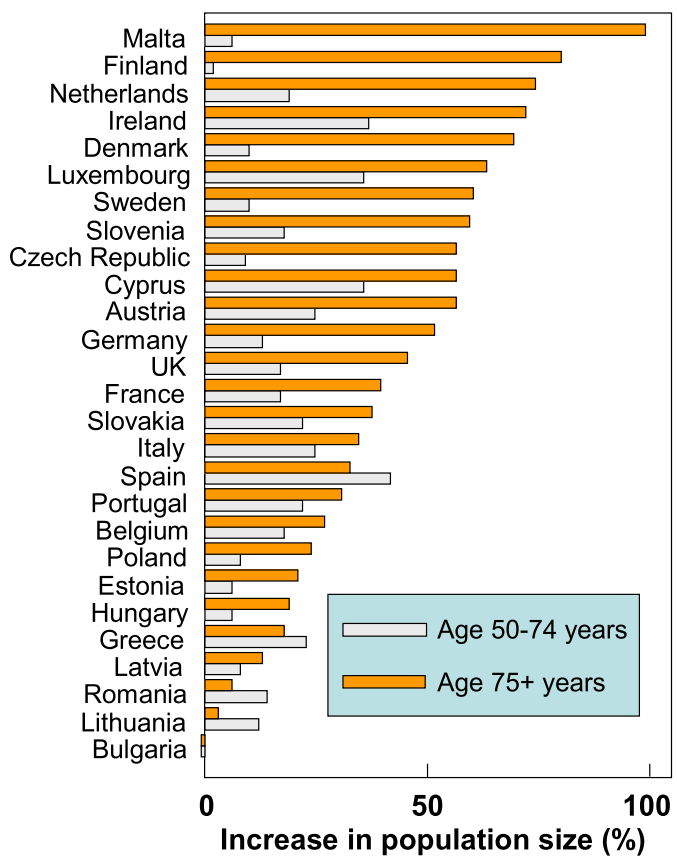

Fig. 31 Relative change in demography in men by age group and country between 2010 and $2025(\%)$ expected to result in an increase in the number of incident osteoporotic fractures from approximately 3.5 million in 2010 to approximately 4.5 million in 2025 , corresponding to an increase of $28 \%$. The absolute increase ranged from about 1,000 fractures in Malta to approximately 203,000 fractures in Germany and the relative increase ranged from $4 \%$ in Bulgaria to $53 \%$ in Ireland. In 2025, Germany is expected to have the largest number of fractures with approximately 928,000 fractures, followed by the UK with approximately 682,000 fractures. The estimated number of fractures in the EU27 in 2010 and 2025 is shown in Table 52.

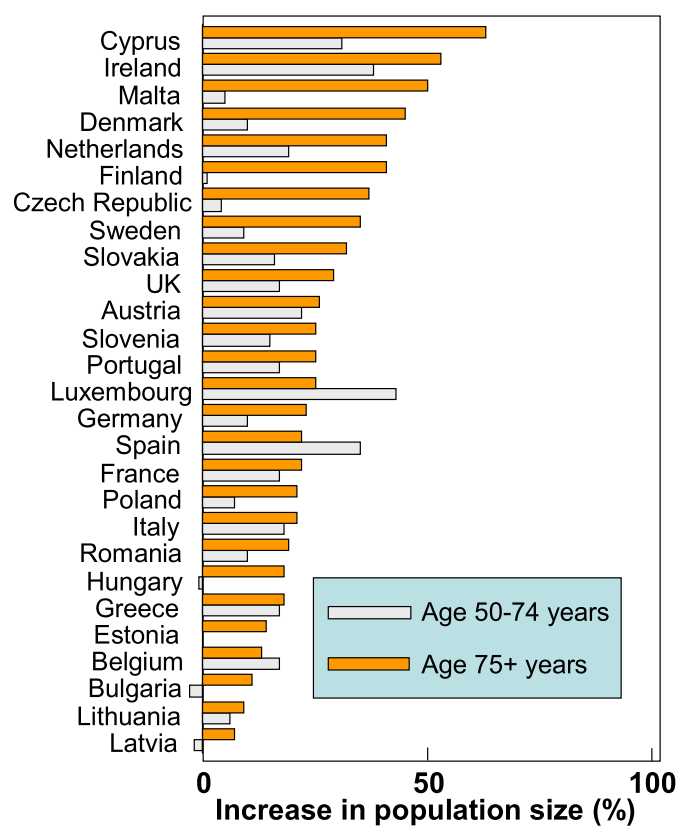

Fig. 32 Relative change in demography in women by age group and country between 2010 and $2025(\%)$ 
Table 51 Number of individuals with osteoporosis defined using the WHO diagnostic criteria

\begin{tabular}{|c|c|c|c|c|c|c|c|c|}
\hline & \multicolumn{8}{|c|}{ Age (years) } \\
\hline & $50-54$ & $55-59$ & $60-64$ & $65-69$ & $70-74$ & $75-79$ & $80+$ & $50+$ \\
\hline & \multicolumn{8}{|c|}{2010} \\
\hline Men & 428,800 & 547,295 & 826,036 & 817,996 & 777,426 & 768,277 & $1,324,680$ & $5,490,510$ \\
\hline Women & $1,106,028$ & $1,577,664$ & $2,188,186$ & $2,522,778$ & $3,408,543$ & $3,875,625$ & $7,350,456$ & $22,029,280$ \\
\hline \multirow[t]{2}{*}{ Total } & $1,534,828$ & $2,124,959$ & $3,014,222$ & $3,340,774$ & $4,185,969$ & $4,643,902$ & $8,675,136$ & $27,519,790$ \\
\hline & \multicolumn{8}{|c|}{2015} \\
\hline Men & 454,075 & 580,905 & 862,344 & 977,836 & 767,832 & 846,969 & $1,551,934$ & $6,041,895$ \\
\hline Women & $1,154,034$ & $1,662,816$ & $2,298,296$ & $2,982,732$ & $3,284,388$ & $4,108,875$ & $8,072,144$ & $23,563,285$ \\
\hline \multirow[t]{2}{*}{ Total } & $1,608,109$ & $2,243,721$ & $3,160,640$ & $3,960,568$ & $4,052,220$ & $4,955,844$ & $9,624,078$ & $29,605,180$ \\
\hline & \multicolumn{8}{|c|}{2020} \\
\hline Men & 467,575 & 618,660 & 921,272 & $1,024,530$ & 923,598 & 847,484 & $1,783,338$ & $6,586,457$ \\
\hline Women & $1,174,257$ & $1,736,832$ & $2,426,853$ & $3,140,898$ & $3,898,188$ & $3,985,875$ & $8,778,728$ & $25,141,631$ \\
\hline \multirow[t]{2}{*}{ Total } & $1,641,832$ & $2,355,492$ & $3,348,125$ & $4,165,428$ & $4,821,786$ & $4,833,359$ & $10,562,066$ & $31,728,088$ \\
\hline & \multicolumn{8}{|c|}{2025} \\
\hline Men & 447,125 & 638,260 & 985,072 & $1,101,194$ & 972,816 & $1,029,073$ & $1,933,900$ & $7,107,440$ \\
\hline Women & $1,114,911$ & $1,769,760$ & $2,540,538$ & $3,325,324$ & $4,116,366$ & $4,762,125$ & $9,159,632$ & $26,788,656$ \\
\hline Total & $1,562,036$ & $2,408,020$ & $3,525,610$ & $4,426,518$ & $5,089,182$ & $5,791,198$ & $11,093,532$ & $33,896,096$ \\
\hline
\end{tabular}

Table 52 Estimated number of fractures in 2010 and 2025

\begin{tabular}{|c|c|c|c|c|c|}
\hline & $\begin{array}{c}\text { Number of } \\
\text { fractures } 2010\end{array}$ & $\begin{array}{c}\text { Number of } \\
\text { fractures } 2025\end{array}$ & $\begin{array}{c}\Delta \text { fractures } \\
2010-2025 \\
\text { (number) }\end{array}$ & $\begin{array}{c}\Delta \text { fractures } \\
2010-2025(\%)\end{array}$ & $\begin{array}{c}\text { Share of EU27 } \\
\text { increase (\%) }\end{array}$ \\
\hline Austria & 86,536 & 116,307 & 29,771 & 34 & 3 \\
\hline Belgium & 79,892 & 99,316 & 19,424 & 24 & 2 \\
\hline Bulgaria & 38,197 & 39,627 & 1,430 & 4 & 0 \\
\hline Cyprus & 5,130 & 7,704 & 2,574 & 50 & 0 \\
\hline Czech Republic & 72,194 & 93,643 & 21,449 & 30 & 2 \\
\hline Denmark & 66,359 & 86,488 & 20,129 & 30 & 2 \\
\hline Estonia & 8,689 & 10,220 & 1,532 & 18 & 0 \\
\hline Finland & 36,407 & 49,094 & 12,687 & 35 & 1 \\
\hline France & 376,774 & 491,458 & 114,684 & 30 & 12 \\
\hline Germany & 724,773 & 927,737 & 202,965 & 28 & 21 \\
\hline Greece & 85,518 & 106,733 & 21,215 & 25 & 2 \\
\hline Hungary & 102,456 & 115,817 & 13,361 & 13 & 1 \\
\hline Ireland & 18,084 & 27,579 & 9,495 & 53 & 1 \\
\hline Italy & 465,400 & 597,781 & 132,381 & 28 & 13 \\
\hline Latvia & 14,305 & 16,226 & 1,921 & 13 & 0 \\
\hline Lithuania & 15,075 & 17,474 & 2,399 & 16 & 0 \\
\hline Luxembourg & 2,700 & 4,036 & 1,336 & 49 & 0 \\
\hline Malta & 2,642 & 3,777 & 1,136 & 43 & 0 \\
\hline Netherlands & 75,946 & 106,638 & 30,692 & 40 & 3 \\
\hline Poland & 167,663 & 209,387 & 41,724 & 25 & 4 \\
\hline Portugal & 51,821 & 69,056 & 17,235 & 33 & 2 \\
\hline Romania & 94,283 & 110,148 & 15,865 & 17 & 2 \\
\hline Slovakia & 38,634 & 49,873 & 11,239 & 29 & 1 \\
\hline Slovenia & 15,510 & 21,844 & 6,334 & 41 & 1 \\
\hline Spain & 204,152 & 285,899 & 81,746 & 40 & 8 \\
\hline Sweden & 107,046 & 135,271 & 28,225 & 26 & 3 \\
\hline UK & 535,873 & 682,141 & 146,268 & 27 & 15 \\
\hline EU27 & $3,492,058$ & $4,481,274$ & 989,217 & 28 & 100 \\
\hline
\end{tabular}


Table 53 Number of fractures stratified by fracture type and sex in 2010 and 2025

\begin{tabular}{|c|c|c|c|c|c|}
\hline & $\begin{array}{c}\text { Number of } \\
\text { fractures } 2010\end{array}$ & $\begin{array}{c}\text { Number of } \\
\text { fractures } 2025\end{array}$ & $\begin{array}{c}\text { Increase in } \\
\text { fractures }\end{array}$ & $\begin{array}{l}\text { Increase in } \\
\text { fractures (\%) }\end{array}$ & $\begin{array}{c}\text { Fracture share } \\
\text { of total } \\
\text { Increase }\end{array}$ \\
\hline \multicolumn{6}{|c|}{ Women } \\
\hline Hip fracture & 446,806 & 577,833 & 131,026 & 29 & 22 \\
\hline Vertebral fracture & 327,398 & 405,737 & 78,339 & 24 & 13 \\
\hline Forearm fracture & 464,272 & 555,452 & 91,180 & 20 & 16 \\
\hline Other fractures & $1,059,304$ & $1,343,880$ & 284,577 & 27 & 49 \\
\hline Total & $2,297,780$ & $2,882,903$ & 585,123 & 25 & 100 \\
\hline \multicolumn{6}{|c|}{ Men } \\
\hline Hip fracture & 168,509 & 236,915 & 68,405 & 41 & 17 \\
\hline Vertebral fracture & 188,868 & 251,752 & 62,884 & 33 & 16 \\
\hline Forearm fracture & 96,309 & 121,196 & 24,888 & 26 & 6 \\
\hline Other fractures & 740,591 & 988,508 & 247,917 & 33 & 61 \\
\hline Total & $1,194,277$ & $1,598,372$ & 404,094 & 34 & 100 \\
\hline \multicolumn{6}{|c|}{ Men and Women } \\
\hline Hip fracture & 615,316 & 814,747 & 199,432 & 32 & 20 \\
\hline Vertebral fracture & 516,266 & 657,489 & 141,223 & 27 & 14 \\
\hline Forearm fracture & 560,581 & 676,649 & 116,068 & 21 & 12 \\
\hline Other fractures & $1,799,895$ & $2,332,389$ & 532,494 & 30 & 54 \\
\hline Total & $3,492,058$ & $4,481,274$ & 989,217 & 28 & 100 \\
\hline
\end{tabular}

Table 54 Cost of osteoporosis (excluding values of QALYs lost; million $€$ ) by country in 2010 and 2025

\begin{tabular}{lcccc}
\hline \multicolumn{1}{c}{ Country } & $\begin{array}{c}\text { Cost }(€ \mathrm{~m}) \\
2010\end{array}$ & $\begin{array}{c}\text { Cost }(€ \mathrm{~m}) \\
2025\end{array}$ & $\begin{array}{c}\text { Cost increase } \\
(€ \mathrm{~m})\end{array}$ & $\begin{array}{c}\text { Cost increase } \\
(\%)\end{array}$ \\
\hline Austria & 799 & 1,025 & 226 & 28 \\
Belgium & 606 & 733 & 127 & 21 \\
Bulgaria & 42 & 45 & 2 & 5 \\
Cyprus & 52 & 76 & 24 & 47 \\
Czech Republic & 273 & 352 & 79 & 29 \\
Denmark & 1,055 & 1,344 & 288 & 27 \\
Estonia & 30 & 35 & 5 & 18 \\
Finland & 383 & 514 & 131 & 34 \\
France & 4,853 & 6,111 & 1,258 & 26 \\
Germany & 9,008 & 11,261 & 2,254 & 25 \\
Greece & 680 & 814 & 134 & 20 \\
Hungary & 197 & 226 & 29 & 15 \\
Ireland & 223 & 320 & 97 & 44 \\
Italy & 7,032 & 8,644 & 1,612 & 23 \\
Latvia & 38 & 43 & 5 & 13 \\
Lithuania & 47 & 54 & 7 & 15 \\
Luxembourg & 22 & 31 & 9 & 41 \\
Malta & 17 & 24 & 7 & 40 \\
Netherlands & 824 & 1,069 & 246 & 30 \\
Poland & 593 & 753 & 159 & 27 \\
Portugal & 577 & 717 & 140 & 24 \\
Romania & 129 & 151 & 22 & 17 \\
Slovakia & 107 & 140 & 33 & 31 \\
Slovenia & 56 & 77 & 21 & 37 \\
Spain & 2,842 & 3,680 & 839 & 30 \\
Sweden & 1,486 & 1,828 & 343 & 23 \\
UK & 5,408 & 6,723 & 1,315 & \\
EU27 & 37,378 & 46,790 & & 25 \\
\hline & & & & \\
\hline
\end{tabular}


Table 55 Cost of osteoporosis (excluding values of QALYs lost; million €) stratified by age and sex in 2010 and 2025

\begin{tabular}{|c|c|c|c|c|c|}
\hline Age (years) & Cost $(€ \mathrm{~m}) 2010$ & Cost $(€ m) 2025$ & Cost increase(€m) & Cost increase(\%) & $\begin{array}{c}\text { Share of total } \\
\text { increase (\%) }\end{array}$ \\
\hline \multicolumn{6}{|c|}{ Women } \\
\hline $50-74$ & 6,758 & 7,806 & 1,048 & 16 & 11 \\
\hline 75- & 19,040 & 23,519 & 4,479 & 24 & 48 \\
\hline All & 25,798 & 31,325 & 5,528 & 21 & 59 \\
\hline \multicolumn{6}{|c|}{ Men } \\
\hline $50-74$ & 4,910 & 5,829 & 919 & 19 & 10 \\
\hline 75- & 6,670 & 9,635 & 2,965 & 44 & 32 \\
\hline All & 11,581 & 15,464 & 3,884 & 34 & 41 \\
\hline \multicolumn{6}{|c|}{ Women and Men } \\
\hline $50-74$ & 11,668 & 13,635 & 1,967 & 17 & 21 \\
\hline 75- & 25,710 & 33,155 & 7,444 & 29 & 79 \\
\hline All & 37,378 & 46,790 & 9,411 & 25 & 100 \\
\hline
\end{tabular}

The number of incident fractures in women and men is expected to increase from approximately 2.3 million in 2010 to 2.9 million $(25 \%)$ in women and from 1.2 million to 1.6 million in men (34\%), respectively. Hip fractures are expected to increase at the highest rate in both women (29\%) and men (41\%). However, the increase in the number of fractures is predominately driven by "other fractures", accounting for $49 \%$ of the increase in women and $61 \%$ of the increase in men. The number of fractures stratified by fracture type and sex in 2010 and 2025 is shown in Table 53.

\subsubsection{Cost of osteoporosis up to 2025 excluding QALYs lost}

When costs of osteoporosis (excluding values of QALYs lost) are estimated, three cost components are included in the model: costs first year after fracture, costs subsequent years

Table 56 Table QALYs lost by country in 2010 and 2025

\begin{tabular}{|c|c|c|c|c|}
\hline Country & QALYs lost 2010 & QALYs lost 2025 & $\begin{array}{c}\text { Increase in QALYs } \\
\text { lost }\end{array}$ & $\begin{array}{c}\text { Increase in QALYs } \\
\text { lost (\%) }\end{array}$ \\
\hline Austria & 27,897 & 34,628 & 6,731 & 24 \\
\hline Belgium & 26,763 & 31,303 & 4,539 & 17 \\
\hline Bulgaria & 12,312 & 12,808 & 496 & 4 \\
\hline Cyprus & 1,803 & 2,334 & 531 & 29 \\
\hline Czech Republic & 22,829 & 27,863 & 5,033 & 22 \\
\hline Denmark & 20,188 & 24,905 & 4,717 & 23 \\
\hline Estonia & 2,774 & 3,204 & 429 & 15 \\
\hline Finland & 12,330 & 15,761 & 3,430 & 28 \\
\hline France & 139,418 & 167,927 & 28,509 & 20 \\
\hline Germany & 246,327 & 296,762 & 50,434 & 20 \\
\hline Greece & 30,952 & 35,171 & 4,219 & 14 \\
\hline Hungary & 23,667 & 26,239 & 2,573 & 11 \\
\hline Ireland & 6,097 & 8,187 & 2,089 & 34 \\
\hline Italy & 171,303 & 205,059 & 33,757 & 20 \\
\hline Latvia & 4,498 & 4,993 & 495 & 11 \\
\hline Lithuania & 4,872 & 5,481 & 609 & 13 \\
\hline Luxembourg & 900 & 1,169 & 269 & 30 \\
\hline Malta & 808 & 1,065 & 257 & 32 \\
\hline Netherlands & 26,312 & 33,809 & 7,497 & 28 \\
\hline Poland & 53,272 & 64,781 & 11,509 & 22 \\
\hline Portugal & 17,915 & 21,720 & 3,805 & 21 \\
\hline Romania & 29,721 & 33,815 & 4,094 & 14 \\
\hline Slovakia & 11,712 & 14,478 & 2,766 & 24 \\
\hline Slovenia & 4,858 & 6,325 & 1,467 & 30 \\
\hline Spain & 70,806 & 88,970 & 18,164 & 26 \\
\hline Sweden & 36,025 & 43,273 & 7,248 & 20 \\
\hline UK & 158,726 & 190,453 & 31,727 & 20 \\
\hline EU27 & $1,165,087$ & $1,402,483$ & 237,396 & 20 \\
\hline
\end{tabular}


Table 57 QALYs lost due to fracture stratified by age and incident and prior fracture in 2010 and 2025

\begin{tabular}{|c|c|c|c|c|c|c|c|c|c|}
\hline \multirow{2}{*}{$\begin{array}{l}\text { Age } \\
\text { (years) }\end{array}$} & \multicolumn{3}{|c|}{ Incident fractures } & \multicolumn{3}{|c|}{ Prior fractures } & \multicolumn{3}{|c|}{ All fractures } \\
\hline & 2010 & 2025 & $\Delta(\%)$ & 2010 & 2025 & $\Delta \%$ & 2010 & 2025 & $\Delta(\%)$ \\
\hline \multicolumn{10}{|c|}{ Women } \\
\hline $50-74$ & 121,564 & 142,411 & $17 \%$ & 120,872 & 128,651 & $6 \%$ & 242,436 & 271,062 & 12 \\
\hline 75- & 206,012 & 267,777 & $30 \%$ & 332,550 & 372,361 & $12 \%$ & 538,562 & 640,137 & 19 \\
\hline All & 327,575 & 410,187 & $25 \%$ & 453,422 & 501,011 & $10 \%$ & 780,997 & 911,199 & 17 \\
\hline \multicolumn{10}{|c|}{ Men } \\
\hline $50-74$ & 104,538 & 124,307 & $19 \%$ & 83,778 & 93,939 & $12 \%$ & 188,316 & 218,246 & 16 \\
\hline 75- & 87,965 & 134,116 & $52 \%$ & 107,809 & 138,922 & $29 \%$ & 195,774 & 273,038 & 39 \\
\hline All & 192,503 & 258,423 & $34 \%$ & 191,587 & 232,861 & $22 \%$ & 384,090 & 491,284 & 28 \\
\hline \multicolumn{10}{|c|}{ Women and Men } \\
\hline $50-74$ & 226,101 & 266,718 & $18 \%$ & 204,650 & 222,589 & $9 \%$ & 430,751 & 489,307 & 14 \\
\hline 75- & 293,977 & 401,893 & $37 \%$ & 440,359 & 511,283 & $16 \%$ & 734,336 & 913,176 & 24 \\
\hline All & 520,078 & 668,611 & $29 \%$ & 645,009 & 733,872 & $14 \%$ & $1,165,087$ & $1,402,483$ & 20 \\
\hline
\end{tabular}

after fracture, and the cost of pharmacological intervention including administration and monitoring costs. Fracture costs are driven by the increased number of fractures. The ratio of pharmacological intervention costs to fracture costs is assumed to remain constant over the forecast period.

The cost of osteoporosis was projected to increase from $€$ 37.4 billion in 2010 to $€ 46.8$ billion in 2025 , corresponding to an increase of $25 \%$ (Table 54). The absolute increase ranged from $€ 2$ million in Bulgaria to $€ 2.3$ billion in Germany and the relative increase ranged from $5 \%$ in Bulgaria to $47 \%$ in Cyprus.

The cost of osteoporosis excluding values of QALYs lost in women and men was projected to increase from $€ 25.8$ billion to $€ 31.3$ billion ( $21 \%$ ) and from $€ 11.6$ billion to $€ 15.5$ billion

Table 58 Total cost of osteoporosis including the value of QALYs lost (valued at 2*2010 GDP/capita per QALY; million $€$ ) in 2010 and 2025

\begin{tabular}{|c|c|c|c|c|}
\hline Country & Cost $(€ m) 2010$ & Cost $(€ \mathrm{~m}) 2025$ & Cost increase $(€ \mathrm{~m})$ & Cost increase (\%) \\
\hline Austria & 2,701 & 3,386 & 685 & 25 \\
\hline Belgium & 2,340 & 2,762 & 421 & 18 \\
\hline Bulgaria & 160 & 168 & 7 & 4 \\
\hline Cyprus & 130 & 177 & 47 & 36 \\
\hline Czech Republic & 903 & 1,121 & 218 & 24 \\
\hline Denmark & 2,759 & 3,446 & 687 & 25 \\
\hline Estonia & 89 & 104 & 15 & 16 \\
\hline Finland & 1,211 & 1,573 & 361 & 30 \\
\hline France & 13,162 & 16,119 & 2,957 & 22 \\
\hline Germany & 23,935 & 29,245 & 5,310 & 22 \\
\hline Greece & 1,943 & 2,249 & 306 & 16 \\
\hline Hungary & 661 & 740 & 79 & 12 \\
\hline Ireland & 649 & 892 & 243 & 37 \\
\hline Italy & 15,803 & 19,143 & 3,341 & 21 \\
\hline Latvia & 110 & 123 & 13 & 12 \\
\hline Lithuania & 128 & 145 & 17 & 13 \\
\hline Luxembourg & 169 & 223 & 53 & 31 \\
\hline Malta & 41 & 55 & 14 & 35 \\
\hline Netherlands & 2,686 & 3,463 & 777 & 29 \\
\hline Poland & 1,584 & 1,957 & 373 & 24 \\
\hline Portugal & 1,157 & 1,420 & 263 & 23 \\
\hline Romania & 468 & 537 & 68 & 15 \\
\hline Slovakia & 390 & 491 & 100 & 26 \\
\hline Slovenia & 224 & 296 & 71 & 32 \\
\hline Spain & 6,113 & 7,791 & 1,678 & 27 \\
\hline Sweden & 4,152 & 5,031 & 879 & 21 \\
\hline UK & 14,106 & 17,160 & 3,054 & 22 \\
\hline EU27 & 97,778 & 119,816 & 22,038 & 23 \\
\hline
\end{tabular}


Table 59 Cost of osteoporosis (including values of QALYs lost) stratified by age and sex in 2010 and 2025

\begin{tabular}{|c|c|c|c|c|c|}
\hline $\begin{array}{c}\text { Age } \\
\text { (years) }\end{array}$ & Cost $(€ \mathrm{~m}) 2010$ & Cost $(€ m) 2025$ & Cost increase $(€ \mathrm{~m})$ & Cost increase (\%) & $\%$ of increase \\
\hline \multicolumn{6}{|c|}{ Women } \\
\hline $50-74$ & 19,174 & 21,674 & 2,500 & 13 & 11 \\
\hline $75+$ & 47,291 & 57,121 & 9,830 & 21 & 45 \\
\hline All & 66,465 & 78,795 & 12,330 & 19 & 56 \\
\hline \multicolumn{6}{|c|}{ Men } \\
\hline $50-74$ & 14,341 & 16,771 & 2,429 & 17 & 11 \\
\hline $75+$ & 16,971 & 24,250 & 7,279 & 43 & 33 \\
\hline All & 31,313 & 41,021 & 9,708 & 31 & 44 \\
\hline \multicolumn{6}{|c|}{ Women and men } \\
\hline $50-74$ & 33,515 & 38,444 & 4,929 & 15 & 22 \\
\hline $75+$ & 64,263 & 81,371 & 17,108 & 27 & 78 \\
\hline All & 97,778 & 119,816 & 22,038 & 23 & 100 \\
\hline
\end{tabular}

(34\%), respectively. The increase was projected to be most pronounced in men aged 75 years and above (44\%). Whilst the projected growth was most rapid in men, the majority of the cost increase was incurred in women reflecting the substantially higher cost in women than in men in the index year (2010). The cost of osteoporosis stratified by age and sex in the EU27 in 2010 and 2025 is presented in Table 55.

\subsubsection{Projection of QALYs lost due to osteoporosis up to 2025}

The increased number of fractures reflecting demographic changes will affect the number of QALYs lost due to incident and prior fractures (Table 56). The number of QALYs lost in the European Union was projected to increase from 1.17 million in 2010 to 1.40 million in 2025 , corresponding to an increase of approximately $20 \%$. The absolute increase ranged from approximately 300 in Malta to approximately 50,000 in Germany and the relative increase ranged from $4 \%$ in Bulgaria to $34 \%$ in Ireland.

The number of QALYs lost due to fractures stratified by age, sex and incident and prior fractures in 2010 and 2025 is presented in Table 57. The number of QALYs lost (due to incident and prior fractures jointly) was projected to increase from approximately 781,000 to $911,000(17 \%)$ in women and from 384,000 to 491,000 (28\%) in men. The number of QALYs lost (in both sexes jointly) was projected to increase from approximately 520,000 to 669,000 (29\%) for the incident fractures and from 645,000 to $734,000(14 \%)$ for the prior fractures.

\subsubsection{Cost of osteoporosis up to 2025 including QALYs lost}

When the costs of osteoporosis were combined with the value for QALYs lost (valued at $2 \times \mathrm{GDP}$ ), the cost was projected to increase from $€ 98$ billion in 2010 to $€ 120$ billion, corresponding to an increase of $23 \%$ (Table 58). The EU5 (Germany, France, Italy, Spain and the UK) accounted for $74 \%$ of the increase.

The cost of osteoporosis including QALYs lost in women and men was projected to increase from $€ 66$ billion to $€ 79$ billion (19\%) and from $€ 31$ billion to $€ 41$ billion (31\%), respectively. The increase was most pronounced in men aged 75 years and above (43\%). Whilst the projected growth was most rapid in men, the majority of the projected increase was incurred in women reflecting the substantially higher total cost in women than in men in the index year (2010). The cost of osteoporosis including values of QALYs lost stratified by age and sex in 2010 and 2025 is shown in Table 59.

\section{References}

1. Hodgson TA, Meiners MR (1982) Cost-of-illness methodology: a guide to current practices and procedures. Milbank Mem Fund Q Health Soc 60:429-462

2. Hodgson TA (1983) The state of the art of cost-of-illness estimates. Adv Health Econ Health Serv Res 4:129-164

3. Harris H, R C, Watts J, Ebeling P, Crowley S (1998) The burden of illness and the cost of osteoporosis in Australia. In Centre for health program evaluation.

4. Dimai HP, Redlich K, Peretz M, Borgstrom F, Siebert U, Mahlich J (2012) Economic burden of osteoporotic fractures in Austria. Health Econ Rev 2:12

5. Kanis JA, Delmas P, Burckhardt P, Cooper C, Torgerson D (1997) Guidelines for diagnosis and management of osteoporosis. The European Foundation for Osteoporosis and Bone Disease. Osteoporos Int 7:390-406

6. Borgstrom F, Sobocki P, Strom O, Jonsson B (2007) The societal burden of osteoporosis in Sweden. Bone 40:1602-1609

7. Strom O, Borgstrom F, Kanis JA, Compston J, Cooper C, McCloskey EV, Jonsson B (2011) Osteoporosis: burden, health care provision and opportunities in the EU: a report prepared in collaboration with the International Osteoporosis Foundation (IOF) and the European Federation of Pharmaceutical Industry Associations (EFPIA). Arch Osteoporos 6:59-155 
8. Sanders KM, Seeman E, Ugoni AM, Pasco JA, Martin TJ, Skoric B, Nicholson GC, Kotowicz MA (1999) Age- and gender-specific rate of fractures in Australia: a population-based study. Osteoporos Int 10:240-247

9. Singer BR, McLauchlan GJ, Robinson CM, Christie J (1998) Epidemiology of fractures in 15,000 adults: the influence of age and gender. J Bone Joint Surg Br 80:243-248

10. Drummond MF (2005) Methods for the economic evaluation of health care programmes. Oxford University Press, Oxford

11. Bouee S, Lafuma A, Fagnani F, Meunier PJ, Reginster JY (2006) Estimation of direct unit costs associated with non-vertebral osteoporotic fractures in five European countries. Rheumatol Int 26:1063-1072

12. Kudrna K, Krska Z (2005) Expense analysis of the proximal femoral fractures treatment. Rozhl Chir 84:631-634

13. Ankjaer-Jensen A, Johnell O (1996) Prevention of osteoporosis: cost-effectiveness of different pharmaceutical treatments. Osteoporos Int 6:265-275

14. Strom O, Borgstrom F, Sen SS, Boonen S, Haentjens P, Johnell O, Kanis JA (2007) Cost-effectiveness of alendronate in the treatment of postmenopausal women in 9 European countries - an economic evaluation based on the fracture intervention trial. Osteoporos Int 18:1047-1061

15. Nurmi I, Narinen A, Luthje P, Tanninen S (2003) Cost analysis of hip fracture treatment among the elderly for the public health services: a 1-year prospective study in 106 consecutive patients. Arch Orthop Trauma Surg 123:551-554

16. Visentin P, Ciravegna R, Fabris F (1997) Estimating the cost per avoided hip fracture by osteoporosis treatment in Italy. Maturitas 26:185-192

17. Jansen JP, Gaugris S, Bergman G, Sen SS (2008) Cost-effectiveness of a fixed dose combination of alendronate and cholecalciferol in the treatment and prevention of osteoporosis in the United Kingdom and The Netherlands. Curr Med Res Opin 24:671-684

18. Dzajkovska B, Wertheimer AI, Mrhar A (2007) The burden-ofillness study on osteoporosis in the Slovenian female population. Pharm World Sci 29:404-411

19. Borgstrom F, Zethraeus N, Johnell O, et al. (2006) Costs and quality of life associated with osteoporosis-related fractures in Sweden. Osteoporos Int 17:637-650

20. Stevenson M, Davis S, Kanis J (2006) The hospitalization costs and outpatient costs of fragility fractures. Women's Health Medicine 149-151

21. Stevenson M, Davis S (2006) Analyses of the cost-effectiveness of pooled alendronate and risedronate, compared with strontium ranelate, raloxifene, etidronate and teriparatide. http:// wwwniceorguk/pageaspx?o=370643.

22. Koeck CM, Schwappach DL, Niemann FM, Strassmann TJ, Ebner H, Klaushofer K (2001) Incidence and costs of osteoporosisassociated hip fractures in Austria. Wien Klin Wochenschr 113:371-377

23. Kudrna K, Krska Z (2005) [Expense analysis of the proximal femoral fractures treatment]. Rozhl Chir 84:631-634

24. Azhar A, Lim C, Kelly E, O'Rourke K, Dudeney S, Hurson B, Quinlan W (2008) Cost induced by hip fractures. Ir Med J 101:213-215

25. Mateus M, Cruz C, Alves de Matos A, Branco J (2002) Hospital care costs of osteoporotic hip fractures - comparative study with other prevalent diseases. Osteoporos Int 13 (Suppl 1):S75

26. International Bank for Reconstruction and Development/ The World Bank (2008) 2005 International Comparison Program, Tables of final results.

27. Bielik J, Jureček L, Hroncová D (2010) Epidemiologické a ekonomické aspekty osteoporózy. Farmakoekonomika a lieková politika 6:25-28

28. Brecht JG, Kruse HP, Mohrke W, Oestreich A, Huppertz E (2004) Health-economic comparison of three recommended drugs for the treatment of osteoporosis. Int $\mathrm{J}$ Clin Pharmacol Res 24:1-10

29. Kanis JA, Oden A, Johnell O, Jonsson B, De Laet C, Dawson A (2001) The burden of osteoporotic fractures: a method for setting intervention thresholds. Osteoporos Int 12:417-427

30. Melton LJ, III, Gabriel SE, Crowson CS, Tosteson AN, Johnell O, Kanis JA (2003) Cost-equivalence of different osteoporotic fractures. Osteoporos Int 14:383-388

31. Brecht JG, Kruse HP, Felsenberg D, Mohrke W, Oestreich A, Huppertz E (2003) Pharmacoeconomic analysis of osteoporosis treatment with risedronate. Int $\mathrm{J}$ Clin Pharmacol Res 23:93-105

32. Eurostat (2011) Statistics database. Data retrieved November, 2011. http://epp.eurostat.ec.europa.eu,

33. Stadsledningskontoret (2003) Stockholms stads budgetavräkning.

34. Jonsson B, Christiansen C, Johnell O, Hedbrandt J, Karlsson G (1996) Cost-effectiveness of fracture prevention in established osteoporosis. Scand J Rheumatol Suppl 103:30-38

35. Zethraeus N, Strom O, Borgstrom F (2006) What is the risk of institutionalization after hip fracture? Osteoporos Int 17 (Suppl 1):57-58

36. National Board of Health and Welfare (2006) Care and sevices to elderly persons 2005, The National Board of Health and Welfare, Stockholm, Sweden

37. Scottish Hip Fracture Audit (2009) The patient journey post hip fracture: What constitutes rehabilitation? - A report from the Scottish hip fracture audit

38. Seniorenheim (2011) Austria Nursing Home Cost. Accessed November 2012. www.seniorenheim.at

39. Latvia Ministry (2011) Latvijas Republikas - Labklajibas Ministrija. www.lm.gov.lv/index.php

40. Autier P, Haentjens P, Bentin J, Baillon JM, Grivegnee AR, Closon MC, Boonen S (2000) Costs induced by hip fractures: a prospective controlled study in Belgium. Belgian Hip Fracture Study Group. Osteoporos Int 11:373-380

41. Republic of Lithuania - Ministry of Health (2011) Kauno Territorial Health Insurance Fund. www.sam.lt/index.php?3474664842

42. MIA-2004 LTD,Home For Elderly People (2011) Personal communication, Alexandrovska and Vlad - Jordanka Vladimirova ET average of three Bulgarian nursing homes $(750,650$, and 550 lev/month).

43. Meerding WJ, Mulder S, van Beeck EF (2006) Incidence and costs of injuries in The Netherlands. Eur J Public Health 16:272-278

44. Kronborg C, Vass M, Lauridsen J, Avlund K (2006) Cost effectiveness of preventive home visits to the elderly: economic evaluation alongside randomized controlled study. Eur J Health Econ 7:238-246

45. Schulz SE (2011) Alten- und Pflegeheim Wiblingen. Senioren Centrum. Domicil. www.pflegeheim-haus-am-see.de, www.aphwtelebus.de, www.hausstiftstrasse.de, www.domicilseniorenresidenzen.de.

46. Hujanen T, Kapiainen S, Tuominen U, Pekurinen M (2008) Terveydenhuollon yksikkökustannukset Suomessa vuonna 2006.

47. Kobelt G, Berg J, Lindgren P, Izquierdo G, Sanchez-Solino O, PerezMiranda J, Casado MA (2006) Costs and quality of life of multiple sclerosis in Spain. Eur J Health Econ 7 Suppl 2:S65-S74

48. Garaiacu A (2011) Personal communication-National Health Insurance House.

49. Seniorville Nursing Home (2011) www.seniorville.sk

50. Health Insurance Institute of Slovenia (ZZZS) (2011) www.zzZs.si and Maja Tomšic, personal communication

51. Freyler P, Hungarian National Health Insurance Fund OEP (2011) Personal communication.

52. IMS Health (2010) IMS data on pharmaceutical sales 2010.

53. International Osteoporosis Foundation (IOF) (2011) Osteoporosis in the European Union in 2008: Ten years of progress and ongoing challenges. IOF, Nyon 
54. The International Osteoporosis Foundation (IOF) (2011) Eastern European \& Central Asian Regional Audit-Individual Country Reports. www.iofbonehealth.org/publications/easterneuropean-central-asian-audit-2010.html;

55. NÖ Gebeitskrankenkasse (2011) Zusatzvereinbarung Honorarordning 2009. Accessed June 2011, www.noegkk.at

56. Hauptverband und Österreichischen (2011) Hauptverband und Österreichischen, Accessed July 2011. www.hauptverband.at/portal27/ portal/hvbportal/emed/

57. INAMI-RIZIV Institut national d'assurance maladie-invalidité (2011) Accessed June 2011. http://www.inami.fgov.be/insurer/fr/ rate/pdf/last/doctors/rx20110601fr.pdf

58. Vatkova J (2011) National Health Insurance Fund in Bulgaria. Personal communication

59. Ministry of Health Bulgaria (2011) http://www.mh.government.bg/ Articles.aspx ?lang=bg-BG\&pageid=383\&categoryid $=3999$. Accessed June 2011

60. Ministry of Health, Cyprus (2011) www.moh.gov.cy. Accessed June 2011

61. SÚKL State Institute for Drug Control in Czech Republic (2011) Accessed in June 2011. www.sukl.eu/

62. The Danish Ministry of Health (2000) Takstsystem 2011 ISBN 978-87-7601304-2:

63. Danish Medicines Agency (2011) Accessed July 2011. http:// www.medicinpriser.dk

64. Estonian Health Insurance Fund (2011) Available at Riigi Teataja. www.riigiteataja.ee/akt/121062011024\#para121062011017

65. Estonian Medicine Information (Raviminfo) (2011) Accessed August 2012. http://www.raviminfo.ee/otsing.php

66. The Social Insurance Institution of Finland (2011) Accessed July. http://kela.fi/

67. Saraux A, Brun-Strang C, Mimaud V, Vigneron AM, Lafuma A (2007) Epidemiology, impact, management, and cost of Paget's disease of bone in France. Joint Bone Spine 74:90-95

68. Vidal-pro (L'information de référence sur le médicament) (2004).

69. Lordick F, Ehlken B, Ihbe-Heffinger A, Berger K, Krobot KJ, Pellissier J, Davies G, Deuson R (2007) Health outcomes and cost-effectiveness of aprepitant in outpatients receiving antiemetic prophylaxis for highly emetogenic chemotherapy in Germany. Eur J Cancer 43:299-307

70. Rote Liste (2011) www.rote-liste.de

71. IKA Social Insurance Instiute G (2011) Accessed July 2012. http:// www.ika.gr/

72. Hellenic Association of Pharmaceutical Companies (2011) SFEE. Accessed July 2011. www.sfee.gr

73. Hungarian National Health Insurance Fund (OEP) (2011) Communication with Petra Freyler. www.oep.hu

74. Database CED (2011) Accessed June 2012. www.cedd.oep.hu

75. Irish Osteoporosis Society (2011) Personal communication Michele O'Brien, August 2011 and www. irishosteoporosis.ie

76. Gillespie P, O'Shea E, Murphy AW, Byrne MC, Byrne M, Smith SM, Cupples ME (2010) The cost-effectiveness of the SPHERE intervention for the secondary prevention of coronary heart disease. Int J Technol Assess Health Care 26:263-271

77. Capri S, Perlini S (2005) Cost-effectiveness in Italy of preventive treatment with ramipril in patients at high risk of cardiovascular events. Curr Med Res Opin 21:913-921

78. Agenzia Italiana del Farmco (2011) www.agenziafarmaco.it

79. Health Payment Center in Latvia (VNC) (2011) communication with Toms Noviks August, 2011. http://www.vnc.gov.lv/

80. Health RoL-Mo (2011) Lithuanian National Health Insurance Fund under the Ministry of Health. www.vlk.lt

81. Caisse Nationale de Santé Luxembourg (2011) www.cns.lu

82. Ministry for Health (2011) Elderly and Community Care, Malta. Mater Dei Hospital price. www.sahha.gov.mt,

83. Malta Competition and Consumer Affairs Authority (2011) www.msa.org.mt and personal communication with Gianpiero Fava
84. The Dutch Healthcare Authority (NZa) (2011) Accessed August 2012. www.nza.nl

85. Health Care Insurance Board's medicine price list (2011) Accessed August. www.medicijnkosten.nl

86. Dal NR, Piskorz P, Vives R, Guilera M, Sazonov K, V, Badia X (2007) Healthcare utilisation and costs associated with adding montelukast to current therapy in patients with mild to moderate asthma and co-morbid allergic rhinitis: PRAACTICAL study. Pharmacoeconomics 25:665-676

87. Portal da Saudé Portugal (2011) Accessed in July 2012. www.portaldasaude.pt

88. Secretaria-Geral Ministério da Saudé Portugal (2011) Communication with Lina Freitas. http://www.sg.min-saude.pt/

89. National Authority of Medicines and Health Products Portugal (2011) Accessed July 2012. http://www.infarmed.pt/

90. Casa de Asagurari de Sanatate a Municipiului Bucuresti (2011) Accessed August, 2011. http://www.casmb.ro/

91. Casa National de Asigurari de Sanatate (2011) Accessed August, 2011. http://www.cnas.ro/medicamente/lista-medicamentelor-2011

92. Portal Farma (2011) www.portalfarma.com

93. FASS (2009) www.fass.se

94. Curtis L (2008) Unit Costs of Health and Social Care, Personal Social Services Research Unit, University of Kent, www.pssru.ac.uk/ project-pages/unit-costs/2010/index.php. Accessed Dec 2010

95. British National Formulary (2011) http://www.bnf.org/bnf/

96. Kobelt G (2002) Health Economics: An introduction to economic evaluation. Office of Health Economics, London

97. Szende A, Oppe M, Devlin N EQ-5D Value Sets: Inventory, Comparative Review and User Guide. In Springer (ed) Series: EuroQol Group Monographs, Vol 2

98. WHO (2003) The burden of musculoskeletal conditions at the start of the new millennium.

99. Borgstrom F, Lekander I, Strom O, et al. (2013) The International Costs and Utilities Related to Fractures Study (ICUROS) - Quality of Life During the First 4 Months After Fracture. Osteoporos Int 24: 811-23

100. Peasgood T, Herrmann K, Kanis JA, Brazier JE (2009) An updated systematic review of Health State Utility Values for osteoporosis related conditions. Osteoporos Int 20:853-868

101. Borgstrom F, Johnell O, Kanis JA, Oden A, Sykes D, Jonsson B (2004) Cost effectiveness of raloxifene in the treatment of osteoporosis in Sweden: an economic evaluation based on the MORE study. Pharmacoeconomics 22:1153-1165

102. Kanis JA, Oden A, Johnell O, De Laet C, Jonsson B (2004) Excess mortality after hospitalisation for vertebral fracture. Osteoporos Int 15:108-112

103. Parker MJ, Anand JK (1991) What is the true mortality of hip fractures? Public Health 105:443-446

104. OTosteson AN, Gottlieb DJ, Radley DC, Fisher ES, Melton LJ, III (2007) Excess mortality following hip fracture: the role of underlying health status. Osteoporos Int 18:1463-1472

105. Gauthier A, Kanis JA, Jiang Y, Martin M, Compston JE, Borgstrom F, Cooper C, McCloskey EV (2011) Epidemiological burden of postmenopausal osteoporosis in the UK from 2010 to 2021: estimations from a disease model. Arch Osteoporos 6:179188

106. Hirth RA, Chernew ME, Miller E, Fendrick AM, Weissert WG (2000) Willingness to pay for a quality-adjusted life year: in search of a standard. Med Decis Making 20:332-342

107. WHO Commission on Macroeconomic Health (2001) Macroeconomics and Health: investing in health for economic development. Report of the Commission on Macroeconomics and Health.

108. Murray C, Lopez A (1996) Global and regional descriptive epidemiology of disability. Incidence, prevalence, health expectancies and years lived with disability. In Murray C, Lopez A (eds) The global burden of disease: a comprehensive assessment of mortality and disability from diseases, 
injuries and risk factors in 1990 and projected to 2020. Cambridge University Press, Cambridge, pp 201-246

109. Eichler HG, Kong SX, Gerth WC, Mavros P, Jonsson B (2004) Use of cost-effectiveness analysis in health-care resource allocation decision-making: how are cost-effectiveness thresholds expected to emerge? Value Health 7:518-528

110. Zethraeus N, Borgstrom F, Strom O, Kanis JA, Jonsson B (2007) Cost-effectiveness of the treatment and prevention of osteoporosis - a review of the literature and a reference model. Osteoporos Int 18:9-23

111. Kanis JA, Adams J, Borgstrom F, Cooper C, Jonsson B, Preedy D, Selby P, Compston J (2008) The cost-effectiveness of alendronate in the management of osteoporosis. Bone 42:4-15

112. Borgstrom F, Jonsson B, Strom O, Kanis JA (2006) An economic evaluation of strontium ranelate in the treatment of osteoporosis in a Swedish setting: Based on the results of the SOTI and TROPOS trials. Osteoporos Int 17:1781-1793

113. Gustavsson A, Svensson M, Jacobi F, et al. (2011) Cost of disorders of the brain in Europe 2010. Eur Neuropsychopharmacol 21:718779

114. Leal J, Luengo-Fernandez R, Gray A, Petersen S, Rayner M (2006) Economic burden of cardiovascular diseases in the enlarged European Union. Eur Heart J 27:1610-1619

115. Pugliatti M, Beghi E, Forsgren L, Ekman M, Sobocki P (2007) Estimating the cost of epilepsy in Europe: a review with economic modeling. Epilepsia 48:2224-2233

116. Wancata J, Musalek M, Alexandrowicz R, Krautgartner M (2003) Number of dementia sufferers in Europe between the years 2000 and 2050. Eur Psychiatry 18:306-313

117. National Institutes of Health (2011) NIH Estimates of Funding for Various Research, Condition and Disease Categories.

118. Cooper C, Cole ZA, Holroyd CR, Earl SC, Harvey NC, Dennison EM, Melton LJ, Cummings SR, Kanis JA (2011) Secular trends in the incidence of hip and other osteoporotic fractures. Osteoporos Int 22:1277-1288

119. Palvanen M, Kannus P, Niemi S, Parkkari J (2010) Secular trends in distal humeral fractures of elderly women: nationwide statistics in Finland between 1970 and 2007. Bone 46:1355-1358
120. Balasegaram S, Majeed A, Fitz-Clarence H (2001) Trends in hospital admissions for fractures of the hip and femur in England, 1989-1990 to 1997-1998. J Public Health Med 23:1117

121. Icks A, Haastert B, Wildner M, Becker C, Meyer G (2008) Trend of hip fracture incidence in Germany 1995-2004: a population-based study. Osteoporos Int 19:1139-1145

122. Boereboom FT, de Groot RR, Raymakers JA, Duursma SA (1991) The incidence of hip fractures in The Netherlands. Neth J Med 38:51-58

123. Pentek M, Horvath C, Boncz I, Falusi Z, Toth E, Sebestyen A, Majer I, Brodszky V, Gulacsi L (2008) Epidemiology of osteoporosis related fractures in Hungary from the nationwide health insurance database, 1999-2003. Osteoporos Int 19:243-249

124. Dimai HP, Svedbom A, Fahrleitner-Pammer A, Pieber T, Resch H, Zwettler E, Chandran M, Borgstrom F (2010) Reversal in the secular trend of hip fracture incidences in Austria. Wien Klin Wochenschr 122:380-381

125. Hernandez JL, Olmos JM, Alonso MA, Gonzalez-Fernandez CR, Martinez J, Pajaron M, Llorca J, Gonzalez-Macias J (2006) Trend in hip fracture epidemiology over a 14 -year period in a Spanish population. Osteoporos Int 17:464-470

126. Becker C, Cameron ID, Klenk J, Lindemann U, Heinrich S, Konig HH, Rapp K (2011) Reduction of femoral fractures in long-term care facilities: the Bavarian fracture prevention study. PLoS One 6:e24311

127. Mahon P, Harvey N, Crozier S, Inskip H, Robinson S, Arden N, Swaminathan R, Cooper C, Godfrey K (2010) Low maternal vitamin D status and fetal bone development: cohort study. J Bone Miner Res 25:14-19

128. Javaid MK, Cooper C (2002) Prenatal and childhood influences on osteoporosis. Best Pract Res Clin Endocrinol Metab 16:349-367

129. United Nations Department of Economic and Social AffairsPopulation Division (2011) World Population Prospects test. Data retrieved in November, 2011. http://esa.un.org/unpd/wpp/unpp/ p2k0data.asp 


\section{Uptake of osteoporosis treatments}

\section{Summary}

This chapter describes current and recent uptake of osteoporosis treatments in the European Union. Since data on the number of patients treated are not readily available in most European countries, international sales data (on volume in mg and value (€)) on drugs used for treatment of osteoporosis from IMS Health was used as a proxy. Sales data from 2001 to 2011 were analysed.

The drugs included in the analysis are alendronate, denosumab, etidronate, ibandronate, parathyroid hormone (PTH) 1-84, raloxifene, risedronate, strontium ranelate, teriparatide and zoledronic acid. Four of these drugs received marketing authorisation before 2001. The latest drug to come to market was denosumab in 2010.

The results are presented as sales and defined daily dosages (DDDs) per 100 of the total population. The number and proportion of the population above 50 years that was treated was also estimated and expressed in relation to the estimated number of patients considered eligible for treatment.

\section{The key messages of this chapter are:}

Alendronate is the most commonly prescribed agent, accounting for approximately a quarter of the total value of sales. In terms of $D D D$ s, alendronate represents almost half of all DDDs used to treat osteoporosis in the European Union.

The treatment uptake of osteoporosis drugs has increased considerably during the study time, however, recently a slight decrease has been observed.

The volume in terms of value of sales has decreased more than the volume in terms of DDDs in the two most recent years, mostly due to the decreasing price of generic bisphosphonates.

Uptake of individual treatments differs between regions in Europe. In general, Southern Europe shows a higher uptake of osteoporosis drugs.

There is a large gap between the number of women who are treated compared to the proportion of the population that could be considered eligible for treatment based on their fracture risk.

\subsection{Uptake of osteoporosis treatment}

This section discusses the extent and type of osteoporotic drugs used in the respective countries of the European Union. In order to analyse the uptake of treatments in different countries, data on the number of patients currently treated, treatment type and treatment compliance in each country are required. Unfortunately, in most countries, individual patient data are not readily available and there are only a few European nations (e.g., the Nordic countries and the Netherlands) that hold sufficiently large databases to allow a detailed analysis on filled prescription at an individual level. In the absence of country- and patient-specific data on filled prescriptions, we utilised international sales data in order to compare treatment uptake and osteoporosis medication sales between countries and over time. A similar, but more extensive, data analysis has been performed for EU5 + Sweden report in a previous report [1]. The analyses were conducted using international sales of osteoporosis drugs from IMS Health to estimate the use of osteoporosis treatment in the EU27 in value $(€)$ and volume (DDD).

\subsection{Data and methods}

IMS Health data are currently the only source of comparative data on sales of pharmaceuticals at an international level. However, the data have a number of shortcomings. It is unlikely that $100 \%$ of sales are captured in any country, but it is difficult to define the magnitude of underestimation. For some countries, it is known that part or all of hospital sales are omitted and that certain wholesalers or other channels of distribution are not included. Similarly, it is possible that sales are overestimated in some countries as a consequence of the sample of pharmacies and hospitals that provide data. Since IMS Health attempts to correct for under- and over-estimation, and in the absence of any additional information, we have refrained from any overall adjustment of the available sales figures.

Another difficulty may arise from parallel trade. Although drugs launched in the last two decades generally have a rather narrow price band across Europe, price control mechanisms, adaptation to distribution channels and currency fluctuations have created a price difference that give incentives for parallel trade. IMS Health adjusts the data for parallel trade but it is difficult to estimate the accuracy of these corrections. Also, not 
all countries have adjustments for parallel trade. The countries included in this report for which adjustments have been made are: Austria, Belgium, Czech Republic, Denmark, Finland, France, Germany, Italy, the Netherlands, Poland, Spain, Sweden and the UK.

The number of patients treated is an important component in the analysis of treatment uptake. The IMS Health sales data allow the estimation of how many treatment years the sales volume can cover. However, not all patients are completely adherent to therapy, and such an approach would consequently result in an underestimation of the actual number of patients that have started a treatment since some patients only are treated for a part of the year. This has further implications for clinical outcome, and also means that the treatment effect is lower than that reported from clinical trials where persistence and compliance is high. To correct for suboptimal adherence, an adjustment factor was estimated from data from the Swedish Prescribed Drug Register (see below). The adjustment factor was employed irrespective of country because similar data were not readily available for any other country. The data from IMS Health were available as monthly number of defined daily doses (as defined by WHO, http:// www.whocc.no/atc_ddd_index [DDDs]) sold per country, and the following steps were included in the estimations:

- For comparisons of uptake between countries, the number of DDDs in each year was expressed as DDDs $/ 100$ of the population aged 50 years or above residing in the respective country [2]. This analysis does not take into account that more women than men are treated, potentially overestimating treatment uptake in countries with a relatively high proportion of women over 50 years of age and vice versa. However, the proportion of women and men eligible for treatment that could be treated is assessed in a separate analysis.

- Almost all osteoporosis drugs are prescribed to patients aged 50 years or older $(97.2 \%$ based on Swedish prescription data). Therefore, it was assumed that only patients 50 years or older were given osteoporosis treatments.

- Population coverage is the proportion of the population at or above the age of 50 years in each country that could theoretically be covered by a full year of treatment based on the sales volume. It can be estimated by dividing the DDDs per 100 of the total population by 365 (alternatively 366 days in a leap year).
- Based on an analysis of filled prescriptions from the Swedish Prescribed Drug Register between 2006 and 2009 , it was estimated that the total volume of the prescription could cover $73 \%$ of the total observed time (i.e., the sum of the days from treatment start to end of the year) for all patients that were prescribed an osteoporosis treatment during this period. This estimate was not found to vary with age. This factor was used to approximate the number of patients being treated during a year for all countries.

- Additionally, to differentiate between men and women, it was assumed that $87 \%$ of the sales were directed to women and $13 \%$ to men. This assumption was made based on Swedish prescription data.

No data were available for Cyprus or Malta and these two countries were therefore excluded from all analyses of treatment uptake and population coverage.

\subsection{Pharmacological treatment}

There are a number of pharmacological options available in the European Union for the treatment of osteoporosis. Table 60 shows the year of introduction in Europe (EMA marketing authorisation) for the agents indicated for osteoporosis. The bisphosphonates were the first group of drugs to be approved, followed by the SERM raloxifene in 1998. In the 2000s, additional bisphosphonates as well as novel groups of drugs have become available. The patent of alendronate expired and generic versions of the drug became available in Europe in 2006. Also risedronate has been available in generic formulations since 2010 .

Table 60 Year of first introduction in Europe

\begin{tabular}{ll}
\hline & Year \\
\cline { 2 - 2 } Bisphosphonates & \\
Alendronate & 1995 \\
Etidronate & 1980 \\
Ibandronate & 2005 \\
Risedronate & 2000 \\
Zoledronic acid & 2005 \\
RERMs & \\
Raloxifene & 1998 \\
Parathyroid hormones & \\
Teriparatide & 2003 \\
PTH(1-84) & 2006 \\
Strontium Ranelate & 2004 \\
Antibodies & \\
Denosumab & 2010 \\
\hline
\end{tabular}


The introduction of generic versions has, as expected, driven prices downwards, albeit by a different extent in different countries. The annual prices of generic alendronate and other medications indicated for osteoporosis are shown in Table 61 . The prices differ markedly between the countries, e.g., the yearly price of generic alendronate ranges from $€ 4$ in the Netherlands to $€ 327$ in Cyprus, and generic risedronate from $€ 19$ in Belgium to $€ 514$ in Ireland.

\subsection{Market shares}

Data on estimated population-adjusted total sales and market shares, presented as sales of DDDs and in Euros, are shown in Figs. 33 and 34 for the time period 2001 through 2011 (and related to the size of the population). In terms of value, sales increased rapidly from 2001 to 2005; grew at a slower pace until 2008 and thereafter decreased. Over the entire period, the value of sales in the EU27 increased from approximately $€ 344 / 100$ persons aged 50 or above in 2001 to $€ 883$ in 2011. In terms of volume (DDDs per 100 personyears aged 50 or above) sales increased almost linearly until 2010 decreased slightly in 2011. The discrepancy between the development of sales in terms of value and volume was predominately driven by the decreased price of generic alendronate. DDDs per 100 person-

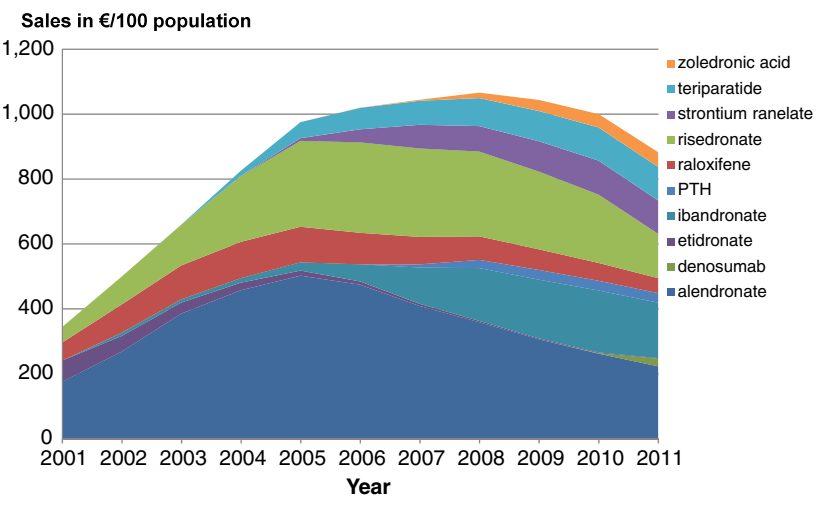

Fig. 33 Estimated market shares in EU27 2001-2011 (sales in Euros/100 persons aged 50 years or above)

years and value of sales for each drug and country are presented in the compendium of country specific summaries published concurrently with this report.

Estimated sales per product in 2010 measured both as DDDs and in Euros along with market shares are shown in Table 62. A comparison of market shares measured as sales and volume shows a substantially higher market share in terms of volume than in sales for alendronate, reflecting the low price of generic alendronate. Conversely, the effect of high price is seen with PTH and teriparatide, which have higher market shares in sales than in volume.

Table 61 Yearly cost $(€)$ of treatment with respective medications indicated for osteoporosis treatment

\begin{tabular}{|c|c|c|c|c|c|c|c|c|c|c|}
\hline Country & $\begin{array}{c}\text { Alendronate } \\
\text { (generic) }\end{array}$ & $\begin{array}{c}\text { Risedronate } \\
\text { (generic) }\end{array}$ & Etidronate & Ibandronate & $\begin{array}{c}\text { Zoledronic } \\
\text { acid }\end{array}$ & Raloxifene & $\begin{array}{l}\text { Strontium } \\
\text { ranelate }\end{array}$ & $\begin{array}{c}\text { Parathyroid } \\
\text { hormone }\end{array}$ & Teriparatide & \\
\hline Austria & 174 & 173 & 337 & 266 & 368 & 463 & 602 & 4,881 & 5,033 & [3] \\
\hline Belgium & 123 & 19 & 93 & 160 & 324 & 395 & 464 & - & 3,656 & [4] \\
\hline Bulgaria & 80 & 147 & - & 142 & 309 & 279 & 389 & - & 3,198 & [5] \\
\hline Cyprus & 327 & 508 & - & 489 & 481 & 1037 & 655 & - & 7,179 & [6] \\
\hline Czech Republic & 187 & 231 & - & 328 & 355 & 454 & 478 & 4,485 & 4,753 & [7] \\
\hline Denmark & 126 & 50 & 103 & 400 & 468 & 430 & 721 & 6,874 & 6,902 & [8] \\
\hline Estonia & 171 & 143 & - & 283 & 202 & - & 446 & - & - & [9] \\
\hline Finland & 40 & 40 & 1072 & 456 & 394 & 488 & 527 & 5,593 & 5,933 & [10] \\
\hline France & 209 & 380 & 99 & 327 & 410 & 365 & 579 & - & 4,829 & [11] \\
\hline Germany & 245 & 509 & 475 & 576 & 562 & 540 & 611 & 7,853 & 7,700 & [12] \\
\hline Greece & 239 & 286 & 79 & 235 & 357 & 332 & 494 & 3,630 & 5,289 & [13] \\
\hline Hungary & 115 & 247 & - & 329 & 254 & 383 & 449 & - & 4,663 & [14] \\
\hline Ireland & 240 & 514 & 138 & 432 & 433 & 420 & 631 & 6,519 & 7,111 & [14] \\
\hline Italy & 294 & 474 & 97 & 524 & 529 & 452 & 665 & 6,528 & 7,445 & [15] \\
\hline Latvia & 85 & 186 & - & 315 & 420 & - & 431 & - & 5,101 & [14] \\
\hline Lithuania & 146 & 321 & - & 402 & - & 516 & 512 & 5,428 & 5,758 & [14] \\
\hline Luxembourg & 109 & 226 & 223 & 379 & 355 & 446 & 375 & - & 4,666 & [16] \\
\hline Malta & 190 & 491 & - & 434 & 560 & 461 & 606 & - & 7,170 & [17] \\
\hline Netherlands & 4 & 23 & 354 & 302 & 377 & 325 & 433 & 5,705 & 5,811 & [18] \\
\hline Poland & 245 & 509 & 475 & 576 & 562 & 611 & 540 & 7,853 & 7,700 & {$[12,14]$} \\
\hline Portugal & 16 & 139 & - & 270 & 443 & 401 & 552 & 6,106 & 6,192 & [19] \\
\hline Romania & 53 & 106 & - & 195 & 747 & 362 & 414 & - & 4,266 & [20] \\
\hline Slovakia & 116 & 320 & - & 404 & 480 & 509 & 610 & 5,651 & 6,414 & [14] \\
\hline Slovenia & 161 & 332 & - & 104 & 360 & 323 & 474 & - & 5,193 & [14] \\
\hline Spain & 201 & 299 & 44 & 416 & 417 & 449 & 644 & 5,168 & 5,220 & [21] \\
\hline Sweden & 27 & 366 & 241 & - & 443 & 358 & 468 & 4,585 & 5,174 & [22] \\
\hline UK & 13 & 217 & 79 & 188 & 242 & 221 & 285 & 2,897 & 3,024 & [23] \\
\hline
\end{tabular}




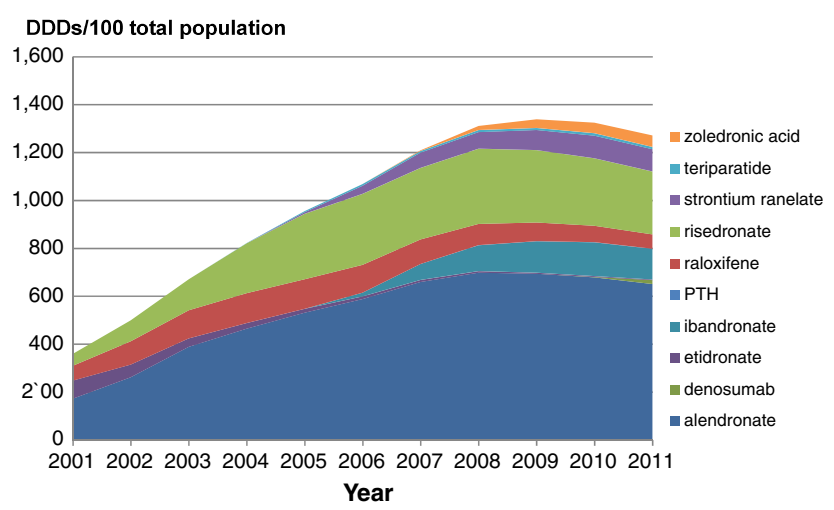

Fig. 34 Estimated market shares in EU27 2001-2011 (DDDs/100 persons aged 50 years or above)

The estimated value of sales per region of the European Union (Northern, Western, Eastern and Southern Europe) for osteoporotic drugs is shown in Figs. 35 to 38. In Northern and Eastern Europe, sales per 100 persons aged 50 years or above were generally lower than the average for EU27, whilst the opposite was observed for countries from Western and Southern Europe.

The average cost per DDD by region is presented in Figs. 39 to 42 . Across all regions, the average cost per DDD remained stable from 2001 to 2005 and subsequently decreased year on year until 2011. If inflation during these years is taken into account, the decrease would be even more marked.

The largest and smallest intra-region variation was observed in Eastern and Southern Europe, respectively. In Western Europe, cost per DDD was comparatively homogenous in 2001 but variation increased thereafter. A similar pattern, albeit less marked, was observed in Northern Europe. Much of the variation seen in the cost per DDD can be explained by the market penetration of generic alendronate. The most notable decrease in cost

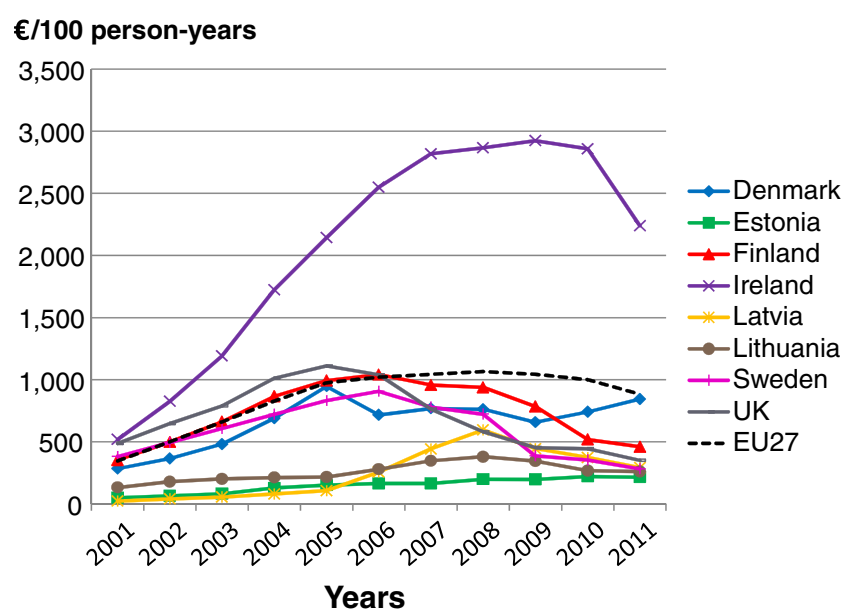

Fig. 35 Estimated annual sales in Northern Europe 2001-2011 (€/100 persons aged 50 years or above)

per DDD was observed in the UK $(€ 1.64$ in 2001 to $€ 0.24$ in 2011).

\subsection{Population coverage}

The population coverage estimations are calculated, as described in the Data and Methods section, using the DDDs sold per year adjusted by the proportion of the population over 50 years that could be treated. This estimate is subsequently adjusted for suboptimal compliance. For the European Union in total, there seems to be an increase up until 2008 , followed by a subsequent plateau or even a decrease in population coverage. The uptake differs among the regions of the European Union, as is shown in Figs. 43 to 46. Generally, uptake is lower than the average for EU27 in Northern and Eastern Europe (exceptions being Ireland and to some extent Hungary), whilst Western Europe shows

Table 62 Estimated sales in EU27 and market shares in 2010 based on IMS Health data

\begin{tabular}{lcccc}
\hline & $\begin{array}{l}\text { Estimated sales in } \\
2010 \text { (DDDs per } \\
100 \text { persons } \\
\text { aged } 50 \text { years and } \\
\text { above) }\end{array}$ & $\begin{array}{c}\text { Estimated sales in } \\
\text { 2010 (Euros per } \\
100 \text { persons } \\
\text { aged } 50 \text { years and } \\
\text { above) }\end{array}$ & $\begin{array}{c}\text { Estimated market } \\
\text { share 2010 (DDDs) }\end{array}$ & $\begin{array}{c}\text { Estimated market } \\
\text { share 2010 (Euros) }\end{array}$ \\
\hline Alendronate & 679.8 & 261.3 & $51.3 \%$ & \\
Denosumab & 1.4 & 1.8 & $0.1 \%$ & $26.1 \%$ \\
Etidronate & 3.8 & 2.7 & $0.3 \%$ & $0.2 \%$ \\
Ibandronate & 140.7 & 190.6 & $10.6 \%$ & $0.3 \%$ \\
PTH & 0.8 & 30.2 & $0.1 \%$ & $19.0 \%$ \\
Raloxifene & 68.3 & 54.9 & $5.2 \%$ & $3.0 \%$ \\
Risedronate & 281.7 & 210.5 & $21.3 \%$ & $5.5 \%$ \\
Strontium ranelate & 94.3 & 105.5 & $7.1 \%$ & $21.0 \%$ \\
Teriparatide & 10.1 & 101.7 & $0.8 \%$ & $10.5 \%$ \\
Zoledronic acid & 43.7 & 41.4 & $3.3 \%$ & $10.2 \%$ \\
Total & $\mathbf{1 , 3 2 4 . 7}$ & $\mathbf{1 , 0 0 0 . 5}$ & $\mathbf{1 0 0 \%}$ & $4.1 \%$ \\
\hline
\end{tabular}




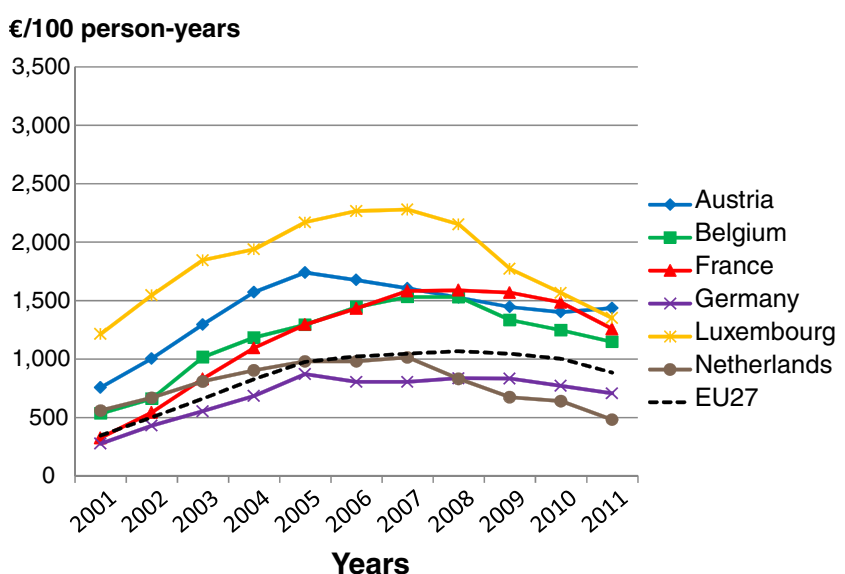

Fig. 36 Estimated annual sales in Western Europe 2001-2011 (€/100 persons aged 50 years or above)

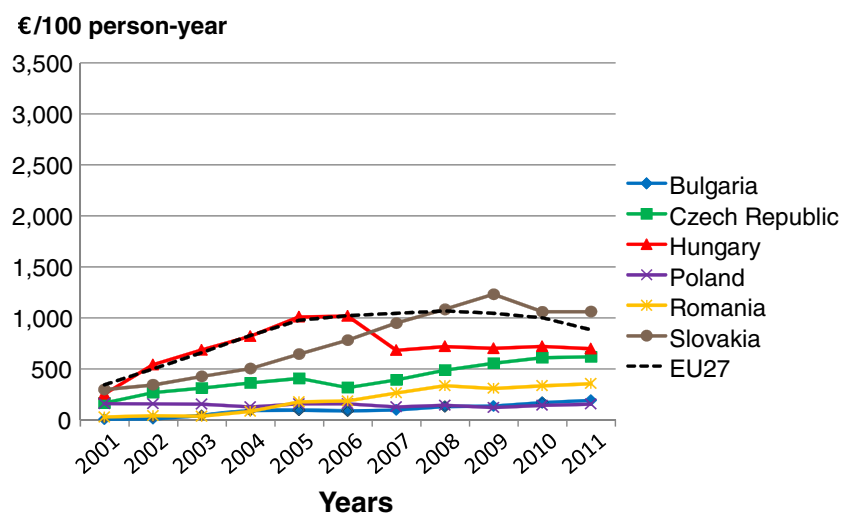

Fig. 37 Estimated annual sales in Eastern Europe 2001-2011 (€/100 persons aged 50 years or above)

\section{$€ / 100$ person-years}

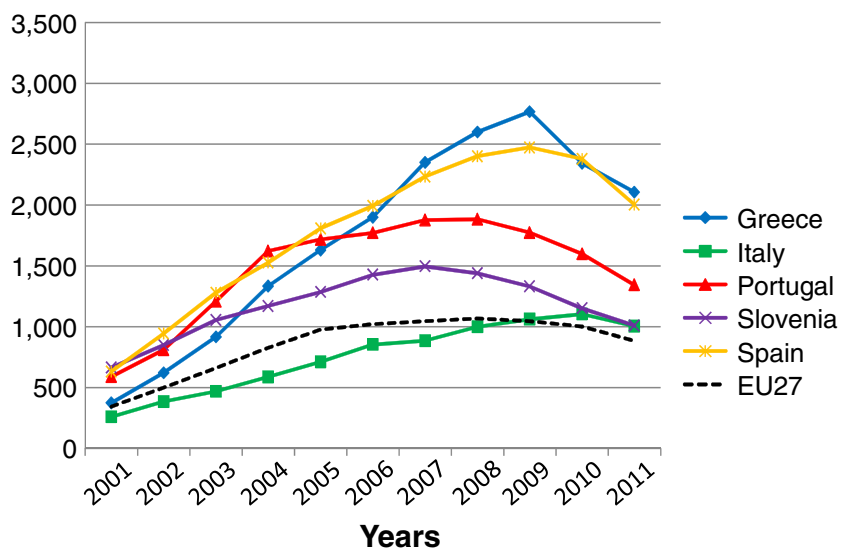

Fig. 38 Estimated annual sales in Southern Europe 2001-2011 (€/100 persons aged 50 years or above)

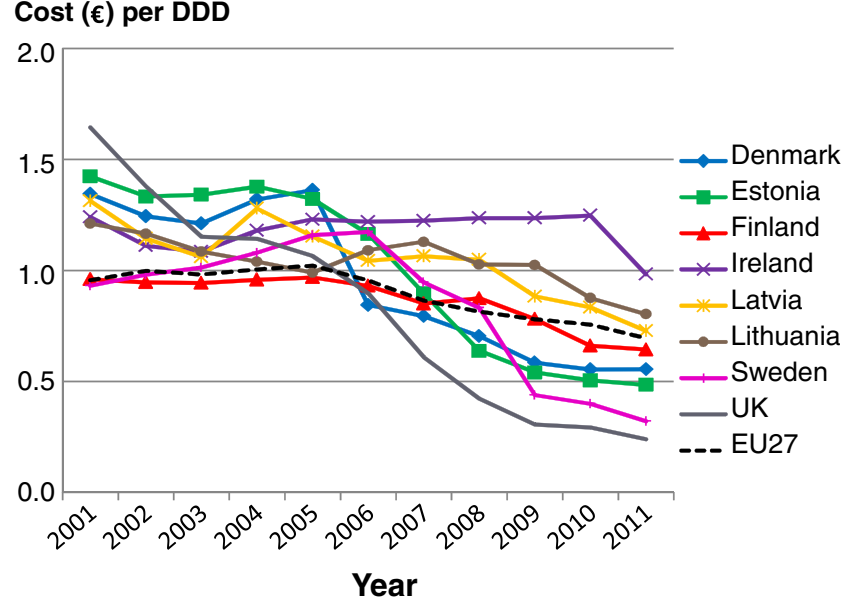

Fig. 39 Cost $(€)$ per DDD in Northern Europe: average for all drugs

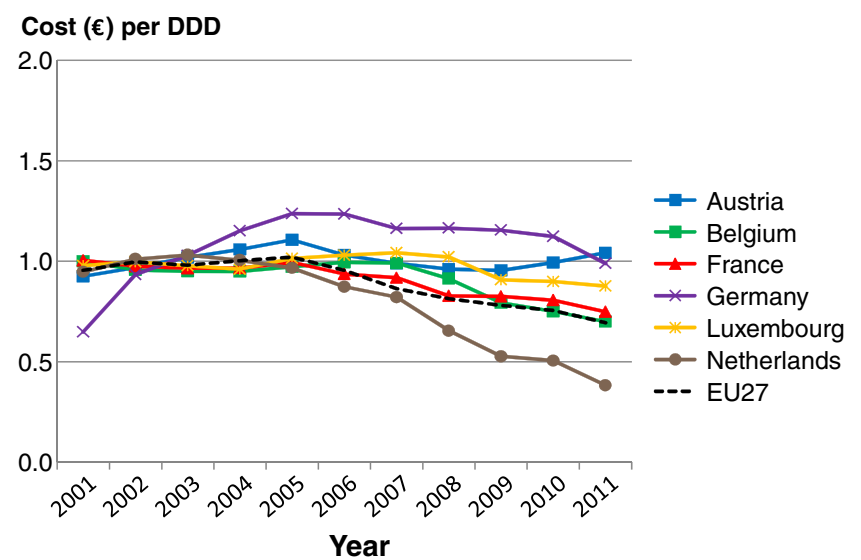

Fig. 40 Cost $(€)$ per DDD in Western Europe: average for all drugs

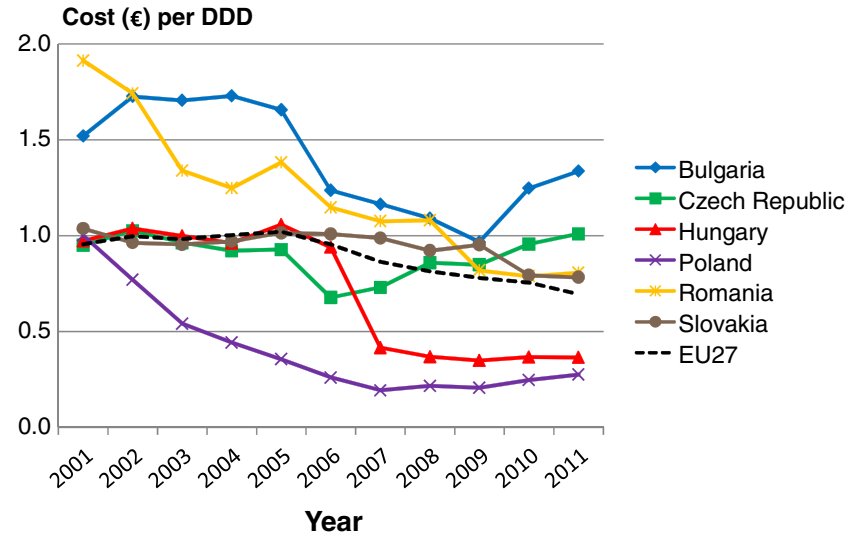

Fig. 41 Cost $(€)$ per DDD in Eastern Europe: average for all drugs 


\section{Cost (€) per DDD}

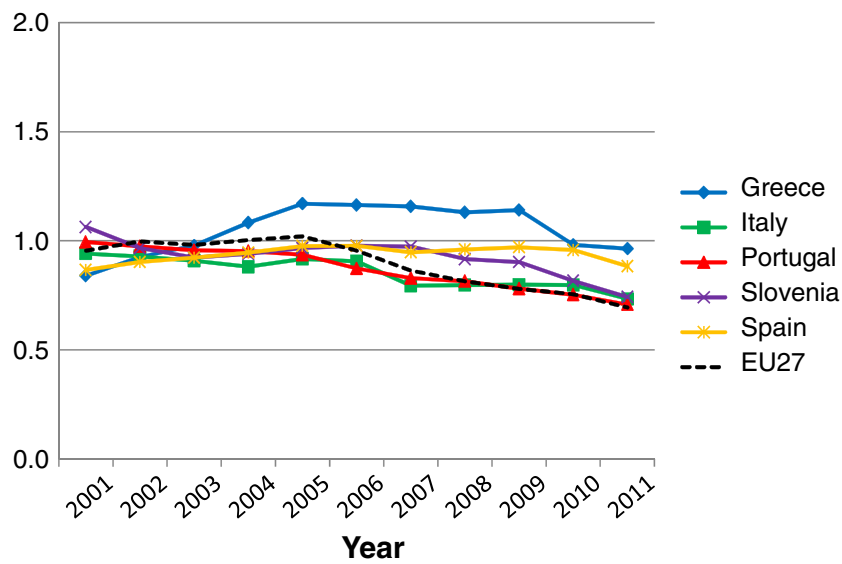

Fig. 42 Cost $(€)$ per DDD in Southern Europe: average for all drugs

slightly higher population coverage. There is no country in Southern Europe that has a lower coverage than the EU27 average from 2010. In 2010, the proportion of persons, aged 50 years or more, potentially treated (assuming treatment for $73 \%$ of the year) ranged from approximately $0.5 \%$ in Bulgaria to $9.3 \%$ in Spain.

\subsection{Uptake of individual treatments}

The uptake, measured by DDDs per 100 of the population aged 50 years or more stratified by country, is shown in the figures below. The countries are grouped into four regions as discussed above.

\subsubsection{Alendronate}

The general trend in the EU27 of the uptake of alendronate was an increase from 2001 to approximately 2008, followed by a plateau. A slight decrease was noted in 2011. This is in

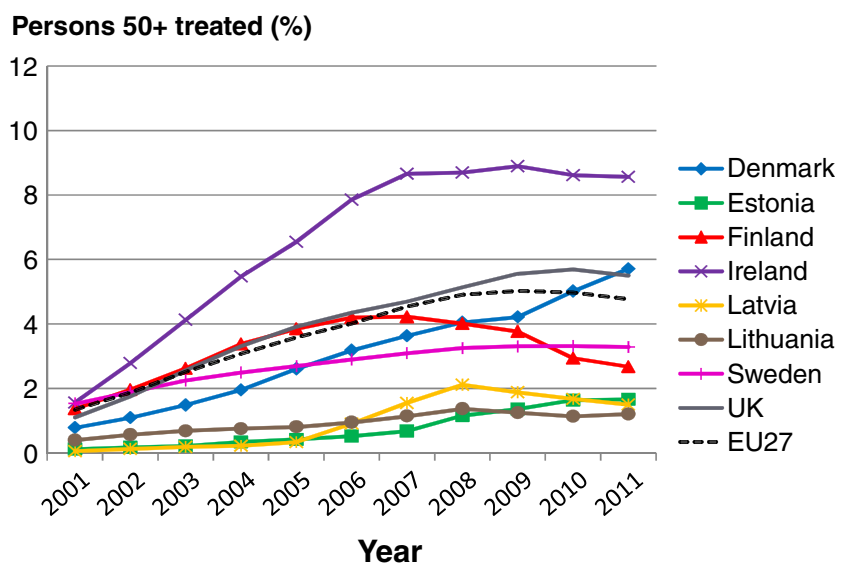

Fig. 43 Estimated proportion (\%) of the population 50 years or older treated in Northern Europe

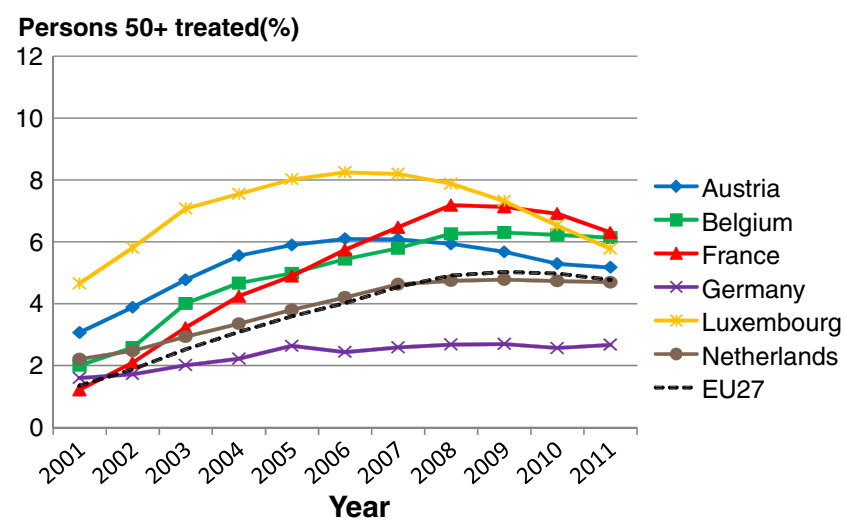

Fig. 44 Estimated proportion (\%) of the population 50 years or older treated in Western Europe

sharp contrast to statins, for example simvastatin, where after patent expiration the sales in volume more than doubled. In the UK, treatments for hypercholesterolaemia and osteoporosis have been available for a similar time period; simvastatin was introduced in 1989 and etidronate in 1992. Simvastatin and alendronate were the most prescribed products in their drug class prior to the introduction of cheap generic equivalents in 2003 and 2005, respectively. In 2007 there was, however, a 5-fold difference between peak annual drug spend on statins and osteoporosis drugs indicating significantly different levels of clinical activity in these two chronic diseases [24]. There may be several reasons for the observed development. One is that there are fewer incentives to market the product or that better alternatives are available. This seems unlikely given the continued dominance of alendronate in the market and the contraction of the general market. A possible factor may be that persistence has reduced over time, and there is some evidence that generic formulations are associated with a greater frequency of adverse effects and poorer persistence than proprietary formulations [25]. The factor that is likely to have affected the market, particularly the bisphosphonates, is the wide publicity given to rare side effects so that many doctors

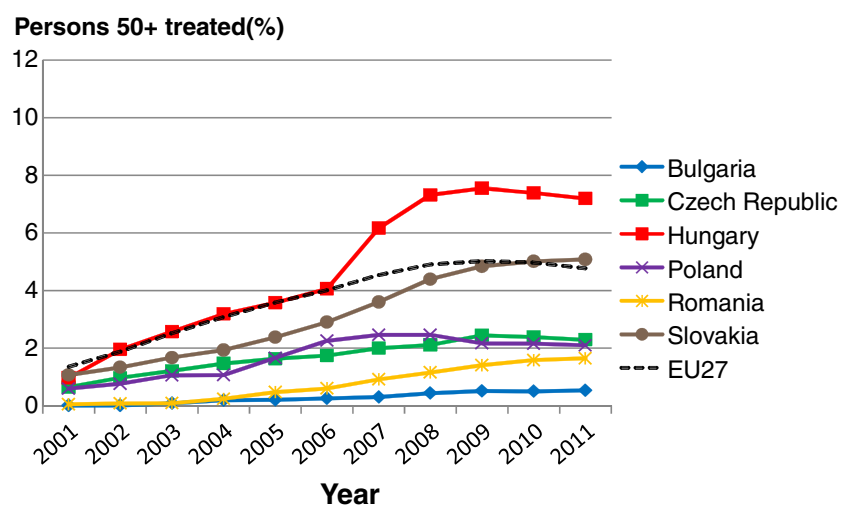

Fig. 45 Estimated proportion (\%) of the population 50 years or older treated in Eastern Europe 


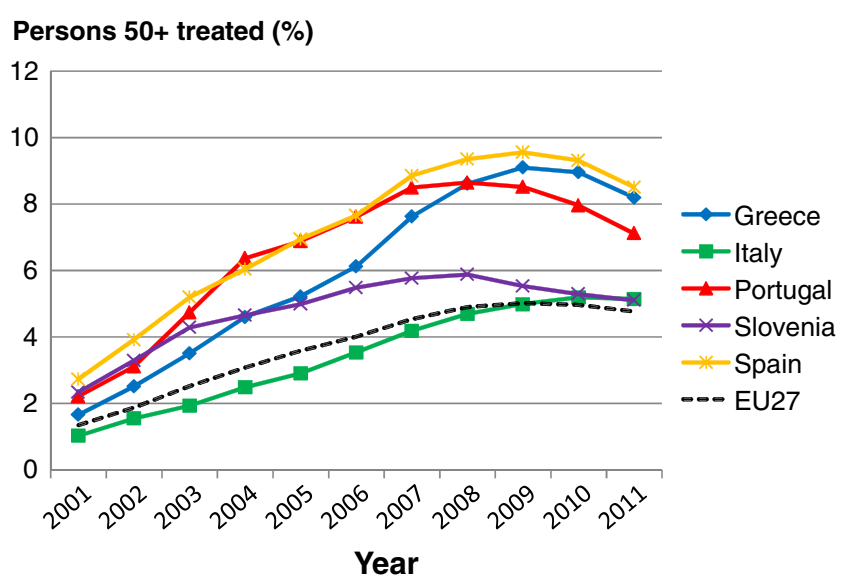

Fig. 46 Estimated proportion (\%) of the population 50 years or older treated in Southern Europe

and patients are more frightened of the side effects than they are of the disease.

The three countries with the highest uptake of alendronate in 2010 were Hungary, Ireland and the UK with approximately $1.68,1.17$ and 1.14 million DDDs per 100 persons aged 50 years or above, respectively. The three countries with the lowest uptake in 2010 were Bulgaria, Lithuania and Slovakia (42, 74 and 75 DDDs per 100 persons aged 50 years or above, respectively). The difference between the country with the highest and the lowest uptake was thus 40 -fold. However, it should be noted that sales from Hungary, for example, are not adjusted for parallel trade, which consequently could be a reason for the high numbers estimated for this country.

In Northern Europe, Baltic countries were below the average for the EU27 (Fig. 47) whereas Denmark, Ireland and the UK were above the average. Finland showed a three-fold increase in uptake between 2001 and 2006,

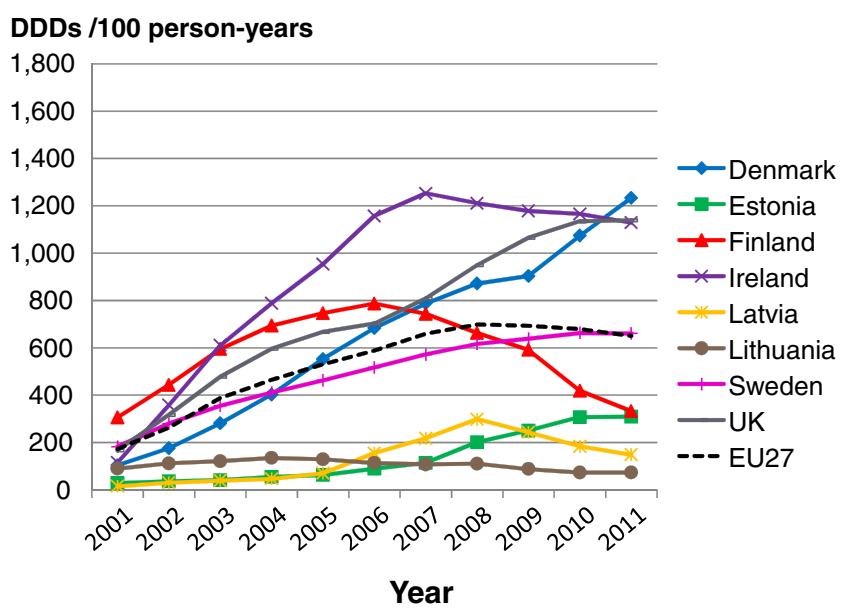

Fig. 47 Uptake of alendronate in Northern Europe (DDDs per 100 persons aged 50 years or above)
DDDs /100 person-years

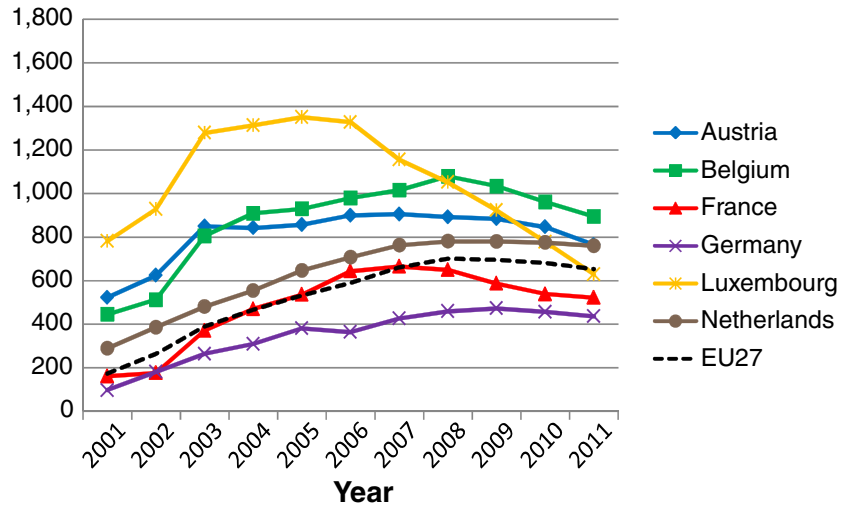

Fig. 48 Uptake of alendronate in Western Europe (DDDs per 100 persons aged 50 years or above)

followed by a decrease over the next 5 years, resulting in a below average uptake in 2011. The highest increase in uptake was observed in Denmark.

In Western Europe, except for Germany, most countries showed an above average uptake for most of the period (Fig. 48). Uptake in all countries decreased in recent years, so that in 2010, Germany, France and Luxemburg had a below average uptake in 2011.

In Eastern Europe, all countries except Hungary had lower uptake than the EU27 average (Fig. 49). The converse was noted for Southern Europe where all countries showed higher uptake than the EU27 average (Fig. 50). Slovenia and Portugal showed a marked decrease in the last few years.

\subsubsection{Denosumab}

The latest drug to be introduced for treatment of osteoporosis was denosumab-a monoclonal antibody. It was

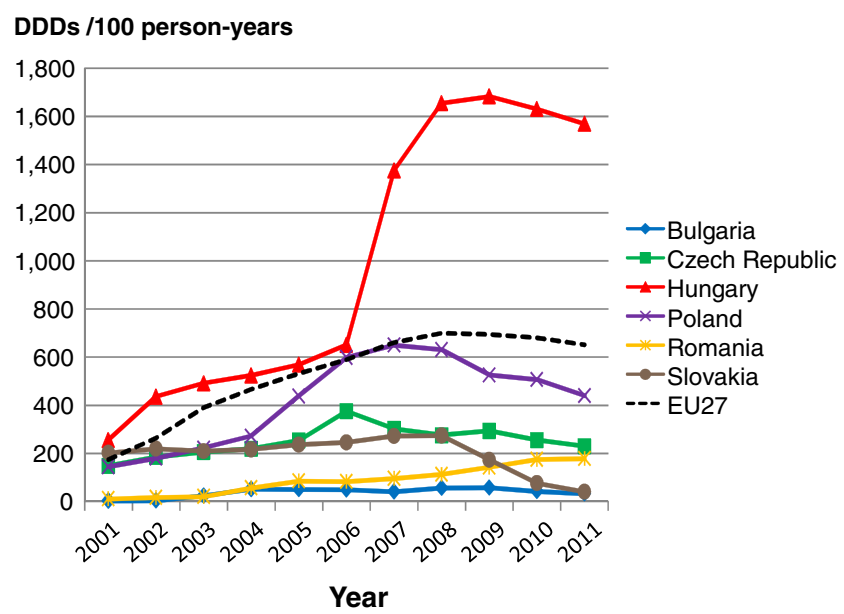

Fig. 49 Uptake of alendronate in Eastern Europe (DDDs per 100 persons aged 50 years or above) 


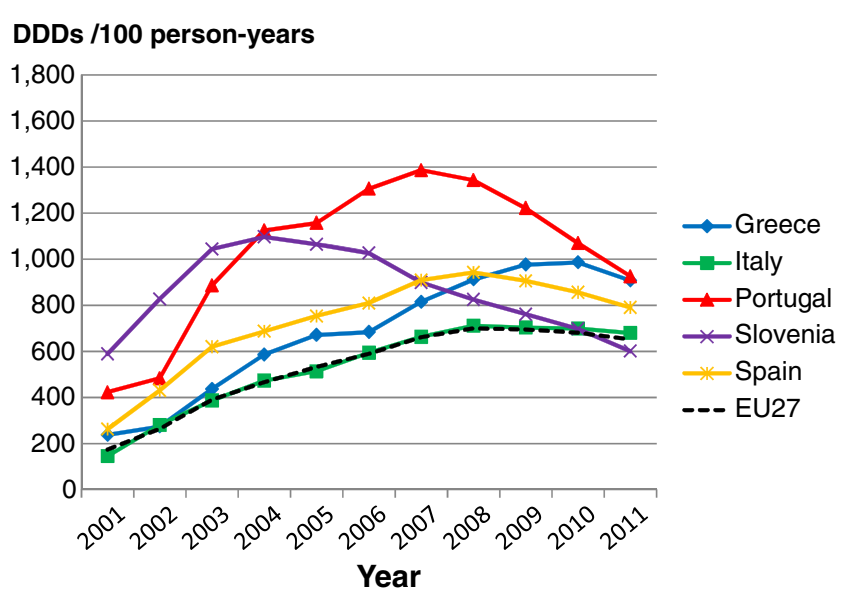

Fig. 50 Uptake of alendronate in Southern Europe (DDDs/100 persons aged 50 years or above)

introduced in 2010, and approved in nine EU countries the same year. In 2011, denosumab was sold in all countries except France, Greece and Portugal. The highest uptake in 2010 was observed in Denmark and Germany with uptakes of 8.4 and 6.4 DDD per 100 persons aged 50 years or above, respectively, and in 2011 in Slovakia (160 DDDs per 100 persons aged 50 years or above) (Fig. 51).

\subsubsection{Etidronate}

In 2011, etidronate was marketed in 11 EU countries. Overall, the uptake decreased markedly from 76 DDDs in 2001 per 100 persons aged 50 years or above to 3 DDDs per 100 persons aged 50 years or above in 2011. The phenomenon likely reflects the availability of new bisphosphonates with more robust evidence for efficacy. Sweden had the highest uptake of the countries in Northern Europe, whilst there was

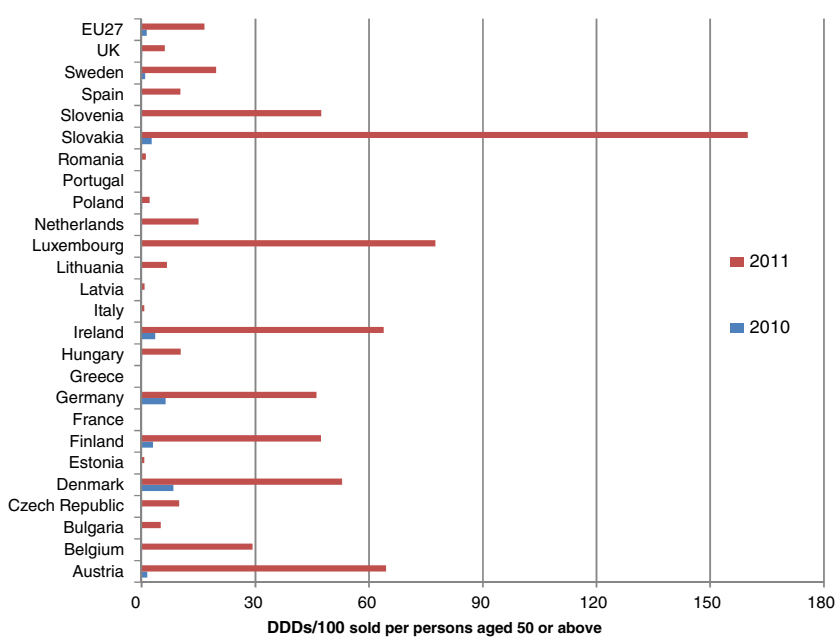

Fig. 51 Uptake of denosumab in 2010 (DDDs per 100 persons aged 50 years or above)
DDDs /100 person-years

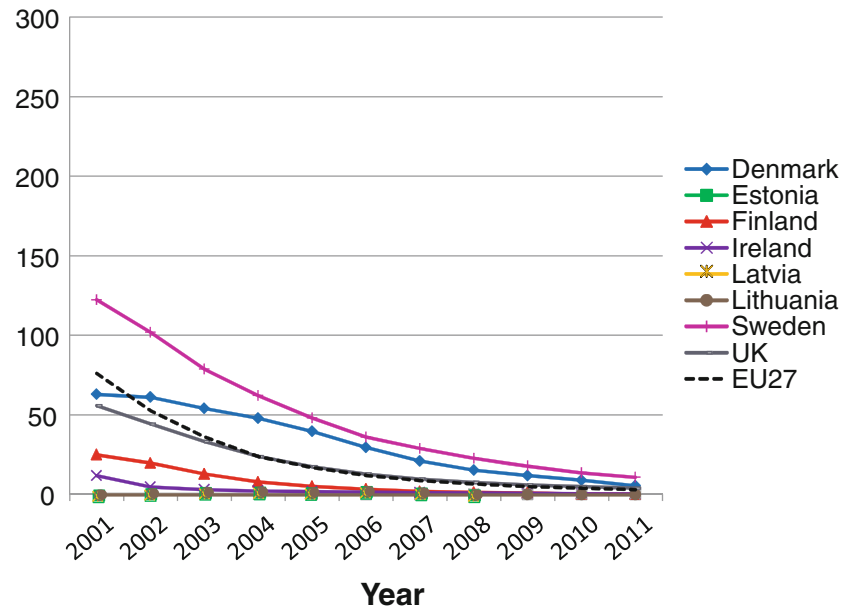

Fig. 52 Uptake of etidronate in Northern Europe (DDDs per 100 persons aged 50 years or above)

no uptake in Lithuania (Fig. 52). Of the countries in Western Europe, France followed the aggregated estimates for EU27, while there was higher uptake in Germany and the Netherlands and lower uptake than average in the other countries (Fig. 53). In Eastern Europe, etidronate was not marketed after 2005 (Fig. 54). Also in Southern Europe the uptake was low (Fig. 55). This decrease in uptake for etidronate may reflect the superior evidence that alendronate and other pharmacological therapies reduce fracture rates more than etidronate.

\subsubsection{Ibandronate}

Since the first approval of ibandronate for treatment of osteoporosis in 2005, the uptake increased in all countries (except for Sweden where ibandronate is not available for the treatment of osteoporosis) (Figs. 5659). The highest uptake in 2010 was seen in Spain, Greece and Slovenia (438, 426, and 407 DDDs per

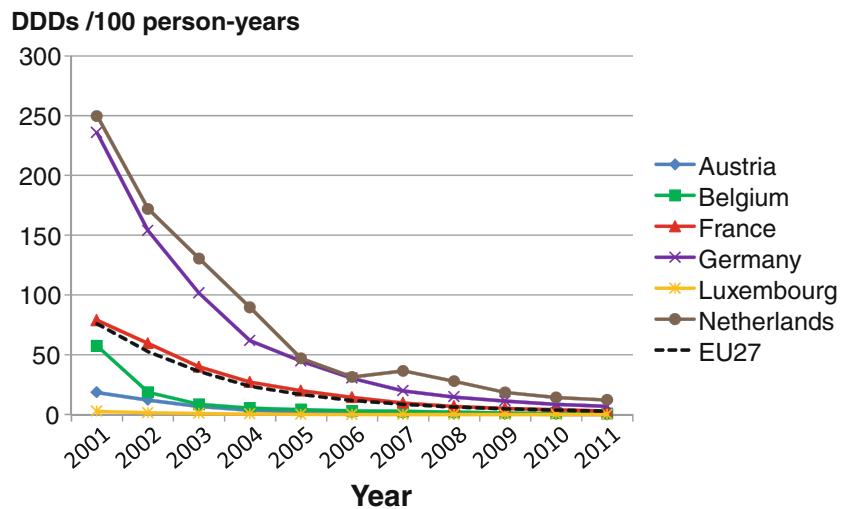

Fig. 53 Uptake of etidronate in Western Europe (DDDs per 100 persons aged 50 years or above) 


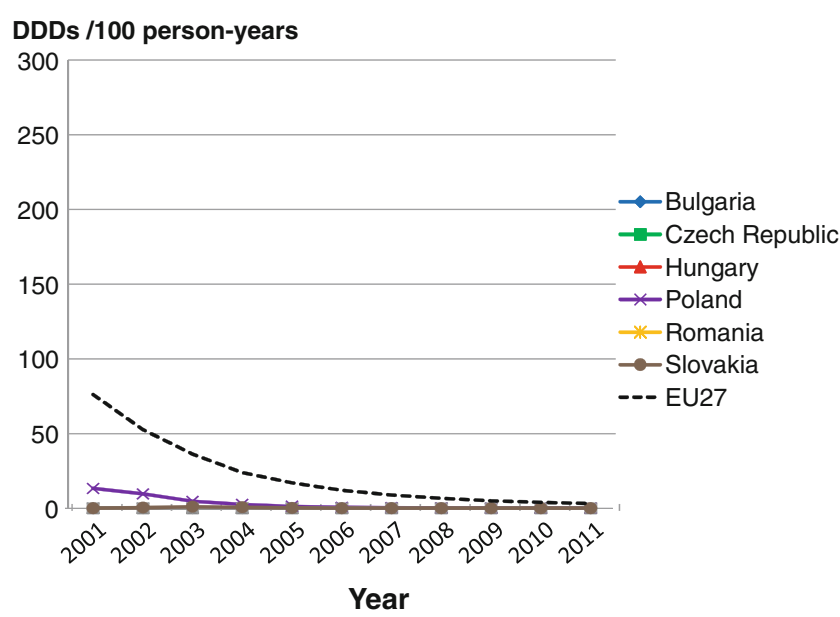

Fig. 54 Uptake of etidronate in Eastern Europe (DDDs per 100 persons aged 50 years or above)

\section{DDDs /100 person-years}

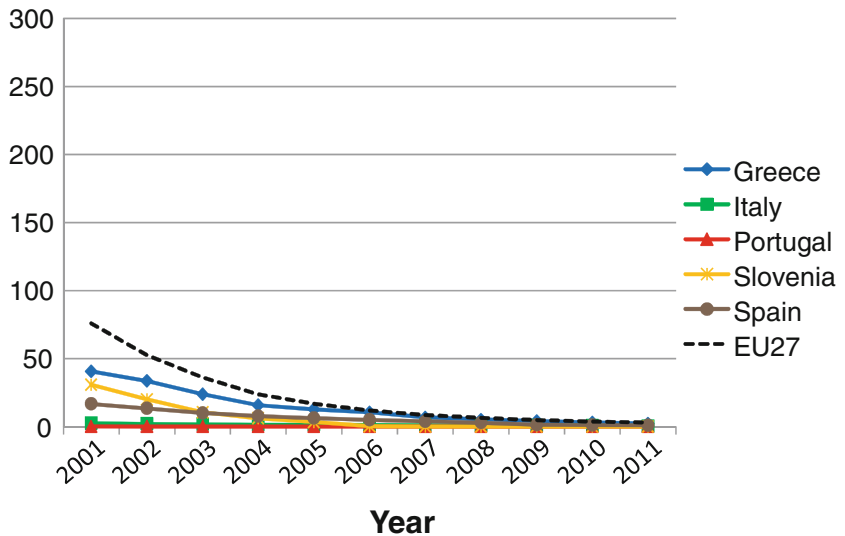

Fig. 55 Uptake of etidronate in Southern Europe (DDDs per 100 persons aged 50 years or above)

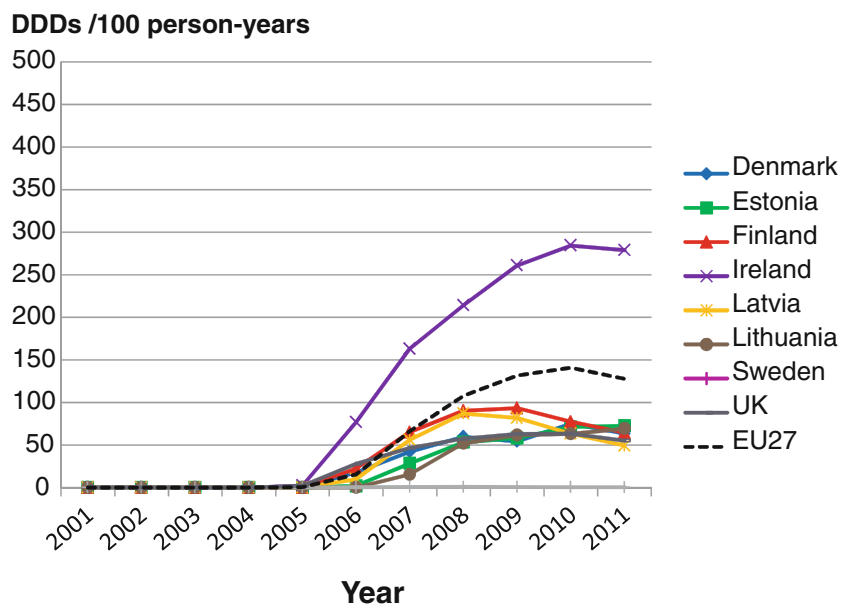

Fig. 56 Uptake of ibandronate in Northern Europe (DDDs per 100 persons aged 50 years or above)

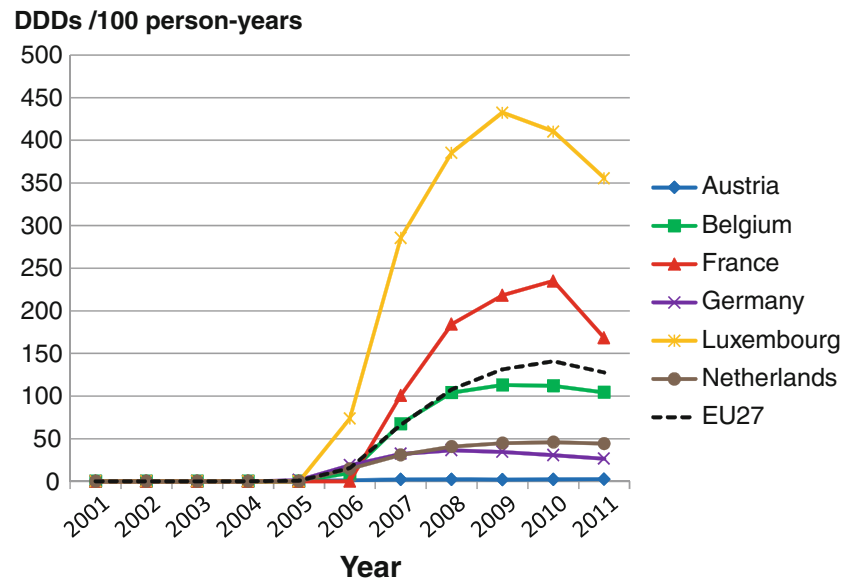

Fig. 57 Uptake of ibandronate in Western Europe (DDDs per 100 persons aged 50 years or above)

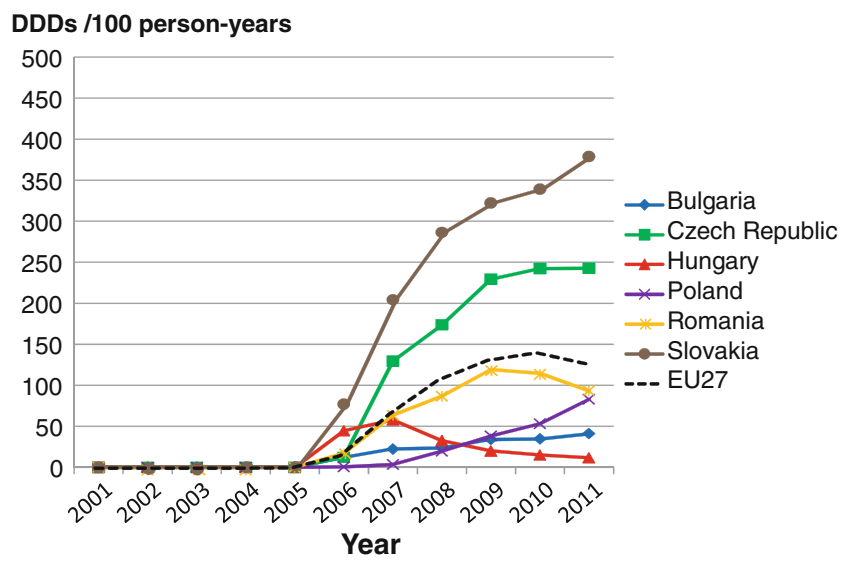

Fig. 58 Uptake of ibandronate in Eastern Europe (DDDs per 100 persons aged 50 years or above)

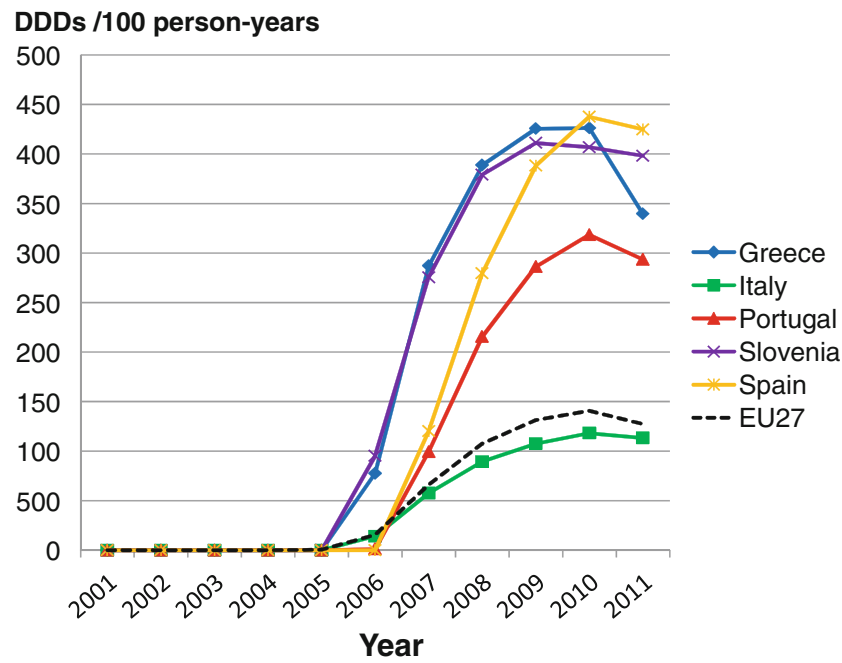

Fig. 59 Uptake of ibandronate in Southern Europe (DDDs per 100 persons aged 50 years or above) 


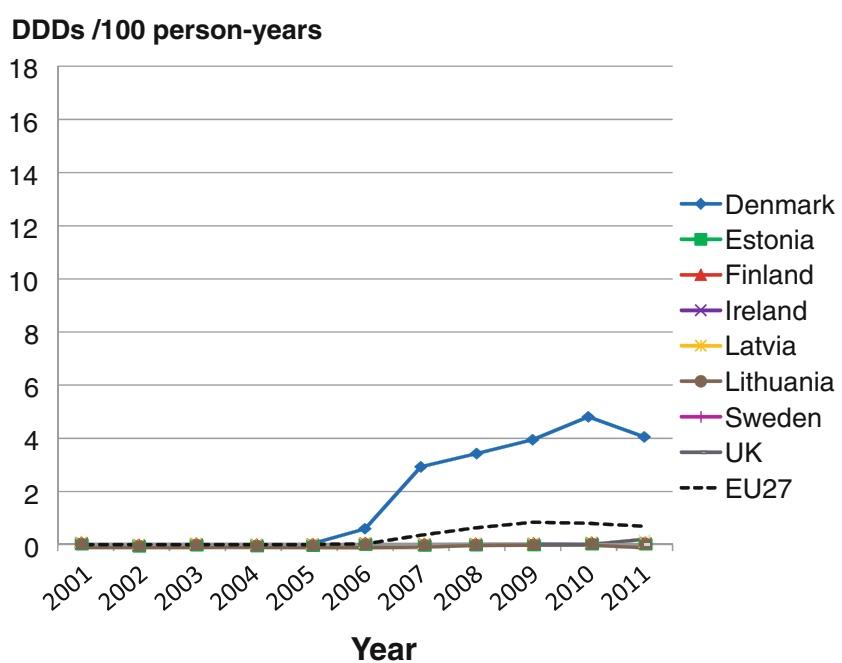

Fig. 60 Uptake of PTH in Northern Europe (DDDs per 100 persons aged 50 years or above)

100 persons aged 50 years or above, respectively). Apart from Sweden, Austria (2.2 DDDs per 100 persons aged 50 years or above), Hungary (15.1 DDDs per 100 persons aged 50 years or above) and Germany (30.6 DDDs per 100 persons aged 50 years or above) show the lowest uptake in 2010. When estimating the uptake of ibandronate, only prescriptions for osteoporosis and not cancer related treatment were considered.

\subsubsection{PTH (1-84)}

The first sales of PTH were registered in 2006. PTH (1-84) is the recombinant full-length PTH protein (amino acids 1-84), in contrast to teriparatide, which comprises the first 34 amino acids of PTH. In 2011, PTH was sold in 16 out of 27 countries in the European Union. In 2010, the highest uptake was observed in

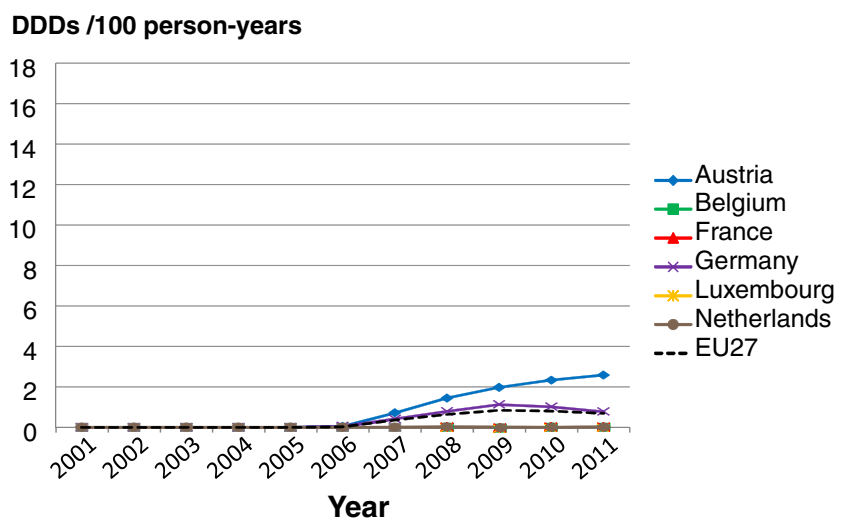

Fig. 61 Uptake of PTH in Western Europe (DDDs per 100 persons aged 50 years or above)

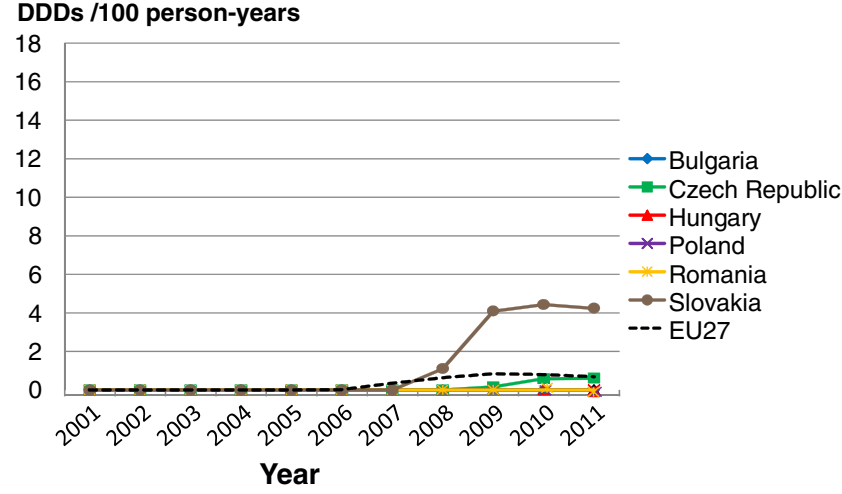

Fig. 62 Uptake of PTH in Eastern Europe (DDDs per 100 persons aged 50 years or above)

Greece, followed by Denmark and Slovakia (11.2, 4.8. and 4.4 DDDs/100 persons aged 50 years or above, respectively) (Figs. 60-63).

\subsubsection{Raloxifene}

In the European Union, the uptake of raloxifene increased from 2001 to 2005 and then decreased continuously. Raloxifene has been shown to increase the risk of venous thromboembolic events when compared to controls. On the other hand, beneficial effects on the risk of breast cancer were seen [26]. The uptake of raloxifene was highest in Spain throughout the time period studied, followed by France and Portugal (232, 202, and 167 DDDs per 100 persons aged 50 years or above, respectively, in 2010). Latvia and Estonia had virtually no uptake of this drug. By region, the uptake was highest in Southern Europe and lowest in Northern and Eastern Europe (Figs. 64 to 67).

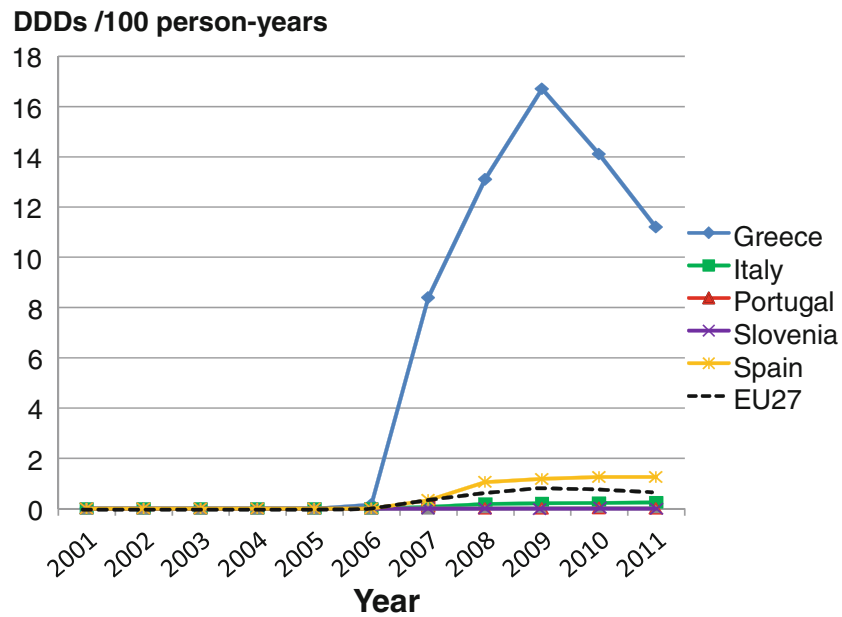

Fig. 63 Uptake of PTH in Southern Europe (DDDs per 100 persons aged 50 years or above) 


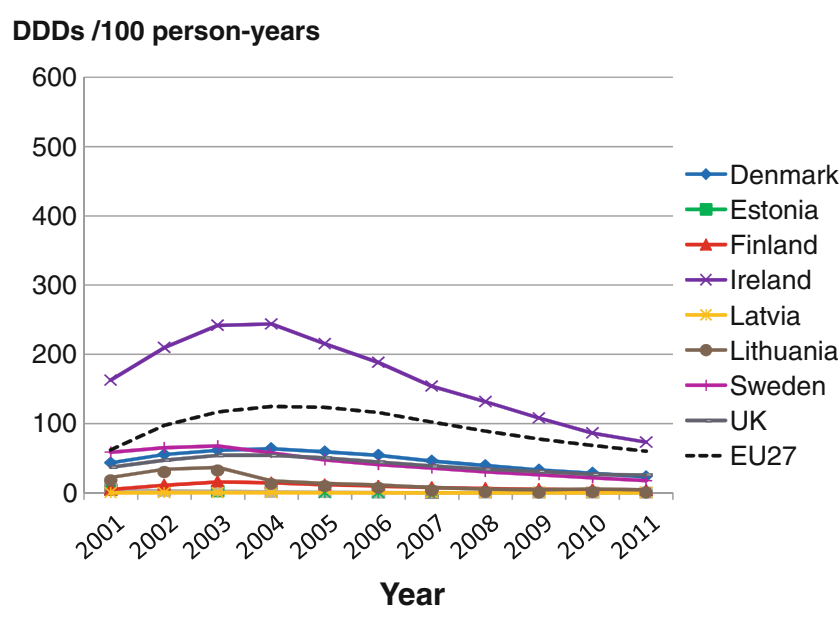

Fig. 64 Uptake of raloxifene in Northern Europe (DDDs per 100 persons aged 50 years or above)

\subsubsection{Risedronate}

The uptake of risedronate increased rapidly between 2001 and 2006 but has not changed substantially between 2006 and 2010 when studied at the level of the European Union, although a slight downward trend is evident in later years (Figs. 68-71). In individual countries, uptake is seen both to increase (e.g., in Slovakia, Spain and Greece) and decrease substantially (e.g., in Austria, Germany and Portugal) over the last 5 years. The highest uptake in 2010 was seen in Spain (715 DDDs per 100 persons aged 50 years or above), Slovakia (606 DDDs per 100 persons aged 50 years or above) and Greece (603 DDDs per 100 persons aged 50 years or above) whilst the lowest was seen in Poland (9.7 DDDs per 100 persons aged 50 years or above), Bulgaria (18.9 DDDs per 100 persons aged 50 years or above) and Denmark (21 DDDs per 100 persons aged 50 years or above).

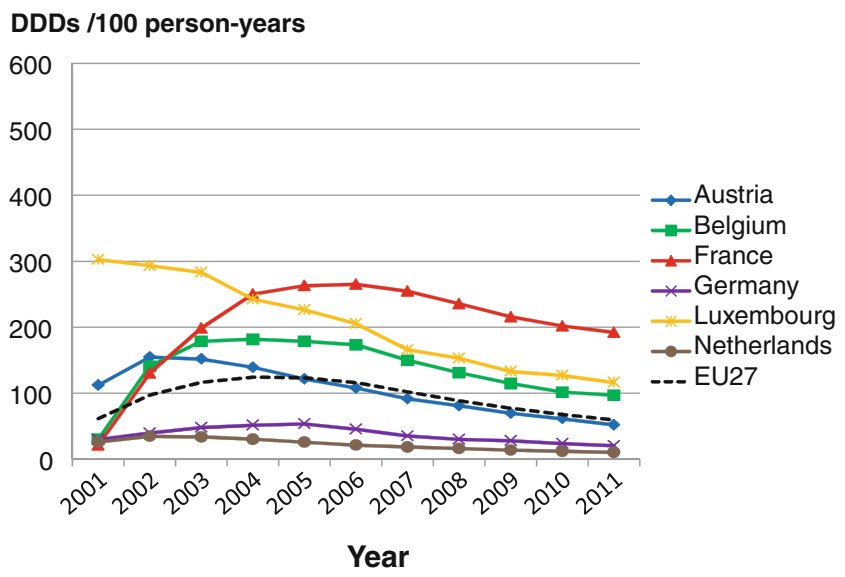

Fig. 65 Uptake of raloxifene in Western Europe (DDDs per 100 persons aged 50 years or above)

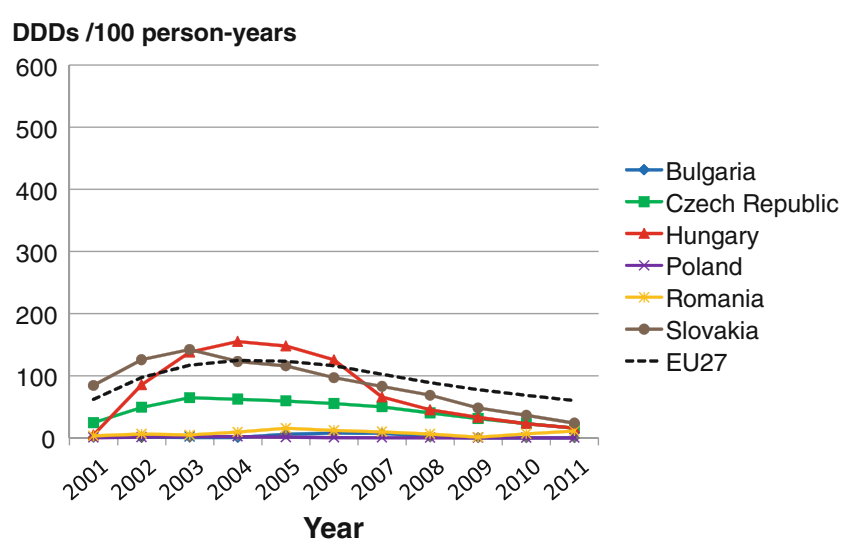

Fig. 66 Uptake of raloxifene in Eastern Europe (DDDs per 100 persons aged 50 years or above)

\subsubsection{Strontium ranelate}

Strontium ranelate showed a progressive increase in uptake in the European Union since its introduction on the market in 2004. This was also the case for most individual countries (exceptions being Latvia, Lithuania and Poland). The uptake by region is shown in Figs. 72 to 75 . Although there was a continuous increase, most countries showed modest absolute uptake of strontium ranelate. Portugal had the highest increase and level of uptake (263 DDDs per 100 persons aged 50 or above in 2010). In Northern, Eastern and Western Europe, all countries but three had an uptake below the average European uptake. In Southern Europe on the other hand, all countries had an uptake above the European average.

\subsubsection{Teriparatide}

Teriparatide is the more commonly used of the two PTH peptides available for treatment of osteoporosis (i.e.,

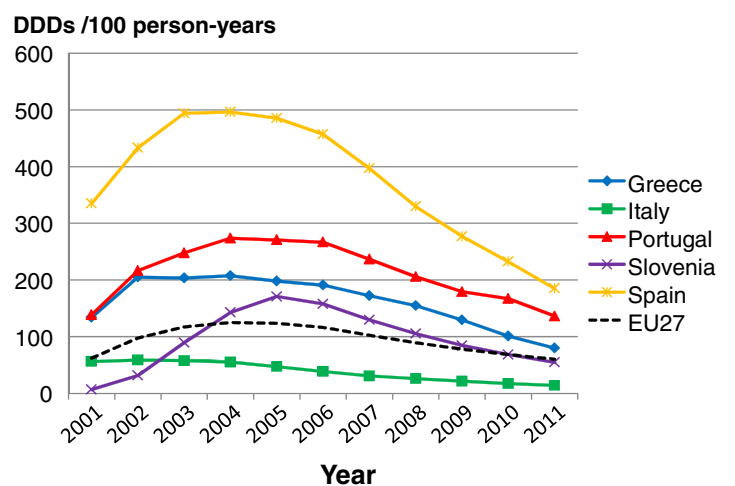

Fig. 67 Uptake of raloxifene in Southern Europe (DDDs per 100 persons aged 50 years or above) 


\section{DDDs /100 person-years}

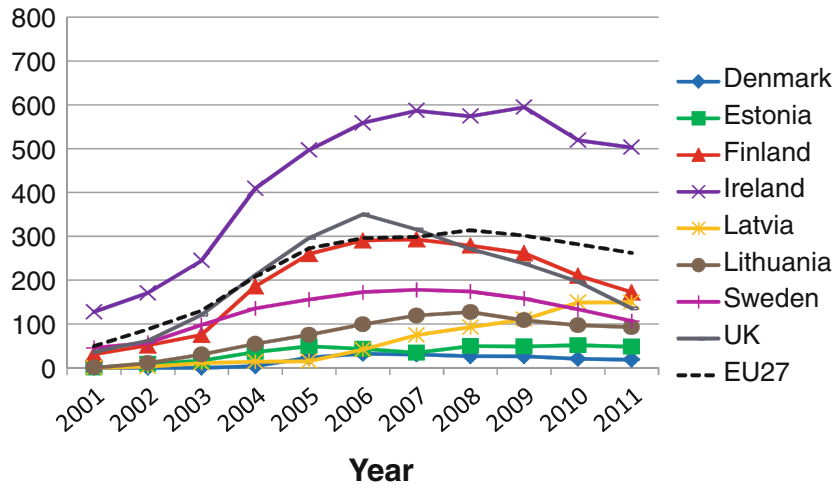

Fig. 68 Uptake of risedronate (DDDs per 100 persons aged 50 years or above) in Northern Europe

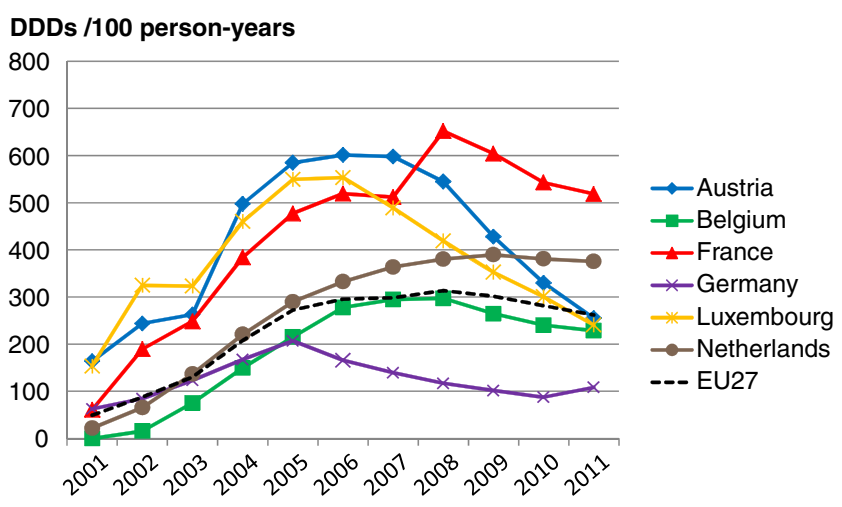

\section{Year}

Fig. 69 Uptake of risedronate (DDDs per 100 persons aged 50 years or above) in Western Europe

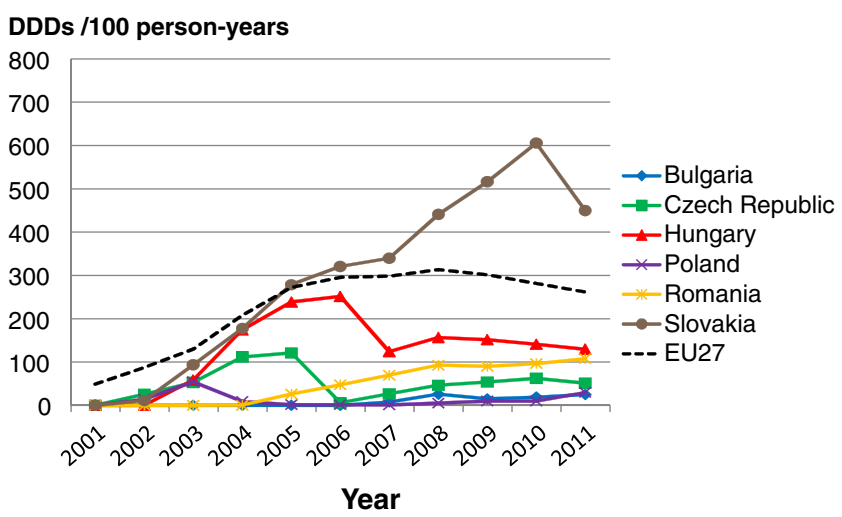

Fig. 70 Uptake of risedronate (DDDs (per 100 persons aged 50 years or above) in Eastern Europe

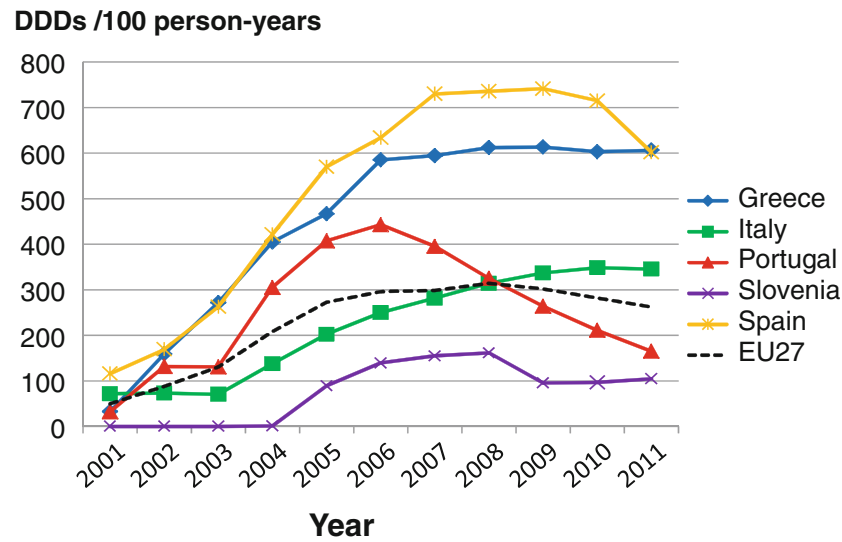

Fig. 71 Uptake of risedronate (DDDs (per 100 persons aged 50 years or above) in Southern Europe

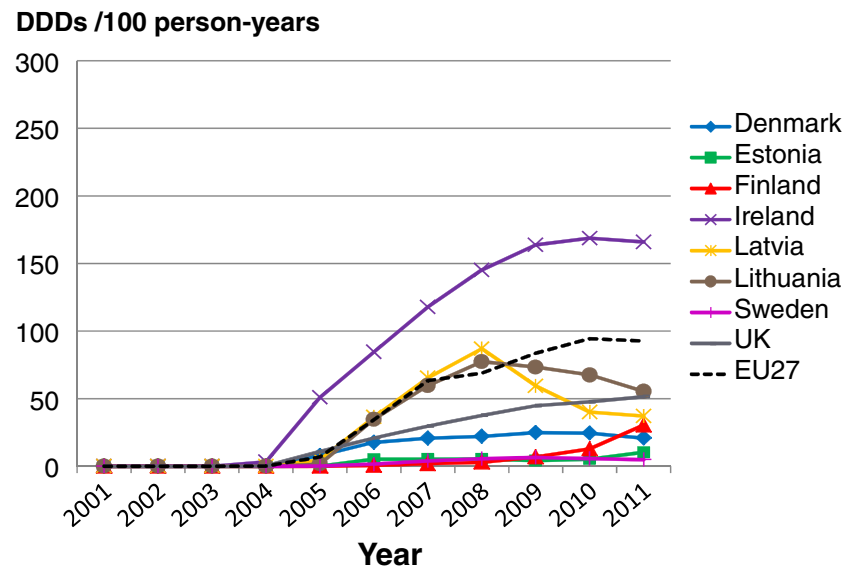

Fig. 72 Uptake of strontium ranelate in Northern Europe (DDDs per 100 persons aged 50 years or above)

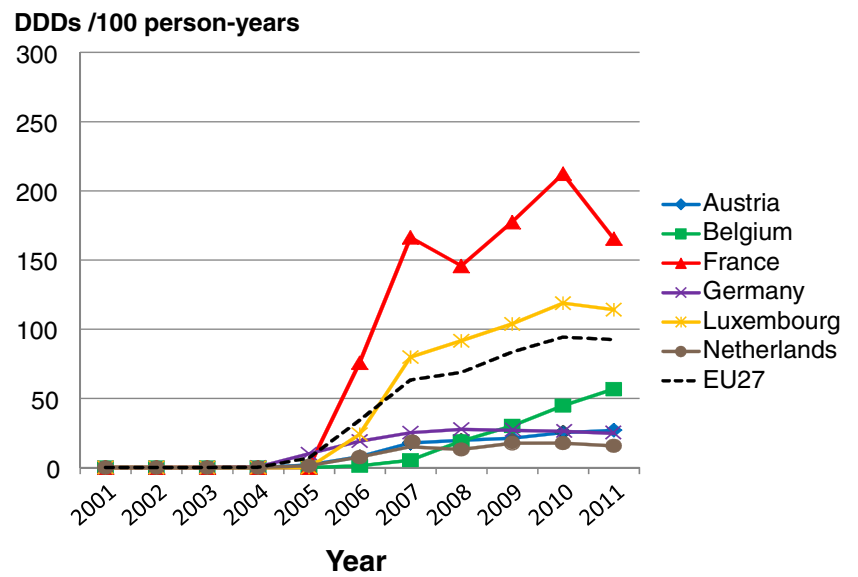

Fig. 73 Uptake of strontium ranelate in Western Europe (DDDs per 100 persons aged 50 years or above) 


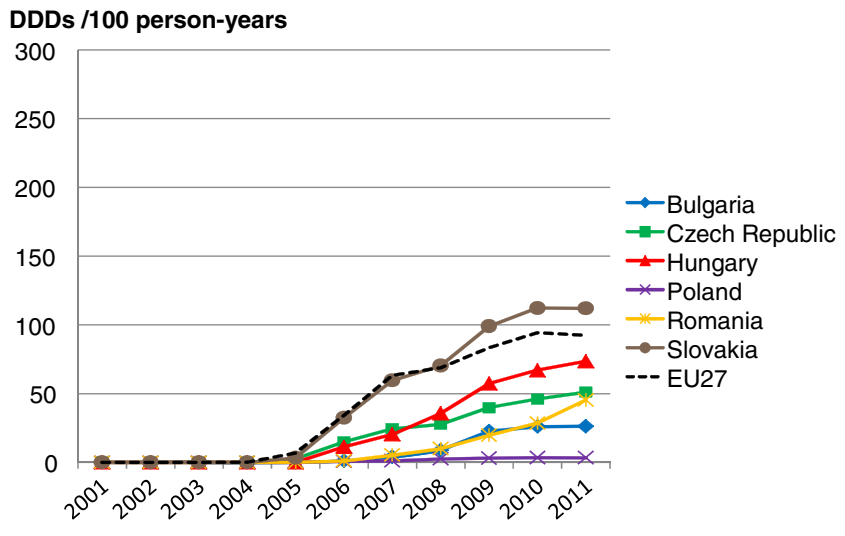

Year

Fig. 74 Uptake of strontium ranelate in Eastern Europe (DDDs (per 100 persons aged 50 years or above)

\section{DDDs /100 person-years}

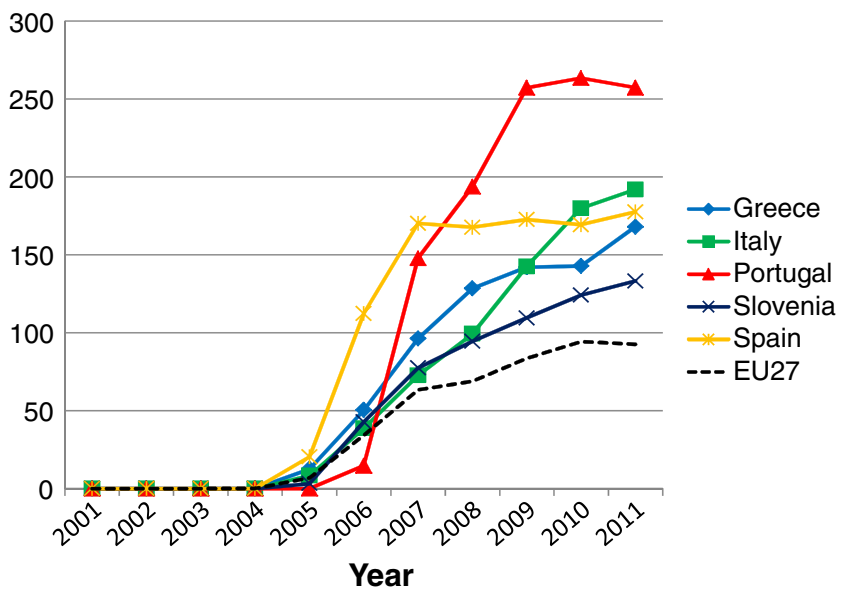

Fig. 75 Uptake of strontium ranelate in Southern Europe (DDDs per 100 persons aged 50 years or above)

\section{DDDs /100 person-years}

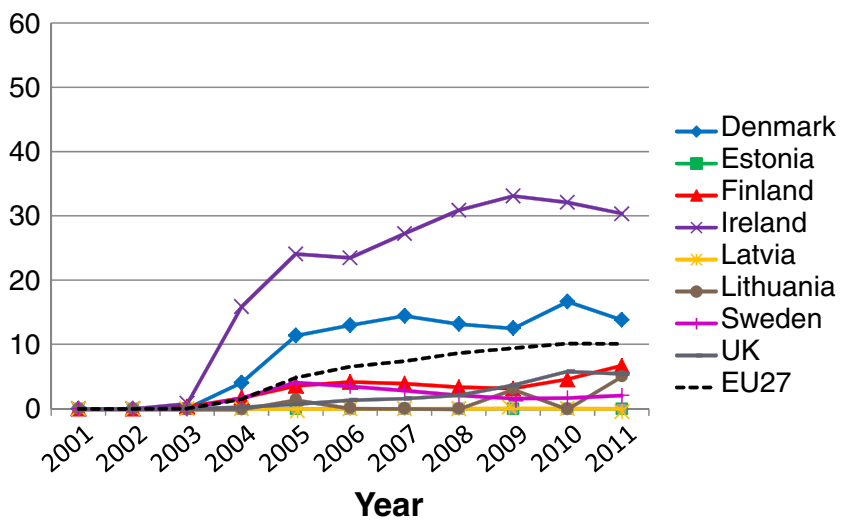

Fig. 76 Uptake of teriparatide in Northern Europe (DDDs per 100 persons aged 50 years or above)
DDDs /100 person-years

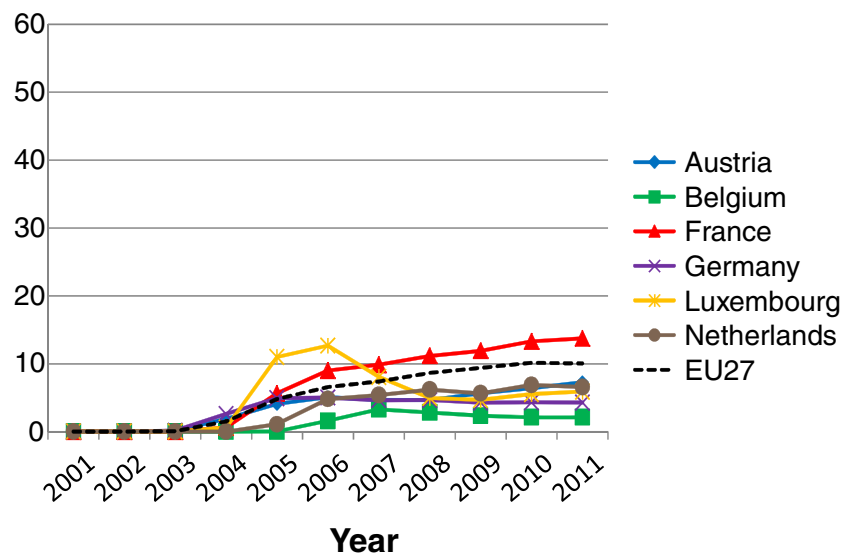

Fig. 77 Uptake of teriparatide in Western Europe (DDDs per 100 persons aged 50 years or above)

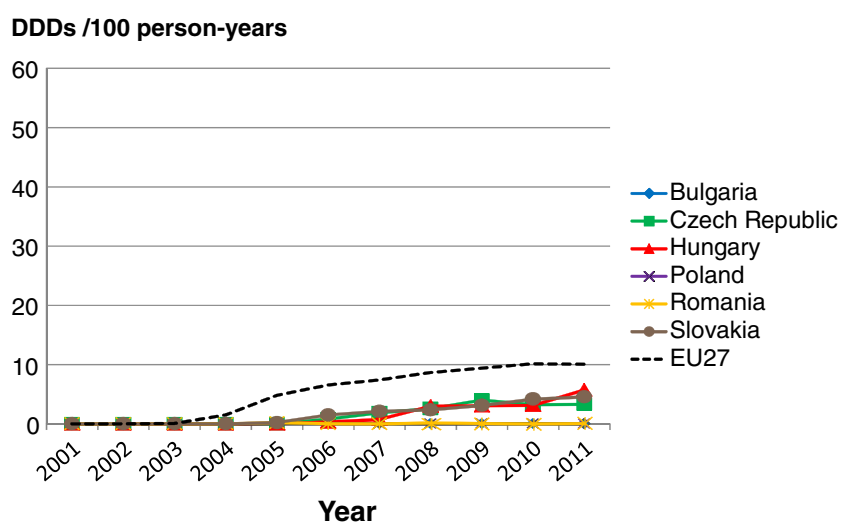

Fig. 78 Uptake of teriparatide in Eastern Europe (DDDs per 100 persons aged 50 years or above)

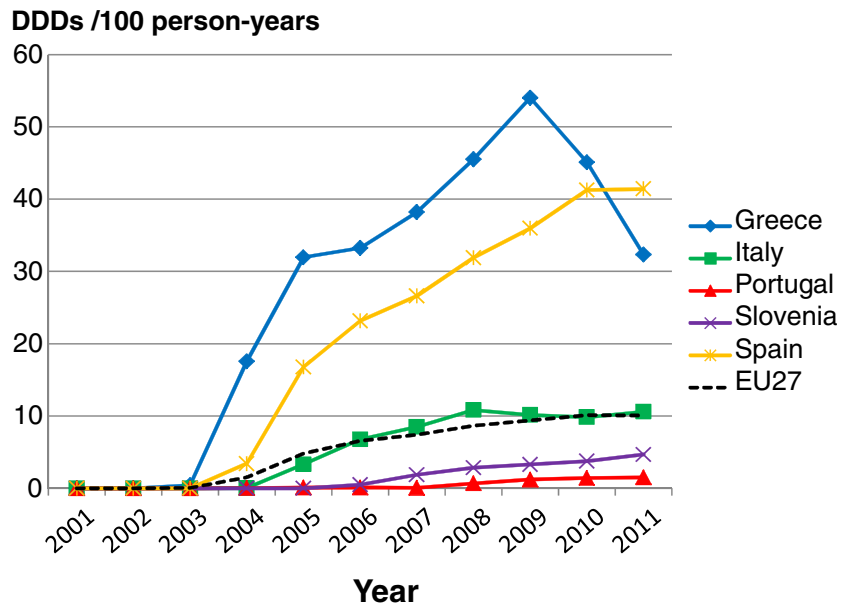

Fig. 79 Uptake of teriparatide in Southern Europe (DDDs per 100 persons aged 50 years or above) 
DDDs /100 person-years

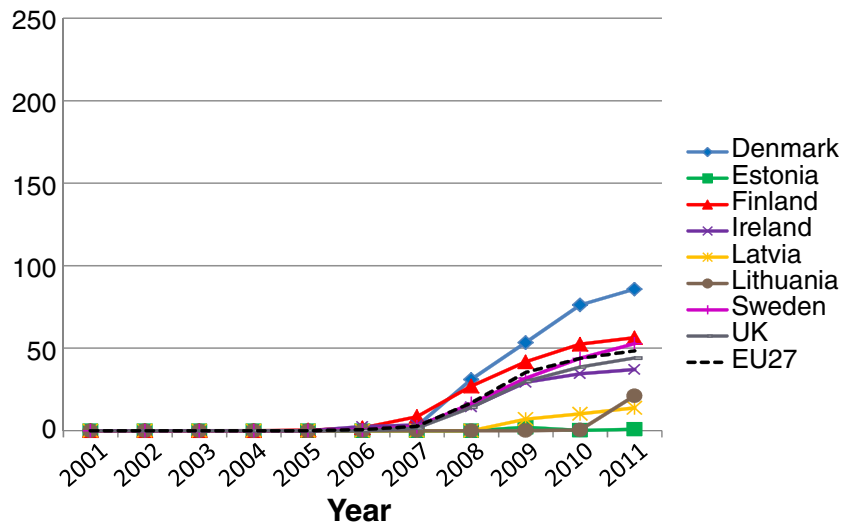

Fig. 80 Uptake of zoledronic acid in Northern Europe (DDDs per 100 persons aged 50 years or above)

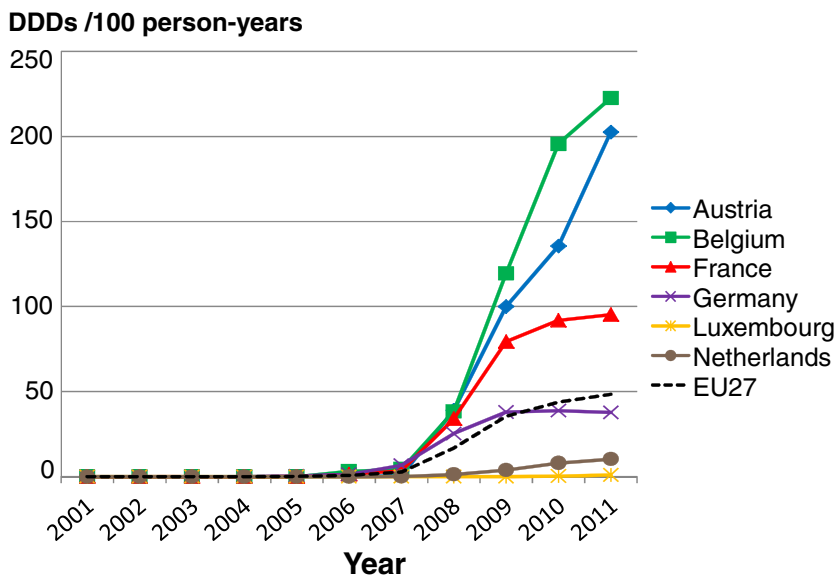

Fig. 81 Uptake of zoledronic acid in Western Europe (DDDs per 100 persons aged 50 years or above)

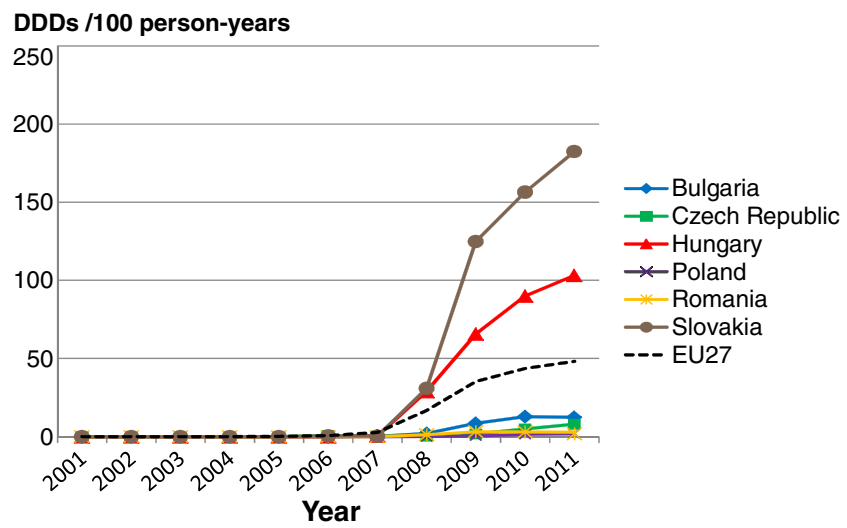

Fig. 82 Uptake of zoledronic acid in Eastern Europe (DDDs per 100 persons aged 50 years or above)
DDDs /100 person-years

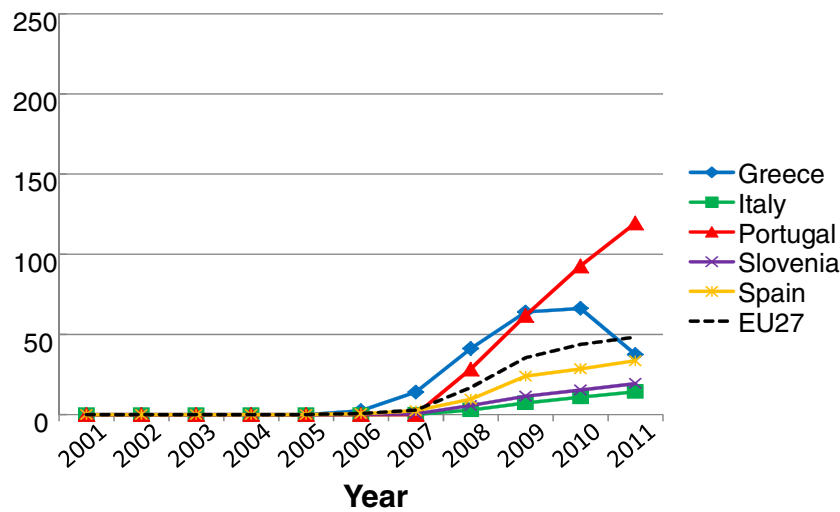

Fig. 83 Uptake of zoledronic acid in Southern Europe (DDDs per 100 persons aged 50 years or above)

teriparatide and $\mathrm{PTH}$ ). It is sold in all countries of the European Union except in Bulgaria. Even though there has been a steady increase in uptake of teriparatide since its introduction on the market in 2003, the absolute numbers remain low. Up until 2011, sales were highest in Greece (peaking at 54 DDDs per 100 persons aged 50 or above in 2009). In 2011, sales were highest in Spain, estimated at 41 DDDs per 100, persons aged 50 years or above, in 2010 . The uptake per region is shown in Figs. 76 to 79. Compared to other regions, Eastern Europe had a low uptake of teriparatide.

\subsubsection{Zoledronic acid}

The uptake of zoledronic acid increased steeply since its approval for osteoporosis in 2005. Note that cancer-related

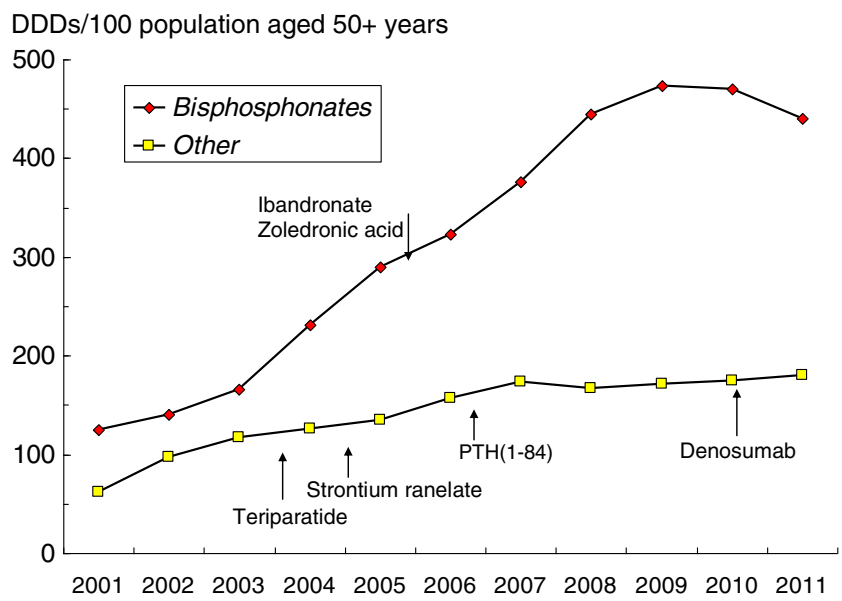

Fig. 84 Estimated sales (DDDs/100 population aged 50+ years) from 2001 to 2011 
use of zoledronic acid was not included in this analysis. Figures 80 to 83 show uptake of zoledronic acid in Northern, Western, Eastern and Southern Europe, respectively. The pattern of uptake was different with zoledronic acid compared to most other drugs, with highest uptake in Western and Eastern Europe and lowest in Northern and Southern Europe. The individual country with the highest uptake was Belgium, followed by Slovakia (196 and 156 DDDs per 100 persons aged 50 years or above in 2010, respectively). Luxembourg and Estonia had very low uptakes of zoledronic acid.

\subsubsection{Summary}

Overall, these data indicate a decrease in the population coverage in the last 2 years (i.e., the proportion of the population treated at or above the age of 50 years). Also the pattern of drugs prescribed has changed over the 11 years studied (2001-2011). The population coverage varies substantially between countries. Ireland is the country where the highest proportion of the population over 50 years is treated, followed by Spain and Greece. The high numbers observed for Ireland and Greece could be a result of parallel trade, since the data from IMS Health were not corrected for this factor in these countries. The lowest proportions treated were found in Bulgaria, Romania and the Baltic States. In Bulgaria, $0.5 \%$ of the population above 50 years is treated. This can be compared to population coverage of almost $9 \%$ in Ireland. The uptake of etidronate and raloxifene was observed to decrease over the study period, whereas the uptake of all other treatments was generally observed to increase. As expected, the increase was highest for drugs approved within the study period. In all years of analysis, the drug with the highest uptake was alendronate. As mentioned in the Data and methods section however, all analyses should be interpreted with caution since the original sales data are imperfect.

The most disturbing finding is the plateau and downward trend in the number of patients being treated. The

Table 63 FRAX 10-year probability (\%) of a major osteoporotic fracture in women with a previous fracture (no other clinical risk factors, BMI of $24 \mathrm{~kg} / \mathrm{m}^{2}$ and without BMD)

\begin{tabular}{|c|c|c|c|c|c|c|c|c|}
\hline \multirow[t]{2}{*}{ Country } & \multicolumn{8}{|c|}{ Age (years) } \\
\hline & 52 & 57 & 62 & 67 & 72 & 77 & 82 & 87 \\
\hline Austria & 10 & 12 & 15 & 19 & 25 & 31 & 38 & 41 \\
\hline Belgium & 6.1 & 8.0 & 11 & 15 & 20 & 26 & 30 & 33 \\
\hline Bulgaria* & 5.8 & 7.2 & 8.7 & 10 & 12 & 13 & 14 & 12 \\
\hline Cyprus* & 6.2 & 8.2 & 12 & 17 & 22 & 24 & 23 & 21 \\
\hline Czech Republic & 6.7 & 8.5 & 11 & 15 & 20 & 27 & 32 & 32 \\
\hline Denmark & 12 & 16 & 20 & 25 & 32 & 40 & 45 & 46 \\
\hline Estonia* & 6.4 & 8.6 & 10 & 12 & 13 & 16 & 23 & 28 \\
\hline Finland & 6.2 & 7.3 & 9.5 & 13 & 17 & 21 & 25 & 26 \\
\hline France & 5.5 & 6.3 & 8.0 & 11 & 16 & 22 & 30 & 36 \\
\hline Germany & 7.1 & 7.8 & 10 & 14 & 18 & 23 & 29 & 31 \\
\hline Greece & 5.9 & 8.2 & 11 & 15 & 20 & 24 & 26 & 24 \\
\hline Hungary & 7.1 & 10 & 12 & 13 & 17 & 24 & 28 & 26 \\
\hline Ireland & 6.9 & 9.6 & 13 & 18 & 23 & 28 & 32 & 33 \\
\hline Italy & 7.4 & 8.5 & 11 & 15 & 19 & 24 & 30 & 31 \\
\hline Latvia* & 6.4 & 8.6 & 10 & 12 & 13 & 16 & 23 & 28 \\
\hline Lithuania & 6.4 & 8.6 & 10 & 12 & 13 & 16 & 23 & 28 \\
\hline Luxembourg* & 6.1 & 8.0 & 11 & 15 & 20 & 26 & 30 & 33 \\
\hline Malta & 6.2 & 8.2 & 12 & 17 & 22 & 24 & 23 & 21 \\
\hline Netherlands & 4.5 & 6.0 & 8.2 & 11 & 15 & 19 & 22 & 22 \\
\hline Poland & 5.4 & 6.4 & 7.6 & 9.3 & 12 & 16 & 20 & 23 \\
\hline Portugal & 3.8 & 4.9 & 6.7 & 9.7 & 14 & 20 & 25 & 28 \\
\hline Romania & 5.8 & 7.2 & 8.7 & 10 & 12 & 13 & 14 & 12 \\
\hline Slovakia & 10 & 13 & 15 & 18 & 21 & 25 & 28 & 27 \\
\hline Slovenia* & 7.1 & 10 & 12 & 13 & 17 & 24 & 28 & 26 \\
\hline Spain & 3.7 & 4.6 & 6.2 & 9.0 & 13 & 18 & 24 & 24 \\
\hline Sweden & 10 & 13 & 17 & 23 & 29 & 36 & 41 & 41 \\
\hline UK & 8.2 & 11 & 14 & 18 & 22 & 25 & 30 & 33 \\
\hline
\end{tabular}

*surrogate country used 
Table 64 The proportion (\%) of the male population in each age category at or above a probability based fracture threshold

\begin{tabular}{|c|c|c|c|c|c|c|c|c|}
\hline \multirow{2}{*}{ Country } & \multicolumn{8}{|c|}{ Age } \\
\hline & $50-54$ & $55-59$ & $60-64$ & $65-69$ & $70-74$ & $75-79$ & $80-84$ & $85-89$ \\
\hline Austria & 3.0 & 4.5 & 3.0 & 2.4 & 2.3 & 3.2 & 3.0 & 3.4 \\
\hline Belgium & 3.2 & 2.6 & 3.1 & 3.4 & 3.6 & 3.2 & 3.8 & 4.0 \\
\hline Bulgaria* & 13 & 7.9 & 6.2 & 5.1 & 4.4 & 3.9 & 3.7 & 5.4 \\
\hline Cyprus* & 2.7 & 2.4 & 2.4 & 2.1 & 2.0 & 2.4 & 3.0 & 3.2 \\
\hline Czech Republic & 10 & 6.7 & 4.6 & 3.4 & 3.9 & 3.5 & 4.1 & 4.5 \\
\hline Denmark & 3.9 & 2.7 & 2.2 & 1.9 & 2.0 & 2.5 & 3.2 & 2.9 \\
\hline Estonia* & 13 & 7.4 & 5.7 & 3.9 & 4.1 & 4.3 & 3.4 & 3.5 \\
\hline Finland & 4.9 & 7.7 & 5.2 & 3.6 & 3.9 & 4.9 & 5.4 & 6.0 \\
\hline France & 2.5 & 4.5 & 2.6 & 1.9 & 2.2 & 2.5 & 2.4 & 1.5 \\
\hline Germany & 3.4 & 6.8 & 3.8 & 2.1 & 2.2 & 2.6 & 3.0 & 2.3 \\
\hline Greece & 1.3 & 1.0 & 1.2 & 1.5 & 2.6 & 4.3 & 4.8 & 4.2 \\
\hline Hungary & 4.6 & 4.7 & 3.2 & 2.8 & 3.1 & 3.8 & 5.1 & 6.0 \\
\hline Ireland & 3.5 & 2.6 & 2.1 & 2.4 & 2.7 & 3.3 & 3.7 & 3.5 \\
\hline Italy & 0.7 & 1.7 & 2.1 & 2.3 & 2.5 & 3.2 & 4.1 & 3.5 \\
\hline Latvia* & 13 & 7.4 & 5.7 & 3.9 & 4.1 & 4.3 & 3.4 & 3.5 \\
\hline Lithuania & 13 & 7.4 & 5.7 & 3.9 & 4.1 & 4.3 & 3.4 & 3.5 \\
\hline Luxembourg* & 3.2 & 2.6 & 3.1 & 3.4 & 3.6 & 3.2 & 3.8 & 4.0 \\
\hline Malta & 2.7 & 2.4 & 2.4 & 2.1 & 2.0 & 2.4 & 3.0 & 3.2 \\
\hline Netherlands & 2.3 & 1.6 & 2.2 & 3.3 & 3.7 & 4.1 & 4.2 & 3.9 \\
\hline Poland & 12 & 8.5 & 5.9 & 3.7 & 2.9 & 2.8 & 3.5 & 3.5 \\
\hline Portugal & 5.4 & 3.1 & 2.1 & 2.3 & 2.5 & 2.0 & 2.4 & 2.0 \\
\hline Romania & 13 & 7.9 & 6.2 & 5.1 & 4.4 & 3.9 & 3.7 & 5.4 \\
\hline Slovakia & 11 & 6.5 & 5.2 & 3.3 & 2.9 & 3.8 & 5.1 & 5.7 \\
\hline Slovenia* & 4.6 & 4.7 & 3.2 & 2.8 & 3.1 & 3.8 & 5.1 & 6.0 \\
\hline Spain & 3.1 & 6.3 & 3.4 & 2.1 & 2.2 & 2.3 & 2.6 & 1.8 \\
\hline Sweden & 2.6 & 2.2 & 1.9 & 2.1 & 3.1 & 3.6 & 2.8 & 1.3 \\
\hline UK & 0.9 & 1.0 & 1.2 & 1.5 & 1.5 & 1.4 & 1.2 & 0.9 \\
\hline
\end{tabular}

*surrogate country used

phenomenon is most marked in the case of the bisphosphonates (Fig. 84). As noted above, many doctors and patients are more frightened of the rare but serious side effects than they are of the disease. The substantial difference in prescribing for hypercholesterolaemia and osteoporosis may also arise because of inconsistent approaches to health technology assessment. For example, the 2008 NICE Technology Appraisals [27, 28] on osteoporosis treatments in the UK restricted access to more costly second-line agents other than generic alendronate until BMD was lower, the patient older or they developed more clinical risk factors. This was not the case for second-line statin therapies described in the relevant guidance (NICE TA 94). This inconsistency of recommendations in the two disease areas is surprising given the volume and costs incurred by the prescribing of non-generic statins by the NHS in England compared to that for bone remodelling agents.

\subsection{Patients eligible for treatments and treatment gap}

To estimate the proportion of patients treated out of those eligible for treatment, it is necessary to define an intervention threshold. There are several approaches to estimate intervention thresholds; they have traditionally been estimated on the basis of T-score for BMD with little consideration of cost-effectiveness. This approach is still largely reflected in the guidance in several European countries.

Efforts have also been made to develop intervention thresholds in osteoporosis treatment based on costeffectiveness. In Europe, several studies have described the hip fracture probability at or over which treatment becomes cost-effective [29-32].

The advent of FRAX (www.shef.ac.uk/FRAX) in 2008 provided a clinical tool for the calculation of fracture probability which can be applied to the development of intervention thresholds [33]. Application of FRAX in 
Table 65 The proportion (\%) of the female population in each age category at or above a probability based fracture threshold

\begin{tabular}{|c|c|c|c|c|c|c|c|c|}
\hline \multirow{2}{*}{ Country } & \multicolumn{8}{|c|}{ Age } \\
\hline & $50-54$ & $55-59$ & $60-64$ & $5-69$ & $70-74$ & $75-79$ & $80-84$ & $85-89$ \\
\hline Austria & 15 & 13 & 17 & 21 & 21 & 22 & 19 & 15 \\
\hline Belgium & 15 & 18 & 20 & 22 & 23 & 21 & 21 & 16 \\
\hline Bulgaria* & 8 & 11 & 15 & 18 & 20 & 20 & 18 & 20 \\
\hline Cyprus* & 17 & 19 & 22 & 23 & 23 & 21 & 19 & 16 \\
\hline Czech Republic & 10 & 13 & 17 & 18 & 21 & 19 & 18 & 16 \\
\hline Denmark & 14 & 16 & 20 & 23 & 23 & 20 & 18 & 16 \\
\hline Estonia* & 9.2 & 12 & 16 & 16 & 21 & 23 & 21 & 19 \\
\hline Finland & 11 & 12 & 15 & 19 & 20 & 20 & 18 & 16 \\
\hline France & 19 & 18 & 20 & 23 & 23 & 23 & 21 & 18 \\
\hline Germany & 16 & 15 & 18 & 22 & 22 & 21 & 19 & 17 \\
\hline Greece & 20 & 22 & 24 & 23 & 21 & 22 & 21 & 18 \\
\hline Hungary & 12 & 12 & 14 & 19 & 21 & 19 & 18 & 17 \\
\hline Ireland & 16 & 19 & 21 & 21 & 22 & 21 & 20 & 18 \\
\hline Italy & 22 & 21 & 20 & 22 & 22 & 21 & 19 & 16 \\
\hline Latvia* & 9.2 & 12 & 16 & 16 & 21 & 23 & 21 & 19 \\
\hline Lithuania & 9.2 & 12 & 16 & 16 & 21 & 23 & 21 & 19 \\
\hline Luxembourg* & 15 & 18 & 20 & 22 & 23 & 21 & 21 & 16 \\
\hline Malta & 17 & 19 & 22 & 23 & 23 & 21 & 19 & 16 \\
\hline Netherlands & 18 & 19 & 21 & 22 & 22 & 21 & 19 & 18 \\
\hline Poland & 8.8 & 12 & 15 & 19 & 21 & 21 & 21 & 19 \\
\hline Portugal & 14 & 18 & 21 & 24 & 24 & 23 & 22 & 17 \\
\hline Romania & 8 & 11 & 15 & 18 & 20 & 20 & 18 & 20 \\
\hline Slovakia & 9.6 & 12 & 17 & 19 & 20 & 20 & 19 & 15 \\
\hline Slovenia* & 12 & 12 & 14 & 19 & 21 & 19 & 18 & 17 \\
\hline Spain & 21 & 16 & 19 & 23 & 23 & 23 & 20 & 17 \\
\hline Sweden & 16 & 19 & 20 & 23 & 23 & 23 & 20 & 17 \\
\hline UK & 20 & 21 & 21 & 21 & 22 & 21 & 20 & 19 \\
\hline
\end{tabular}

clinical practice provides a tool for determination of the fracture probability at which to intervene. This can be done using two approaches: firstly to translate the current practice in the light of FRAX and justify the thresholds developed by cost-effectiveness analyses or secondly, to determine the fracture probability at which intervention becomes cost-effective. The second approach has been used in North America [34, 35] whereas the former has been favoured in Europe.

The UK guidance for the identification of individuals at high fracture risk developed by the NOGG is an example of the translation of former guidance provided by the Royal College of Physicians (RCP) [36, 37] into probability based assessment [37]. The RCP guidance indicates that women with a prior fragility fracture may be considered for intervention without the necessity for a BMD test, and the management of women over the age of 50 years on this basis has been shown to be costeffective [38]. For this reason, the intervention threshold set by NOGG was at the 10 -year fracture probability equivalent to women with a prior fragility fracture without knowledge of BMD [36]. Thus, the intervention threshold can be likened to a fracture threshold expressed in terms of fracture probability. The same intervention threshold was applied to men, since the effectiveness of intervention in men is broadly similar to that in women for equivalent risk. This translational approach from existing treatment guidelines is characterised by an intervention threshold that increases progressively with age. The major reason for this is that the source guidelines took little or no account of age. Since age is an important independent factor for fracture risk, the fracture probability of an individual with a prior fracture is higher at the age of 70 years than at the age of 50 years. This age-dependent increase in the intervention threshold is not found when intervention thresholds are derived from health economic analyses alone [37].

The NOGG guideline provides an opportunity to determine the burden of disease in terms of FRAX. In other words, to determine the number of individuals that have a 10 -year fracture probability that is equivalent to or exceeds the fracture threshold (i.e., 


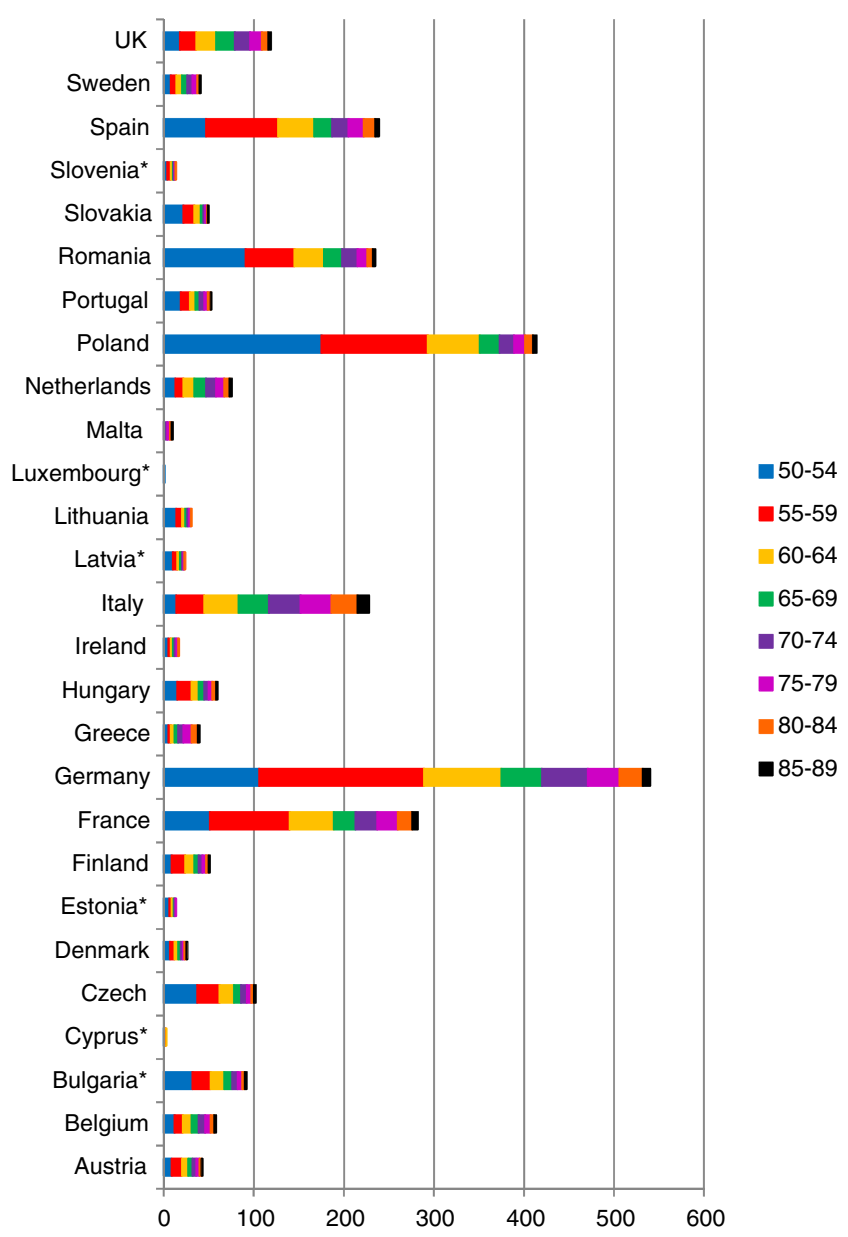

Fig. 85 Number (in thousands) of men in each age group that have a 10 -year probability for osteoporotic fracture above the probability threshold for fracture

the age and country specific probability of fracture in a woman with a prior fragility fracture). The 10-year probability of a major osteoporotic fracture of women at the fracture threshold is provided for the countries of the European Union for different ages in Table 63. The fracture thresholds differ between countries due to the differences in fracture risk in the respective countries. For example, the fracture threshold at the age of 87 years ranged from a 10 -year probability of $12 \%$ (Bulgaria and Romania) to $46 \%$ (Denmark). Note that FRAX models are not available for Bulgaria, Cyprus, Estonia, Latvia, Luxembourg and Slovenia. For these countries surrogate FRAX models were used (Romania, Malta, Lithuania, Lithuania, Belgium and Hungary, respectively). The surrogate countries were chosen on the likelihood that the fracture rate (and mortality) was similar to that of the index country.

The proportion of men and women who exceed the probability threshold for fracture can be computed by simulation based on the distribution of the risk-score among the cohorts used by WHO to develop FRAX and the epidemiology of fracture and death in each EU country. Tables 64 and 65 show the proportion of men and women with a probability of a major osteoporotic fracture exceeding that of a woman with a previous fracture and no other clinical risk factor, an average BMI and unknown BMD. This proportion, which in this report represents the proportion that could be eligible for treatment, varied between countries and by age and sex. The relative difference between countries was larger in men than in women. Greece and the UK appear to have the highest proportion of women falling above the fracture threshold, whilst the UK shows the lowest proportion of men. This variation across countries is caused by differences in fracture risk between women and men and differences in population prevalence of the risk factors used by FRAX.

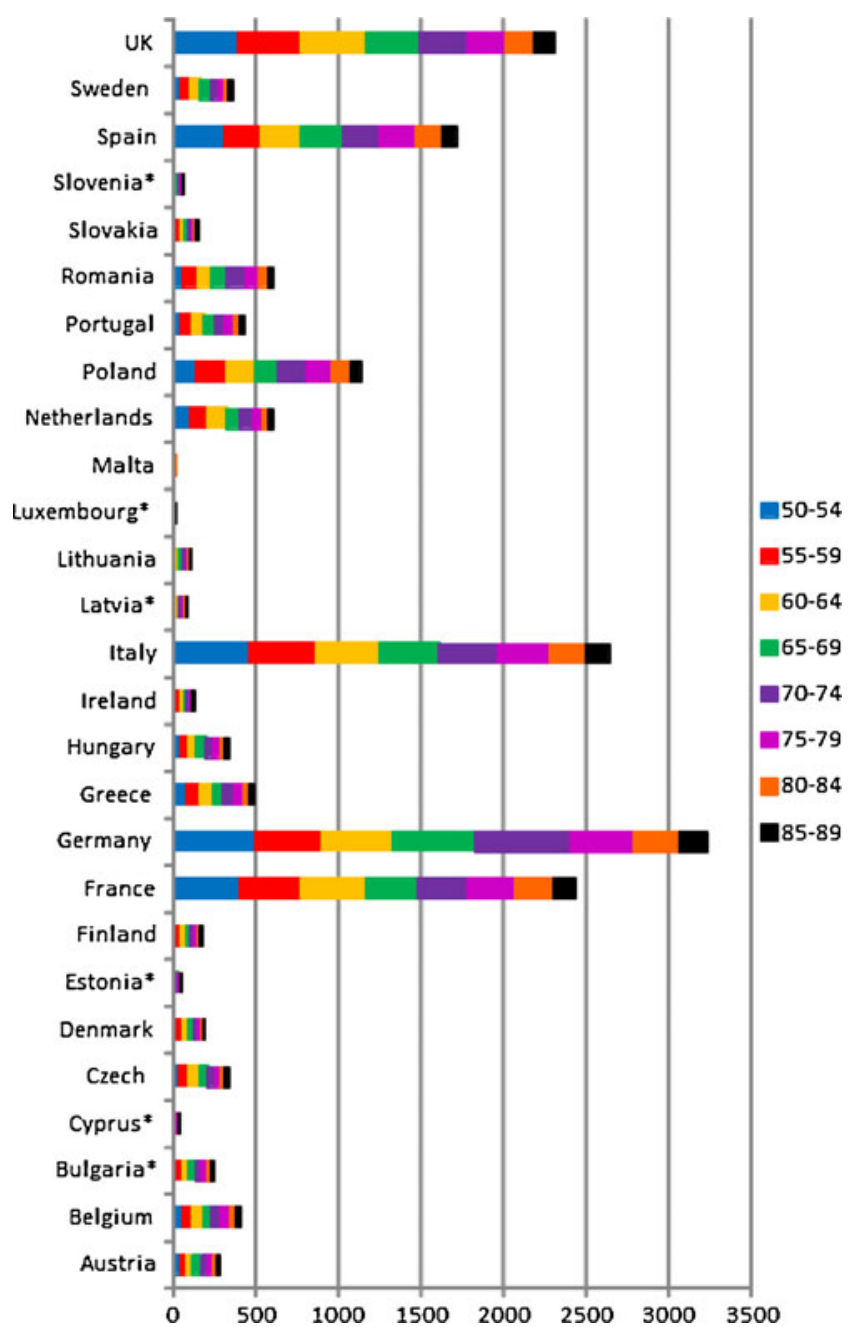

Fig. 86 Number (in thousands) of women in each age group that have a 10 -year probability for osteoporotic fracture above the probability threshold for fracture 


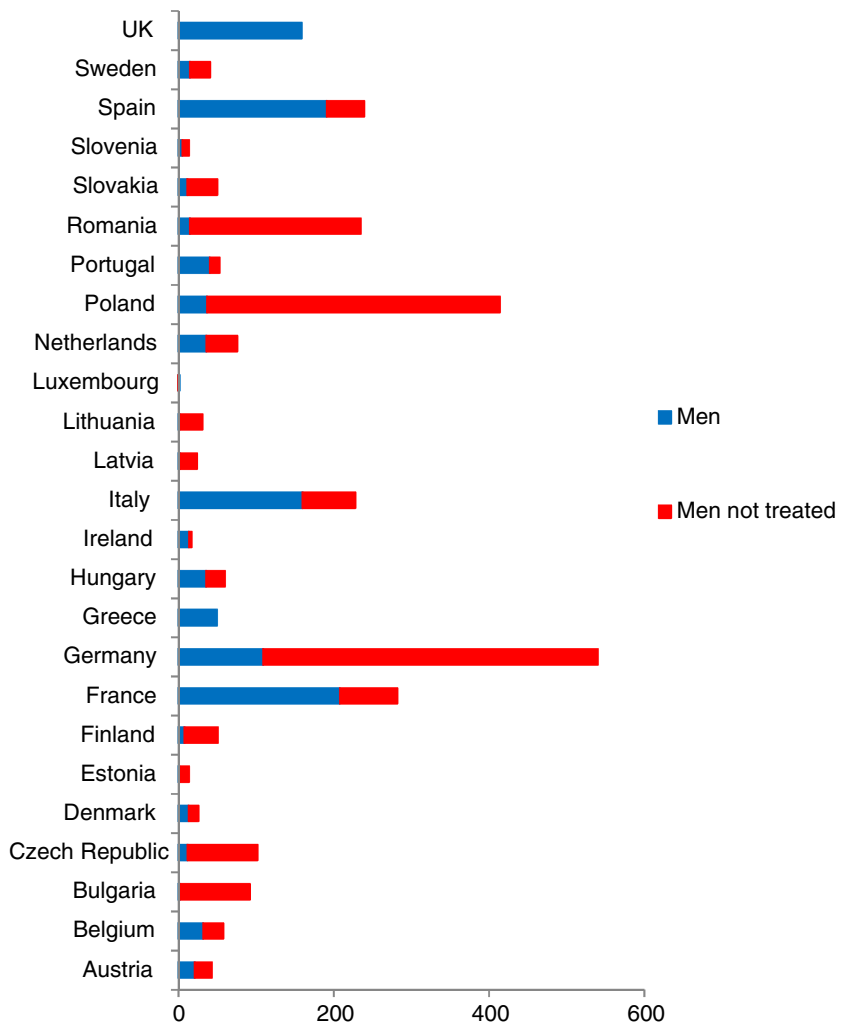

Fig. 87 Estimated number (in thousands) of men treated (blue) and patients eligible for treatment that are not treated (red) in 2010

Combined with UN data on population demography [39], the resulting number of persons with a fracture probability at or above the fracture threshold, and thus here regarded eligible for treatment, is shown for the countries of the European Union in Figs. 85 and 86.

\subsection{Proportion of patients treated}

Figures 87 and 88 show the number of men and women that could be treated for the year 2010 given sales in 2010 and adjusted for suboptimal adherence, compared to the remaining number of persons eligible for treatment according to risks described in the section above. The proportion of patients estimated to be eligible for treatment but not receiving treatment can be viewed as an approximation of the treatment gap. The treatment gap varies between countries, in accordance with different sales of anti-osteoporotic treatments as well as differences in fracture risk between countries. The highest treatment gap for women is noted for Bulgaria and the Baltic states, where less than $15 \%$ of the population eligible for treatment receives an osteoporotic drug. The same countries, with the addition of Romania, also show the highest treatment gap for men.
All of the countries in the European Union have higher estimates for women that should be treated than the estimates of patients actually treated. The lowest treatment gap is seen for Spain, where sales are high and fracture risks relatively low, with approximately $75 \%$ of the women eligible for treatment potentially treated. Other countries with low treatment gaps are Ireland and Hungary. More detailed data for men and women are shown in Table 66 and Table 67 , respectively.

For men, the data indicate that the volume of sold osteoporosis drugs would be sufficient to cover treatment for more patients than the number that fall above the fracture threshold in Greece, Luxembourg and the UK. It should be noted, however, that the results from this analysis should be interpreted with some caution since it has been assumed that the distribution of drug use between genders observed in Sweden is valid for all countries. In addition, it is not known how well treatment is targeted to the high risk population. In total in the EU, 1.7 million men out of the 2.9 million men that exceed the risk level are not treated. Corresponding numbers for women are 10.6 million out of 18.4 million women exceeding the fracture threshold.

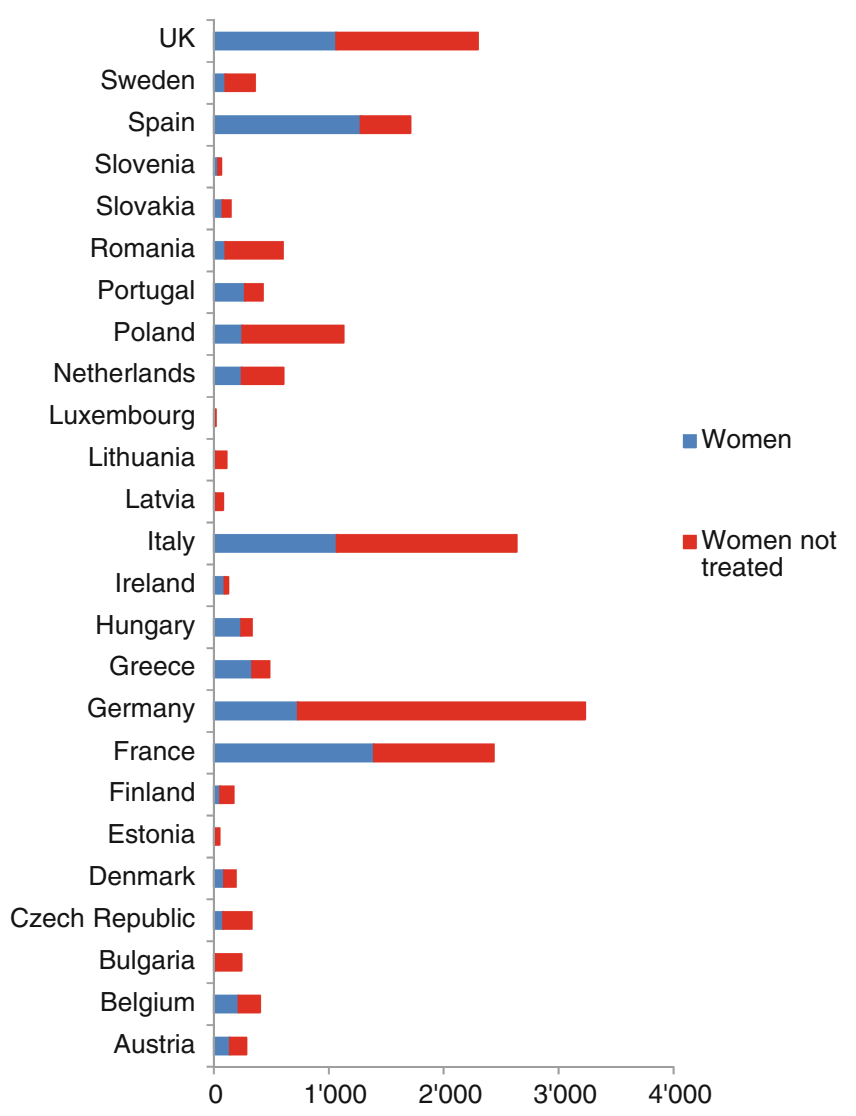

Fig. 88 Estimated number (in thousands) of women treated (blue) and patients eligible for treatment that are not treated (red) in 2010 
Table 66 Number of men eligible for treatment, treated and treatment gap in 2010

\begin{tabular}{|c|c|c|c|c|}
\hline Country & $\begin{array}{c}\text { Number } \\
\text { potentially } \\
\text { treated (1000s) }\end{array}$ & $\begin{array}{l}\text { Number exceeding } \\
\text { fracture risk } \\
\text { threshold (1000s) }\end{array}$ & $\begin{array}{l}\text { Difference } \\
\text { (1000s) }\end{array}$ & $\begin{array}{c}\text { Treatment } \\
\text { gap (\%) }\end{array}$ \\
\hline Austria & 21 & 43 & 22 & 52 \\
\hline Belgium & 32 & 58 & 26 & 45 \\
\hline Bulgaria & 2 & 92 & 90 & 98 \\
\hline Czech Republic & 12 & 102 & 90 & 88 \\
\hline Denmark & 13 & 26 & 13 & 50 \\
\hline Estonia & 1 & 14 & 13 & 93 \\
\hline Finland & 8 & 51 & 43 & 84 \\
\hline France & 208 & 282 & 74 & 26 \\
\hline Germany & 109 & 540 & 431 & 80 \\
\hline Greece & 50 & 40 & -10 & -25 \\
\hline Hungary & 36 & 60 & 24 & 41 \\
\hline Ireland & 14 & 17 & 3 & 20 \\
\hline Italy & 160 & 228 & 68 & 30 \\
\hline Latvia & 2 & 24 & 22 & 93 \\
\hline Lithuania & 2 & 31 & 29 & 95 \\
\hline Luxembourg & 1 & 1 & 0 & -35 \\
\hline Netherlands & 36 & 76 & 40 & 52 \\
\hline Poland & 37 & 414 & 377 & 91 \\
\hline Portugal & 40 & 53 & 13 & 24 \\
\hline Romania & 15 & 235 & 220 & 94 \\
\hline Slovakia & 11 & 50 & 39 & 78 \\
\hline Slovenia & 5 & 14 & 9 & 63 \\
\hline Spain & 191 & 239 & 48 & 20 \\
\hline Sweden & 15 & 41 & 26 & 63 \\
\hline UK & 159 & 119 & -40 & -34 \\
\hline EU27 & 1,178 & 2,850 & 1,672 & 59 \\
\hline
\end{tabular}

These analyses suggest that there is wide intercountry variation in the treatment penetration of women with higher risk for osteoporotic fractures. Large treatment gaps are identified in countries with populations of both high and low risks of fracture. The strength of the information based on IMS Health data is that information is available for nearly all EU member states. However, the pattern of use cannot be ascertained, so that it is not possible to determine whether treatment is targeted appropriately to high risk individuals. There are several indicators that suggest that the targeting of treatment is heterogeneous in the EU. Good evidence comes from the Global Longitudinal Study of Osteoporosis in Women (GLOW) which is a general practice based observational cohort study in women aged 55 years or more conducted in 10 countries, including several EU countries [40]. In the EU, there was heterogeneity of treatment uptake between countries with the lowest proportion of women aged 55 years or more treated in the Netherlands (7\%) and the highest in Spain (23\%) (Fig. 89). Although treatment uptake was higher in women at very high risk (a prior hip or spine fracture), a minority (45 \%) was receiving treatment in these countries.
Again, there was heterogeneity in treatment uptake with a range from $36 \%$ in the Netherlands to $57 \%$ in Italy. Moreover, some low risk women were targeted in all countries.

These data demonstrate that a large number of women at high risk of fractures are not receiving treatment, that a substantial number of women at low risk are prescribed treatment and that there are important differences in the uptake of treatment between countries.

The differences could not be explained by other clinical risk factors, and the regional difference in probability of treatment thus seems to have little correlation to existing evidence of best practice and cost-effectiveness.

\section{Comparing data for Sweden from IMS Health and the} Swedish Drug Register and Sales Data

To validate the data from IMS Health, a comparison of the data was made with data from the Swedish Prescribed Drug Register. Information on all filled prescriptions outside of the hospital setting are available from 2006 (available on the website of National Board of Health and Welfare [www.sos.se]). The database 
Table 67 Number of women eligible for treatment, treated and treatment gap in 2010

\begin{tabular}{|c|c|c|c|c|}
\hline Country & $\begin{array}{l}\text { Number } \\
\text { potentially } \\
\text { treated (1000s) }\end{array}$ & $\begin{array}{l}\text { Number exceeding } \\
\text { fracture risk } \\
\text { threshold (1000s) }\end{array}$ & $\begin{array}{c}\text { Difference } \\
\text { (1000s) }\end{array}$ & $\begin{array}{c}\text { Treatment } \\
\text { gap (\%) }\end{array}$ \\
\hline Austria & 139 & 282 & 143 & 51 \\
\hline Belgium & 214 & 402 & 188 & 47 \\
\hline Bulgaria & 13 & 240 & 227 & 95 \\
\hline Czech Republic & 79 & 330 & 251 & 76 \\
\hline Denmark & 87 & 190 & 103 & 54 \\
\hline Estonia & 7 & 48 & 41 & 86 \\
\hline Finland & 53 & 172 & 119 & 69 \\
\hline France & 1,390 & 2,437 & 1,047 & 43 \\
\hline Germany & 730 & 3,231 & 2,501 & 77 \\
\hline Greece & 333 & 482 & 149 & 31 \\
\hline Hungary & 238 & 332 & 94 & 28 \\
\hline Ireland & 91 & 124 & 33 & 26 \\
\hline Italy & 1,069 & 2,635 & 1,566 & 59 \\
\hline Latvia & 12 & 80 & 68 & 85 \\
\hline Lithuania & 11 & 109 & 98 & 90 \\
\hline Luxembourg & 9 & 16 & 7 & 43 \\
\hline Netherlands & 242 & 605 & 363 & 60 \\
\hline Poland & 245 & 1127 & 882 & 78 \\
\hline Portugal & 269 & 425 & 156 & 37 \\
\hline Romania & 100 & 599 & 499 & 83 \\
\hline Slovakia & 75 & 148 & 73 & 49 \\
\hline Slovenia & 35 & 62 & 27 & 44 \\
\hline Spain & 1,277 & 1,709 & 432 & 25 \\
\hline Sweden & 100 & 358 & 258 & 72 \\
\hline UK & 1,064 & 2,298 & 1,234 & 54 \\
\hline EU27 & 7,881 & 18,441 & 10,560 & 57 \\
\hline
\end{tabular}

Proportion treated (\%)

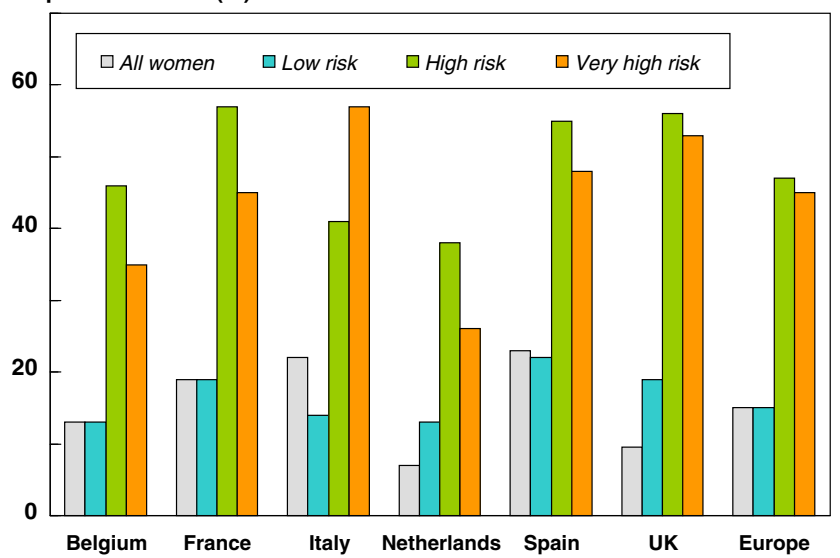

Fig. 89 Proportion of women, included in the GLOW study, receiving treatment in six EU member states according to category of risk. All women refer to women aged 55 years or more $(n=24,249)$. Low risk comprises women aged less than 75 years with a T-score for BMD in the range of osteopenia, no prior fracture, no maternal hip fracture or osteoporosis $(n=1166)$. High risk refers to women reported to have a BMD measurement in the range of osteoporosis $(n=5258)$. Very high risk comprises women with a previous hip or spine fracture $(n=913)$ [41] contains information on the number of patients filling a prescription, the number of prescriptions and the number of DDDs. Figure 90 shows the number of DDDs of alendronate sold as reported by the Swedish drug registry database and by IMS Health. These numbers correspond well with the data in this report, although IMS Health reports slightly higher numbers (2-3\%).

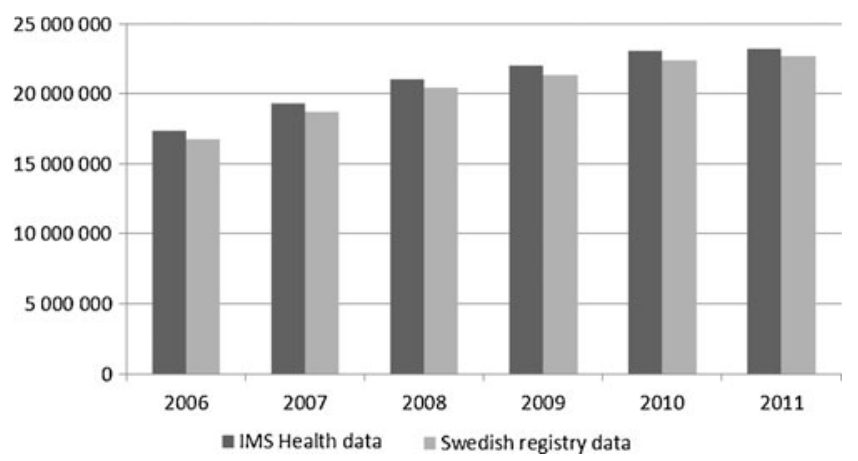

Fig. 90 DDDs of alendronate sold in Sweden as reported by IMS Health and the Swedish Prescribed Drug Register 


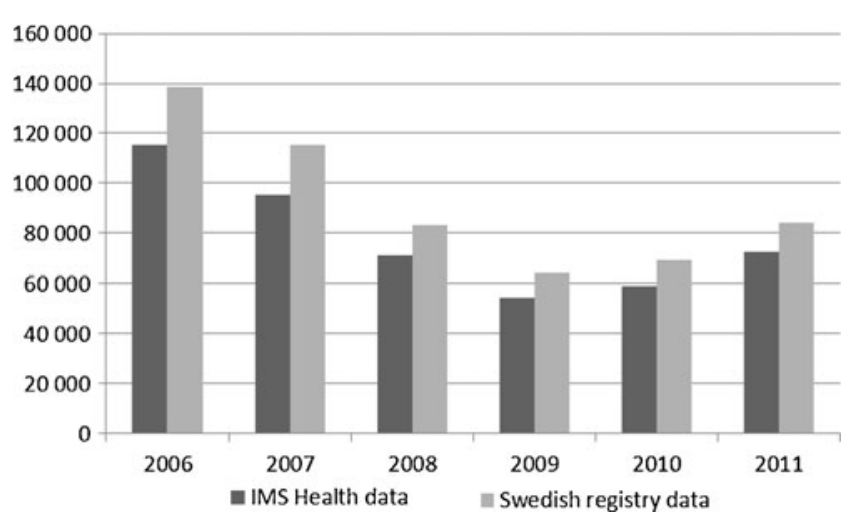

Fig. 91 DDDs of teriparatide sold in Sweden as reported by IMS Health and the Swedish Prescribed Drug Register

Comparison of bisphosphonates used in cancer treatment is not as easily undertaken since only data from IMS Health discriminates the two indications.

The sales of teriparatide, on the other hand, show a greater discrepancy between the numbers from the Swedish Prescribed Drug Register and IMS Health, and the trend is reversed with IMS Health data being 14-17\% lower than the numbers from the Swedish Prescribed Drug Register (Fig. 91). The reasons for these differences, however small, are not evident, since neither the data from IMS Health nor the Swedish registry data claim to take hospital use into account.

Using Swedish data from the National Board of Health and Welfare, it appears that treatment variation could exist

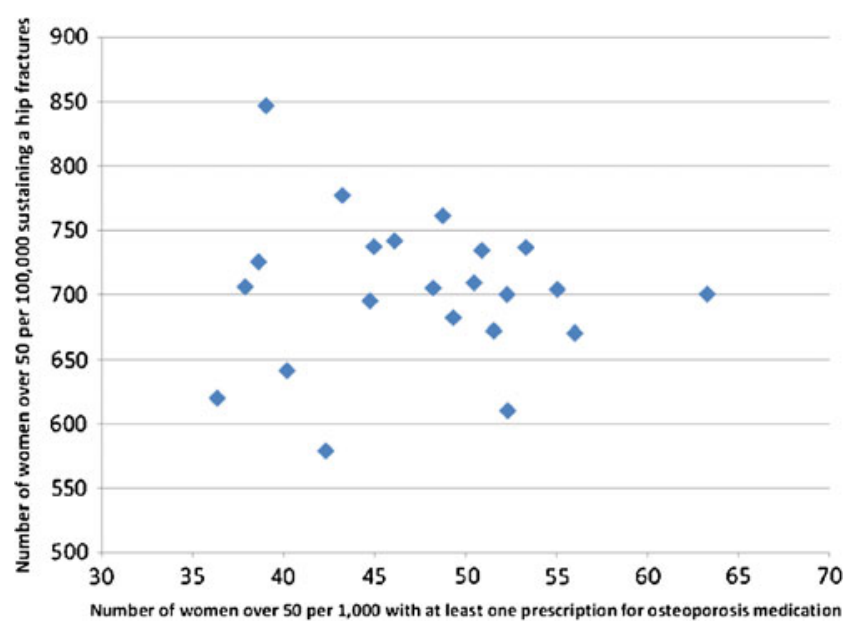

Fig. 93 Correlation of hip fracture and prescription rates on county level in women aged 50 years or above in Sweden 2011

within countries as well as between countries, suggesting a lack of evidence based treatment for osteoporosis on the national level: Among the 21 county councils in Sweden, the number of women aged over 50 years per 1,000 who filled at least on prescription of medications used to treat osteoporosis (ATC code M05B) in 2011 ranged from 36 to 63 (Fig. 92) with an average of 48.

This variation in prescription rates among counties does not appear to be explained by differences in fracture risk given that there were no significant correlations $(r=-0.3 p=$ $0.9)$ between prescription and hip fracture rates (ICD-10 code S72) (Fig. 93).

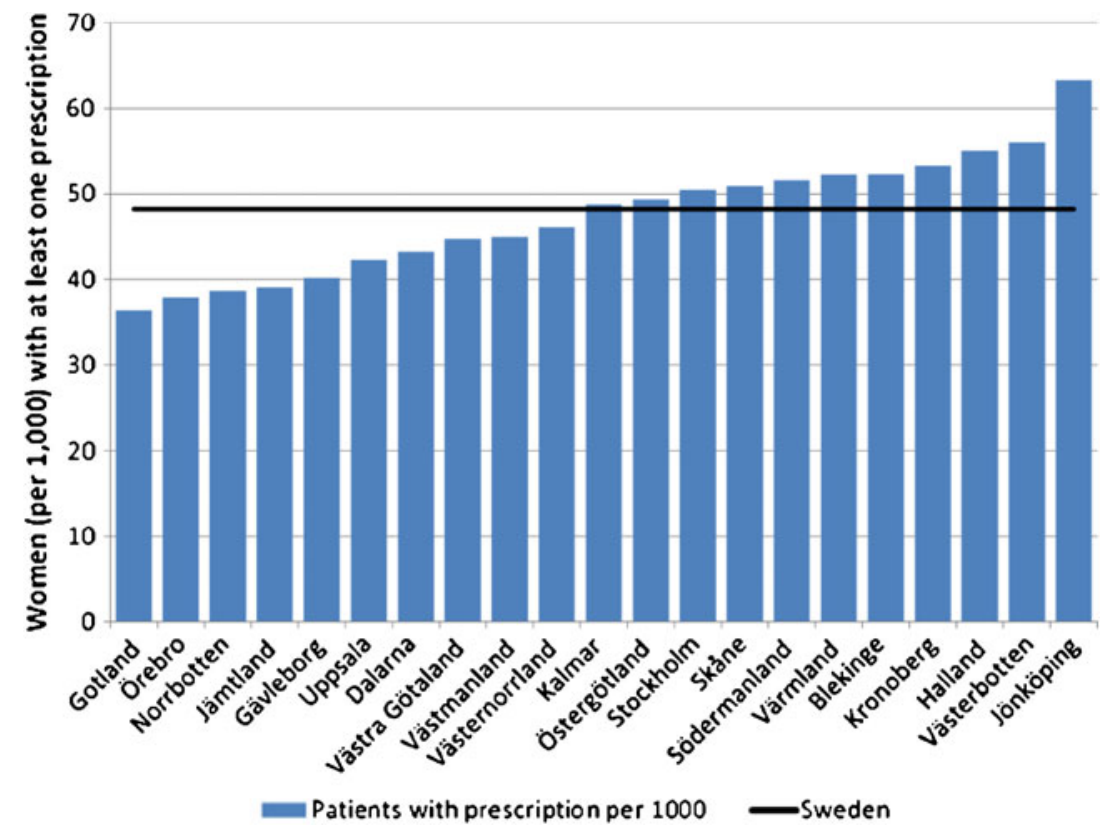

Fig. 92 Number of women per $(1,000)$ aged 50 years or above prescribed medication to treat osteoporosis (M05B) 


\section{References}

1. Strom O, Borgstrom F, Kanis JA, Compston J, Cooper C, McCloskey EV, Jonsson B (2011) Osteoporosis: burden, health care provision and opportunities in the EU: a report prepared in collaboration with the International Osteoporosis Foundation (IOF) and the European Federation of Pharmaceutical Industry Associations (EFPIA). Arch Osteoporos 6:59-155

2. Eurostat (2011) Statistics database. Data retrieved in November, 2011. http://epp.eurostat.ec.europa.eu,

3. Hauptverband der Österreichischen Sozialversiche- nungstüger (2011) Accessed July 2011, www. hauptverband.at/portal27/portal/hvbportal/ emed/.

4. INAMI-RIZIV Institut national d'assurance maladie-invalidité (2011) Accessed June. http://www.inami. fgov.be/insurer/fr/rate/ pdf/last/doctors/rx20110601fr.pdf

5. Ministry of Health Bulgaria (2011) http://www.mh. government.bg/Articles.aspx?lang=bg-BG\&pageid= 383\&categoryid=3999. Accessed June, 2011.

6. Ministry of Health Cyprus (2011) www.moh.gov.cy. Accessed June 2011.

7. SÚKL State Institute for Drug Control in Czech Republic (2011) www.sukl.eu/ Accessed June 2011

8. Danish Medicines Agency (2011) http://www.medicinpriser.dk Accessed July 2011.

9. Estonian Medicine Information (Raviminfo) (2011) http:// www.raviminfo.ee/otsing.php Accessed August 2011

10. The Social Insurance Institution of Finland (2011) http://kela.fi/ Accessed July 2011

11. Vidal-pro (2004) L'information de référence sur le médicament (2004) www.vidalpro.net

12. Rote Liste (2011) www.rote-liste.de Accessed June 2011

13. Hellenic Association of Pharmaceutical Companies (2011) SFEE. Accessed July 2011. www.sfee.gr

14. Database CEDD (2011) www.cedd.oep.hu Accessed June 2011

15. Agenzia Italiana del Farmco (2011) www.agenziafarmaco.it

16. Caisse National de Santé du Luxembourg (2011) www.cns.lu

17. Malta Competition and Consumer Affairs Authority (2011) www.msa.org.mt and personal communication with Gianpiero Fava

18. Health Care Insurance Board's medicine price list (2011) www.medicijnkosten.nl Accessed August 2011

19. National Authority of Medicines and Health Products Portugal (2011) http://www.infarmed.pt/ Accessed July 2012

20. Casa National de Asigurari de Sanatate (2011) http://www.cnas.ro/ medicamente/lista-medicamentelor-2011 Accessed August, 2011

21. Portal Farma (2011) www.portalfarma.com

22. FASS (2009) www.fass.se Accessed June 2011

23. British National Formulary (2011) http://www.bnf.org/bnf/

24. Mitchell PJ, Bayly JR (2009) A comparative analysis of drug prescribing and costs for osteoporosis and hypercholesterolaemia in England for 1998-2007. J Bone Miner Res 24, Suppl 1, :

25. Kanis JA, Reginster JY, Kaufman JM, Ringe JD, Adachi JD, Hiligsmann M, Rizzoli R, Cooper C (2012) A reappraisal of generic bisphosphonates in osteoporosis. Osteoporos Int 23:213-221

26. Barrett-Connor E, Mosca L, Collins P, Geiger MJ, Grady D, Kornitzer M, McNabb MA, Wenger NK (2006) Effects of raloxifene on cardiovascular events and breast cancer in postmenopausal women. N Engl J Med 355:125-137

27. National Institute for Health and Clinical Excellence (NICE) (2010) Osteoporosis- primary prevention. Alendronate, etidronate, risedronate, raloxifene and strontium ranelate for the primary prevention of osteoporotic fragility fractures in postmenopausal women: guidance 29 October 2008. Technology appraisal TA 160 . www.nice.org.uk/guidance/TA160

28. National Institute for Health and Clinical Excellence (NICE) (2011) Osteoporosis- secondary prevention including strontium ranelate: guidance 29 October 2008. Technology appraisal TA 161. www.nice.org.uk/guidance/TA161

29. Borgstrom F, Johnell O, Kanis JA, Jonsson B, Rehnberg C (2006) At what hip fracture risk is it cost-effective to treat? International intervention thresholds for the treatment of osteoporosis. Osteoporos Int 17:1459-1471

30. Kanis JA, Oden A, Johnell O, Jonsson B, De Laet C, Dawson A (2001) The burden of osteoporotic fractures: a method for setting intervention thresholds. Osteoporos Int 12:417-427

31. Kanis JA, Johnell O, Oden A, De Laet C, Oglesby A, Jonsson B (2002) Intervention thresholds for osteoporosis. Bone 31:26-31

32. Kanis JA, Johnell O, Oden A, Borgstrom F, Johansson H, De Laet C, Jonsson B (2005) Intervention thresholds for osteoporosis in men and women: a study based on data from Sweden. Osteoporos Int 16:6-14

33. Kanis JA, McCloskey EV, Johansson H, Oden A, Melton LJ, III, Khaltaev N (2008) A reference standard for the description of osteoporosis. Bone 42:467-475

34. NOF (2003) Physicians Guide to prevention and treatment of osteoporosis. National Osteoporosis Foundation. Washington, DC

35. Tosteson AN, Melton LJ, III, Dawson-Hughes B, Baim S, Favus MJ, Khosla S, Lindsay RL (2008) Cost-effective osteoporosis treatment thresholds: the United States perspective. Osteoporos Int 19:437-447

36. Compston J, Cooper A, Cooper C, Francis R, Kanis JA, Marsh D, McCloskey EV, Reid DM, Selby P, Wilkins M (2009) Guidelines for the diagnosis and management of osteoporosis in postmenopausal women and men from the age of 50 years in the UK. Maturitas 62:105-108

37. Kanis JA, McCloskey EV, Johansson H, Strom O, Borgstrom F, Oden A (2008) Case finding for the management of osteoporosis with FRAX - assessment and intervention thresholds for the UK. Osteoporos Int 19:1395-1408

38. Kanis JA, Adams J, Borgstrom F, Cooper C, Jonsson B, Preedy D, Selby P, Compston J (2008) The cost-effectiveness of alendronate in the management of osteoporosis. Bone 42:4-15

39. United Nations Department of Economic and Social Affairs Population Division (2011) World Population Prospects test. Data retrieved in November, 2011. http://esa.un.org/unpd/wpp/unpp/ p2k0data.asp

40. Diez-Perez A, Hooven FH, Adachi JD, et al. (2011) Regional differences in treatment for osteoporosis. The Global Longitudinal Study of Osteoporosis in Women (GLOW). Bone 49:493-498

41. Hooven FH, Adachi JD, Adami S, et al. (2009) The Global Longitudinal Study of Osteoporosis in Women (GLOW): rationale and study design. Osteoporos Int 20:1107-1116

Acknowledgments This report has been sponsored by an unrestricted educational grant from the European Federation of Pharmaceutical Industry Associations (EFPIA) and the International Osteoporosis Foundation (IOF). We thank Judy Stenmark who provided the liaison between the two organizations, respectively. We acknowledge the assistance of Helena Johansson and Prof Anders Oden for their help in the calculations of fracture probability. We thank Oskar Ström and Fredrik Borgström who were prominent authors of an earlier report covering a similar topic in a sample of EU countries and provided the 
template for the present report. We also thank Dr Dominique Pierroz and Dr Fina Liu of the IOF for their help in editing the report. The report has been reviewed by the members of the IOF EU Osteoporosis Consultation Panel and the IOF European Parliament Osteoporosis Interest Group, and we are grateful for their local insights on the management of osteoporosis in each country. The report has been reviewed and endorsed by the Committee of Scientific Advisors of the IOF and benefitted from their feedback.
Conflicts of interest All authors have received research funding from pharmaceutical companies involved in marketing products for treatment of osteoporosis. Competing interests have been lodged with IOF.

Open Access This article is distributed under the terms of the Creative Commons Attribution License which permits any use, distribution, and reproduction in any medium, provided the original author(s) and the source are credited. 